\title{
INTEGRATED CONSERVATION OF \\ THE WHENUA HOU DIVING PETREL
}

BY

JOHANNES H. FISCHER

\author{
A thesis \\ submitted to Victoria University of Wellington \\ in fulfilment of the requirements for the degree of \\ Doctor of Philosophy
}

School of Biological Sciences

Faculty of Sciences

Victoria University of Wellington 


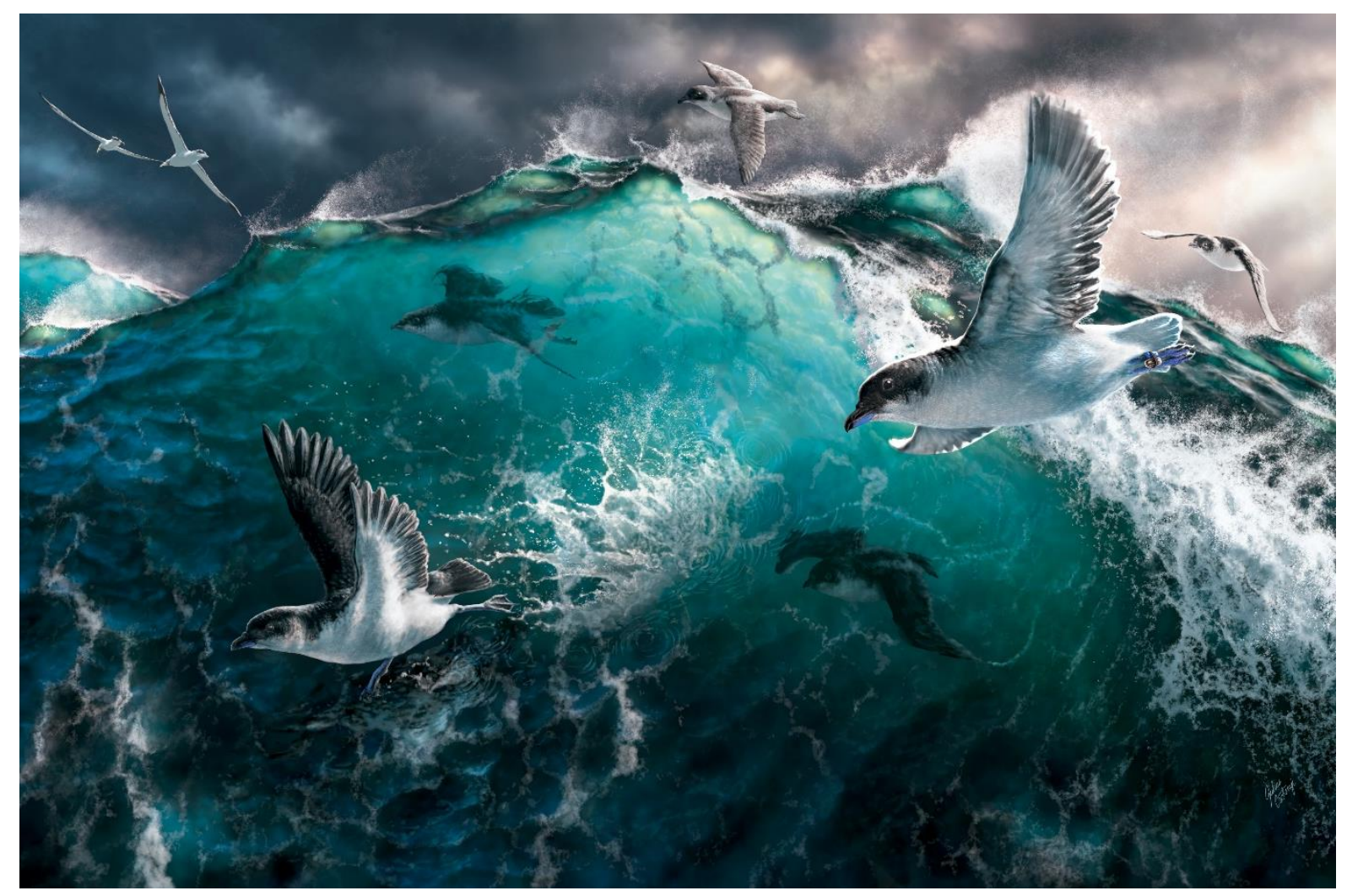

\section{Supervisors:}

Heiko U. Wittmer,

Associate Professor, School of Biological Sciences, Victoria University of Wellington.

Doug P. Armstrong,

Professor, Wildlife Ecology Group, Massey University.

Igor Debski,

Principal Science Advisor, Aquatic Unit, New Zealand Department of Conservation.

(C) Johannes H. Fischer. December 2020. Integrated conservation of the Whenua Hou Diving Petrel. 
Tēnā koutou katoa,

E rere te manu kit e tihi o Puke Hou.

Rere iho te manu mā te awa o Waituna.

Tau ana te manu ki te whenua o Whenua Hou.

Ko Kāi Tahu te mana whenua, te iwi whakaruruhau.

Nō Tiamana ōku tipuna.

Nō Hōrana ahau.

Kei Whanganui-A-Tara taku kāika i nāianei.

Ko Johannes tōku ikoa.

Tēnā koutou, tēnā koutou, tēnā koutou tatou katoa. 


\section{Abstract}

Seabirds are one of the most threatened taxa on the planet. These species are also considered ecosystem engineers. Therefore, seabirds are of particular conservation interest. One of the most threatened seabirds is the critically endangered Whenua Hou Diving Petrel (Pelecanoides whenuahouensis; WHDP). The WHDP is restricted to a minute $\left(0.018 \mathrm{~km}^{2}\right)$ breeding colony on a single island - Whenua Hou (Codfish Island), Aotearoa (New Zealand). The WHDP population was estimated at 150 adults in 2005. The WHDP is threatened by storms and storm surges, which erode its breeding habitat (fragile foredunes), and potentially by competition for burrows with congenerics.

I aimed to inform suitable conservation strategies for the WHDP. I first quantified the efficacy of past conservation actions (eradications of invasive predators). I compiled burrow counts across four decades to estimate and compare population growth before and after predator eradications. I then investigated offshore threats using tracking data to quantify WHDP offshore distribution, behaviour, and overlap with commercial fishing efforts. Subsequently, I estimated the potential impact and success of WHDP translocations. Specifically, I combined capture-recapture, nest-monitoring, and count data in an integrated population model (IPM) to predict the impact of harvesting chicks for translocations on the source population and to project the establishment of a second population. I then informed future translocation protocols using nest-monitoring data to quantify nest survival and breeding biology. Finally, I tested if WHDP presence had a positive influence on unrelated species groups. I counted two skink species at sites with and without burrows and used occupancy modelling to quantify the influence WHDP burrows had on skink occurrence.

Estimates of population growth before and after predator eradications illustrated that WHDP population growth remained comparatively low and unaffected by this conservation strategy. Therefore, additional interventions are required. WHDP tracking revealed that the non-breeding distribution did not overlap with commercial fishing efforts. However, considerable fishing efforts were present within the breeding distribution. Despite these findings, onshore threats remain present and conservation strategies aimed at addressing terrestrial threats may be more feasible. Results from my IPM showed that translocations could successfully establish a second WHDP population without impacting the source excessively, provided translocation cohorts remain small 
and translocations are repeated over long time periods (5-10 years). Nest survival was not clearly influenced by interannual variation, distance to sea, and intra- or interspecific competition. Furthermore, I informed future translocation protocols by identifying the preferred harvest window, measurements of ideal translocation candidates, and feeding regimes. Occurrence of one skink species was $114 \%$ higher at sites with burrows than at sites without, suggesting that WHDP presence benefits unrelated species.

The information provided in this thesis facilitates the identification of future management strategies for this critically endangered species. However, future conservation management of the WHDP should be based on structured decision-making frameworks that apply iterative adaptive management loops and must acknowledge the unique position of tangata whenua (people of the land). This approach could address the consequences and trade-offs of each alternative, account for uncertainty, facilitate the decolonisation of conservation biology, and would ultimately result in the best potential outcome of the target species in a truly integrated fashion. 


\section{Acknowledgements}

For the duration of this thesis, I was supported by a Victoria University of Wellington Doctoral Scholarship (2017-20), a Postgraduate Students' Association Research Excellence Award (2019), and a Wellington Doctoral Submission Scholarship (2020). In addition, this research was generously supported by the New Zealand Department of Conservation, the National Geographic Society (Grant WW-249C-17), Birds New Zealand (Bird NZ Research Fund 2015, 2017, 2019, 2020), the Mohamed Bin Zayed Species Conservation Fund (Project 192520234), the Encounter Foundation, Forest and Bird (JS Watson Trust 2017), the Centre for Biodiversity and Restoration Ecology (Student Award 2015, 2017, 2019), a public Experiment.com crowd funder (DOI: 10.18258/7331), the Coastal Restoration Trust of New Zealand (Postgraduate Student Study Award 2016), IDEA WILD (Equipment Grant 2017), The Royal Society of New Zealand (Hutton Fund 2017), and the Australasian Seabird Group (Student Grant 2016).

This thesis is a product of the unconditional belief and support of both my parents, Hartmut and Sabine Fischer, my granddad Karl-Heinz Wünsch, and my late grandma Margarete Fischer, in me and my work. Words cannot express my gratitude. I have been truly privileged to have been in your care as a child and I am still blessed with your continuing support and guidance as an adult. Without you, I would not have been where I am today.

I also feel overwhelming gratitude towards supervisors. I cannot thank my primary supervisor, Heiko Wittmer, enough for his unwavering belief in me and my research, for pushing me to grow further than I could have ever imagined, and for helping me become the conservationist I am today. I am truly grateful for his willingness to diverge from his usual ungulate and feline studies and indulge in the (much more fascinating) world of seabird conservation for the last five years. Igor Debski and Graeme Taylor deserve a huge thanks for sharing their love and passion for seabirds, their never-ending insights, and their unfaltering support of me and the project from its very inception. Doug Armstrong has also been an irreplaceable influence, elevating my analytical skills beyond my wildest dreams, and I am deeply grateful for his patience, insights, guidance, and humour. I believe that, thanks to him, my analytical skillset no longer belongs in the Pleistocene. 
Tēnei te mihi aroha ki Te Rūnanga o Ngāi Tahu otirā, ngā mema o te Kōmiti Whenua Hou mō ōu koutou tautoko mai i ngā tau kua pahure. He mihi manahau ki a Tāne Davis, kua tākoha mai i tōna wā me ōna mātauranga mō tēnei kaupapa. Mei kore ake koe, kāore tēnei mahi ka puāwai. Ngā mihi nui ki a koe mō tō tautoko.

None of this work would have been possible without the tireless support from all the research assistants across five breeding periods, some of whom dedicated their time and energy twice, or even three times. Thank you, Graeme Miller, Igor Debski, Juliet O'Connell, Jesse Golden, Johannes Chambon, Graeme Taylor, Brooke Tucker, Regan McKinlay, Victor Anton, Cora McCauley, Heiko Wittmer, Hannah Hendriks, Thomas Burns, Grace Tocker, David Thomas, Jason Preble, Kris Kokame, Eric Vanderwerf, Doug Armstrong, Jake Tessler, Janne de Hoop, and Brooke Friswold (Fig. 1). You have been my dream team through hundreds of sleepless nights, and you have supported me through the highs and lows that came with close to two cumulative years in the field. I cannot express my aroha and gratitude to all of you enough. You are the embodiment of the Flying Penguin Force. From the bottom of my heart: thank you. Next to the research assistants, a small army of additional volunteers, too numerous to name individually, also deserve a big thanks here.
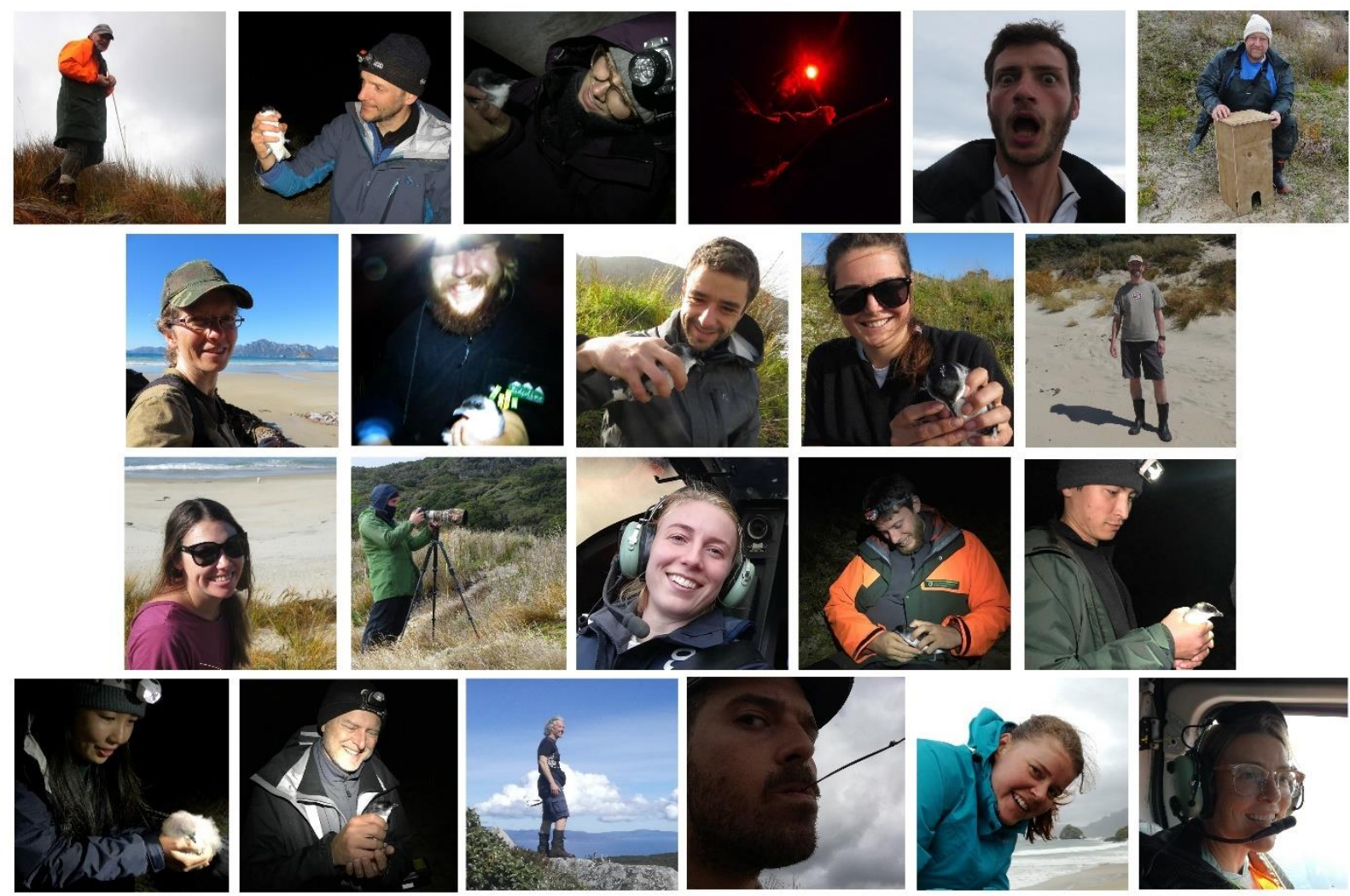

Fig. 1. The Flying Penguin Force. Included here with consent from all members. 
The fieldwork on Whenua Hou would not be possible without the support of dozens of amazing people working in the background and I will attempt to thank everyone here. First and foremost, Ros Cole deserves a massive thank you for her ongoing support and guidance. Sharon Trainor has also been a pillar of good spirits through the years and I am very grateful for her support. Brooke Tucker has my deepest gratitude for her archaeological insights and for helping me navigate the complexities of working in and around a field site full of cultural heritage. I am hugely indebted to the entire Kākāpō Recovery whānau for their support and their irreplaceable companionship on Whenua Hou. I will miss you all dearly. The quarantine store team, Rhuaridh Hannan, Janice Kevern, and John Peterson in particular, also played a big role in making this project become reality. I am also indebted to Dominique Filippi (Sextant Technology), James Fox (Migrate Technology), Stu Cockburn and Steve McKevitt (Department of Conservation), Jake Tessler (BDB Enterprises), and Johannes Chambon for their technical support. Finally, Raymond Hector and Bill Moffatt (Stewart Island Flights), Paul Garlick and Fraser Sutherland (Te Anau Helicopters), and Dale Green (Heli My Way) have my everlasting gratitude for facilitating safe passage to and from Whenua Hou for the entire team.

Outside the fieldwork, another large assembly of people have made this work possible. The Wittmer lab whānau has been fantastic. I am grateful for the insights and companionship from Victor Anton, Amy Brasch, Samhita Bose, Bibek Yumnam, Michelle McLellan, Grace Tocker, Rachel Selwyn, Henry Mackenzie, Frowin Becker, and Eric van Dam. Additional acknowledgments go to David Boyle, Michelle Bradshaw, William Brockelsby, Jody Crane, Thomas Clay, Andy Cox, Daryl Eason, Graeme Elliott, Brooke Friswold, Jo Hiscock, Sarah Herbert, Colin Miskelly, Nicola Nelson, Ron Nilsson, Matt Rayner, Yvan Richards, Peter Ritchie, Rachael Sagar, Dena Spatz, Derek Spitz, Hendrik Schultz, Alan Tennyson, Eric Vanderwerf, Murray Williams, and Lindsay Young for many invaluable insights. I am grateful to the experts who participated in the expert elicitation in Ch. 2. Furthermore, I thank Victor Anton, Sarah Converse, Johannes Chambon, Ben Dilley, Sabine Fischer, Matt Hayward, Sarah Herbert, Michelle McLellan, Colin Miskelly, Jason Preble, Matt Rayner, Alice Rogers, Rachel Selwyn, Jeff Shima, Grace Tocker, and a range of anonymous reviewers for providing feedback on various manuscripts, which have helped me improve this thesis. Victor Anton, Samhita Bose, Johannes Chambon, Janne de Hoop, Ayuwat Jearwattanakanok, and David Young deserve thanks for providing electronic artwork. Julius Csotonyi kindly provided the amazing frontispiece. 
Last but not least, a huge thank you goes to the Whenua Hou Diving Petrels themselves, for being the cutest, friendliest, most forgiving, and most rewarding study species I could have ever wished for. This thesis is dedicated to you. May you burrow into the dunes of Aotearoa for many generations to come. 


\section{Contents}

Abstract

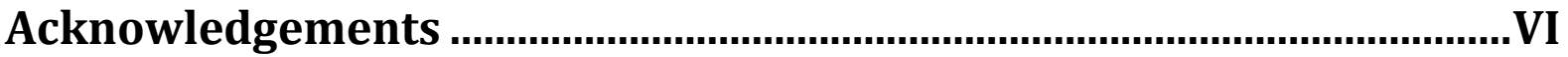

List of Figures

List of tables

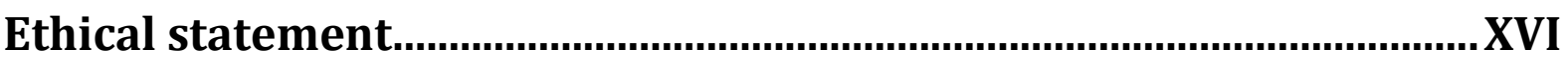

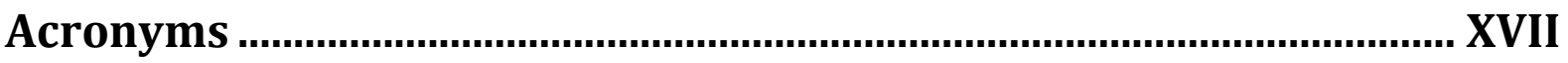

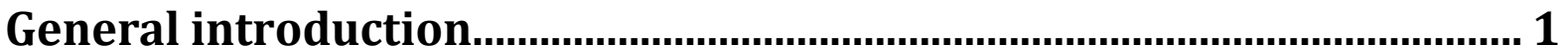

CONSERVATION IN THE SIXTH MASS EXTINCTION …………………………………..... 1

SEABIRD CONSERVATION ......................................................................................... 3

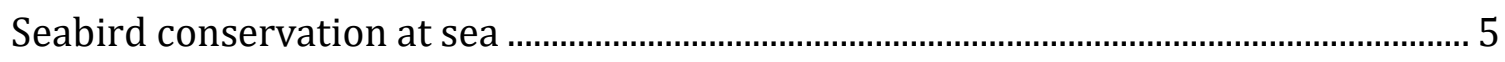

Seabird conservation on land............................................................................................. 6

WHENUA HOU DIVING PETREL CONSERVATION .................................................................. 9

THESIS STRUCTURE .......................................................................................................12

Population growth estimates of a threatened seabird indicate necessity for additional management following invasive predator eradications ...............................................................................................15

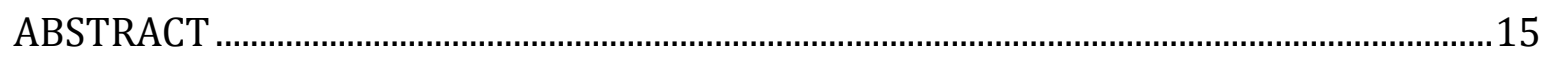

TUHINGA WHAKARĀPOPOTO_..............................................................................................16

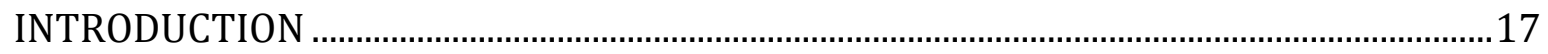

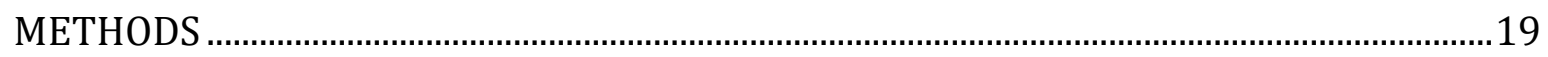

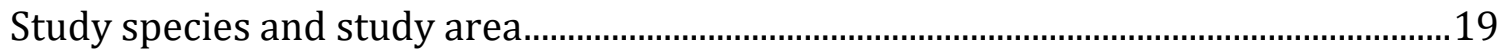

Burrow counts ..................................................................................................................2

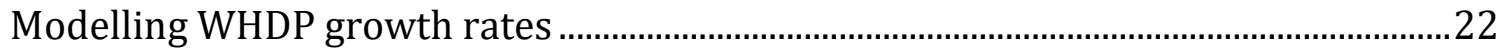

Comparison with other Procellariiformes..............................................................................2

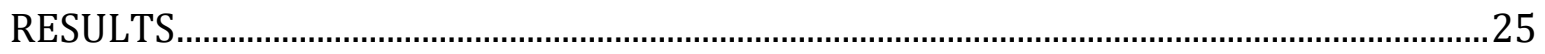

WHDP population growth rates ..................................................................................2

Comparison with other Procellariiformes.......................................................................28

DISCUSSION ........................................................................................................................29

Year-round offshore distribution, behaviour, and overlap with commercial fisheries of a critically endangered small petrel ...............33

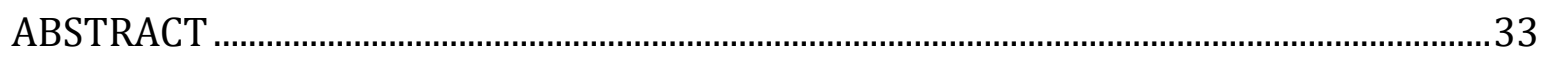

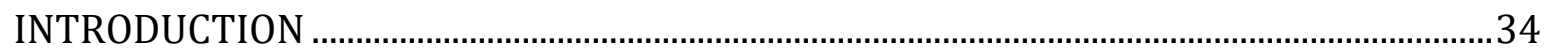

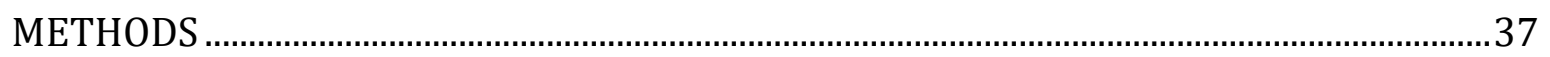

Deployment and retrieval of geolocators ……………………………………………...37

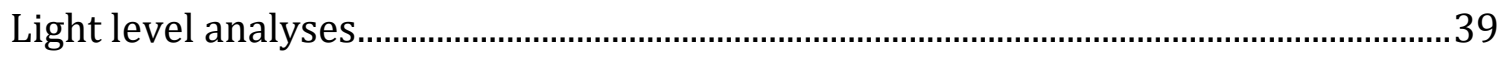

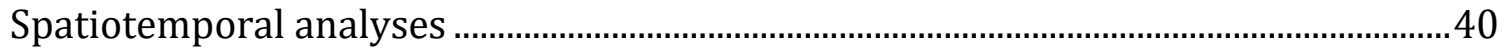

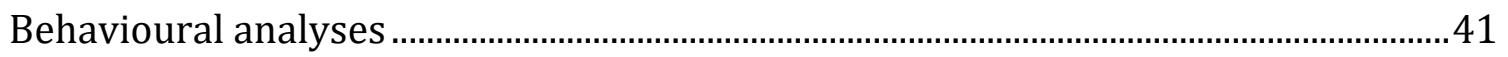

Overlap with commercial fishing effort................................................................................ 42

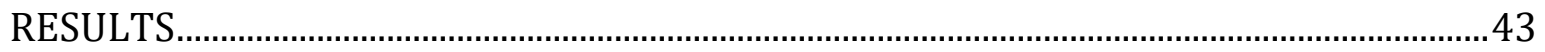




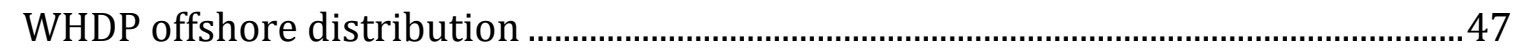

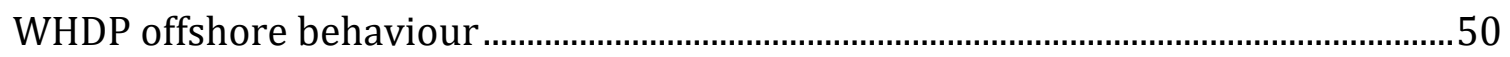

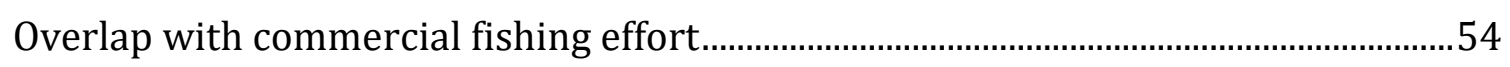

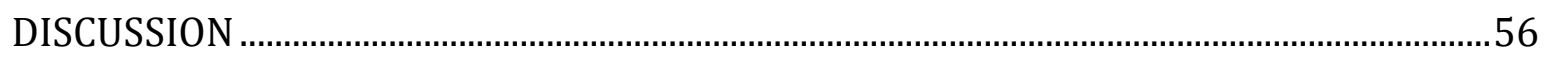

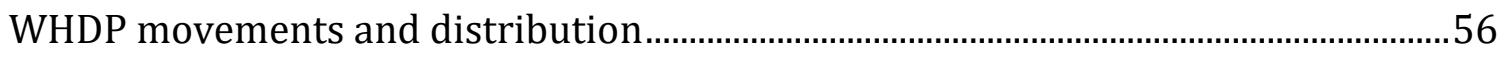

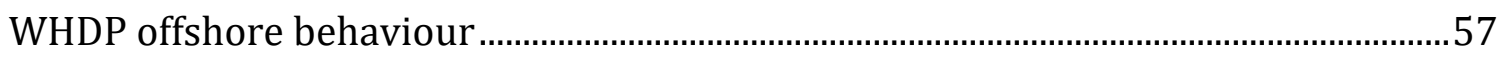

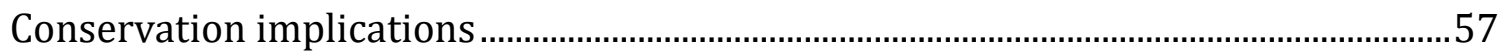

Predicting harvest impact and translocation success in small

populations: a case study of a critically endangered petrel ..................61

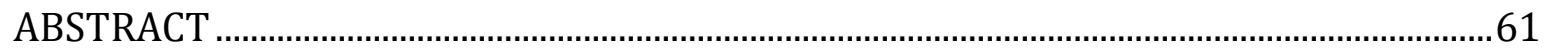

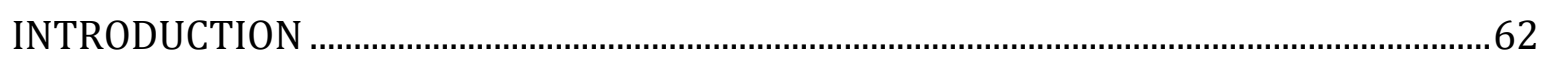

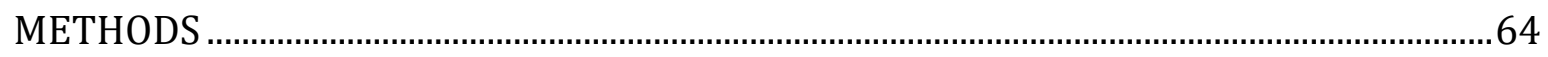

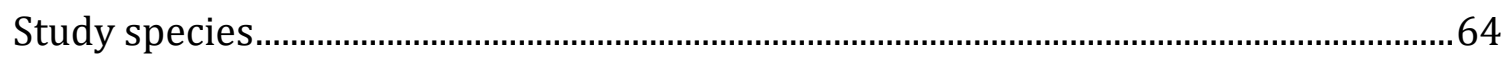

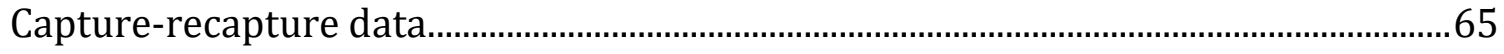

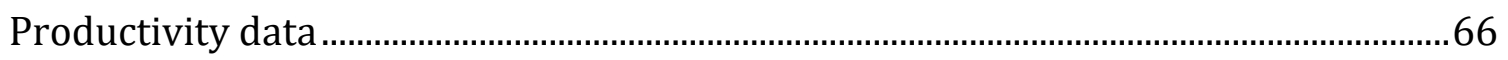

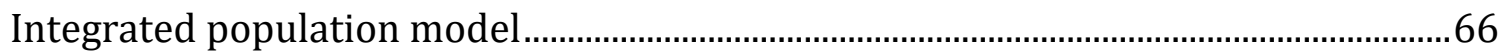

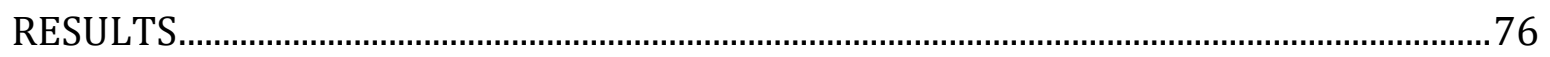

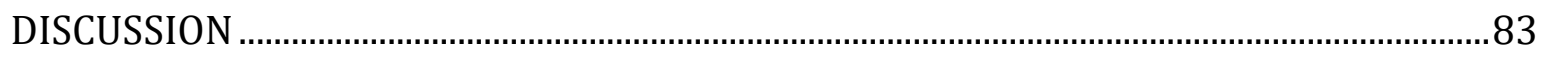

Preparing for translocations of a critically endangered petrel through targeted monitoring of nest survival and breeding biology...................87

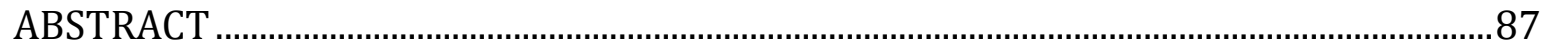

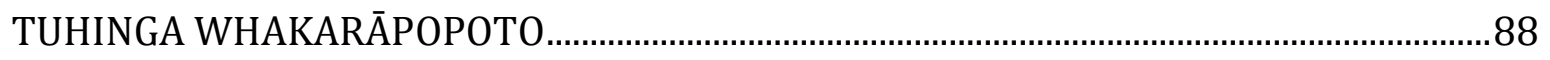

INTRODUCTION

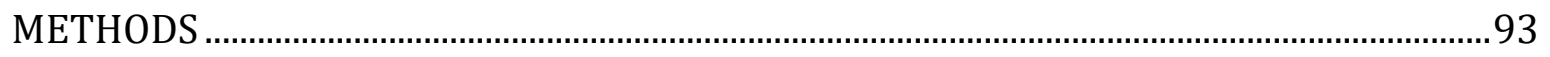

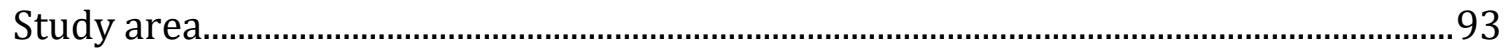

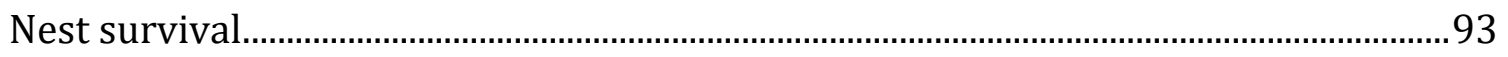

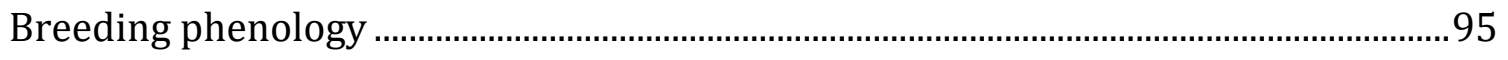

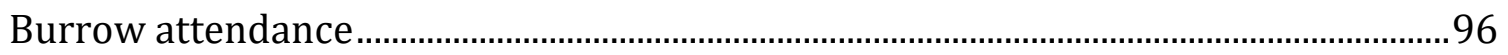

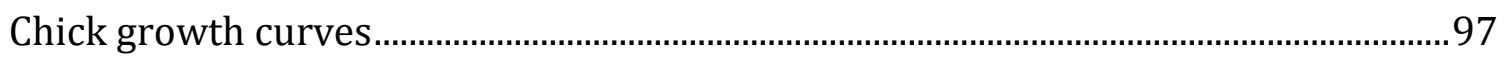

RESULTS

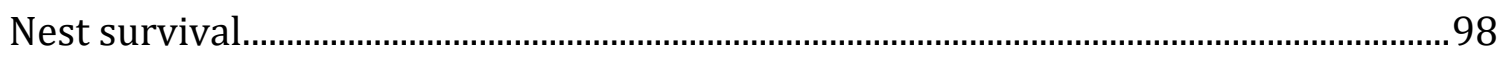

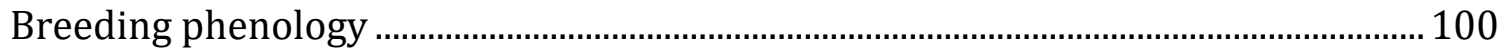

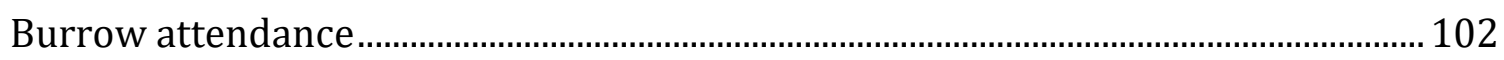

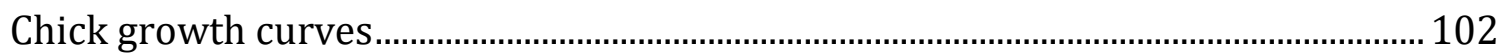

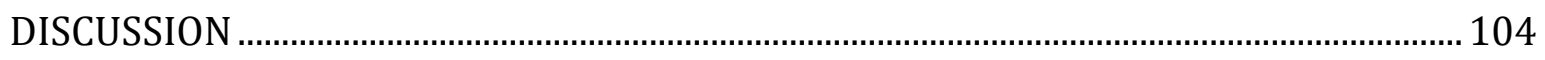

Contrasting responses of lizard occurrences to burrowing by a

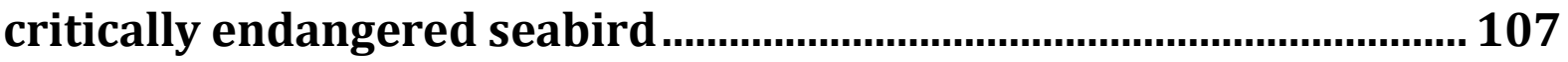

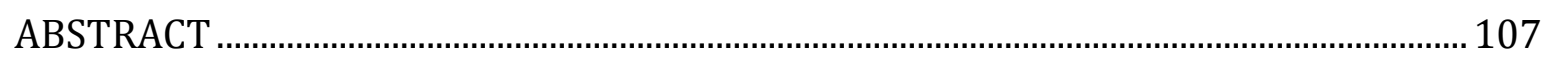

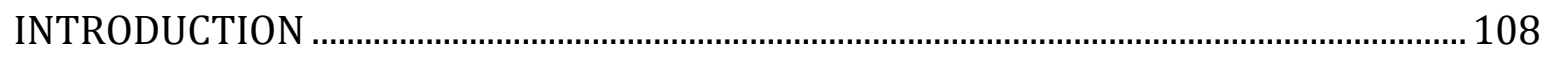

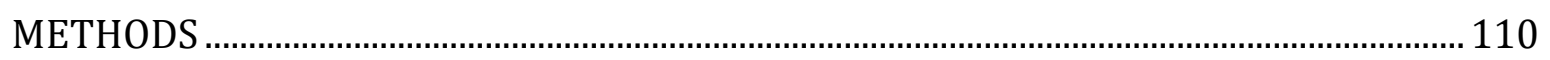

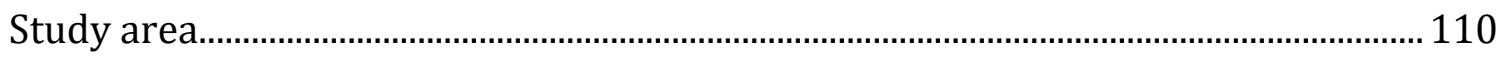

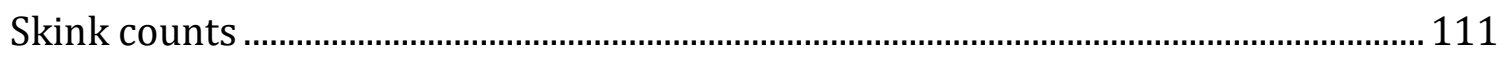




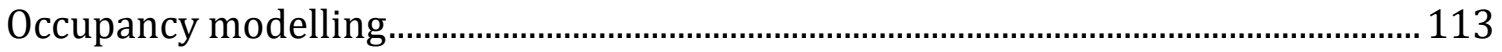

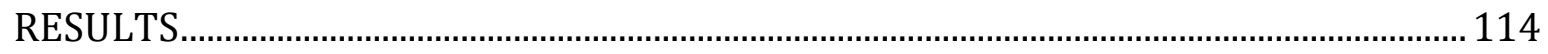

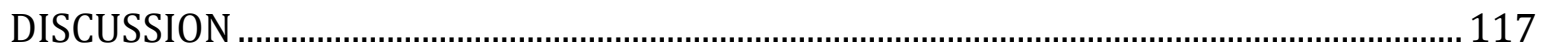

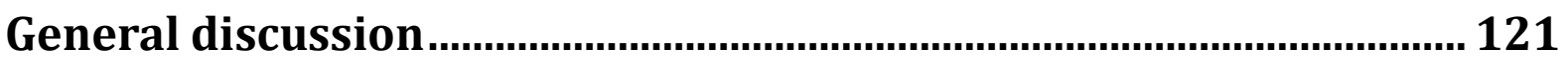

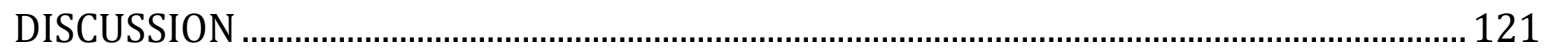

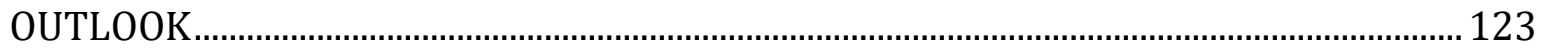

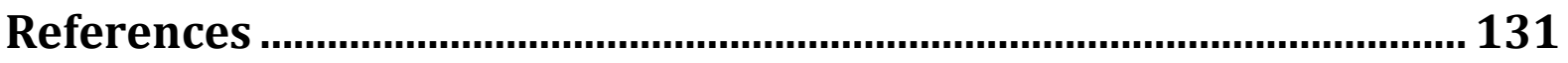

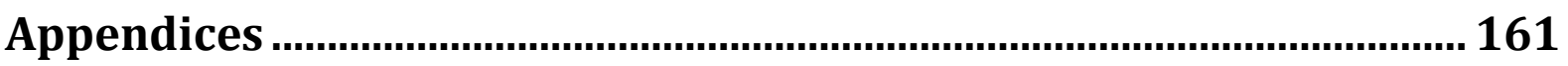

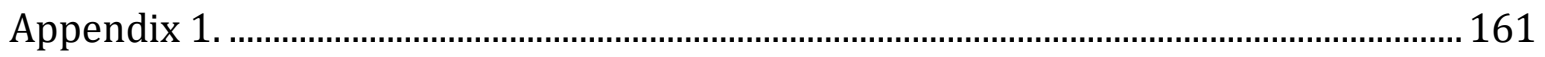

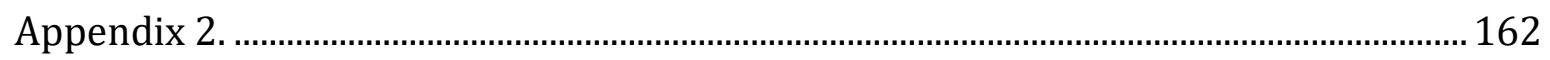

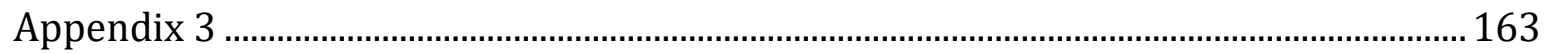

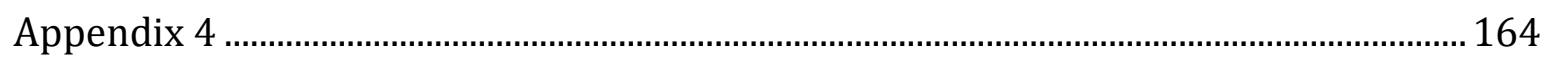

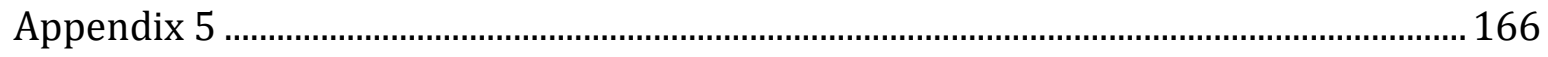

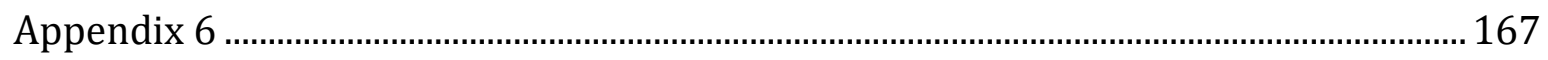

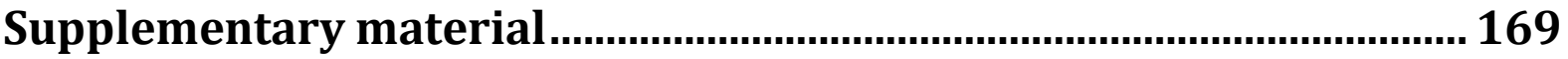

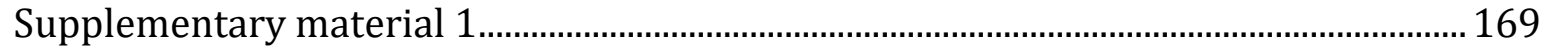

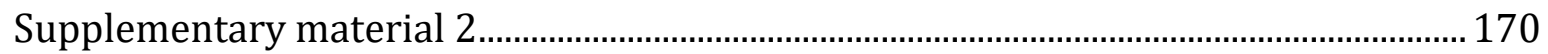

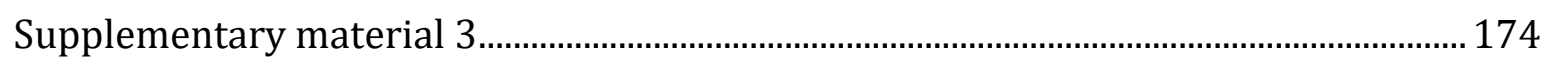




\section{List of Figures}

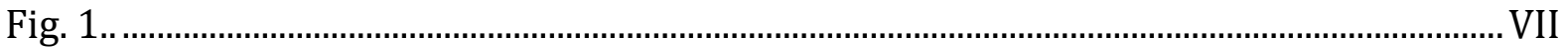

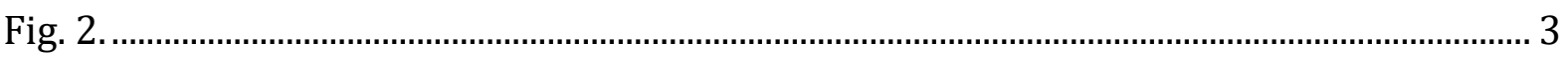

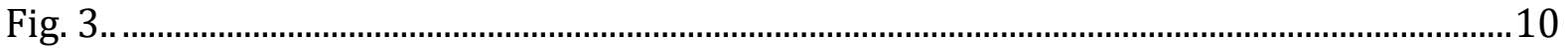

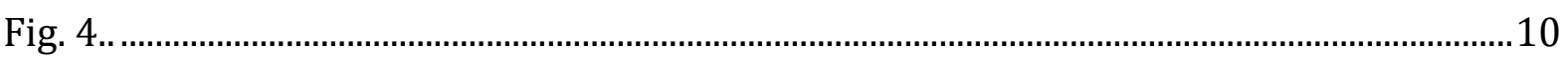

Fig. 5.

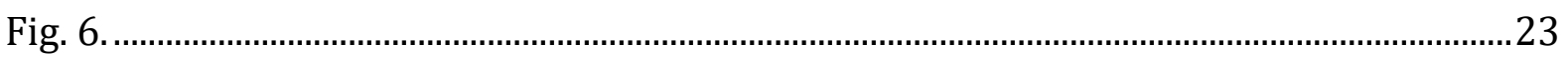

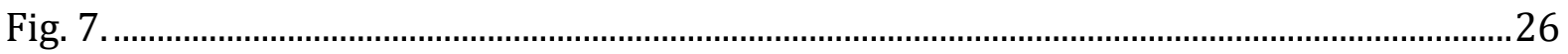

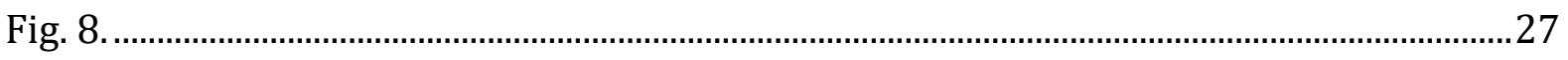

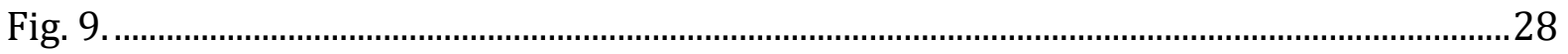

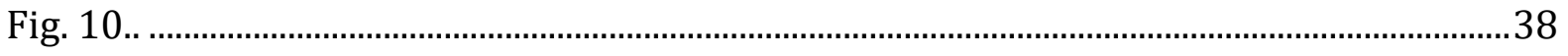

Fig. 11..

Fig. 12.

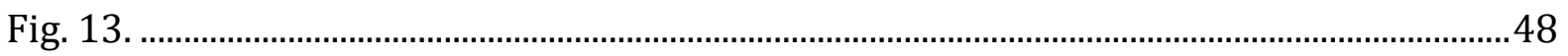

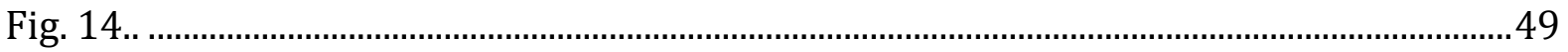

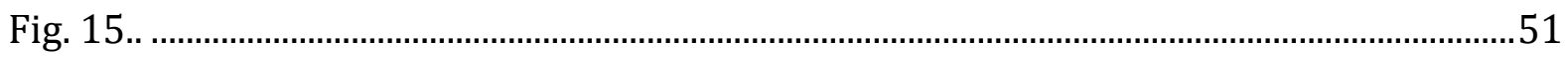

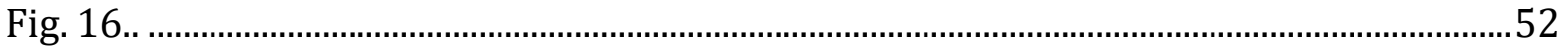

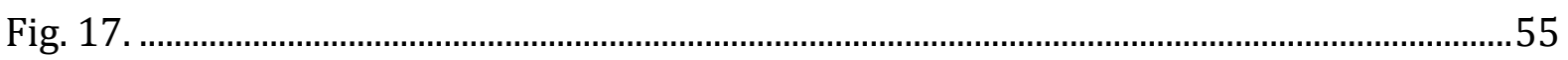

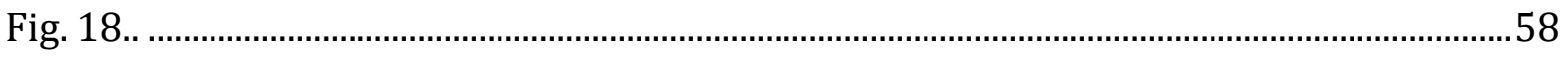

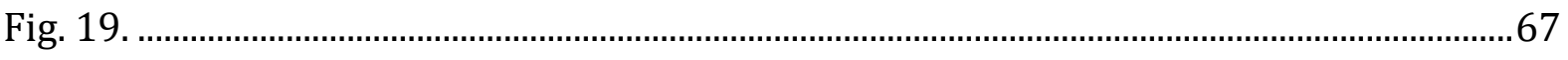

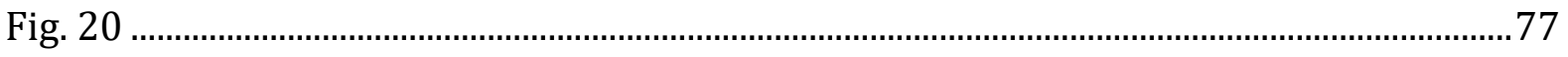

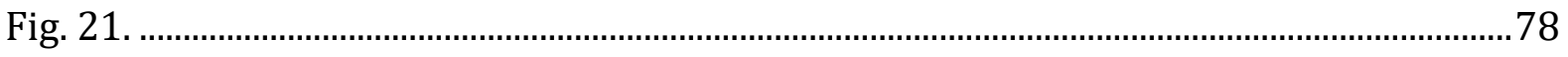

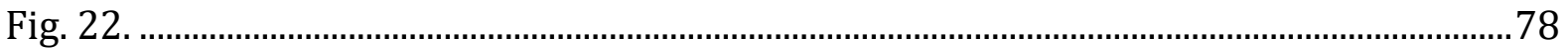

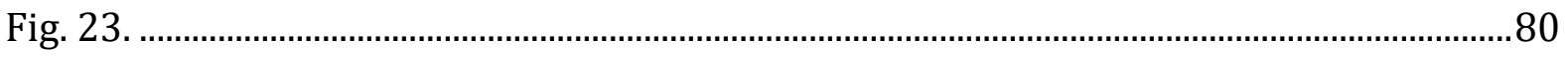

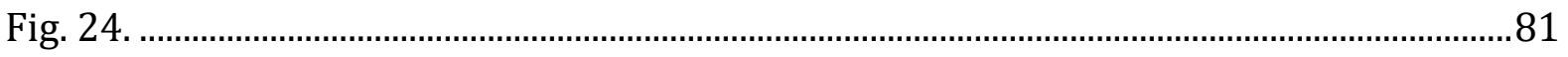

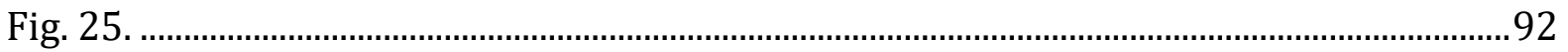

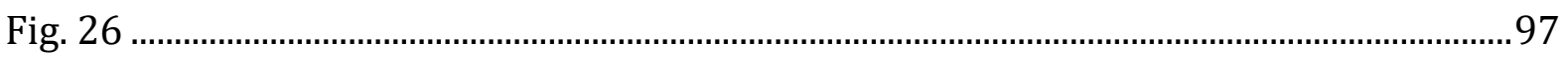

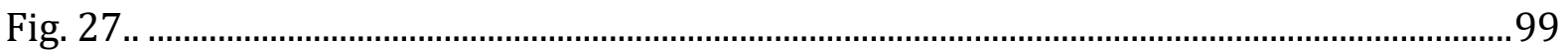

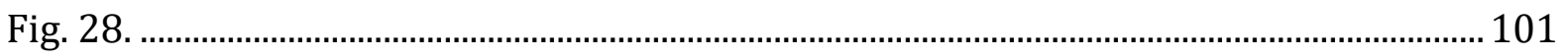

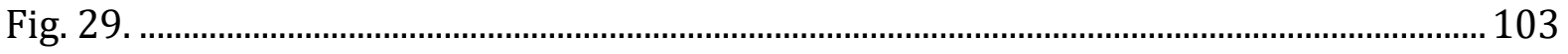

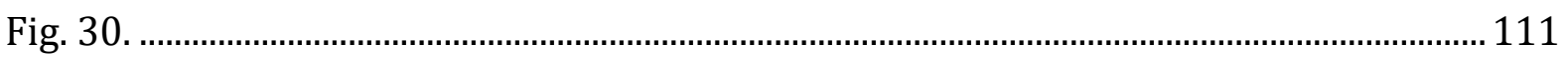

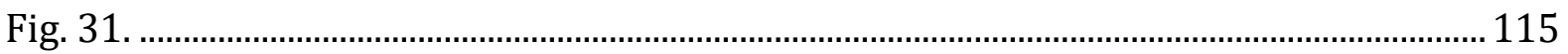

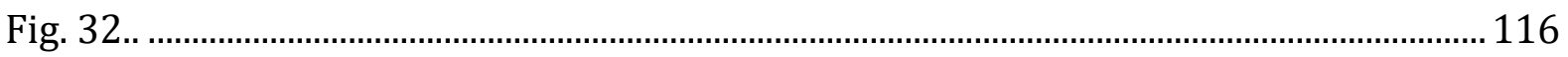

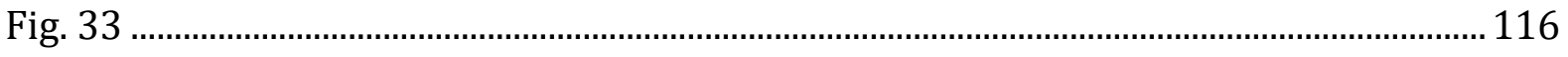

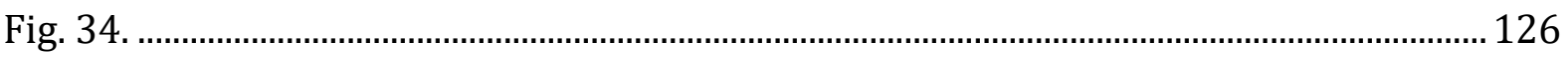




\section{List of tables}

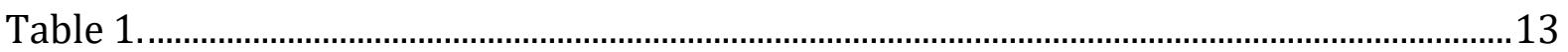

Table 2

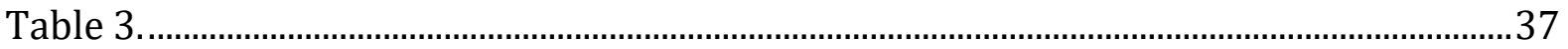

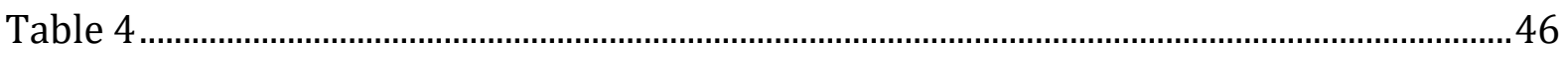

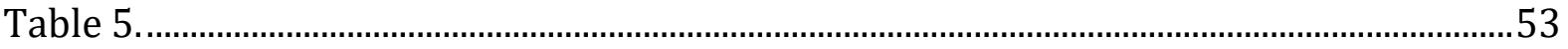

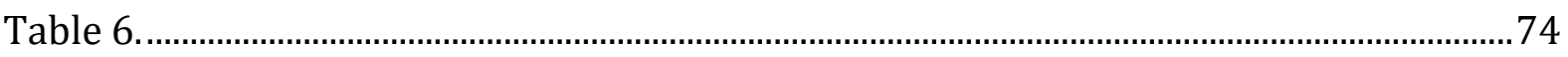

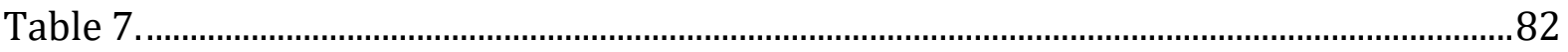

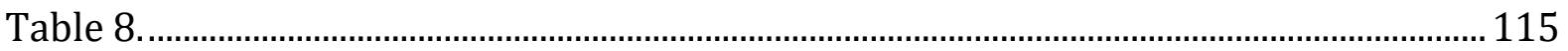




\section{Ethical statement}

All methods were approved by the Whenua Hou Komiti, Kaitiaki Rōpū, the Victoria University of Wellington Animal Ethics Committee (VUW AEC 22252, VUW AEC 23283, and VUW AEC 27621), and the New Zealand Department of Conservation (Wildlife Authority Act 45407-FAU and 45907-FAU, Entry Permit 47920-LND-1516/04, 52029LND, M1718/01, M1819/01, and M1920/02). 


\section{Acronyms}

AIC Akaike information criterion

AM Adaptive management

BA Bhattacharyya's affinity

CDP Common Diving Petrel (Pelecanoides urinatrix)

CI Confidence intervals

CrI Credible intervals

EEZ Economic exclusive zone

ENSO El Niño southern oscillation

GLM Generalized model

GLMM Generalized linear mixed effects model

IBA Important Bird and Biodiversity Area

IPM Integrated population model

IUCN International Union for the Conservation of Nature

MCMC Markov chain Monte Carlo

NSD Net squared displacement

RVI Relative variable importance

SDM Structured decision-making

SE Standard error

SST Sea surface temperature

UD Utilization distribution

WHDP Whenua Hou Diving Petrel (Pelecanoides whenuahouensis) 
Chapter 1

\section{General introduction}

\section{CONSERVATION IN THE SIXTH MASS EXTINCTION}

Biodiversity loss in the last century has been exceptionally rapid and Earth has entered the sixth mass extinction (Pimm et al. 1995, Barnovsky et al. 2011, Ceballos et al. 2015, 2017). The sixth mass extinction is human-induced and driven by the exponentially rising demand for resources (Diaz et al. 2019). This planetary devastation is overwhelmingly evident in every indicator of the state of nature including extinction rates, population declines, global biomass allocation, and the integrity of ecosystems worldwide. Since the $15^{\text {th }}$ century, $\sim 700$ animal species and $\sim 600$ plant species have gone extinct (Diaz et al. 2019, Humphreys et al. 2019). Extinction rates are now 100 to 1,000 times higher than natural background rates (Pimm et al. 1995). An estimated 1,000,000 species are at risk of extinction (Diaz et al. 2019). Globally, populations are collapsing, and species ranges are contracting (Ceballos et al. 2017). Global plant biomass, and therefore virtually all biomass on Earth, has decreased by 66\% (Bar-on et al. 2018, Erb et al. 2018). Biomass declines have been equally pronounced in many other taxonomic groups. In the $21^{\text {st }}$ century, biomass of humans outnumbers the combined biomass of all wild mammals and birds by $1: 7$. In addition, more than $70 \%$ of the land surface and more than $80 \%$ of the oceans' surfaces has been altered by humans (Watson et al. 2016, Kendall et al. 2018). The negative trends in these indicators of the state of the planet are projected to worsen (Diaz et al. 2019).

While the sixth mass extinction accelerates, conservation efforts can slow the loss of biodiversity (Butchart et al. 2006, Hoffman et al. 2010, Bolam et al. 2020). Conservation biology is the science aimed at halting and reversing current extinction rates, population declines, range contractions, and biodiversity loss (Soulé 1985). Caughley (1994) identified two key paradigms within conservation biology: the declining population paradigm and the small population paradigm. The declining population paradigm is aimed at countering the agents of decline (e.g., invasive species, habitat destruction, overkill, and climate change). The small population paradigm is aimed at addressing the problems arising from the smallness of a population (e.g., inbreeding depression, demographic stochasticity, and environmental stochasticity). Conservation biologists 
operate in both paradigms, as species recovery is case-specific and complex (Hoffman et al. 2010). Conservation efforts have been successful in reducing further escalation of the sixth mass extinction (Butchart et al. 2006, Hoffman et al. 2010). For example, conservation efforts between 1980 and 2010 have decreased the extinction risk of at least 68 species of birds, mammals, and amphibians (Hoffman et al. 2010). Conservation efforts are particularly effective when focused on species at extreme risk of extinction, i.e., those listed as critically endangered on the IUCN Red List (Monroe et al. 2019). Conservation efforts have prevented the extinction of 21-32 bird and 7-16 mammal species between 1993 and 2020 (Bolam et al. 2020). Without these efforts, extinction rates for birds and mammals would have been at least 2.4-4.2 times higher. Conservation efforts have also ensured that $\sim 15 \%$ of the planet's terrestrial surface and $\sim 5 \%$ of the oceans' surfaces have received some form of formal protection (Geldman et al. 2019, Marine Conservation Institute 2020).

Despite encouraging conservation successes, biodiversity loss continues to accelerate, and conservation efforts must be strengthened, and direct, rapid, and integrated action is required immediately (Butchart et al. 2010, Diaz et al. 2019). Extinction risks are unequally allocated among conservation paradigms (Caughley 1994), among taxonomic groups (Fig. 2; Hoffman et al. 2010, Diaz et al. 2019), through space (e.g., habitats and geographic regions; Brooks et al. 2002, Butchart et al. 2010) and through time (e.g., among life-cycle stages, phenophases, and years; Finkelstein et al. 2010, Pardo et al. 2017, Robinson et al. 2020). Identifying and quantifying threats across this multi-dimensional playing field is complex and relies on long-term monitoring (Willis et al. 2007). Designing adequate countermeasures following the identification of threats is equally, if not more, challenging. While lessons can be learned from similar systems and/or species, conservation biology remains reliant on species- or population-specific long-term studies across time and space (Willis et al. 2007). Finally, bridging the gap between the identification of adequate conservation measures and the subsequent successful implementation of these measures remains a major challenge in conservation biology (Jarvis et al. 2015). Each conservation measure represents a complex decision landscape with a range of consequences and trade-offs, affecting an assemblage of stakeholders, and is often surrounded by considerable uncertainty (Converse et al. 2013, Johnson et al. 2015). Given these substantial challenges, it is not surprising that conservation biologists have focussed their efforts predominantly on species at the very brink of extinction 
(Monroe et al. 2019). However, conservation efforts must be further integrated, expanded, and increased around the world to curb the ongoing sixth mass extinction (Diaz et al. 2019).

\section{SEABIRD CONSERVATION}

Seabird conservation is a striking example of the challenging nature of conservation biology. Seabirds, and Procellariiformes in particular, are one of the most threatened taxa on the planet (Fig. 2; Croxall et al. 2012, Dias et al. 2019, Rodríguez et al. 2019). Of the extant bird species, $13.5 \%$ are threatened with extinction (i.e., critically endangered, endangered, or vulnerable; BirdLife International 2020). Seabirds (defined following Dias et al. 2019 but including taxonomic updates) are considerably more threatened (31.5\%) and seven seabird species are already considered extinct. Procellariiformes (e.g., albatrosses, petrels, and shearwaters) are even more threatened than seabirds in general (46.9\%) and two Procellariiformes are already listed as extinct. While the Jamaica Petrel (Pterodroma caribbaea) and Guadeloupe Storm Petrel (Hydrobates macrodactylus) are listed as critically endangered, both are most likely extinct as well (Tobias et al. 2006, BirdLife International 2020). Given the dire conservation status of many seabirds, securing seabird species is of disproportionate conservation interest.

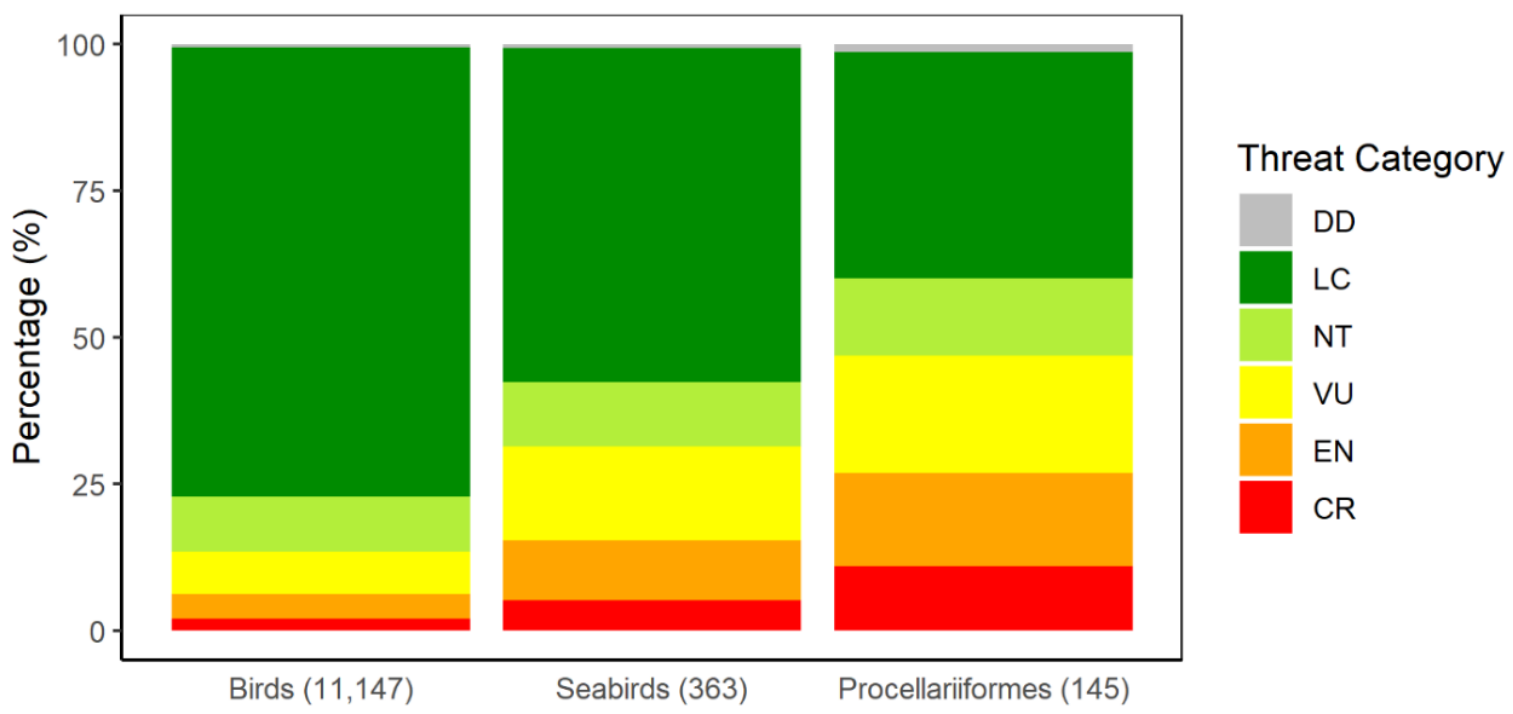

Fig. 2. Threat status of all extant birds, seabirds, and Procellariiformes $(n)$. DD = data deficient, $\mathrm{LC}=$ least concern, $\mathrm{NT}=$ near-threatened, $\mathrm{VU}=$ vulnerable, $\mathrm{EN}=$ endangered, and $\mathrm{CR}=$ critically endangered. 
The life history traits of many seabirds, and Procellariiformes in particular, render these birds disproportionately vulnerable. Seabirds are among the most long-lived birds on the planet (Bird et al. 2020). The oldest known wild bird is a Laysan Albatross (Phoebastria immutabilis) named "Wisdom", which is at least 69 years old (Jensen 2019). In addition to long lifespans, many seabirds exhibit delayed sexual maturity (e.g., Wandering Albatrosses Diomedea exulans only start breeding when they are 6-15 years old; Weimerskirch 2018). Seabirds also exhibit low fecundity. Procellariiformes only lay a singular egg per breeding period (Warham 1996) and several species breed only once every two years (Weimerskirch 2018, Taylor et al. 2020). Species exhibiting these life history traits are known as $K$-strategists. $K$-strategists are highly vulnerable to extinction drivers, especially those that impact adult survival (Halley et al. 2018).

Seabird conservation is also of disproportionate interest because these species are considered ecosystem engineers. Seabirds enable biochemical, biophysical, and biological processes at their breeding colonies that have knock-on effects on species in the surrounding terrestrial and marine ecosystems (Bancroft et al. 2005, Graham et al. 2018, Otero et al. 2018). Seabirds form a crucial link between pelagic and terrestrial ecosystems, as they facilitate nutrient cycling (particularly of nitrogen and phosphorus; Otero et al. 2018). The increased nutrient deposition on land also results in increased nutrient deposition in the coastal marine ecosystems surrounding seabird breeding colonies (Lorrain et al. 2017, Graham et al. 2018). Seabirds consequently increase productivity in terrestrial and marine ecosystems (Bancroft et al. 2005, Graham et al. 2018). Seabirds provide bioturbation (the movement of soil by organisms e.g., by digging of burrows) which aerates the soil and further enables bottom-up effects (Buxton et al. 2016, Orwin et al. 2016). Seabirds are also seed dispersers (Ellis 2005). The increased nutrient deposition and subsequent elevation of primary productivity facilitated by seabirds ultimately results in increased diversity and abundance of unrelated species groups on land (e.g., invertebrates; Markwell \& Daugherty 2002) and at sea (e.g., reef fish; Graham et al. 2018). As such, the decline and extirpation of seabird populations worldwide (Paleczny et al. 2015, Dias et al. 2019) has wide-reaching implications for the ecosphere. 


\section{Seabird conservation at sea}

Seabirds face a variety of threats at sea. Accidental bycatch in commercial fisheries is a prominent offshore threat to many seabirds. Hundreds of thousands of seabirds annually succumb to this threat (Phillips et al. 2016, Dias et al. 2019, Rodríguez et al. 2019) which drives some species to the brink of extinction (Oro et al. 2004, Genovart et al. 2016). Different fisheries affect different seabird species. Albatrosses and larger petrels are particularly affected by long line fisheries (Anderson et al. 2011, Dias et al. 2019, Rodríguez et al. 2019). Pursuit divers such as auks and penguins are especially at risk of becoming bycatch in gill nets (Žydelis et al. 2013, Crawford et al. 2017). Thousands of seabirds are also killed annually in trawl fisheries, mostly due to collision and entanglement with fishing gear (Sullivan et al. 2006, Watkins et al. 2008, Maree et al. 2014). In addition, deck strikes (caused by artificial lights at sea) is a poorly understood threat which affects smaller seabirds such as diving petrels (Ryan 1991, Black 2005, Glass \& Ryan 2013). Another pelagic threat that affects many seabird species globally is environmental pollution (Ryan et al. 2009, Wilcox et al. 2015). Plastic pollution is especially prevalent, and several trillion pieces of plastic now contaminate the world's oceans (Eriksen et al. 2014). Ingestion of plastic can be lethal and virtually all seabird species are expected to suffer from plastic pollution in the near future (Lavers et al. 2014, Wilcox et al. 2015, Roman et al. 2019). Resource competition between humans and seabirds is another widespread threat that continues to impact seabirds, despite global seabird declines (Grémillet et al. 2016, 2018). This threat is likely to increase as global fisheries target lower and lower trophic levels (Pauly et al. 1998). Finally, climate change and weather extremes also have considerable negative impacts on seabirds at sea (Pardo et al. 2017, Piatt et al. 2020).

To counter the widespread and disastrous impacts of accidental bycatch on seabird populations, a variety of bycatch mitigation techniques has been developed, many of which show promising conservation outcomes (Agreement on the Conservation of Albatrosses and Petrels 2014, 2017). Refraining from discharging fishery discards has proven to reduce bycatch (Pierre et al. 2012). Operating at night further reduces bycatch of diurnal species (Paterson et al. 2017). Other, more technical measures have also been developed. Bird-scaring (tori) lines reduce collision and entanglement with trawl fishing gear (Maree et al. 2014, Tamini et al. 2015). Weighting down long lines reduces the accessibility of hooks and therefore seabird bycatch (Moreno et al. 2008, Paterson et al. 
2017). In addition, more sophisticated methods that shield long line hooks until specific depths are reached are advancing (Sullivan et al. 2018, Goad et al. 2019). In gill net fisheries, acoustic and visual deterrents are being trialled, although with less promising results so far (Martin \& Crawford 2015, Phillips et al. 2016, Mangel et al. 2018). Each method has advantages and disadvantages, and results appear most beneficial to seabirds when techniques are combined (Domingo et al. 2017, Paterson et al. 2017).

Another approach to protecting seabirds (and many other wide-ranging pelagic species) is the designation of Marine Protected Areas. When designating Marine Protected Areas, information on the offshore distribution of seabird species is crucial (Delord et al. 2014, Lascelles et al. 2016). The number of seabird species whose offshore distribution has been identified is growing steadily due to rapidly improving tracking technologies (Phillips et al. 2008, BirdLife International Seabird Tracking Database 2020). Consequently, seabird tracking data has been used in an expanding body of literature informing the allocation of candidate Marine Protected Areas on ocean-wide and global scales (e.g., Delord et al. 2014, Lascelles et al. 2016, Hindell et al. 2020). The extent of ocean secured as Marine Protected Areas has increased in the last decade from $2.8 \%$ of the world's oceans in 2013 to $5.3 \%$ in 2020 (Lascelles et al. 2014, Brander et al. 2020, Marine Conservation Institute 2020). Yet, one of the targets of the Convention of Biological Diversity was to protect of $10 \%$ of the global oceans by 2020 (Convention of Biological Diversity 2010) and thus this goal has not been met.

\section{Seabird conservation on land}

Seabirds also face a wide variety of threats on land at their breeding colonies (Dias et al. 2019, Rodríguez et al. 2019). Habitat destruction is common and widespread and affects a wide range of seabirds, especially those breeding in coastal environments (Bird et al. 2014, Raine et al. 2017, Rodríguez et al. 2019). Light pollution from land-based artificial lights threatens seabirds worldwide by causing disorientation, grounding of fledglings (but also adults), and indirectly, death (Rodríguez et al. 2017). Due to the colonial breeding habits of seabirds, environmental stochasticity (e.g., catastrophic weather events) can have a detrimental impact on seabird populations (Cole 2004, Reynolds et al. 2017). Human-induced climate change is likely to further exacerbate such stochastic events (Knutson et al. 2010, Adam et al. 2020). Future sea level rise caused by climate change will further threaten seabirds, especially coastal breeders (Spatz et al. 2017). 
Predation by, and competition with, native species can cause seabird populations to decline when these population are already under pressure (Gummer et al. 2015, Rodríguez et al. 2019). Despite impacts from this wide variety of terrestrial threats, predation by invasive species (especially mammals, but also other taxa) forms the most pervasive and devastating terrestrial threat to seabirds (Spatz et al. 2014, Dias et al. 2019, Rodríguez et al. 2019). For example, the four Procellariiformes that are (likely to be) extinct were extirpated by invasive species (Tobias et al. 2006, BirdLife International 2020). Especially smaller seabird species, such as petrels, prions, storm petrels, and diving petrels, suffer heavily from predation by invasive mammals (Jones et al. 2008). Invasive species also drastically alter habitats that seabirds rely on, which can lead to population declines and extinctions (Taylor 2000ab, Cleeland et al. 2020).

Due to the severe impacts of invasive species, eradicating these problematic species from islands is one of the most successful strategies to secure seabird populations on land (Brooke et al. 2018a, Rodríguez et al. 2019). A disproportionate number of threatened species, including seabirds, are restricted to islands (Tershy et al. 2015, Spatz et al. 2017). Therefore, island-wide eradication of invasive species is a cost-effective method of conserving global biodiversity (Jones et al. 2016). To date > 1,200 island-wide eradications of invasive species have been attempted (Database of Island Invasive Species Eradications 2020). The majority of these eradications were successful ( 87\%). Island-wide eradications of invasive species have proven extremely beneficial for the recovery of the native flora and fauna, including seabirds, which respond quickly to eradications despite their slow life histories (Jones 2010, Jones et al. 2016). Population growth rates of seabirds increased considerably following invasive species eradications (Brooke et al. 2018a). A horizon-scanning exercise identified 292 islands on which the eradication of invasive species would result in considerable biodiversity gains, including the conservation of highly threatened seabirds (Holmes et al. 2019). Eradications of invasive species have mostly been focussed on uninhabited islands, but this focus is changing towards inhabited islands, which will further benefit seabird populations (Glen et al. 2013, Russell et al. 2018). The development of mammal-proof fences also allows for small-scale eradications of invasive predators, and consequently the conservation of mainland seabird populations (e.g., Young et al. 2013).

Translocating seabirds is another widely used terrestrial conservation strategy. A translocation is defined as the intentional movement of organisms for conservation or 
restoration purposes (Seddon et al. 2007, IUCN 2013, Seddon et al. 2014). Translocations are effective conservation strategies if I) suitable habitat is available, II) the species is unlikely to naturally (re)colonize that habitat, and III) the translocation is unlikely to cause negative impacts on source populations. Seabirds are desirable translocation candidates as they are disproportionally threatened with extinction (Fig. 2; Dias et al. 2019), but also provide ecosystem functions (e.g., Graham et al. 2018, Otero et al. 2018). Seabird translocations can be active or passive. Active seabird translocations rely on physically moving individuals to translocation sites. Many seabird species, especially Procellariiformes, exhibit extreme natal philopatry (potentially based on magnetism; Wynn et al. 2020). Therefore, translocating chicks prior to fledging is required to ensure imprinting on the translocation site (Miskelly \& Taylor 2004, Priddel et al. 2006, Miskelly et al. 2009). Passive seabird translocations rely on the colonial and social nature of these species and use sensory cues to attract individuals to translocation sites. Sensory cues used in passive translocations can be auditory (e.g., broadcasting of calls), visual (e.g., decoys or mirrors), and olfactory (e.g., scented materials) (Podolsky \& Kress 1992, Buxton \& Jones 2012, Jones \& Kress 2012, Friesen et al. 2017). The use of active or passive seabird translocation techniques is often dependent on the habits of the focal species but techniques can be used jointly to increase translocation success (Miskelly et al. 2009, Jones \& Kress 2012, Friesen et al. 2017). 


\section{WHENUA HOU DIVING PETREL CONSERVATION}

One of the most threatened seabirds in the world is the Whenua Hou Diving Petrel (Pelecanoides whenuahouensis; WHDP; Fig. 3). The WHDP is a recently described, nocturnal Procellariiform seabird species that was previously considered conspecific to the South Georgian Diving Petrel (P. georgicus). The WHDP was split from the South Georgian Diving Petrel based on preliminary genetic, phenotypic, and ecological differences (Paterson et al. 2000, Fischer et al. 2018b, Tizard et al. 2019). The WHDP was once a widespread and abundant breeder in coastal dune systems throughout southern Aotearoa (New Zealand). WHDP breeding colonies were present on Maukahuka (Auckland Islands, specifically Dundas and Enderby Islands), Rakiura (Stewart Island, specifically Te One Roa/Mason Bay), Muaupoko (Otago Peninsula, specifically Ōrau/Sandfly Bay), and Rēkohu (Chatham Islands) (Fig. 4; Falla et al. 1979, Worthy 1998, Taylor et al. 2000b, Holdaway et al. 2003, Wood \& Briden 2008, Wood 2016, Fischer et al. 2017b, Tennyson 2020). However, predation and habitat destruction by invasive species (and New Zealand sea lions Phocarctos hookeri on Dundas Island) caused multiple local extinctions (Falla et al. 1979, Taylor 2000b). One single WHDP breeding colony remains on Whenua Hou (Codfish Island), $3 \mathrm{~km}$ west of Rakiura. Here, the WHDP breeding colony is restricted to a small $\left(0.018 \mathrm{~km}^{2}\right)$ dune system (Fischer et al. 2018c) and the global population was estimated at 150 adults in 2005 (Wood \& Briden 2008). As such, the WHDP is listed as nationally critical by the threat classification system of Aotearoa (Robertson et al. 2017) and as critically endangered on the IUCN Red List (BirdLife International 2020). 


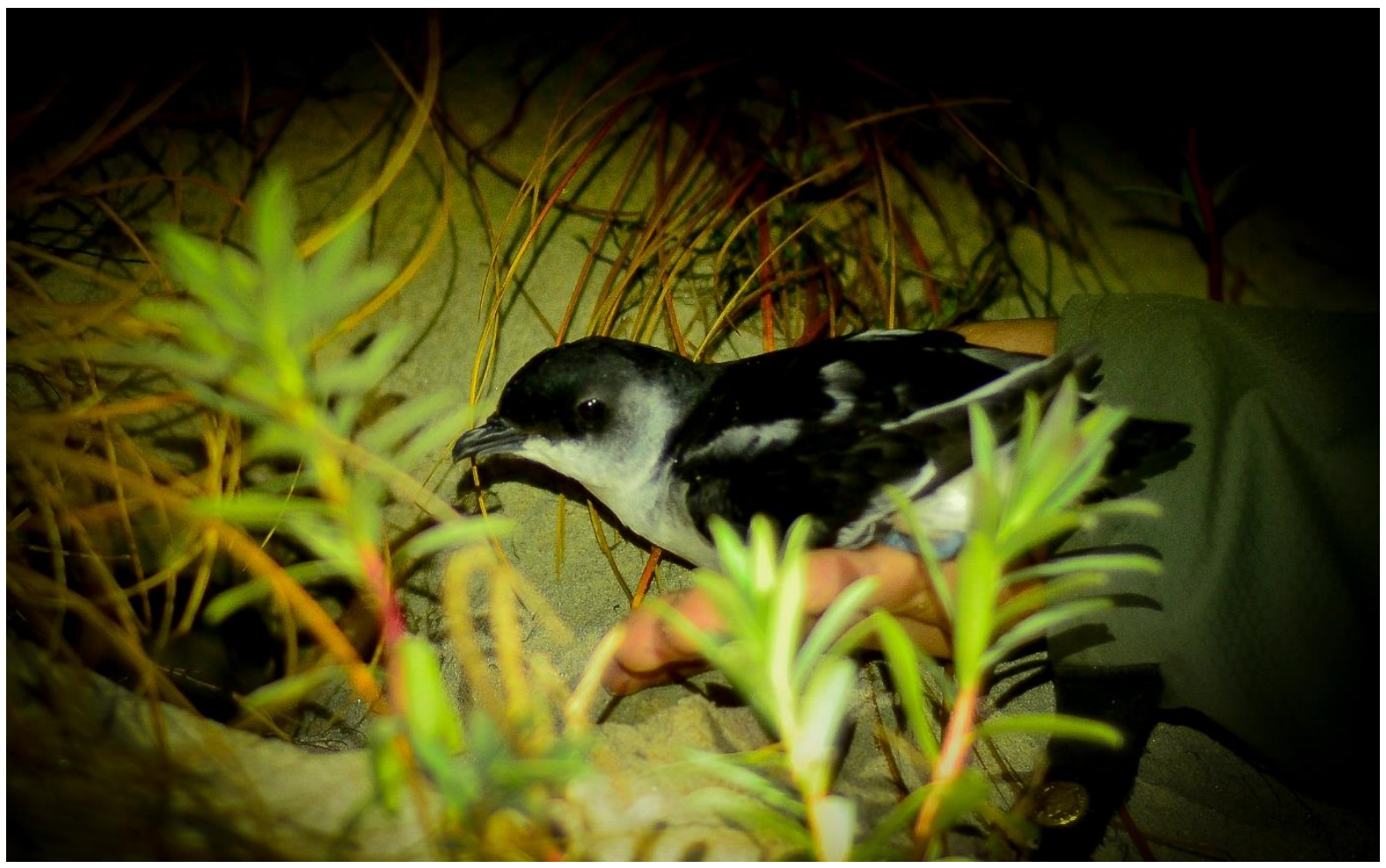

Fig. 3. Adult Whenua Hou Diving Petrel. Photo credit: Mithuna Sothieson.

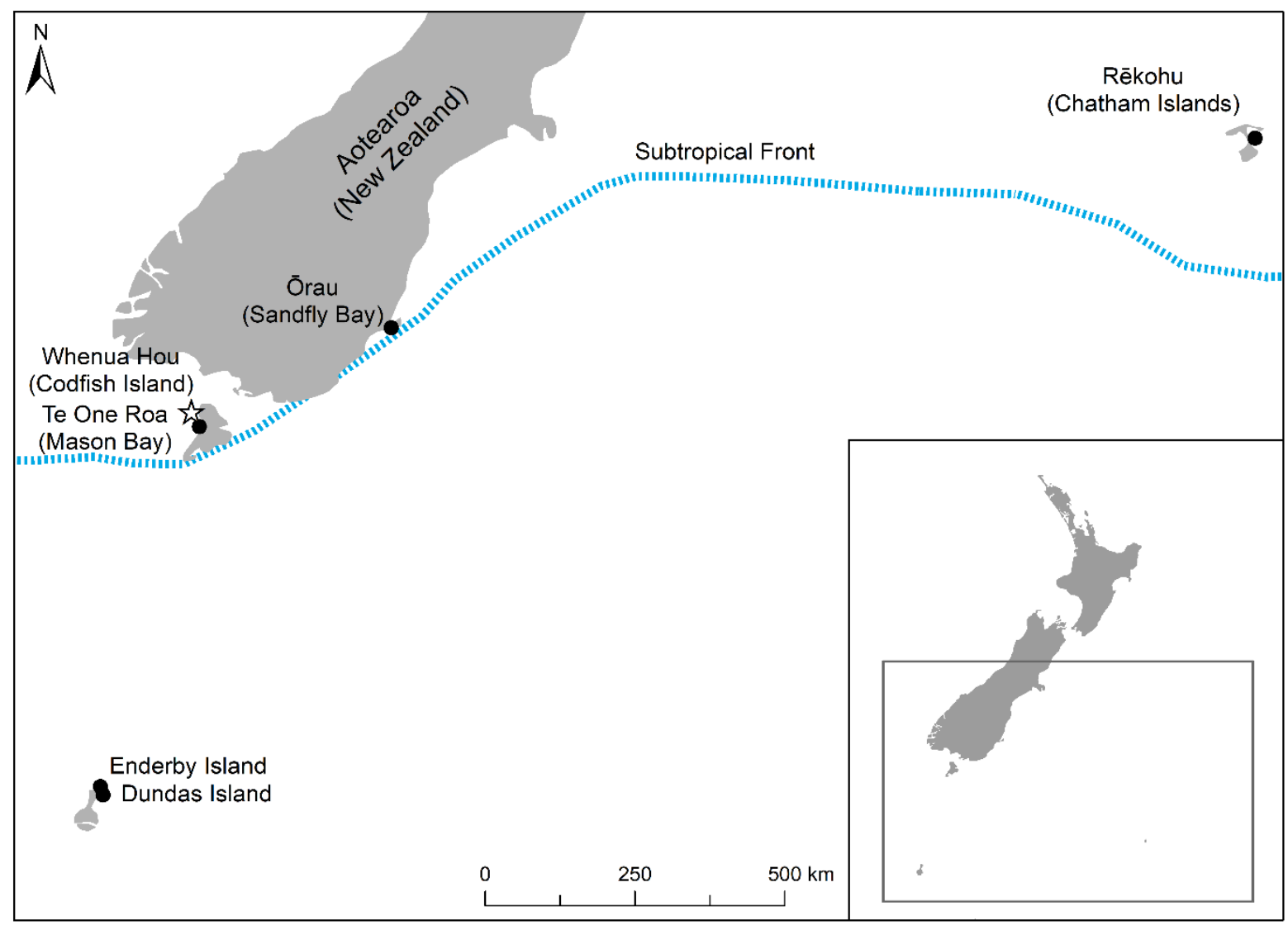

Fig. 4. Extant (white star) and extirpated (black circles) Whenua Hou Diving Petrel colonies. Approximate location of Subtropical Front is based on Harris \& Orsi (2006). 
Insights into the threats affecting the WHDP remain limited, inhibiting decisionmaking on adequate conservation measures. Whenua Hou is free of invasive predators following the eradications of Weka (Gallirallus australis), brush-tailed possums (Trichosurus vulpecula), and kiore (Rattus exulans; Brown \& Sherley 2002, McClelland 2002, Middleton 2007). Yet, after these eradications, additional threats to the WHDP may remain. The specialization of the WHDP to burrow in steep fragile foredunes $<20 \mathrm{~m}$ from the springtide line renders the species vulnerable to erosion caused by storms and storm surges (Fischer et al. 2018c). For example, a single storm event in 2003 caused $\sim 40 \%$ of all nest attempts to fail and entombed adults, causing adult mortality (Cole 2004). The onset of human-induced climate change will only exacerbate this threat. Stochastic events such as storms and storm surges are expected to increase in severity and frequency (Adam et al. 2020). In addition, 30-50\% of sandy coastlines in New Zealand are projected to recede by $>100 \mathrm{~m}$ in the next century due to increased coastal erosion (Vousdoukas et al. 2020). Competition for burrows with the closely related Common Diving Petrel (P. urinatrix) may also be a threat to the WHDP (Fischer et al. 2017a). No pelagic threats have been identified, but this is most likely due to the lack of knowledge on the offshore distribution and behaviour of the WHDP. Diving petrels are one of the taxa most effected by deck strikes (Ryan 1991, Black 2005, Glass \& Ryan 2013). Diving petrels have also been recorded as bycatch in trawl, gill net, and longline fisheries (Žydelis et al. 2013, Abraham \& Richard 2019, Richard et al. 2020). Additionally, diving petrels may be one of the taxa most heavily affected by offshore resource-competition with humans (Grémillet et al. 2018). However, these birds are also one of the least-monitored seabirds. This lack of monitoring is also true for the WHDP (e.g., Imber \& Nilsson 1980, West \& Imber 1989, Fischer et al. 2018c). Lack of monitoring prevents the quantification of threats and therefore the evaluation of potential conservation measures (e.g., Sutherland \& Dann 2012, Genovart et al. 2016, Rodríguez et al. 2019). Translocations of WHDPs to a different island may be a suitable conservation strategy to mitigate the impacts from storms, storm surges, climate change, and interspecific competition (Cole 2004, Fischer et al. 2017a). However, detailed understanding of WHDP population dynamics are required to quantify the potential impact and success of conservation strategies, including translocations (Panfylova et al. 2019). 


\section{THESIS STRUCTURE}

The objective of this thesis is to facilitate the identification of a suitable conservation strategy to prevent the extinction of the WHDP. This thesis consists of five data chapters. In Ch. 2, I investigate the efficacy of past interventions (eradications of invasive predators) for conservation of the WHDP. I used intermittent burrow counts (19782018) with retrospective corrections to estimate population growth before and after predator eradications. In Ch. 3, I investigate pelagic threats to the WHDP by using tracking data (2016-19) to quantify WHDP offshore distribution, behaviour, and overlap with commercial fishing effort. In Ch. 4, I assess the feasibility of WHDP translocations as a conservation strategy by combining intermittent capture-recapture data (2002-19), nest-monitoring data (2017-19), and count data (2002-19) in an integrated population model to quantify population dynamics and simulate the impact and success of a future WHDP translocation. In Ch. 5, I use nest-monitoring data (2017-19) to quantify WHDP nest survival and breeding biology to inform future WHDP translocation protocols. In Ch. 6, I investigate the impact of WHDPs on unrelated species groups. I combined skink counts and occupancy modelling to estimate the influence of WHDP burrows on skink occurrence. Combined these five chapters will inform future conservation management of the WHDP and how management could affect larger dune communities in southern Aotearoa.

This thesis consists of five separate papers which address separate topics relevant to conservation. Addressing these topics does not only benefit WHDP conservation but also contributes to a wider understanding of seabird ecology and conservation globally. Four of these papers (Ch. 2, 3, $5 \& 6$ ) have been submitted to or published by peer-reviewed scientific journals prior to the submission of this thesis (Table 1). I am the lead author of all five papers. My supervisors, Heiko U. Wittmer, Doug P. Armstrong, and Igor Debski, are co-author on (almost) all these papers. In addition, Graeme A. Taylor is a co-author on the papers that arose (or will arise) from $\mathrm{Ch}$. 2-5, for providing previously collected data and technical insights. Ros Cole is a co-author on the paper that arose from Ch. 2 for providing previously collected data. Derek Spitz is a co-author on the paper arising from Ch. 3 for assisting with the net squared displacement modelling. Cora F. McCauley is a coauthor on the paper that arose from Ch. 6 for covering a substantial amount of fieldwork. All chapters that have been published or submitted are reproduced here with minor 
modifications, formatting, and inclusion of cross-referencing among chapters. As a consequence, some chapters include te reo Māori abstracts (tuhinga whakarāpopoto), while others do not (yet).

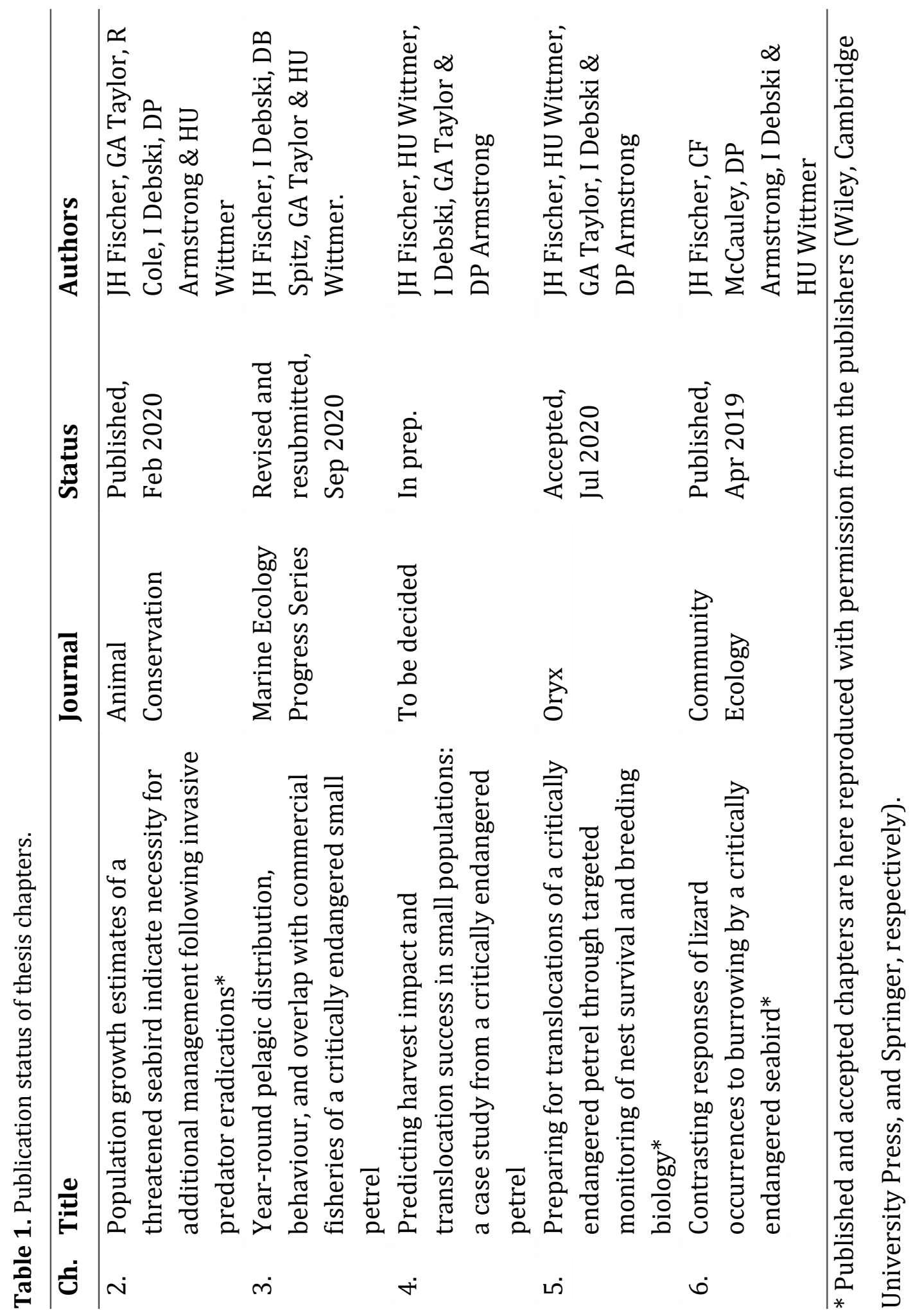


Chapter 1 
Chapter 2

\title{
Population growth estimates of a threatened seabird indicate necessity for additional management following invasive predator eradications
}

\begin{abstract}
The eradication of invasive predators from islands is a successful technique to safeguard seabird populations, but adequate post-eradication monitoring of native species is often lacking. The Whenua Hou Diving Petrel (Pelecanoides whenuahouensis; WHDP) is a critically endangered seabird, restricted to Whenua Hou (Codfish Island), Aotearoa (New Zealand). Invasive predators, considered the major threat to WHDP, were eradicated on Whenua Hou in 2000. However, estimates of WHDP population size and trends remain unknown, hindering assessments of the success of the eradications. I collated intermittent burrow counts $(n=20)$ conducted between 1978 and 2018. To estimate the population growth rate $(\lambda)$ before and after predator eradications, I used log-linear models in a Bayesian hierarchical framework while retrospectively accounting for differences in detection probabilities among burrow counts, due to differences in effort, marking, and timing. The number of WHDP burrows was estimated at 40 (36-46) in 1978 and 100 (97-104) in 2018. The pre-eradication $\hat{\lambda}$ was estimated at 1.023 (0.959-1.088), while the post-eradication $\hat{\lambda}$ was estimated at 1.017 (1.006-1.029). The WHDP population appears to be increasing, yet the rate of increase is low compared to other Procellariiformes following predator eradications. The comparatively low posteradication $\hat{\lambda}$, combined with an apparent lack of change between pre- and posteradication $\hat{\lambda}$, indicates that additional threats might be limiting WHDP population growth and that further conservation management is required. The continuation of affordable and simple, albeit imperfect, monitoring methods with retrospective corrections facilitated the assessment of invasive predator eradications outcomes and should guide future management decisions.
\end{abstract}


Chapter 2

\section{TUHINGA WHAKARĀPOPOTO}

He tikanga whaihua te whakakorenga o ngā kaikonihi urutomo mai i ngā motu hei tiaki i ngā taupori manu moana, engari i ètahi wā he koretake te aroturuki i ngā momo manu taketake i muri i te whakakore kaikonihi. Ko te kuaka o Whenua Hou (Pelecanoides whenuahouensis) he manu moana e noho tata korehāhā ana, kātahi anō ka whakaahuatia, ā, e noho ana anake ki te moutere o Whenua Hou, Aotearoa. Ko ngā tino kaikonihi urutomo o te kuaka i whakawāteahia mai i Whenua Hou i te tau 2000. Engari, kāore i te mōhiotia ngā tatau me ngā ia o te tapori o te kuaka o Whenua Hou, nā reira e whakararurarutia ana ngā aromatawai o te angitu o ngā mahi whakakore kaikonihi. I kohia e mātau ngā tatau tūrua ( $n=20$ ngā tau) tāmutumutu i waenga i te tau 1978 me te 2018. Hei whakatau tata i te pāpātanga tipu o te taupori $(\lambda)$ i mua me muri i ngā whakakorenga kaikonihi, i whakamahia e mātau ngā tauira rārangi-pūkōaro i roto i tētahi mahere raupapa Bayes, me te whakauru i muri mai i ngā rerekētanga mō te tautuhi i ngā tūponotanga i roto i ngā tatau tūrua, nā te rerekē o ngā mahi, te waitohu me te wā. Ko te whakatau tata o ngā tūrua o ngā kuaka o Whenua Hou he 40 (36-46) i te tau 1978 me te 100 (97-104) i te tau 2018. Ko te whakatau tata i te $\hat{\lambda}$ i mua i te whakakorenga he 1.023 (0.959-1.088), ā, ko te whakatau tata i te $\hat{\lambda}$ i muri i ngā whakakorenga he 1.017 (1.0061.029). Te āhua nei kei te piki haere te taupori o te kuaka o Whenua Hou, engari he pāpaku noa iho te pāpātanga o taua piki haere ina ka whakatauritea ki etahi atu Procellariiformes i muri i ngā whakakorenga kaikonihi. Nā te iti o te $\hat{\lambda}$ i muri mai i ngā whakakorenga me te kore rerekēhaeretanga i waenga i te $\hat{\lambda}$ i mua me muri i ngā whakakorenga e tohu ana kei te whakatikia pea e ngā mōrea atu anō te tipuranga o te taupori o te kuaka o Whenua Hou, ā, e hiahiatia ana anō ngā whakahaerenga tauwhiro atu anō. Nā ngā tikanga aroturuki iti te utu me te māmā ukiuki, ahakoa takarepa, me ngā whakatikatanga i muri mai, i āhei te aromatawai i ngā putanga o ngā whakakorenga o ngā kaikonihi urutomo, ā, me ārahi i ngā whakatau whakahaerenga anamata. 


\section{INTRODUCTION}

Close to two-thirds of all reported extinctions in the sixth mass extinction have occurred on islands, the majority of which have been attributed to predation from invasive species (Tershy et al. 2015, Jones et al. 2016). To counter the detrimental effects of invasive predators, eradications of these problematic species are attempted on many islands. Native species generally respond positively to eradication efforts. Over 200 native animal species found on islands have benefited from invasive predator eradications through increases in abundance and/or distribution (Jones et al. 2016, Brooke et al. 2018a). Given these benefits, eradications of invasive predators have become a widespread conservation practise with at least 850 island-wide eradications around the globe between 1950 and 2015 (Database of Island Invasive Species Eradications 2015).

Invasive predator eradications from islands often play a key role in seabird conservation, as many seabird species breed on islands, or are even endemic to them (Taylor 2000ab, Spatz et al. 2017, Brooke et al. 2018a, Rodríguez et al. 2019). Seabirds, and notably members of the order Procellariiformes, are one of the most threatened taxonomic groups on the planet (Fig. 2; Croxall et al. 2012, Rodríguez et al. 2019). Many Procellariiformes are $K$-strategists (i.e., low fecundity and high longevity). Therefore, these species are highly susceptible to the reduced hatching/fledging success and heightened adult mortality that are typical consequences of invasive predators (Jones et al. 2007, Spatz et al. 2017, Brooke et al. 2018a, Rodríguez et al. 2019). Smaller species (< $1 \mathrm{~kg}$ ) are especially susceptible to invasive predators (Jones et al. 2007). While Procellariiformes are $K$-strategists, they can respond surprisingly quickly and positively to invasive predator eradications (Jones 2010, Brooke et al. 2018a). However, despite the clear conservation gains of invasive predator eradications, systematic post-eradication monitoring remains rare (Jones et al. 2016), hindering the evaluation of success and assessments of complementary threats (Spatz et al. 2017, Towns 2018).

Whenua Hou (Codfish Island), Aotearoa (New Zealand), hosts a diverse community of small Procellariiform seabirds and invasive predators were eradicated from the island to restore this seabird community (Middleton 2007). Specifically, Weka (Gallirallus australis; a predatory bird species native to Aotearoa but invasive to Whenua Hou; Taylor 2000a) were eradicated in 1984, followed by brush-tailed possums (Trichosurus Vulpecula) in 1987, and kiore (Rattus exulans) in 2000 (dates here represent the year in 
which the eradications were completed; Brown \& Sherley 2002, McClelland 2002, Middleton 2007). One of the Procellariiform species that breeds on Whenua Hou is the critically endangered Whenua Hou Diving Petrel (Pelecanoides whenuahouensis; WHDP). This species faced major range restrictions and population declines due to the impacts of invasive predators and is now restricted to a single colony on Whenua Hou (Fig. 4; Taylor 2000b, Holdaway et al. 2003, Fischer et al. 2018bc). While invasive predators have been removed from Whenua Hou, little is known about past and contemporary population estimates and trends of the WHDP, hindering any assessment of the population responses to the eradication efforts.

To better understand the effects of the eradications of invasive predators on the WHDP, I collated intermittent WHDP burrow counts ( $n=20)$ between 1978 and 2018. I then modelled the annual WHDP population growth rates over two biologically relevant time periods: the pre-eradication period (1978-85) and the post-eradication period (2002-18). I accounted retrospectively for differences in detection probability among burrow counts due to differences in effort, marking, and timing, using expert elicitation and data on patterns of WHDP colony attendance. Finally, I used existing literature to compare the annual WHDP population growth rate post-eradications with the posteradication growth rates of other Procellariiform species breeding on Whenua Hou. 


\section{METHODS}

\section{Study species and study area}

The Whenua Hou Diving Petrel is a small ( $130 \mathrm{~g})$ Procellariiform seabird, which was previously considered conspecific with the South Georgian Diving Petrel (P. georgicus; Fischer et al. 2018b). Following the designation as a new species, the WHDP has been listed as critically endangered on the IUCN Red List (Fischer et al. 2018b, BirdLife International 2020). WHDPs were historically widespread through southern Aotearoa, but predation by invasive species caused local extinctions throughout their range, including Rēkohu (Chatham Islands), Maukahuka (Auckland Islands), Rakiura (Stewart Island), and Muaupoko (Otago Peninsula) (Fig. 4; Worthy 1998, Taylor 2000b, Holdaway et al. 2003, Wood \& Briden 2008, Fischer et al. 2017b). Today, the WHDP is restricted to Whenua Hou (14 km²; Fig. 5) located circa 3 km west of Rakiura. I conducted my study within the only WHDP colony, which is located in the dunes of Waikoropūpū (Sealers Bay $-46.766^{\circ} \mathrm{S}, 167.645^{\circ} \mathrm{E}$; Fischer et al. 2017a, 2018c). WHDPs breed in burrows in these dunes from early September to late January, but colony attendance varies with breeding stages (i.e., the species' phenology), which complicates burrow counts.

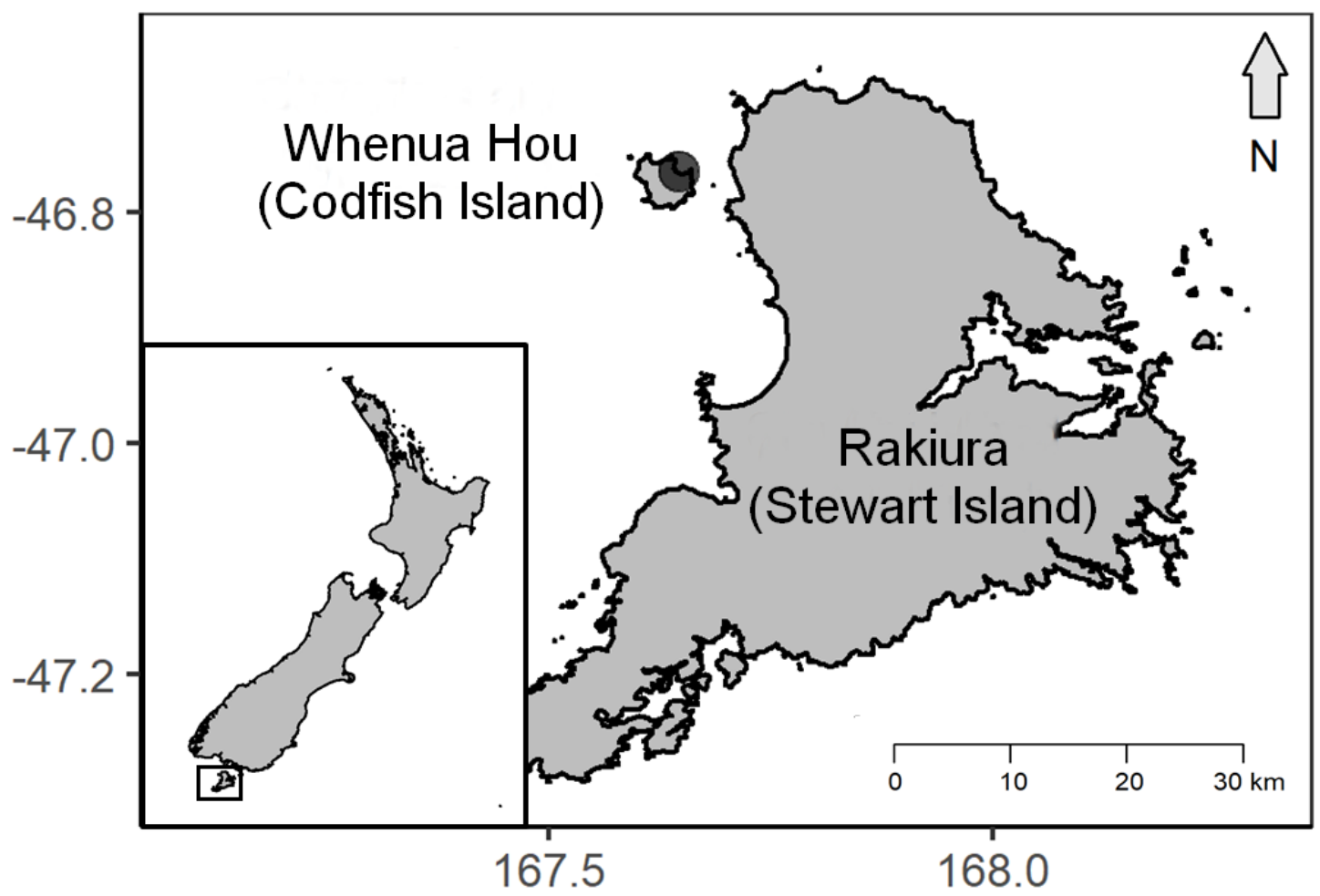

Fig. 5. Location of the study site, Waikoropūpū (Sealers Bay), Whenua Hou (Codfish Island), Aotearoa (New Zealand), as indicated by the dark-grey circle. 


\section{Burrow counts}

I collated intermittent counts of WHDP burrows based on I) my own WHDP burrow counts (2015-18; reporting the calendar year in which breeding started.), II) the scientific literature, and III) unpublished management reports from the New Zealand Department of Conservation (Table 2). All burrow counts were conducted by walking the entirety of the extremely small $\left(0.018 \mathrm{~km}^{2}\right)$ breeding colony back and forth (Taylor \& Cole 2002, Fischer et al. 2018c). After the first count in 1978 (the year in which the colony was discovered; Imber \& Nilsson 1980), all detected burrows were marked with stakes during each count (Cox 1991, R Nilsson pers. comm. 2018). When I found more than one count per breeding period in the literature, I used the earlier count. I only considered counts of occupied WHDP burrows, because a small number of Common Diving Petrels $(P$. urinatrix) also breeds in the study area (Fischer et al. 2017a). I assessed burrow occupancy through stick palisades, sometimes in combination with playback/human mimics (Imber \& Nilsson 1980, Taylor 1991, Taylor \& Cole 2002, Fischer et al. 2018b). As occupancy assessments require $>1$ day, I excluded counts conducted within a single day. 


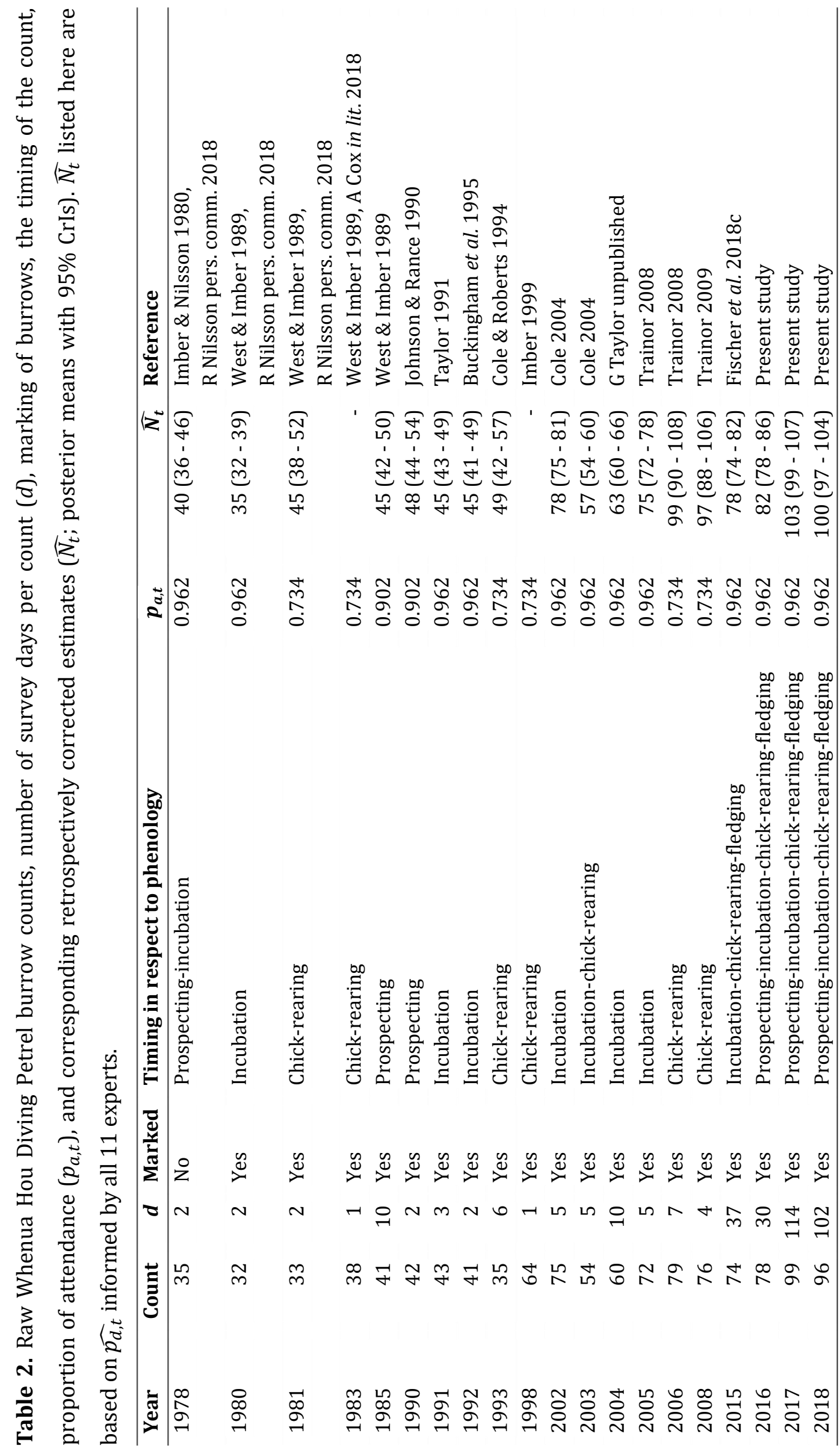


Chapter 2

\section{Modelling WHDP growth rates}

To estimate the yearly rate of WHDP population growth before and after the invasive predator eradications on Whenua Hou while retrospectively correcting estimates of burrow counts, I fitted log-linear models with a Poisson error term in a Bayesian hierarchical framework. Specifically, I fitted the data to:

1. $\log \left(N_{t}\right)=\alpha+r_{t}+\varepsilon_{t}$

in which $N_{t}$ is the number of WHDP burrows at year $t, \alpha$ is $\log \left(N_{0}\right)$ (the number of WHDP burrows at year 0 ), $r$ is the $\log$ of $\lambda$ (the finite rate of increase), $t$ is the number of years between 0 and $t$, and $\varepsilon_{t}$ is random annual variation (Caughley 1977, Caughley \& Sinclair 1994). I used log-linear models because I assumed the WHDP population to exhibit exponential growth rates. I considered the number of burrows counted each year $\left(n_{t}\right)$ to be a sampled from a binomial distribution:

2. $n_{t} \sim \operatorname{Bin}\left(p_{t}, N_{t}\right)$

in which $p_{t}$ is the probability that a burrow was detected in year $t$. I modelled the expected variation in $p_{t}$ as:

3. $p_{t}=1-\left(1-p_{d, t}\right)^{d} \times p_{a, t}$

in which $p_{d, t}$ is the daily probability that a burrow was detected and identified as occupied by WHDPs, $d$ is the number of survey days in year $t$, and $p_{a, t}$ is the proportion of the WHDP burrows that were attended to at the time of the breeding period that the count was conducted. I thus retrospectively accounted for imperfect detection in WHDP burrow counts by modelling I) the search effort each year, II) the marking of the burrows, and III) the timing of the count in relation to the species' phenology.

To obtain probability distributions for $p_{d, t}$, I designed an expert elicitation based on the Delphi method (Linstone \& Turoff 1975, Kuhnert et al. 2010, Martin et al. 2012). I consulted every living person who had conducted a WHDP burrow count and considered them an expert ( $n=18)$. My approach (Delphi method) consisted of two rounds. In round one, I asked experts independently to provide me with a three-point estimate (their best 
guess, the minimum and the maximum) of $p_{d}$, provided the colony is I) marked or II) unmarked. I thus requested separate values for a marked (i.e., after 1978) and an unmarked colony (i.e., 1978) from the experts, allowing me to adjust $p_{d, t}$ according to whether burrows were marked that year. I assumed that $p_{d, t}$ was otherwise constant (e.g., no variation due to learning curves of observers, changes in dune vegetation, or other factors that may have varied among years other than marking). In addition, I assumed that all burrows were equally likely to be detected and that misidentification of WHDP burrows was impossible. The experts were aided in their decision in round one by a graph depicting hypothetical detection probabilities $\left(p_{d}=0.1-0.9\right)$ as a function over time (Appendix 1). I then compiled responses $(n=11 ; 61 \%)$ and sent anonymous summary statistics to each respondent, allowing them to adjust their initial response (round two; Linstone \& Turoff 1975, Kuhnert et al. 2010, Martin et al. 2012). Only one response (6\%) was adjusted in round two (Fig. 6). I obtained beta.PERT distributions (Clark 1962) for $p_{d, t}$ based on the three-point estimates from the expert responses in round two.
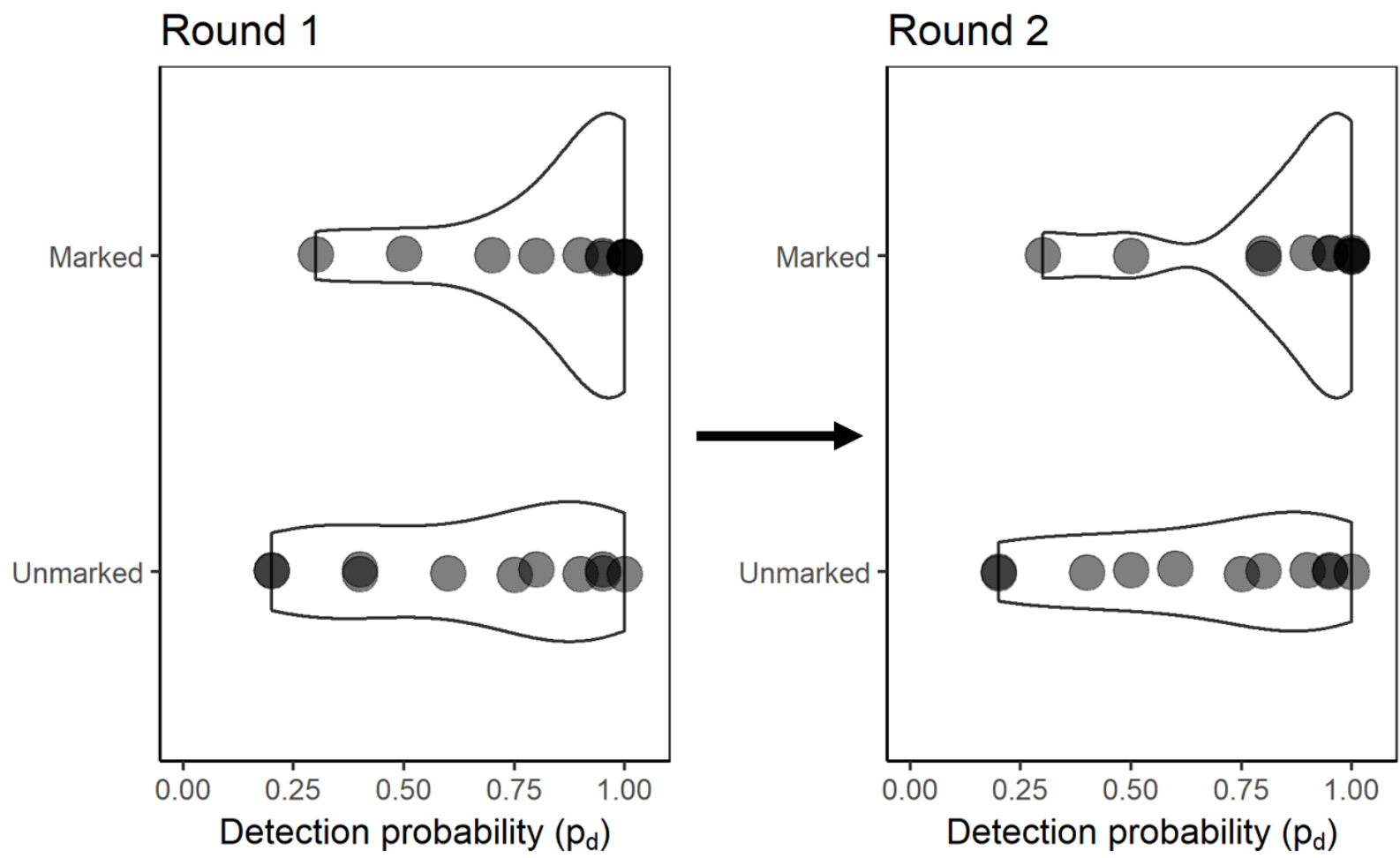

Fig. 6. Violin plots illustrating the distribution of best guesses of detection probabilities $\left(p_{d}\right)$ of Whenua Hou Diving Petrel burrows in marked/unmarked systems, as provided by experts $(n=$ 11) during the two rounds of an expert elicitation following the Delphi method. 
To obtain a meaningful numerical value for $p_{a, t}$, I monitored WHDP burrows during the entire 2017 and 2018 period ( $n=86$ and 81, respectively). Specifically, I monitored the daily activity of these burrows using stick palisades (Imber \& Nilsson 1980, Taylor \& Cole 2002, Fischer et al. 2018c) to create a colony attendance curve throughout the breeding period. At the same time, I monitored a subset of burrows in 2017 and 2018 ( $n$ $=29$ and 25, respectively) with a burrowscope (Taupe model, Sextant Technologies, Wellington, New Zealand; Lavers et al. 2019) to assess mean dates of key phenology events (i.e., lay, hatch, and fledge dates). I summed the daily burrow attendance per week and allocated these into phenologically relevant stages based on the timing of the count (i.e., prospecting, incubation, chick-rearing or fledging). I then obtained $p_{a, t}$ by averaging the weekly values per phenological category. When counts fell into several phenological stages, I allocated the count into the category with the highest $p_{a, t}$. I assumed that the timing of key phenology events during the 2017 and 2018 breeding period were representative off other years.

I used Equation 1-3 to estimate $\lambda$ for two biologically relevant time periods: before and after the predator eradications. To estimate the $\lambda$ before the predator eradications, I fitted a model to data between 1978 and 1985. I used the 1978-1985 timeframe because I anticipated a 2-year lag (i.e., expected age at first breeding; Miskelly \& Taylor 2004, 2007) of the WHDP population to respond to eradication efforts, in the absence of immigration (Whenua Hou hosts the only WHDP colony). To estimate $\lambda$ after the predator eradications, I fitted a model to data between 2002 and 2018. In addition, to explore the influence of the expert assessment of $p_{d, t}$ on $\widehat{N_{t}}$ and $\hat{\lambda}$, I repeated my analysis three times using distributions for $p_{d, t}$ that were informed by: I) the average best guess, minimum and maximum from all experts, II) the values provided by the most pessimistic expert, and III) the values provided by the most optimistic expert.

I fitted the models using OpenBugs 3.2.3, which uses Markov chain Monte Carlo (MCMC) algorithms to obtain posterior distributions for parameters, allowing all sources of error to be propagated into those distributions (Lunn et al. 2000, Spiegelhalter et al. $2014)$. I used vague priors $(N[$ mean $=0$, precision $=0.01])$ for $\alpha$ and $r$. In most cases I pooled three independent MCMC chains with 100,000 iterations each after a burn-in of 50,000 iterations, resulting in posterior distributions based on 150,000 iterations. Inspection of the Gelman-Rubin statistic $(\hat{R})$ showed slow convergence of chains for the pre-eradication data based on pessimistic values for $p_{d, t}$, so I increased the number of 
iterations to $2,100,000$ with a burn-in of 50,000, giving satisfactory convergence for all estimates $(\hat{R}<1.05)$ (Paxton et al. 2016). I report posterior distributions of $N_{t}$ and $\lambda$ as means with 95\% credible intervals (CrI). The OpenBUGS code of my models can be found in Supplementary Material 1.

\section{Comparison with other Procellarifformes}

I compared the $\lambda$ of the WHDP population after the eradications of invasive predators with the post-eradication $\lambda$ of other small Procellariform populations breeding on Whenua Hou. Specifically, I used existing literature to source $N_{t}$ of both Cook's Petrels (Pterodroma cookii; $190 \mathrm{~g}$ ) and Mottled Petrels (P. inexpectata; $315 \mathrm{~g}$ ) on Whenua Hou and calculated the $\lambda$ post eradications using Equation 1 (Marchant \& Higgins 1990). When population estimates were reported as a range only, I used the midpoint as $N_{t}$. As published estimates of both Cook's and Mottled Petrels lacked detail (e.g., details of historical counts were lost and/or counts were only conducted in small parts of the colonies), I did not apply Equation 2 and 3 to retrospectively correct these estimates.

\section{RESULTS}

\section{WHDP population growth rates}

A total of 20 raw WHDP burrow counts were collated from 1978 to 2018 (one per breeding period), but two single-day counts were excluded from my analyses (Table 2). The estimates of daily detection probability $\left(\widehat{p_{d, t}}\right)$ obtained by averaging the data from the 11 experts were 0.83 (minimum $=0.76$, maximum $=0.90$ ) in a marked colony and $0.66(0.58-0.75)$ in an unmarked colony. The data from the most pessimistic expert produced an $\widehat{p_{d, t}}$ of $0.30(0.01-0.60)$ for a marked system and $0.20(0.01-0.40)$ for an unmarked system. The data from the most optimistic expert produced an estimate of $\widehat{p_{d, t}}$ of $0.99(0.97-1.00)$ for a marked system and $0.99(0.95-1.00)$ for an unmarked system. The proportion of attended WHDP burrows $\left(p_{a, t}\right)$ per phenological stage was as following: prospecting: September - mid October, $p_{a, t}=0.90$; incubation: mid-October late November, $p_{a, t}=0.96$; and chick rearing: late November - mid-January, $p_{a, t}=0.73$ (Fig. 7). No counts were conducted solely during fledging. 


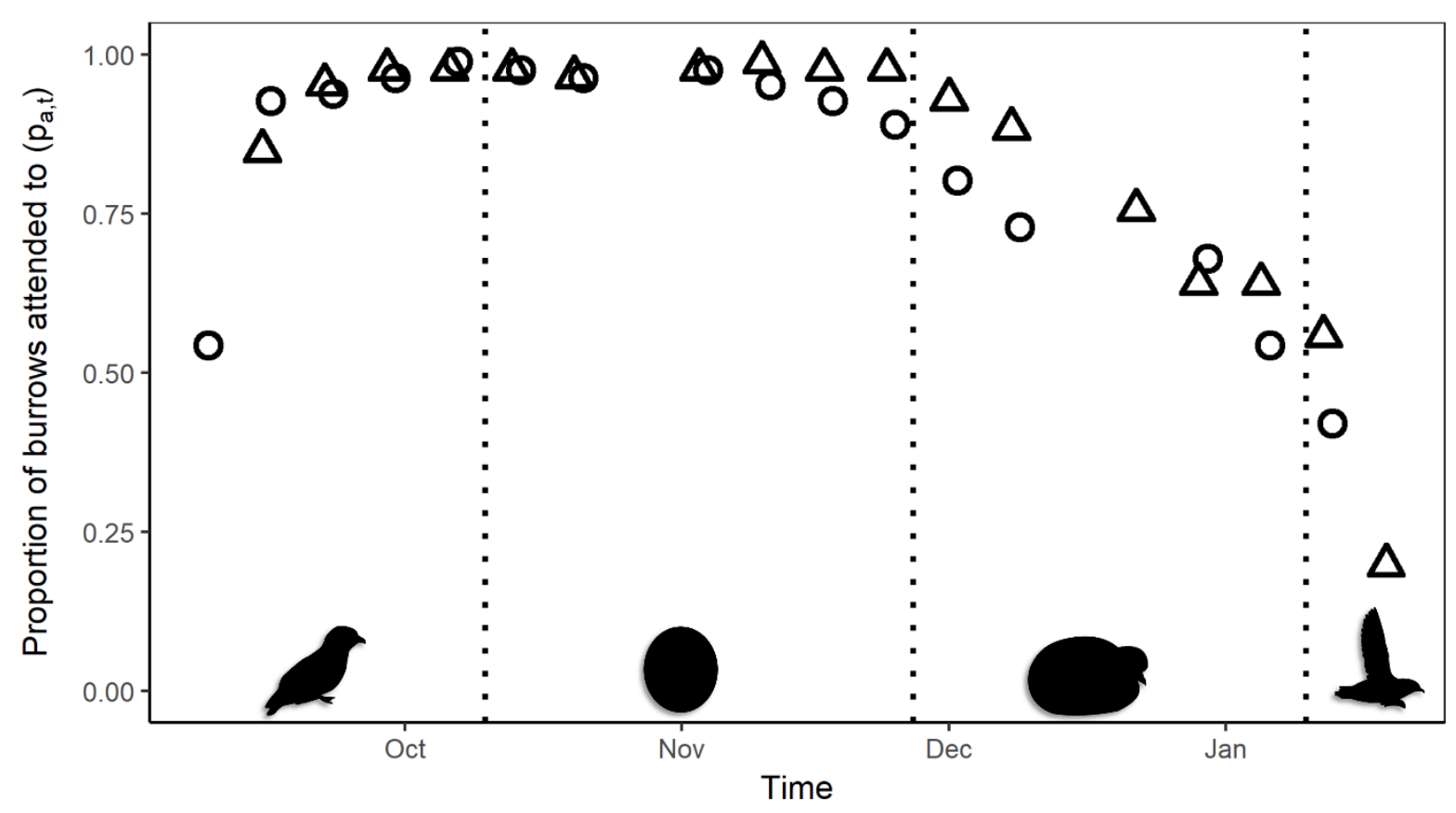

Fig. 7. The proportion of Whenua Hou Diving Petrel burrows that were attended to $\left(p_{a, t}\right)$ in relation to key phenology events (prospecting, incubation, chick-rearing or fledging) during the 2017 (triangles; $n=86$ ) and the 2018 (circles, $n=81$ ) breeding periods. Dotted lines represent mean lay (09 October), hatch (26 November) and fledge dates (11 January).

When using $\widehat{p_{d, t}}$ informed by the 11 experts, the estimated number of WHDP burrows $\left(\widehat{N_{t}}\right)$ varied from 40 (36-46) in 1978 to 100 (97-104) in 2018 (Table 2, Fig. 8), the preeradication $\hat{\lambda}$ (1978-85) was estimated at 1.023 (0.959-1.088), and the post-eradication $\hat{\lambda}(2002-18)$ was estimated at 1.017 (1.006-1.029) (Fig. 9). However, when using the $\widehat{p_{d, t}}$ informed by the most pessimistic expert, $\widehat{N_{t}}$ varied from 59 (48-72) in 1978 to 100 (96104) in 2018 (Appendix 2), the pre-eradication $\hat{\lambda}$ was estimated at 0.915 (0.833-0.991), and the post-eradication $\hat{\lambda}$ was estimated at 1.014 (1.002-1.026). When using the $\widehat{p_{d, t}}$ informed by the most optimistic expert, $\widehat{N_{t}}$ varied from 36 (35-39) WHDP burrows in 1978 to 100 (97-104) WHDP burrows in 2018 (Appendix 3), the pre-eradication $\hat{\lambda}$ was estimated at $1.038(0.975-1.103)$, and post-eradication $\hat{\lambda}$ was estimated at 1.017 (1.0061.029). 


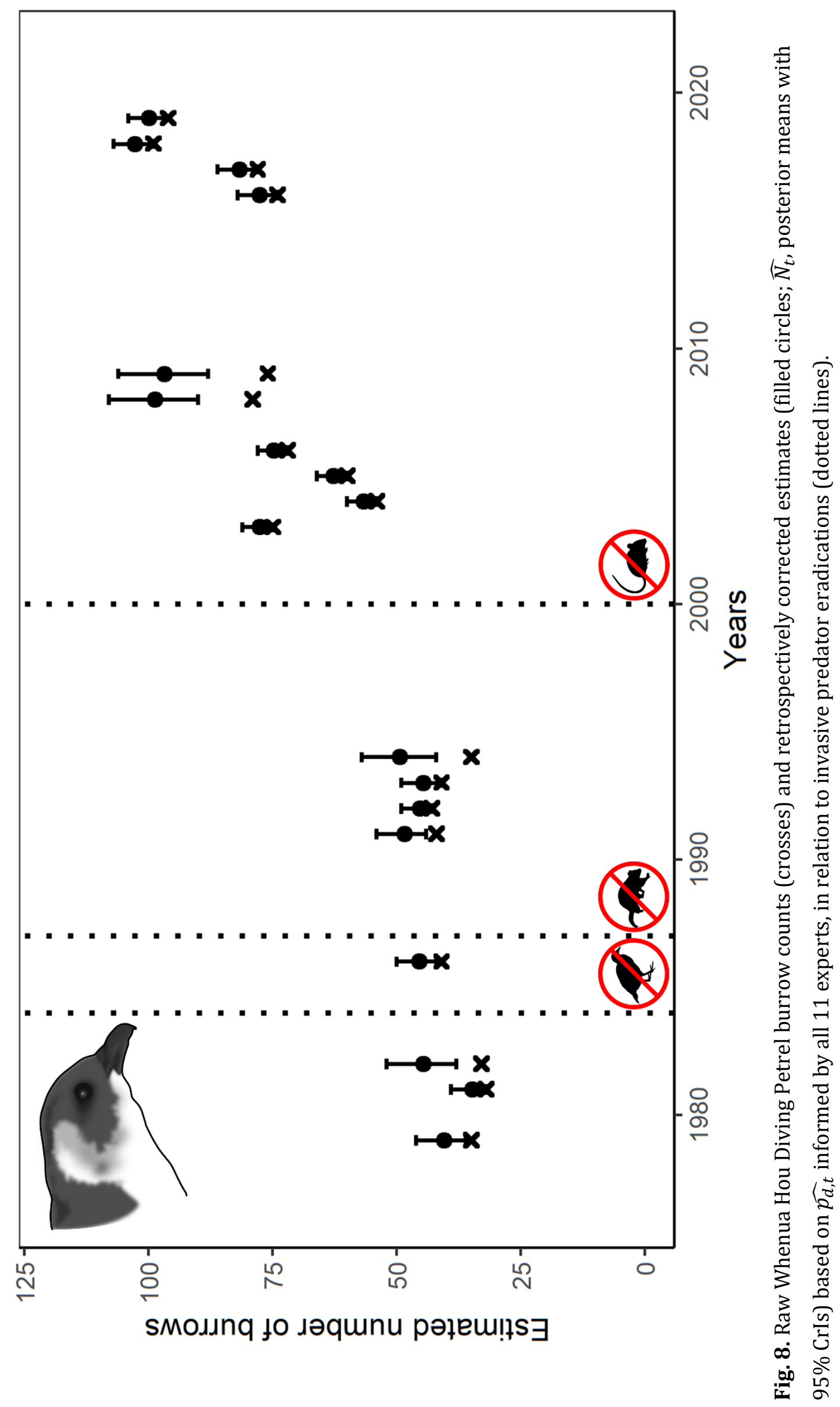




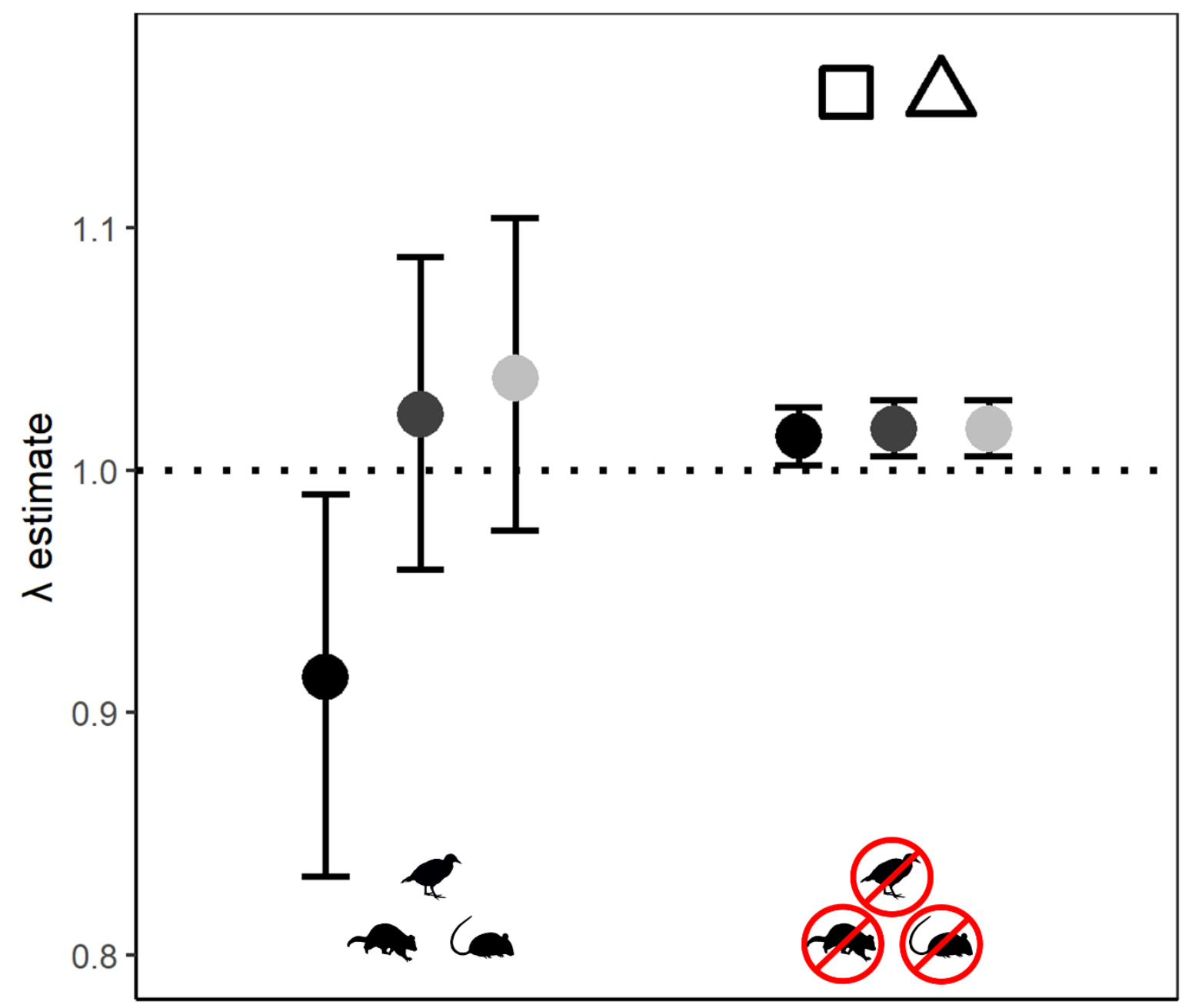

Fig. 9. Estimates of yearly rates of Whenua Hou Diving Petrel population growth $(\hat{\lambda})$, before and after eradications of invasive predators (filled circles; posterior means with 95\% CrIs; black = based on $\widehat{p_{d, t}}$ informed by most pessimistic expert, grey $=$ based on $\widehat{p_{d, t}}$ informed by all 11 experts, and light-grey $=$ based on $\widehat{p_{d, t}}$ informed by most optimistic expert), in comparison with estimates of Cook's Petrel (hollow triangle) and Mottled Petrel (hollow square) $\lambda$ post eradications. Cook's and Mottled Petrel population $\lambda$ are based on (Robertson $\&$ Bell 1984, Taylor 2000a, Imber et al. 2003, Rayner et al. 2008b).

\section{Comparison with other Procellariiformes}

The Cook's Petrel population on Whenua Hou grew from 100 burrows in 1980 to approximately $5,000(3,500-7,000)$ burrows in 2007 . The $\lambda$ for this period for Cook's Petrel was 1.156 (Fig. 9). The Mottled Petrel population on Whenua Hou grew from 10,000-50,000 burrows in 1980 to $300,000-400,000$ burrows in 1996 . The $\lambda$ for this period for Mottled Petrel was 1.155. 


\section{DISCUSSION}

I presented WHDP burrow estimates for the last four decades, which ranged from $\widehat{N_{t}}=$ 40 (36-46) burrows in 1978 to $\widehat{N_{t}}=100$ (97-104) burrows in 2018 (using $\widehat{p_{d, t}}$ informed by all 11 experts). Under the assumption that every burrow was occupied by two adults, these estimates would equate to 80 (72-92) adults in 1978 and 200 (194-208) adults in 2018. These estimates highlighted that the WHDP population slowly increased over the last 40 years but still remained very low. In addition, I also presented the first estimates of the annual population growth rate of the WHDP. The pre-eradication $\hat{\lambda}$ (1978-85) was 1.023, while the post-eradication $\hat{\lambda}(2002-18)$ was 1.017 using $\widehat{p_{d, t}}$ informed all 11 experts. Both $\widehat{N_{t}}$ and $\hat{\lambda}$ (based on $\widehat{p_{d, t}}$ informed by all 11 experts) indicated that the WHDP population was slowly increasing before invasive predator eradications and still is slowly increasing afterwards.

Comparing raw burrow counts with my estimates derived from retrospective corrections highlighted the importance of accounting for differences in detection probability among burrow counts due to differences in effort and timing. Years in which counts were conducted during chick-rearing (i.e., counts with the lowest $p_{a, t}$ ) had the greatest difference between the raw burrow counts and $\widehat{N_{t}}$. Furthermore, burrow counts with a low number of survey days $(d)$ resulted in $\widehat{N}_{t}$ with larger CrIs, highlighting the importance of spending adequate time in the field (MacKenzie et al. 2002, 2003). The increased confidence in estimates caused by increased survey effort is also apparent in the $\hat{\lambda}$. The time spent in the WHDP colony after the eradications is considerably higher than before the eradications. Consequently, the $\hat{\lambda}$ post-eradications do not vary, even with different $\widehat{p_{d, t}}$. In contrast, the pre-eradication $\hat{\lambda}$ vary substantially under different $\widehat{p_{d, t}}$. Most noticeably, when using the $\widehat{p_{d, t}}$ informed the most pessimistic expert, the preeradication $\hat{\lambda}$ indicated a decreasing WHDP population $(\hat{\lambda}=0.915)$. However, when compared to detection probabilities of burrows of other Procellariiform species that breed in more vegetated habitats than the WHDP (Barbraud et al. 2009, Defos du Rau et al. 2015), the $\widehat{p_{d, t}}$ informed by the most pessimistic expert appeared to be underestimates. As such, the $\widehat{p_{d, t}}$ based on values provided by all eleven experts seemed a more realistic estimate. 
The post-eradication $\hat{\lambda}$ of the WHDP population contrasted with the $\lambda$ of other small Procellariiformes post eradications. For example, the population doubling time $\left(t_{d}\right)$ for the Cook's ( $t_{d}=4.49$ years) and Mottled Petrels ( $t_{d}=4.52$ years) on Whenua Hou was 9.2 and 9.1 times shorter, respectively, than the population doubling time of the WHDP $\left(t_{d}=\right.$ 41.18 years) (Caughley \& Sinclair 1994). The average population growth rate of 24 Procellariiform populations (17 small, i.e., $<1 \mathrm{~kg}$, species) after invasive predator eradications was $\lambda=1.079$ (populations established after the eradications were excluded; Brooke et al. 2018a). Therefore, the average population doubling time of small Procellariiformes population was $t_{d}=8.86$ years, which is 4.65 times shorter than the $t_{d}$ of the WHDP. Brooke et al. (2018a) highlighted that many seabird species respond rapidly to eradications, potentially due to a pool of immature birds. My intermittent time series did not cover the two years after the eradications (2000-02; the timeframe in which WHDP immatures would have responded; Miskelly \& Taylor 2004, 2007), preventing assessments of WHDP responses immediately after the eradications. Regardless of this shortcoming in my study, the population responses of most other Procellariiformes post-eradication efforts were considerably higher than the population response of the WHDP.

The lack of change between the pre- and post-eradication $\hat{\lambda}$ and the low posteradication $\hat{\lambda}$ indicated that after the invasive predator eradications other factors remained that limit the WHDP population growth and that additional management is required. Various factors could be limiting WHDP population recovery. The distinct preference of the WHDP to only breed in fragile foredunes suggests that the species is extremely vulnerable to storms and storm surges (Fischer et al. 2018c). For example, a storm in October 2003 eroded the foredune in which the WHDP breeds, caused nest failures, and increased adult mortality (Cole 2004). Translocations could reduce the vulnerability of the WHDP to these stochastic events (Ch. 4 \& 5, Miskelly \& Taylor 2004, Miskelly et al. 2009). Density dependence could be another explanation to the limited population growth of the WHDP. However, diving petrel colonies have been shown to reach much higher densities (e.g., 6 burrows $/ \mathrm{m}^{2}$; Taylor 2000b) than the current density of the WHDP colony (0.02 burrows $/ \mathrm{m}^{2}$; Ch. 5 ). Negative interspecific interactions between WHDPs and Common Diving Petrels (Fischer et al. 2017a) could also be limiting population growth. While the (meta)population of the Common Diving Petrel within the WHDP colony appeared small (Taylor \& Cole 2002, Fischer et al. 2018c), measures 
reducing interspecific interactions (e.g., burrow flaps; Gummer et al. 2015) could be considered. Furthermore, no pelagic threats to the WHDP have been assessed to date. Therefore, its pelagic distribution and associated threats, including deck strikes, accidental bycatch in commercial fisheries, or environmental variability, should be investigated (Ch. 3, Taylor, 2000ab, Black 2005, Pardo et al. 2017).

While I was unable to identify the factor(s) limiting WHDP population growth, my study illustrated the value of inexpensive and simple, albeit imperfect, field data in combination with retrospective corrections to evaluate the success invasive predator eradications. Eradications of invasive predators from islands have been extremely successful in restoring seabird populations (Jones et al. 2016, Spatz et al. 2017, Brooke et al. 2018a) and the eradications on Whenua Hou clearly were beneficial for the Cook's and Mottled Petrel populations (Fig. 9). Yet, eradications of invasive predators do not exclude the need for follow-up conservation measures (e.g., translocations for WHDPs). Brooke et al. (2018a) found that seven seabird populations did not respond to eradication efforts (e.g., Gould's Petrel Pterodroma gouldii ) and at least 23 seabird populations responded negatively $(\lambda<1)$, suggesting that the limited population response of the WHDP was not an isolated case. Due to the prevalent assumption that native species will be secured following island eradications, monitoring of native fauna post-eradication is rare and thus cases requiring additional management are unlikely to be recognized (Jones et al. 2016, Brooke et al. 2018ab, Towns 2018). The "unavailability of economical ways to measure change" was listed as another impediment to post-eradication monitoring (Towns 2018). In addition, the allocation of sparse funds towards I) monitoring the responses of native species following eradications or II) future eradications continues to be debated (Brooke et al. 2018b). This conundrum is aggravated by the longevity of seabirds (among other long-lived species), as the post-eradication monitoring of these species would ideally span decades, further elevating monitoring costs (Brooke et al. 2018ab, Towns 2018). Both Towns (2018) and Brooke et al. (2018b) highlight the need for simple, inexpensive monitoring methods that have the potential to assess eradication outcomes over extended time periods. Although detailed (and thus often expensive) monitoring schemes following invasive predator eradications (or even in general) are largely missing (Paleczny et al. 2015, Towns 2018), basic, but imperfect data (such as burrow counts) do often exist (e.g., Taylor 2000ab). My results demonstrate that relatively inexpensive monitoring approaches (e.g., burrow-counts), combined with 
Chapter 2

retrospective corrections, can be informative and allow for evaluations of management success across extended time periods, even when monitoring has been intermittent. I thus advocate the use of imperfectly collected historical data and recommend the continuation of similar simple and inexpensive monitoring methods post-eradications to inform outcomes of invasive predator eradications and consequently, future conservation management. 
Chapter 3

\title{
Year-round offshore distribution, behaviour, and overlap with commercial fisheries of a critically endangered small petrel
}

\begin{abstract}
Year-round offshore distributions, movements, and behaviours of many small $(<0.3 \mathrm{~kg})$ seabirds remain largely unknown, despite increasing conservation concern. Without such insights, effective conservation management cannot be applied. The Whenua Hou Diving Petrel (Pelecanoides whenuahouensis; WHDP) is a critically endangered small seabird whose offshore habits and threats remain unknown. We tracked WHDPs year-round in 2015/16, 2017/18, and 2018/19 using global location-sensing immersion loggers to identify offshore distribution, movements, behaviour, and overlap with commercial fishing effort. During the breeding period, WHDPs ranged from the south of Aotearoa (New Zealand) to Maukahuka (Auckland Islands). After breeding, WHDPs migrated south-west towards the Polar Front south of Australia, exhibited clockwise movements, and returned to their breeding grounds via the Subantarctic Front. During the nonbreeding period, WHDPs exhibited extreme aquatic behaviour and spent up to $99 \%$ of their time on, or under, water. Distributions were consistent across years and spatial segregation, either between sexes or between failed and successful breeders, was absent. The core areas used during both breeding and non-breeding periods warrant listing as Important Bird and Biodiversity Areas. Spatiotemporal overlap of commercial fishing effort with breeding distributions was considerable (35\%), in contrast with non-breeding distributions (0\%). The lack of fishing effort and the extreme aquatic behaviour suggests that WHDPs may be secure from fisheries-related threats during the non-breeding period. Spatial restrictions around the breeding colony during the breeding period could help protect WHDPs. My results illustrate the importance of year-round distributional and behavioural studies to inform the conservation of marine species.
\end{abstract}




\section{INTRODUCTION}

Assessing the threats that species face across their distributions and throughout their annual cycle is crucial for effective conservation management. Seabirds are among the most threatened taxa on the planet and a variety of threats across terrestrial and pelagic ecosystems affect these birds during various stages of their annual cycles (Ch. 1, Dias et al. 2019). Offshore threats impacting seabirds during their breeding, migratory, and nonbreeding periods include accidental bycatch in fisheries, overfishing, environmental pollution, and attraction to artificial lights at night (Dias et al. 2019, Rodríguez et al. 2019). The impacts of offshore threats on large seabirds (e.g., albatrosses) are more often quantified than the impacts on smaller seabirds (i.e., < $0.3 \mathrm{~kg}$; Paiva et al. 2018, Bolton 2020, Rotger et al. 2020). For example, it has been estimated that hundreds of thousands of large seabirds annually are killed as accidental bycatch in commercial fisheries (e.g., Anderson et al. 2011). However, small seabird species also suffer from offshore threats throughout their annual cycle, including from bycatch in long-line (Anderson et al. 2011), trawl (Rodríguez et al. 2019), purse-seine (Oliviera et al. 2015), and gill net fisheries (Žydelis et al. 2013), as well as from resource competition with humans (Grémillet et al. 2018) and deck strikes (collisions with vessels due to disorientation caused by artificial light pollution at sea; Black 2005).

Understanding of the offshore threats affecting smaller seabird species is limited in part by a lack of year-round insights into their offshore distributions, movements, and behaviour. With technological advances in tracking technologies, opportunities to gain insights into offshore distributions and behaviours of small seabirds have increased. Yet, the distributions and behaviours of the smallest seabird species remain poorly understood (e.g., Paiva et al. 2018, Rotger et al. 2020). For example, only 29\% of the smallest Procellariiformes (families Hydrobatidae, Oceanitidae, and Pelecanoididae) have been tracked for a portion of their annual cycles (Adams \& Takekawa 2008, Navarro et al. 2013, 2015, Rayner et al. 2017, Halpin et al. 2018, Hedd et al. 2018, Paiva et al. 2018, Lago et al. 2019, Pollet et al. 2019, BirdLife International Seabird Tracking Database 2020, Bolton 2020, Dunphy et al. 2020, Rotger et al. 2020, Wikelski \& Keys 2020). Year-round studies covering > 1 annual cycle are virtually absent for any of these species (Pollet et al. 2019). Yet, these small Procellariiformes include four data deficient, four vulnerable, four 
endangered, and two critically endangered species (BirdLife International 2020) and are thus of considerable conservation concern.

Identifying year-round distribution, movements, and behaviour is key to the conservation of small seabird species. If the spatial distribution of species has not been quantified, the threats faced in relevant areas cannot be identified, and conservation management cannot be applied effectively (e.g., Adams \& Takekawa 2008, Hedd et al. 2018, Bolton 2020). Combining temporal information and spatial insights, increases the efficiency of conservation management. For instance, species may be at risk from certain threats during their breeding period, but not during their non-breeding period, or vice versa (Halpin et al. 2018, Clay et al. 2019). Such insights are important as migratory bird species are more vulnerable than residents (e.g., Hardesty-Moore et al. 2018). In addition, offshore behaviour cannot be ignored when assessing threats. For example, endangered Peruvian Diving Petrels (Pelecanoides garnotii) lose their ability to fly during the nonbreeding period due to the complete moult of their flight feathers (Murphy \& Harper 1921, BirdLife International 2020), potentially rendering them less at risk from deck strikes, but more at risk from bycatch in purse-seine or trawl fisheries and environmental pollution.

Offshore distribution, movements, and behaviour can be subject to variation between demographic groups (e.g., failed and successful breeders or different sexes) and among years (e.g., due to environmental stochasticity) and insights into this variation is crucial when implementing conservation management. If different demographic groups are exposed to annually varying threats, population dynamics could be affected considerably (e.g., Pardo et al. 2017, Clay et al. 2019). Underlying drivers of offshore distribution and behaviour have been studied extensively in larger seabird species (e.g., Gonzales-Solis et al. 2000, Clay et al. 2016, Schultz et al. 2018). For example, failed breeding Grey-headed Albatrosses (Thalassarche chrysostoma) use different, less productive areas during the non-breeding period compared to successful breeders (Clay et al. 2016) and male Wandering Albatrosses (Diomedea exulans) exploit areas at higher latitudes than females to take advantage of higher winds to offset their larger wing loadings (Clay et al. 2020). Such detailed insights for smaller seabird species remain largely absent (Paiva et al. 2018), impeding comprehensive assessments of conservation implications.

The Whenua Hou Diving Petrel (Pelecanoides whenuahouensis; WHDP) is a small, critically endangered seabird whose offshore distribution, movements, behaviour, and 
associated threats remain unknown. The WHDP population was once widespread, occupying coastal dunes throughout southern Aotearoa (New Zealand; Fig. 4; Taylor 2000b). However, after humans introduced invasive predators, all breeding colonies except one were extirpated. Now, WHDPs survive in low numbers (182-235 adults; Ch. 4) at one breeding colony on Whenua Hou (Codfish Island; Fig. 5). While Whenua Hou is now free of invasive predators (McClelland 2002), terrestrial threats affecting WHDPs during the breeding period remain (e.g., storms and interspecific competition with Common Diving Petrels P. urinatrix; Fischer et al. 2017a, 2018c). Due to a lack of data, no offshore threats affecting WHDPs during their breeding and/or non-breeding periods have been identified. Common and South Georgian Diving Petrels (P. georgicus) are among the taxa most commonly suffering from deck strikes (Ryan 1991, Black 2005, Abraham \& Richards 2019). Diving petrels are also caught as bycatch in trawl, gill net, and longline fisheries, including in waters around Aotearoa (Žydelis et al. 2013, Abraham \& Richard 2019). As diving petrels are notoriously cryptic, at-sea observations (including records of bycatch events) are often not species-specific (Fischer et al. 2018b, Richard et al. 2020) and thus of limited use to assess offshore distribution, movements, behaviour, and corresponding threats. Therefore, I tracked WHDPs for three full annual cycles to identify I) offshore distributions, II) movements patterns, III) offshore behaviour, and IV) overlap with commercial fishing effort. In addition, I investigated the effects of potential underlying drivers on distribution, movements, and behaviour (i.e., breeding success, sex, and interannual variation). 


\section{METHODS}

\section{Deployment and retrieval of geolocators}

To investigate WHDP offshore distribution, movements, and behaviour, I deployed global location-sensing immersion loggers (geolocators; Migrate Technology, Cambridge, UK; Table 3) on breeding adults ( $>2$ years old) at Whenua Hou $\left(-46.766^{\circ} \mathrm{S}, 167.645^{\circ} \mathrm{E}\right)$, Aotearoa. I captured WHDPs by hand or with custom-made burrow traps (Fig. 10) and attached geolocators to plastic wrap-around leg bands using cable ties and superglue. The combined weight of geolocators and attachment materials was $<1.5 \mathrm{~g}$, equating to $<1.1 \%$ of adult WHDP body weight (average = $133 \mathrm{~g}$ ), below the commonly accepted 3\% threshold (Phillips et al. 2003). While I cannot discount potential negative effects (Quillfeldt et al. 2012, Bodey et al. 2017), WHDPs equipped with geolocators were in good condition upon recapture and had weights that did not clearly differ from individuals without geolocators (I compared 34 WHDPs carrying geolocators with 136 non-equipped WHPDs using a generalized linear model with a Gaussian error distribution and an identity-link function: $\hat{\alpha}=-0.02 \pm 0.09 \mathrm{SE}, \beta_{\text {geolocator }}=0.07 \pm 0.19 \mathrm{SE}$ ). WHDPs equipped with geolocators also did not show clear deviations from the natural breeding phenology (see results and $\mathrm{Ch} .5$ ) or reductions in breeding success (66\% of equipped WHDPs fledged a chick, compared to the multi-year average of 55\%; Ch. 4).

Table 3. Number of Migrate Technology (Cambridge, UK) geolocators deployed, geolocators retrieved, and year-round data sets obtained.

\begin{tabular}{llrrr}
\hline Year & Model & $\boldsymbol{n}$ deployed & $\begin{array}{r}n \text { retrieved } \\
(\%)\end{array}$ & $\begin{array}{r}n \text { data sets obtained } \\
(\% ; \% ; \bigcirc)\end{array}$ \\
\hline $2015 / 16$ & Intigeo-W65A9-SEA & 10 & $7(70 \%)$ & $4(57 \% ; 1 ; 3)$ \\
$2017 / 18$ & Intigeo-C65-SUPER & 26 & $21(81 \%)$ & $20(95 \% ; 11 ; 9)$ \\
$2018 / 19$ & Intigeo-C65-SUPER & 18 & $14(78 \%)$ & $14(100 \% ; 9 ; 5)$ \\
\hline
\end{tabular}




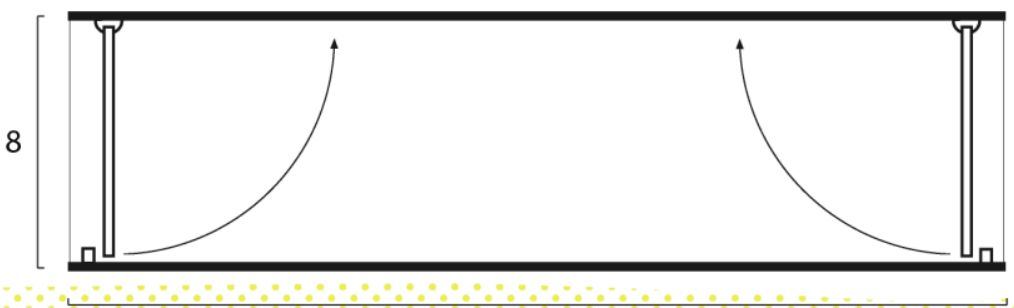

30

Fig. 10. Custom-made burrow trap to (re)capture Whenua Hou Diving Petrels as they enter/exit their burrow. Dimensions are in $\mathrm{cm}$. The main body of the trap consisted of a polyvinyl chloride piping, while the one-way doors were made of acrylic. Hinges were constructed out of braided stainless-steel wire.

I set geolocators to record light levels (lux) every min and save the maximum value every five mins. I also programmed geolocators to record saltwater-immersion every 30 seconds (0 or 1 which correspond with "dry" or "wet", respectively) and to save the cumulative wet count every $10 \mathrm{~min}$. Recorded values thus ranged from 0 (dry) to 20 (fully immersed). Geolocators deployed after 2015 recorded sea-surface temperature (SST) when immersed in saltwater for $>20 \mathrm{~min}$ and saved temperature every eight hours (mean, minimum, and maximum in ${ }^{\circ} \mathrm{C}$ ). Finally, I collected four contour feathers during geolocator attachment and used these for genetic sex determination (using polymerase chain reaction primers specific to the chromodomain-helicase-DNA-binding gene on the W-chromosome; Norris-Caneda \& Elliott 1998).

Geolocators are non-transmitting devices and thus I recaptured WHDPs in subsequent years to retrieve devices. I obtained a total of 38 datasets from 24 individuals providing year-round insights (mean geolocator deployment: 317 days). 


\section{Light level analyses}

To infer offshore locations of WHDPs from recorded light levels, I applied the threshold method to quantify twilight events, followed by an iterative forward step selection to reduce location errors with I) a twilight model, II) a movement model, and III) several spatial masks using the package ProbGLS in program R 3.5.3 (Merkel et al. 2016, R Core Team 2019). I selected a light threshold of 1.5 for twilight events (Schultz et al. 2018) and a solar angle window of $-7^{\circ}$ to $-1^{\circ}$ for the twilight model (Taylor et al. 2020). I used a bimodal movement model for dry periods (i.e., bird in flight; mean $\pm \sigma=1.4 \pm 0.5 \mathrm{~m} / \mathrm{s}$, $\max =10 \mathrm{~m} / \mathrm{s}$ ) and wet periods (i.e., bird on water; $0.5 \pm 0.25 \mathrm{~m} / \mathrm{s}, \max =1.7 \mathrm{~m} / \mathrm{s}$ ) (Rayner et al. 2017). I defined wet periods as periods during which the 10 -min cumulative wet counts were "wet" for $\geq 1 \mathrm{~min}$. I applied two binary spatial masks: land and sea ice $\left(0.25^{\circ}\right.$ $\times 0.25^{\circ}$; National Oceanographic and Atmospheric Administration high resolution dataset; available at: ftp://ftp.cdc.noaa.gov/Datasets/noaa.oisst.v2.highres/). I thus assumed that WHDPs completely avoided land and sea ice and set the sea ice concentration threshold at 1\%. For geolocators deployed after 2015, I also applied a continuous SST spatial mask. Specifically, I cross-referenced the minimum SST values recorded by geolocators with satellite-recorded SST values (daily mean \pm SE; $0.25^{\circ} \times$ 0.25; National Oceanographic and Atmospheric Administration high resolution dataset; available at: ftp://ftp.cdc.noaa.gov/Datasets/noaa.oisst.v2.highres/; Reynolds et al. 2007). I used the minimum SST values recorded by geolocators to avoid artefacts caused by the bird's body temperature and allowed the satellite-derived SST values to differentiate from the geolocator records by $0.5^{\circ} \mathrm{C}$. I subsequently estimated the median geographic tracks by I) calculating the weighted probability for a cloud of possible locations (1,000 locations per step), II) selecting the most likely location, and III) repeating this process for 100 iterations (Merkel et al. 2016). This iterative forward step selection allowed for estimation of locations during the equinox periods. Double tagging with GPS loggers at similar latitudes revealed that locations inferred with this iterative forward step selection had an error of $145 \mathrm{~km}$ during the equinoxes (Merkel et al. 2016). Using this method, I inferred a total of 22,372 offshore locations of WHDPs from the collected light data. These locations can be accessed at http://www.seabirdtracking.org/. 


\section{Spatiotemporal analyses}

To objectively identify presence and quantify timing of migratory movements in WHDPs, I fitted a range of models to the net squared displacement (the square of the distance between the starting point and each subsequent point; NSD) of individual WHDPs tracks using the R package MigrateR 1.1.0 (Spitz et al. 2017, DB Spitz, B Cristescu, CC Wilmers, RE Wheat, T Levi \& HU Wittmer unpublished). Specifically, I fitted the NSD of each yearround track to models representing I) residency, II) nomadism, II) dispersal, IV) migration, V) mixed-migration, and VI) multi-range migration (equations are provided in Appendix 4). I compared the fit of these models to the NSD of each track using the Akaike information criterion (Burnham \& Anderson 2002) and selected the best supported model. The NSD of all WHDP tracks was best explained by multi-range migratory models (Equation 6 in Appendix 4), which described pronounced migratory movements to and from the breeding distribution and showed additional spatial structures in the nonbreeding period. I subsequently used the model-estimated migration phenology to objectively delineate the four annual phenophases for each track: breeding period, outbound migration, non-breeding period, and homebound migration.

I used generalized linear mixed effects models (GLMMs) with a Gaussian error distribution and an identity-link function (Clay et al. 2016) within the R package Ime4 (Bates et al. 2015) to test for effects of breeding success, sex, and interannual variation on WHDP movements (departure from the breeding distribution, arrival at the nonbreeding distribution, departure from the non-breeding distribution, arrival at the breeding distribution, length of the outbound migration, length of the stay at the nonbreeding distribution, and length of the homebound migration). I z-transformed all numeric variables. I treated breeding success, sex, and year as fixed effects and individual ID as a random effect in these models.

To quantify year-round WHDP distribution and investigate the underlying drivers, I calculated kernel utilization distributions (UDs) per individual per breeding and nonbreeding period using the adehabitatHR $\mathrm{R}$ package (Calenge 2006). Specifically, to calculate the 50\% UDs (core area of use) and the 95\% UDs (full extent of distribution), I projected WHDP locations on a $50 \mathrm{~km}$ grid using a Lambert Azimuthal Equal Area projection and a kernel smoothing factor $(h)$ that corresponded with the geolocator error during the equinoxes (145 km; Merkel et al. 2016). As some individuals were recaptured immediately after their return to the breeding colony, I did not calculate UDs for 
individuals with $<30$ breeding distribution locations. Subsequently, to create overall distribution maps, I merged individual breeding and non-breeding UDs into overall UDs which accounted for unequal number of locations among individuals (Clay et al. 2017, Schultz et al. 2018). I then calculated spatial overlap among individual breeding and nonbreeding UDs, overall breeding and non-breeding UDs, UDs of different sexes, and UDs of failed and successful breeders (defined as successfully fledging a chick). Specifically, to quantify spatial overlap, I calculated the Bhattacharyya's affinity (BA), which is a function of the product of two UDs, under the assumption that animals use space independently of each other $(\mathrm{BA}=0$ equals no overlap, $\mathrm{BA}=1$ equals complete overlap; Fieberg $\&$ Kochanny 2005).

\section{Behavioural analyses}

I inferred offshore behaviour of WHDPs using the recorded saltwater immersion records (10 min cumulative wet counts) and the online tool Actave.net (Mattern et al. 2015). I defined cumulative counts that were "wet" for $\geq 1 \mathrm{~min}$ as "on or under water" and counts that were "wet" for < 1 min as "in flight". I quantified time spent "on or under water" per day (24 hours) per individual per phenophase. This allowed me to assess if WHDPs, similar to Peruvian Diving Petrels, exhibited periods of flightlessness (Murphy \& Harper 1921). I also quantified the daily number of flight bouts (consecutive data points categorized as "in flight"), duration of flight bouts, and time spent "in flight" per diel category (dawn, day, dusk, and night) per individual per phenophase (Mattern et al. 2015). However, I refrained from quantifying flight behaviour during the breeding period, as I could not differentiate between WHDPs in flight and WHDPs on land at the breeding colony (Schultz et al. 2018). I then investigated the influence of phenophase, breeding success, sex, and interannual variation on offshore behaviour using GLMMs with a Gaussian error structure and an identity-link function. I z-transformed all numerical variables. I treated phenophase, sex, breeding success, and year as fixed effects and individual ID as a random effect in these models. 


\section{Overlap with commercial fishing effort}

To infer year-round offshore threats to WHDPs, I quantified the spatiotemporal overlap between the breeding and non-breeding distributions and commercial fishing effort. I sourced data on daily commercial fishing effort (fishing hours at $0.1^{\circ}$ cell resolution) from 2012 to 2016 from Global Fishing Watch (dataset available at: https://globalfishingwatch.org/data-download/datasets/public-fisshing-effort10:v20200316). Global Fishing Watch uses satellite tracking of commercial fishing vessels equipped with automatic identification systems to derive fishing effort (McCauley et al. 2016, Kroodsma et al. 2018, Taconet et al. 2019). This dataset equates to 50-70\% of the global fishing effort ( $n>70,000$ vessels; Kroodsma et al. 2018). I did not differentiate between vessel types (i.e., based on fishing gear) and summed daily fishing effort from all tracked vessels per breeding and non-breeding period per year. I delineated the breeding and non-breeding periods using the means of the model-estimated migration phenologies (Appendix 4). I then calculated the average fishing effort per breeding and non-breeding period to account for interannual variation. Subsequently, I overlaid the $50 \%$ and 95\% UDs of WHDP breeding and non-breeding distributions and calculated I) the mean fishing effort per $0.1^{\circ}$ cell, II) the sum of fishing effort, and III) the percentage of cells with fishing effort within WHDP breeding and non-breeding distributions during the breeding and non-breeding periods. I conducted these calculations in Program R 3.5.3 (R Core Team 2019) and ArcMap 10.7.1. 


\section{RESULTS}

\section{WHDP movements}

WHDPs showed consistent clockwise migratory movements (Fig. 11 \& 12). After the breeding period, WHDPs left Whenua Hou and migrated south-west past Macquarie Island towards the Polar Front (December/January-March). Subsequently, WHDPs moved north-west towards and along the Subantarctic Front (April-June). Ultimately, WHDPs returned to their breeding colony via the Subantarctic Front (July-September). On average, WHDPs departed their breeding distribution on 27 December, spent 8.9 days on their outbound migration, arrived at their non-breeding distribution on 5 January, spent 235.0 days at their non-breeding distribution, departed their non-breeding distribution on 28 August, spent 14.0 days on their homebound migration, and arrived at their breeding distribution on 11 September.

Breeding success influenced WHDP movements. Specifically, failed breeders departed their breeding distribution earlier, arrived earlier at their non-breeding distribution and spent more time at their non-breeding distributions (Table 4). Sex had little influence on WHDP movements, but males exhibited a slightly more prolonged homebound migrations than females. Interannual variation influenced WHDP movements slightly. Birds in 2016 departed earlier from their breeding distribution, exhibited more prolonged outbound migrations, and spent more time at their non-breeding distributions. Additionally, birds in 2019 arrived later at their non-breeding distributions. 

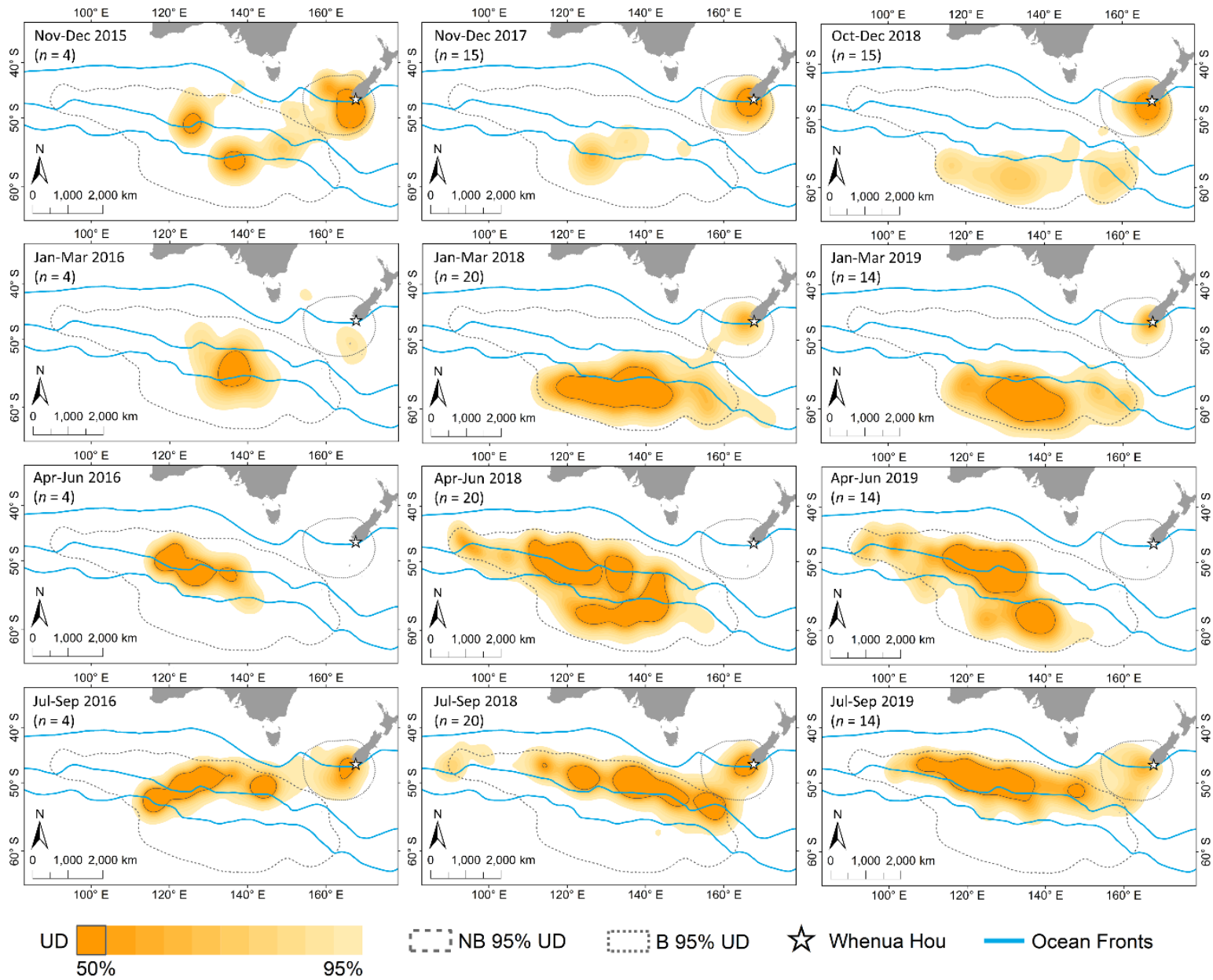

- NB 95\% UD

Fig. 11. Year-round movements and distributions of Whenua Hou Diving Petrels during 2015/16, $2017 / 18$, and $2018 / 19$ illustrated by $50 \%$ to $95 \%$ UDs. $\mathrm{NB}=$ non-breeding distribution, $\mathrm{B}=$ breeding distribution. Raw data can be accessed at http://www.seabirdtracking.org/. Approximate location of fronts (from north to south: Subtropical Front, Subantarctic Front, and Polar Front) are based on Harris \& Orsi (2006). 


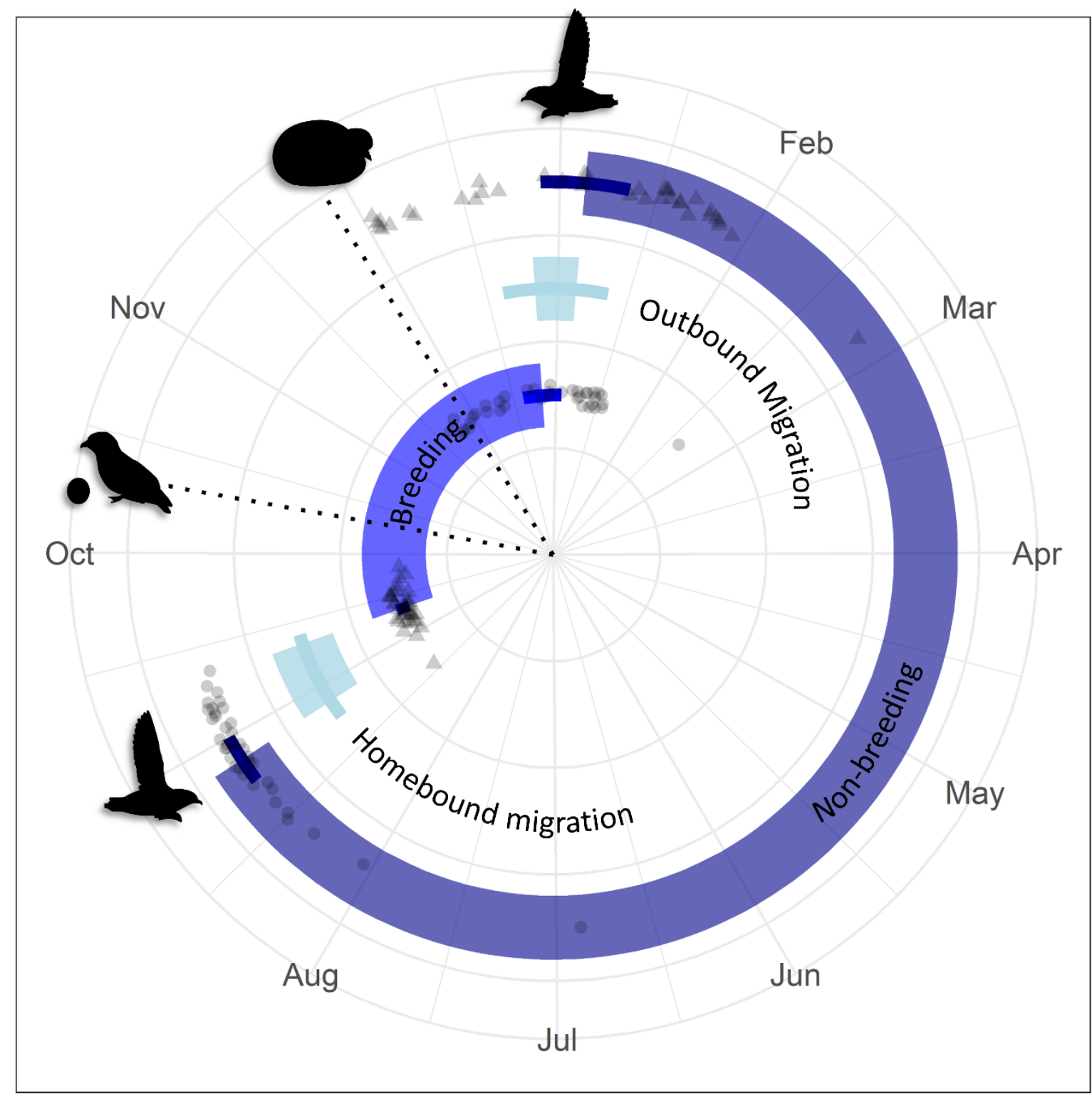

Fig. 12. Estimated year-round Whenua Hou Diving Petrel movement phenology represented by means with 95\% CIs. Grey triangles represent individual estimates of arrival dates. Grey circles represent individual estimates of departure dates. Dotted lines represent mean lay (10 October) and hatch dates (27 November; Ch. 5). 


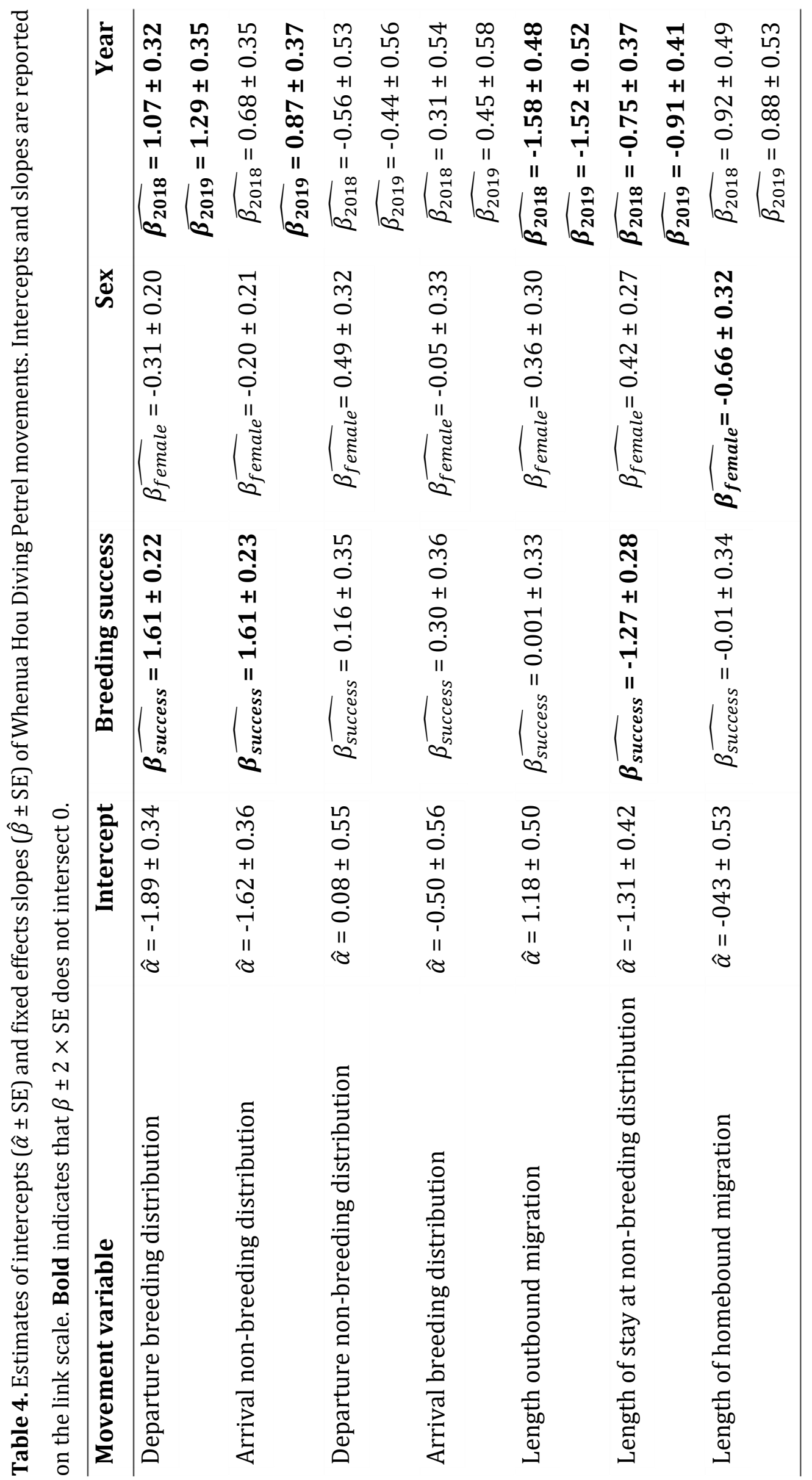




\section{WHDP offshore distribution}

The core breeding distribution of WHDPs $\left(159,497 \mathrm{~km}^{2}\right)$ ranged from Te Tai-o-Rēhua (Tasman Sea) west and south off Te Waipounamu (South Island) to Maukahuka (Auckland Islands) and appeared concentrated around the Subtropical Front and the Snares Islands shelf (Fig. 11, 13A \& 14A). The total breeding distribution $\left(890,632 \mathrm{~km}^{2}\right)$ extended further northwards in Te Tai-o-Rēhua and further south towards Motu Ihupuku (Campbell Island). The WHDP breeding distribution was consistent among years (BA = 0.92; Fig. 11) and individuals $(B A=0.79)$. There was no evidence for spatial segregation of WHDPs during the breeding period between sexes (BA =0.98; Fig. 13A) or failed and successful breeders (BA = 0.99; Fig. 14A).

Both the core area of use $\left(1,521,041 \mathrm{~km}^{2}\right)$ and the total non-breeding distribution $\left(6,069,461 \mathrm{~km}^{2}\right)$ encompassed a vast area in the Southern Ocean. The core non-breeding distribution of WHDPs was centred in the Southern Ocean south of Australia and ranged from south of the Polar Front to north of the Subantarctic Front (Fig. 11, 13B \& 14B). The total non-breeding distribution ranged from the Polar Front south of Macquarie Island to seas north of the Subantarctic Front west of Western Australia. Average maximum distance from the WHDP breeding colony was 3,791 km. While the number of birds tracked in $2016(n=4)$ appeared insufficient to capture the full extent of the nonbreeding distribution (Fig. 11), WHDP non-breeding distribution was highly consistent among years $(\mathrm{BA}=0.82)$ and reasonably consistent among individuals $(\mathrm{BA}=0.47)$. There was no clear evidence for spatial segregation of WHDPs during the non-breeding period between sexes $(B A=0.96$; Fig. 13B) or failed and successful breeders $(B A=0.86$; Fig. 14B), despite some failed breeders that moved further west. 


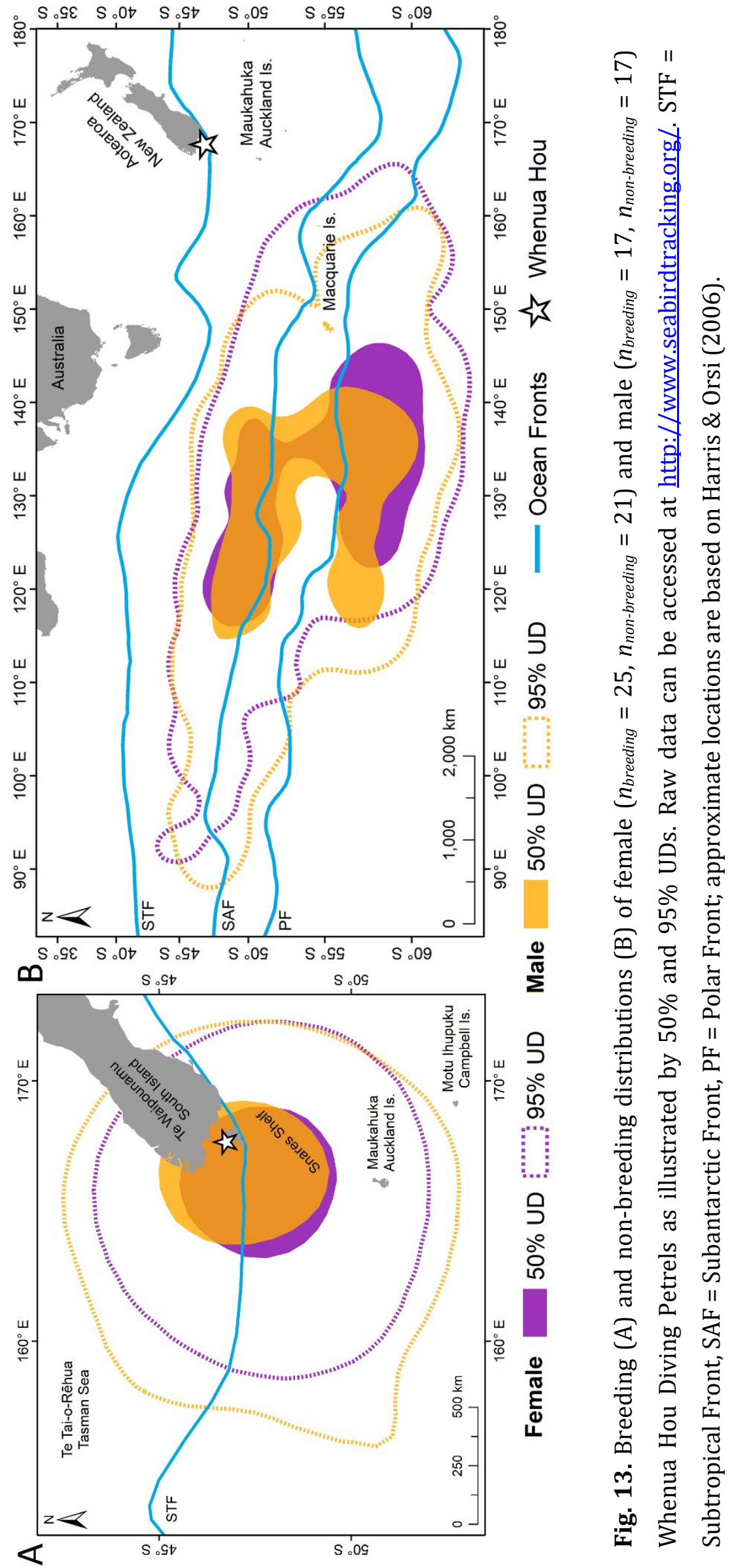



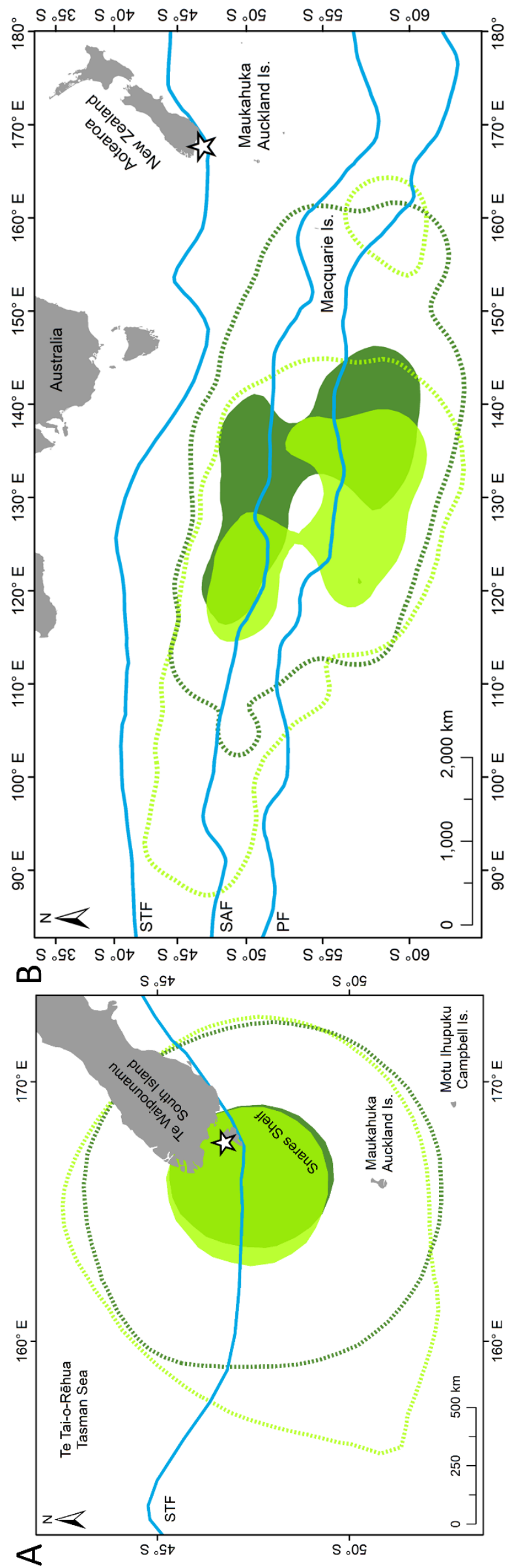

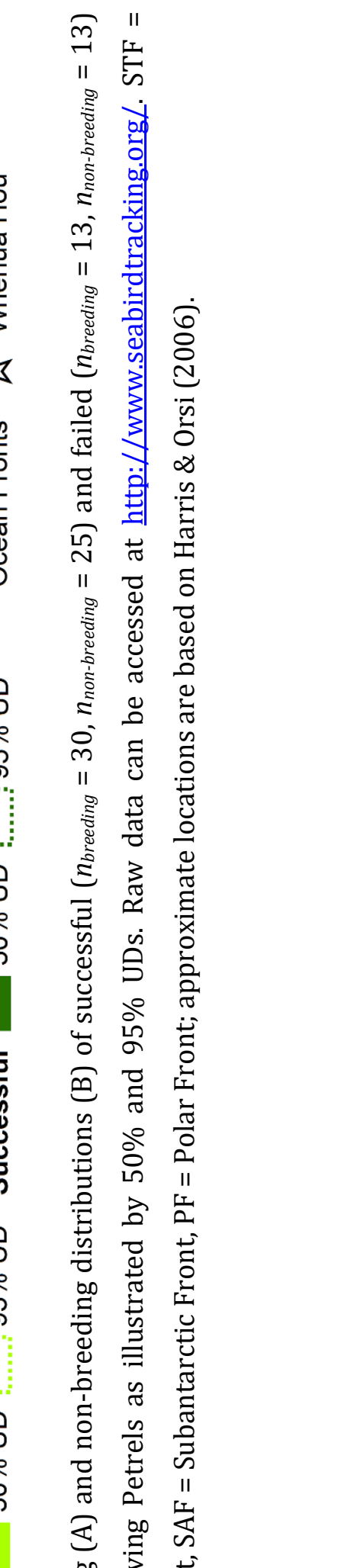

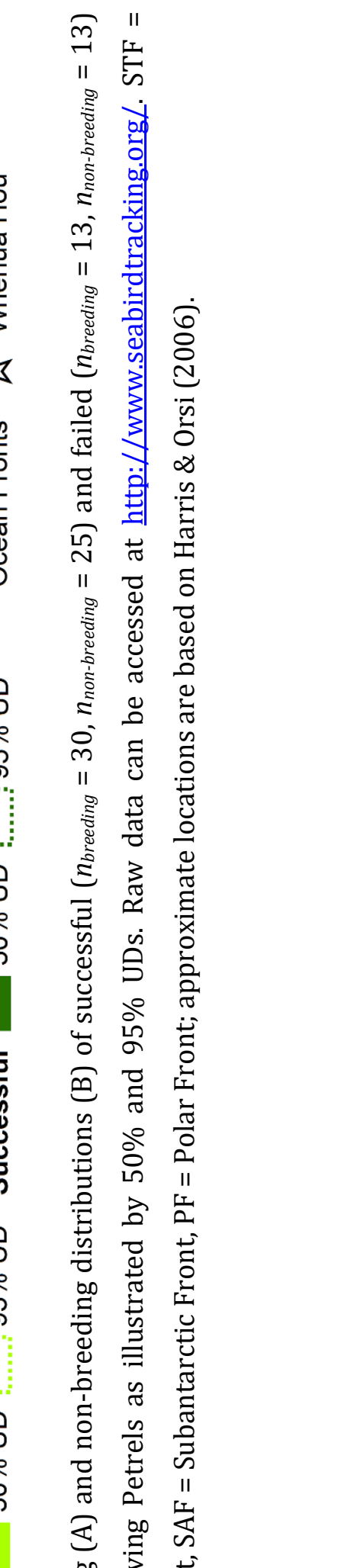

우

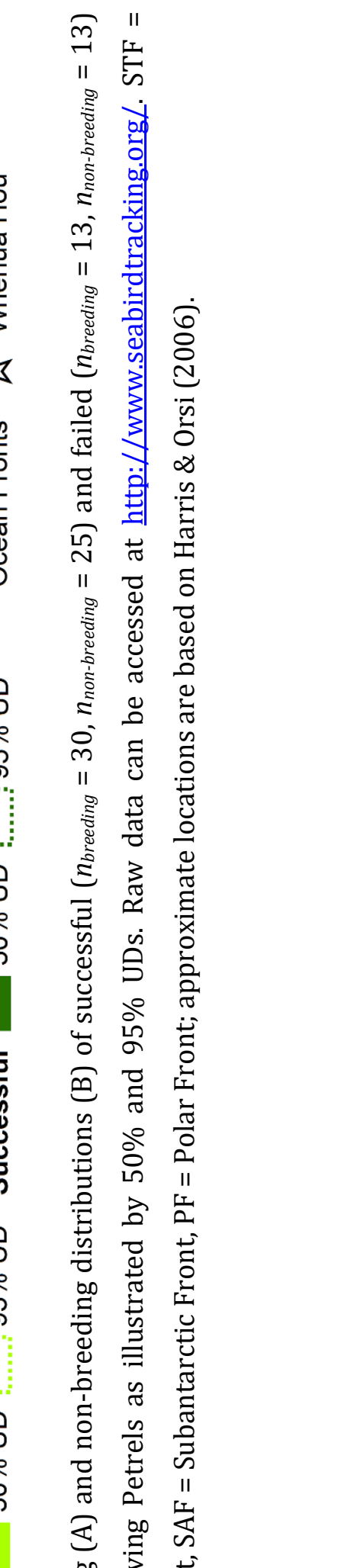

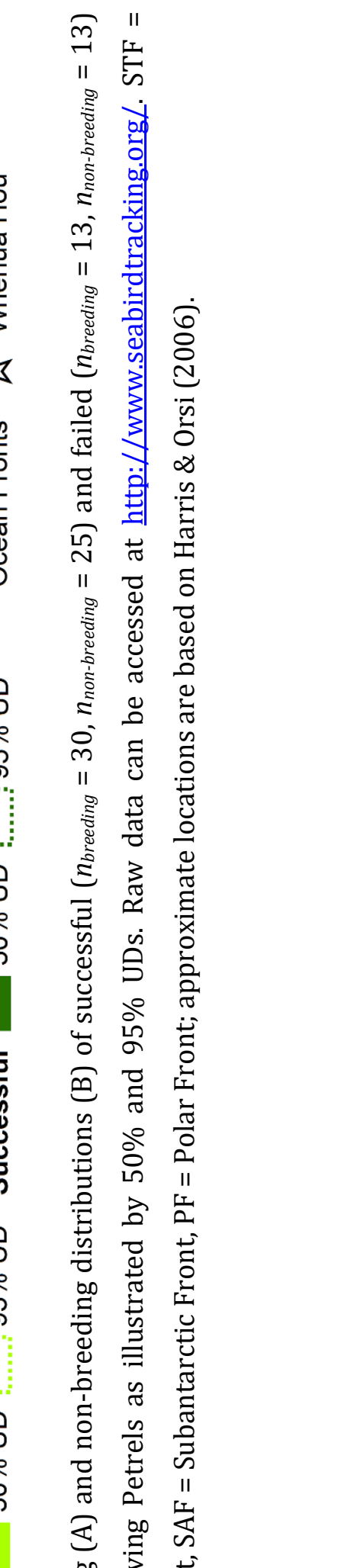

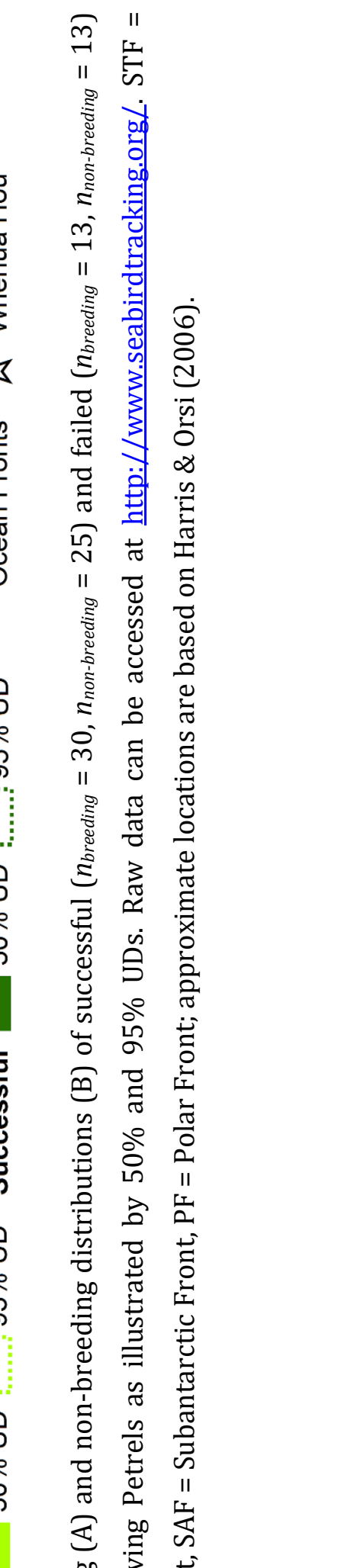

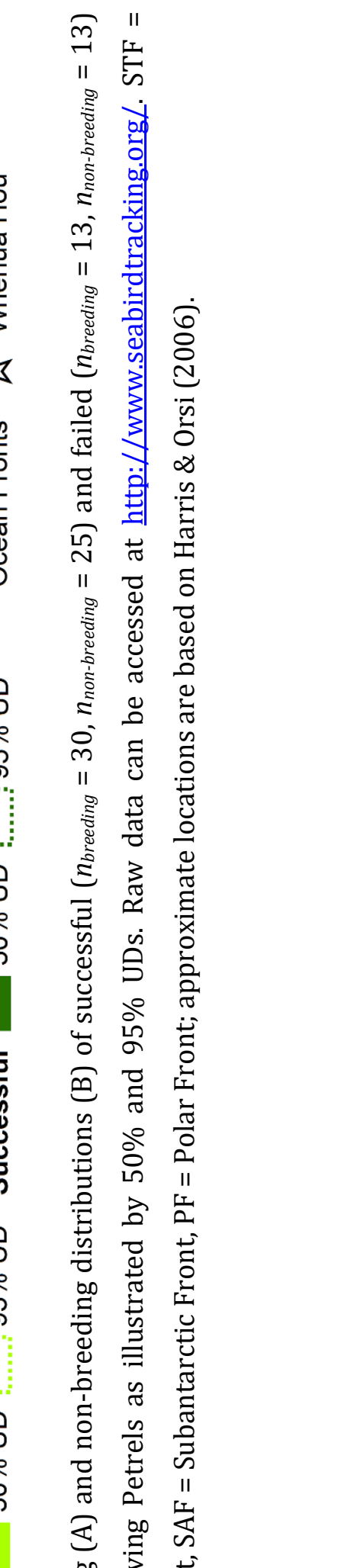

0

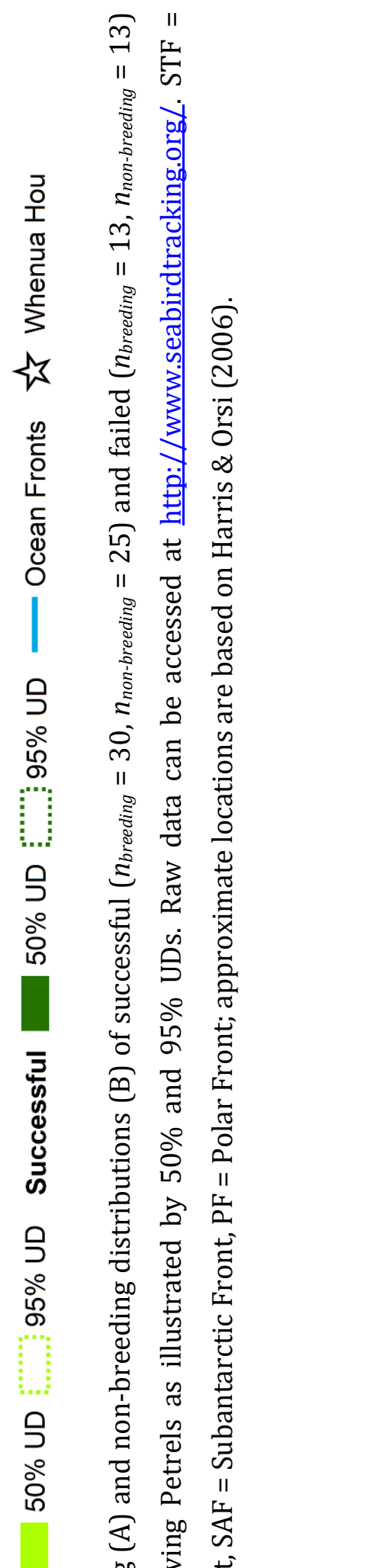

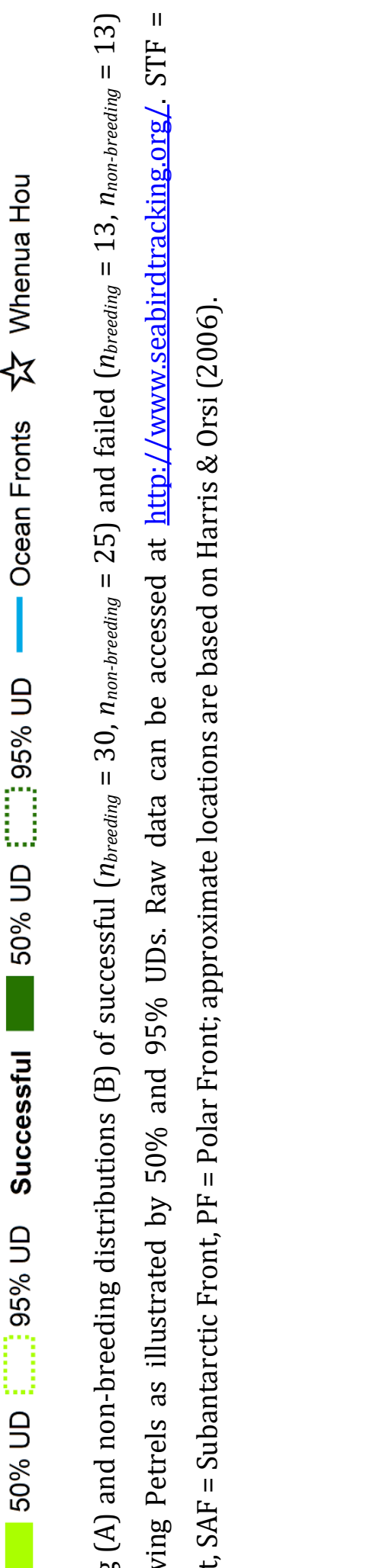

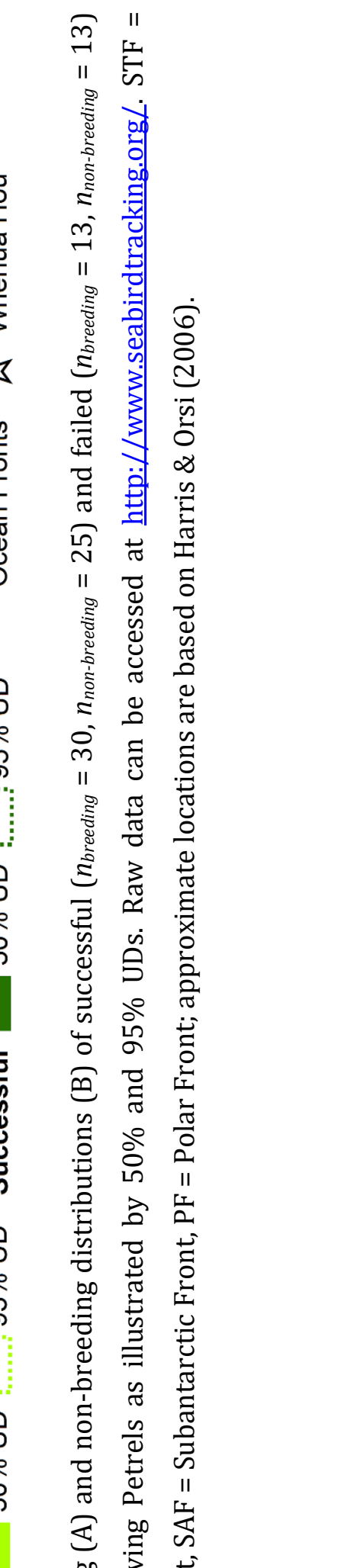

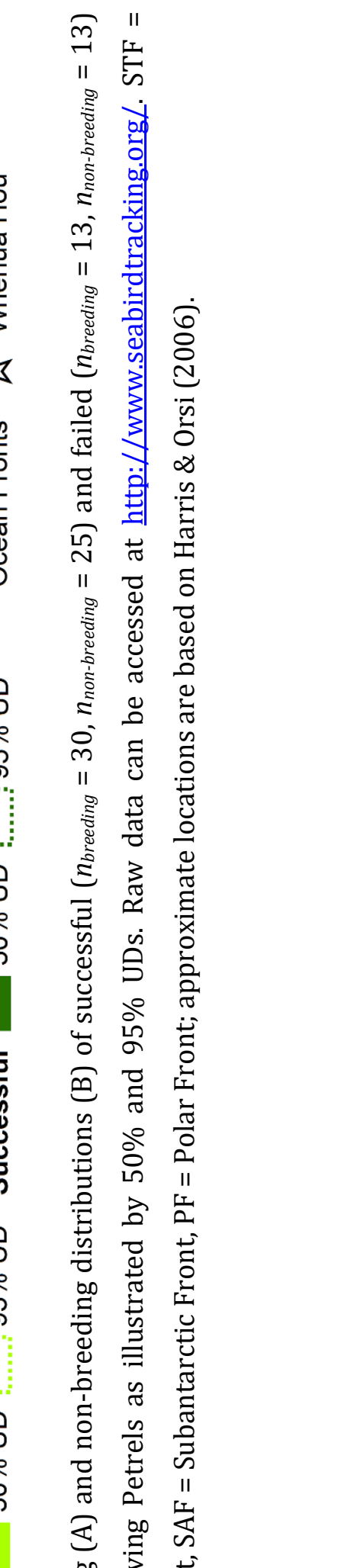

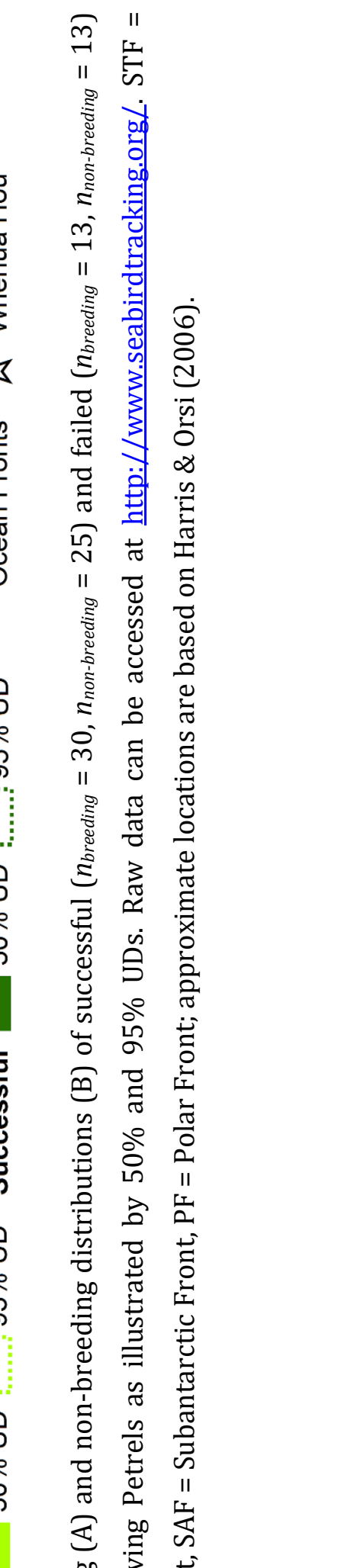

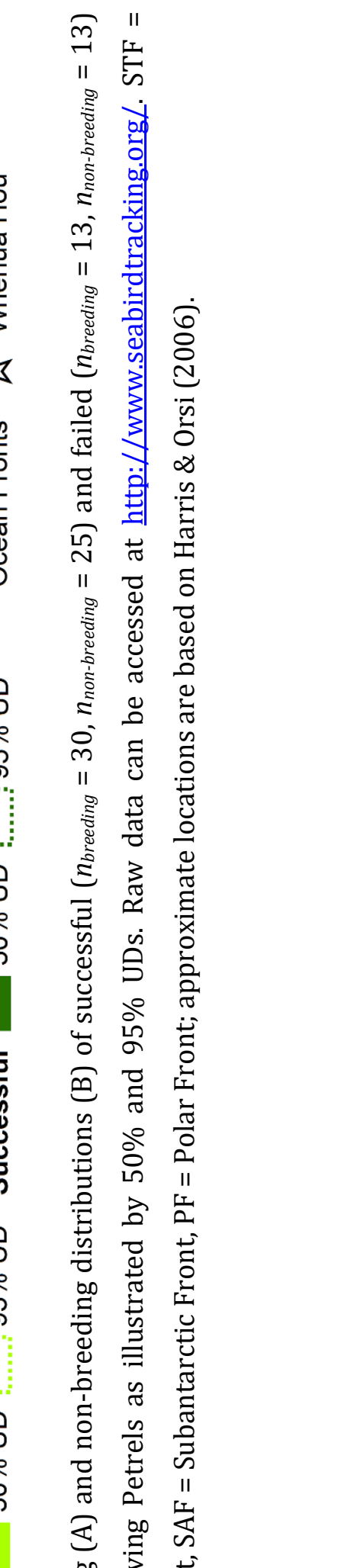

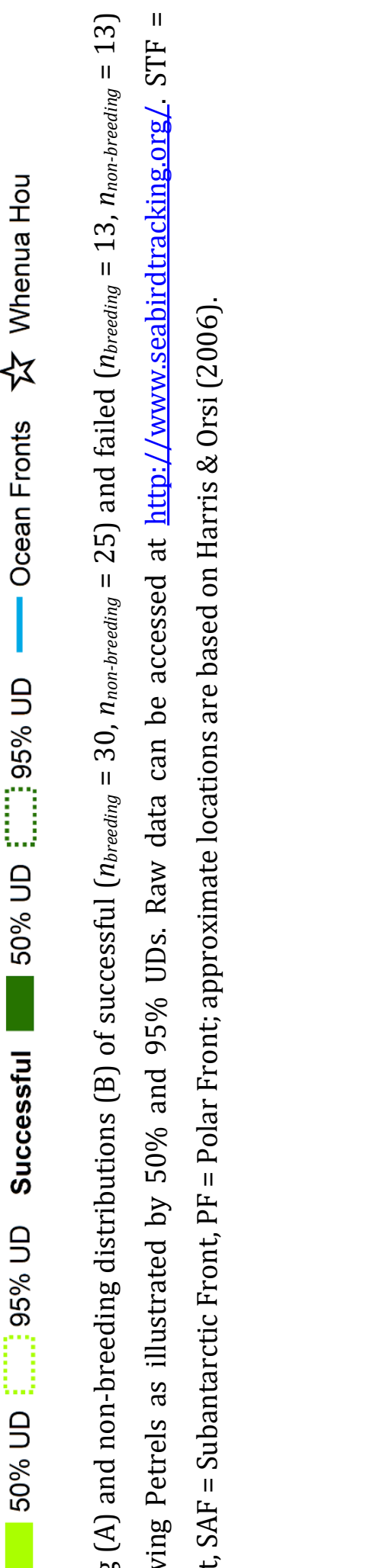

遌

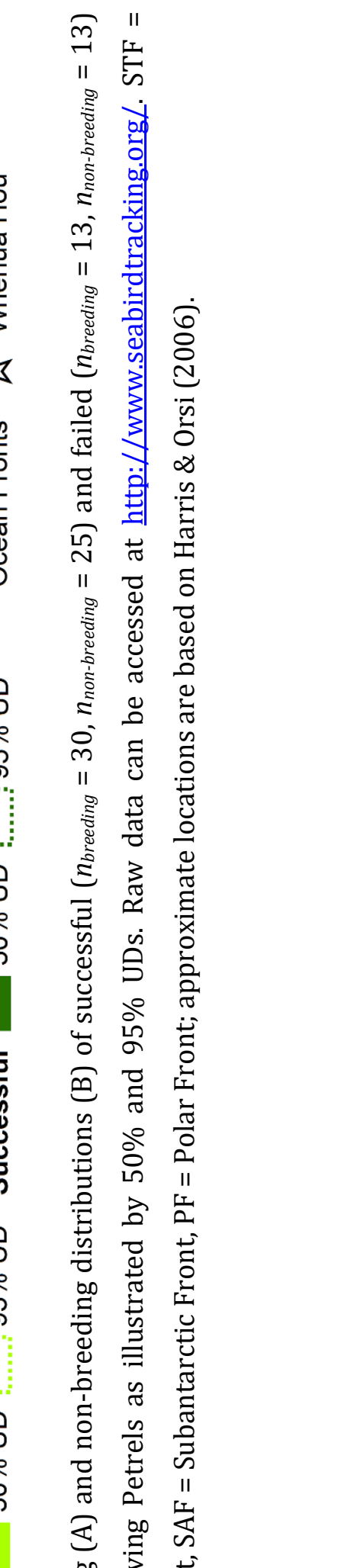

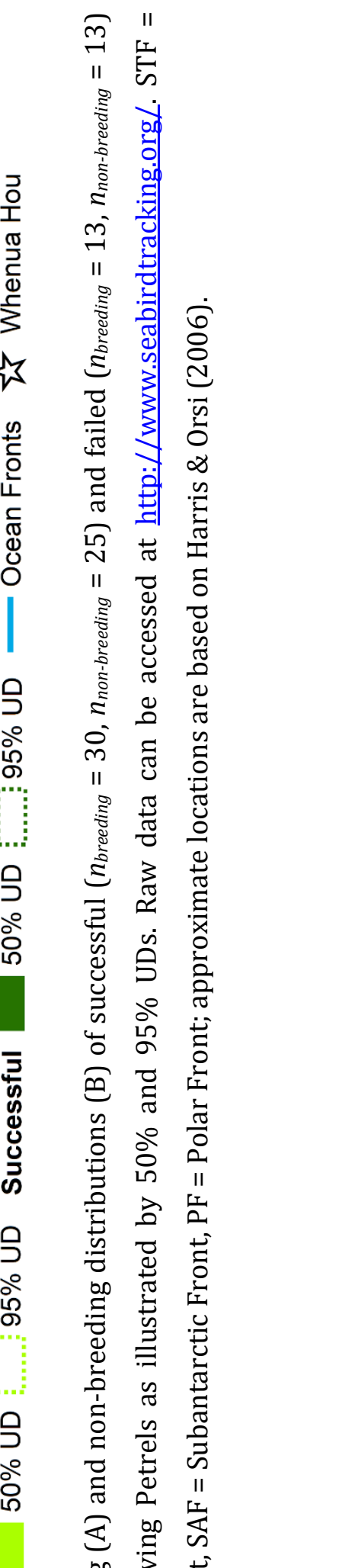

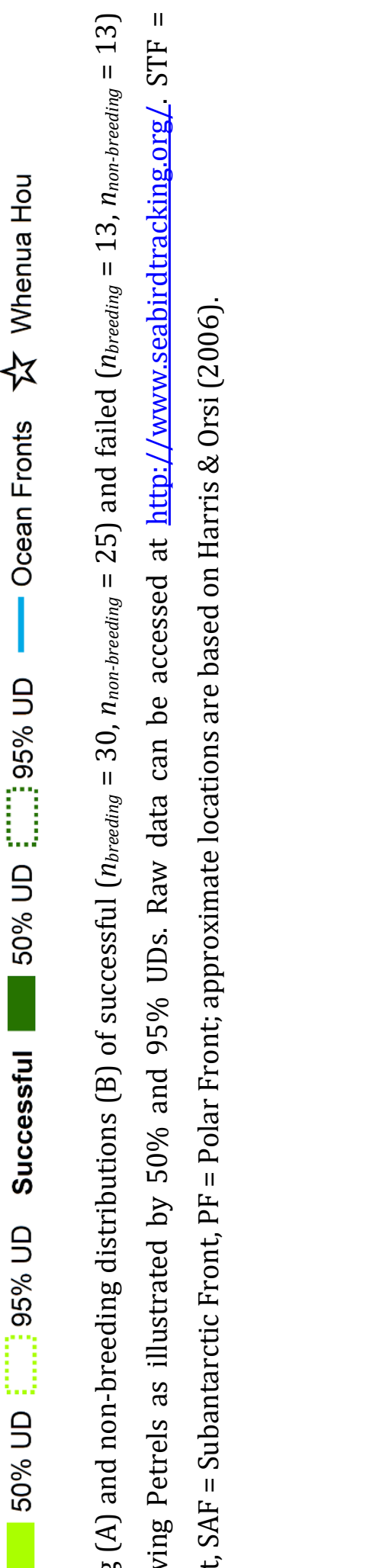

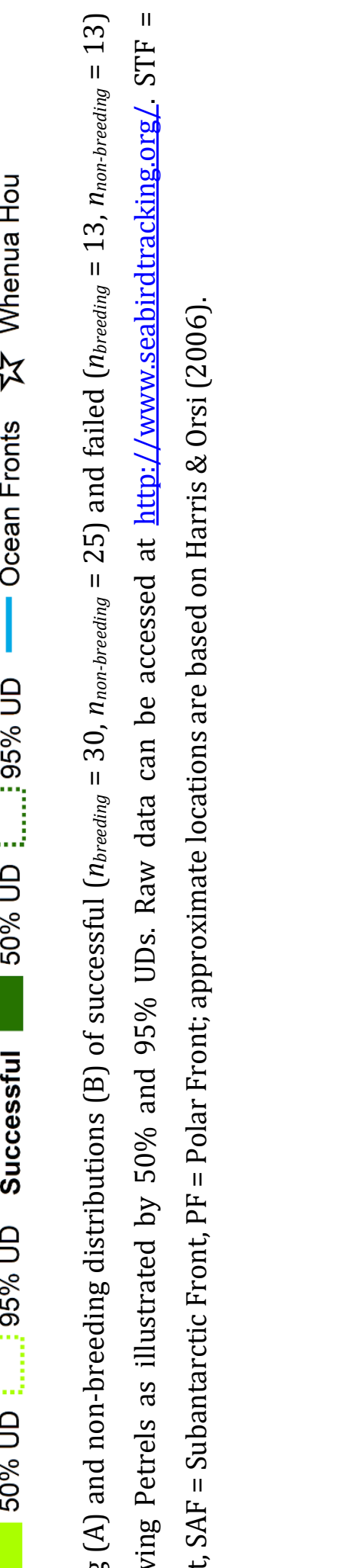

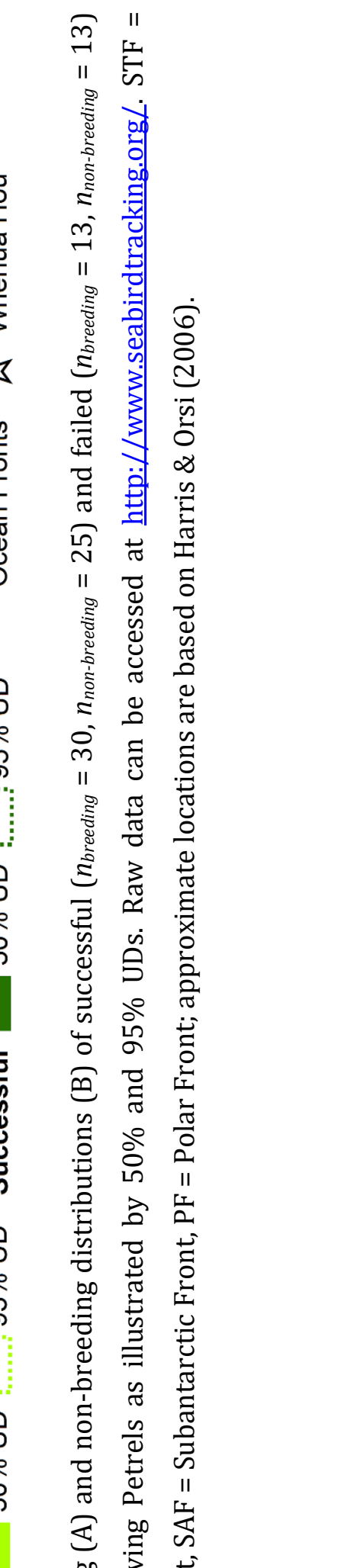

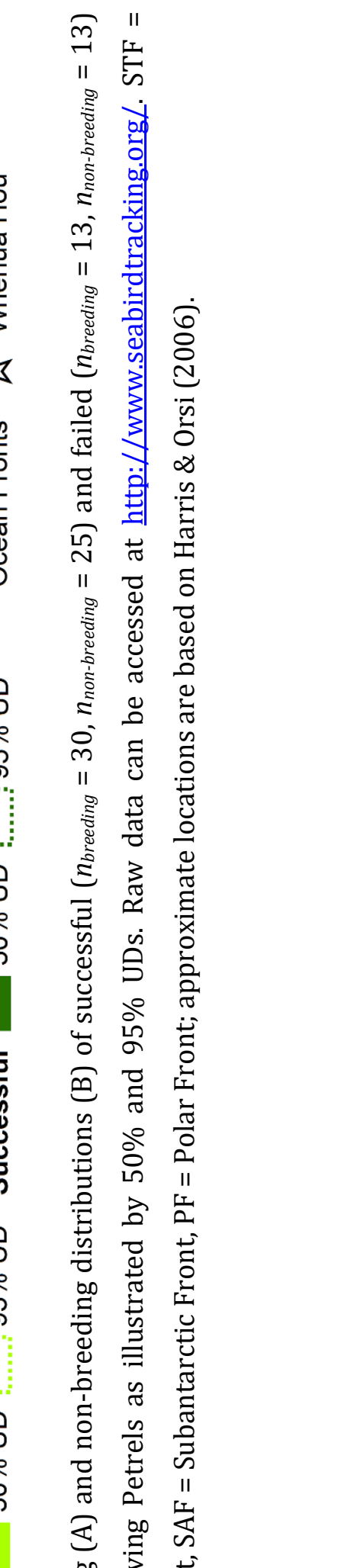

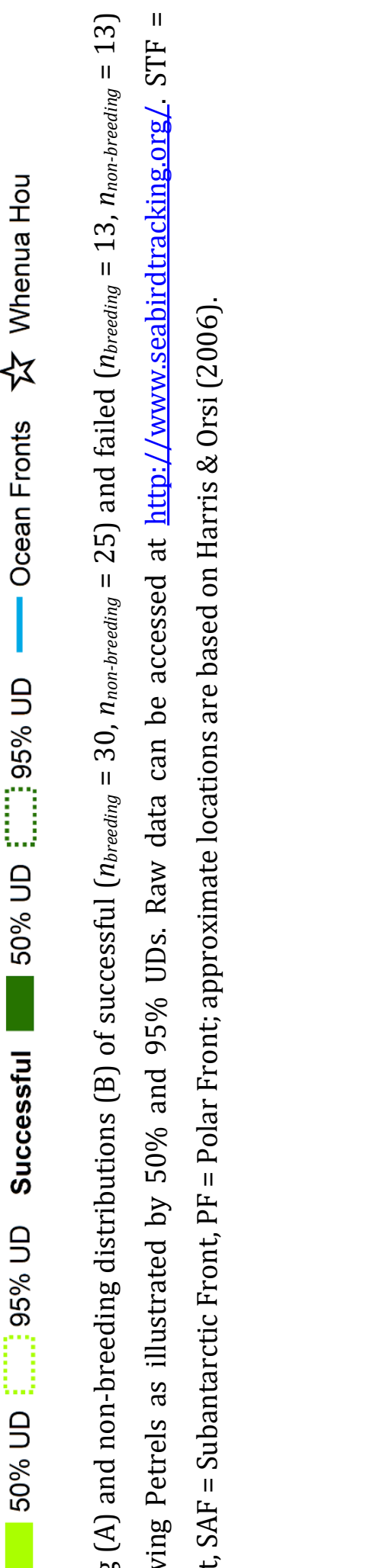

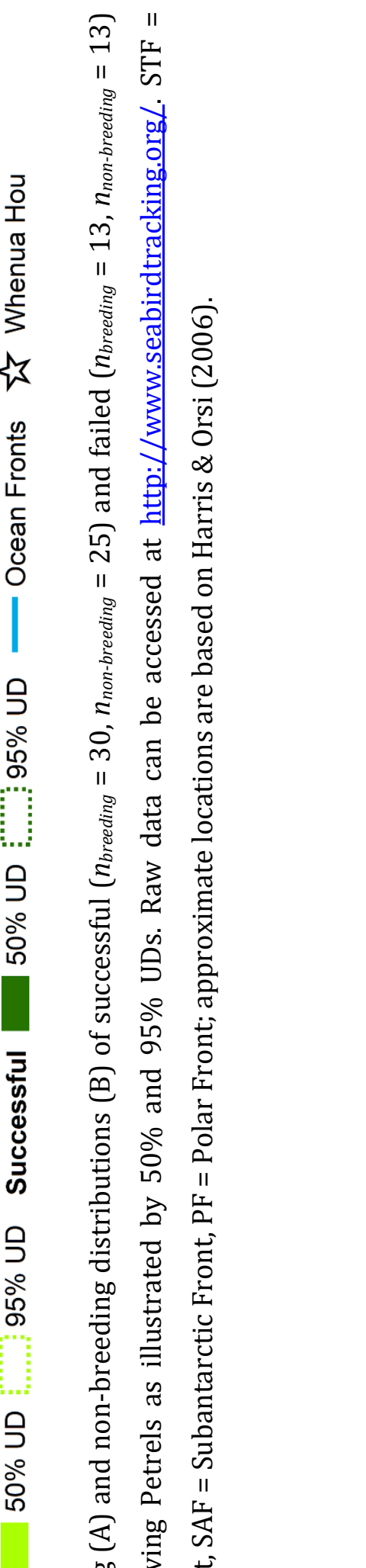

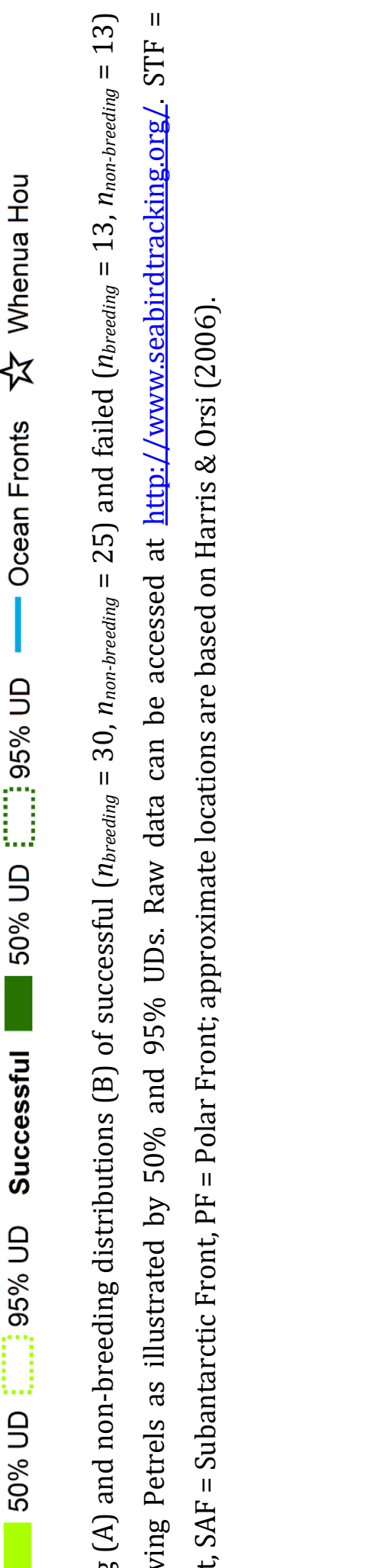

핳

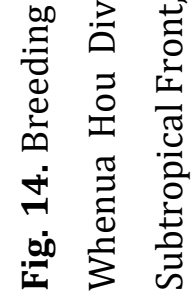




\section{WHDP offshore behaviour}

At their non-breeding distribution, WHDPs spent on average 95\% (22.8 hours/day) and up to $99 \%$ (23.7 hours/day) of their time with at least their legs immersed in saltwater (Fig. 15). During the breeding period, WHDPs spent on average 66\% (15.7 hours/day) of their time immersed. Thus, phenophase had a considerable influence on offshore behaviour (Table 5, Fig. 16). During the non-breeding period WHDPs exhibited little, predominantly nocturnal, flight activity (2.9 bouts/day lasting $33 \mathrm{~min}$ per flight bout). During the rapid outbound migrations, WHDPs exhibited more frequent and more diurnal flight activity (8.7 bouts/day lasting $37 \mathrm{~min}$ per flight bout). During the slower homebound migrations, WHDPs did not exhibited such elevated diurnal flight activity, but flight bouts were longer (3.9 bouts/day lasting $46 \mathrm{~min}$ per flight bout). Despite their flight efforts during their migrations WHDPs still remained largely on, or under, water. Breeding success had little influence on offshore behaviour, but successful breeders spent more time immersed than failed breeders. Sex had no clear influence on offshore behaviour. Interannual variation had a limited influence on offshore behaviour, but birds in 2019 exhibited fewer and shorter flight bouts and spent less time in flight at night. Additionally, birds in 2016 spent less time flying at dawn. 


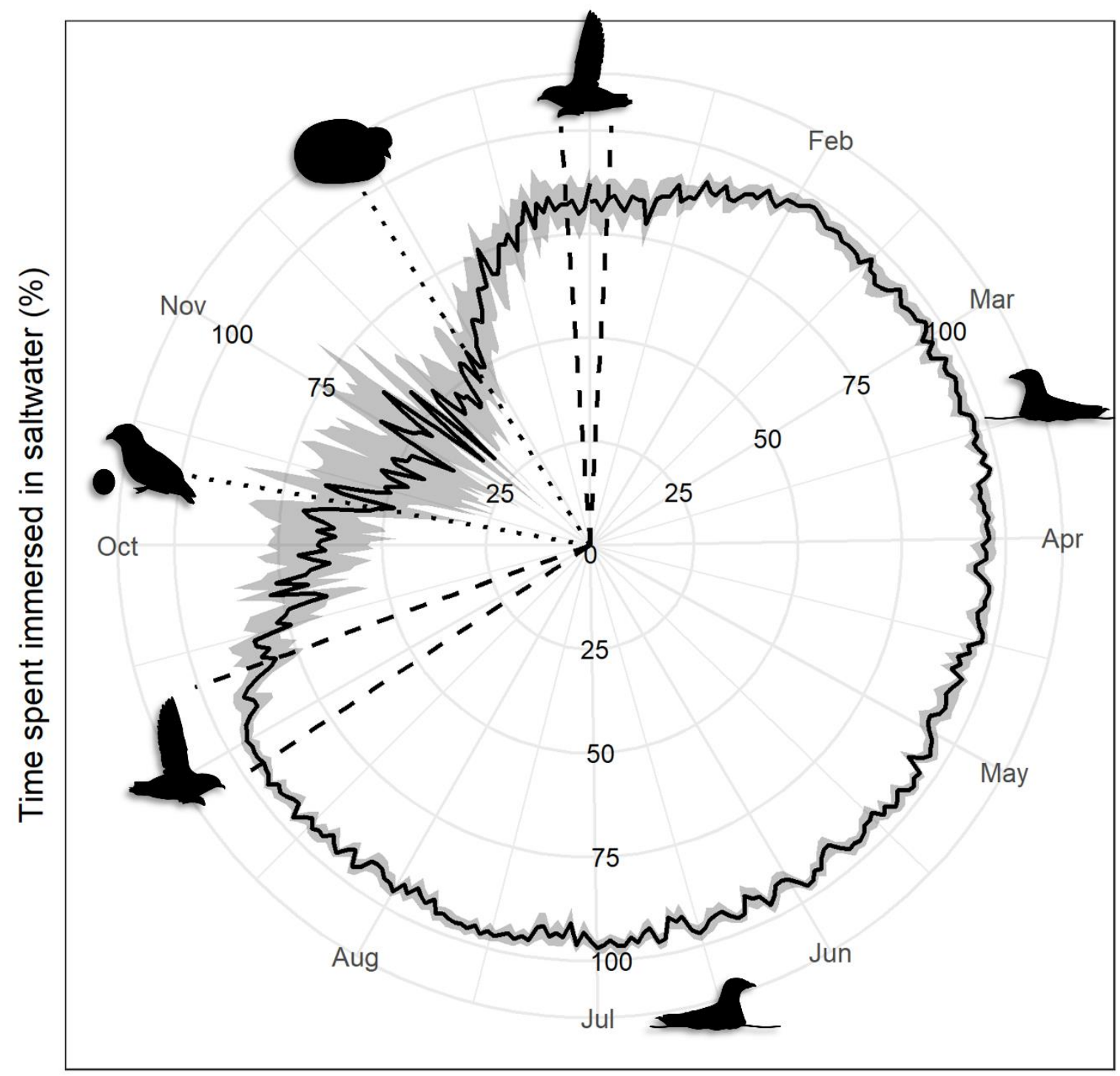

Fig. 15. Proportion of time Whenua Hou Diving Petrels spent immersed in saltwater (\% per day; means with 95\% CIs). Dashed lines indicate model-estimated means of departure from the breeding distribution (27 December), arrival at the non-breeding distribution (5 January), departure from the non-breeding distribution (28 August), and arrival at the breeding distribution (11 September). Dotted lines represent mean lay (10 October) and hatch dates (27 November; Ch. 5). 


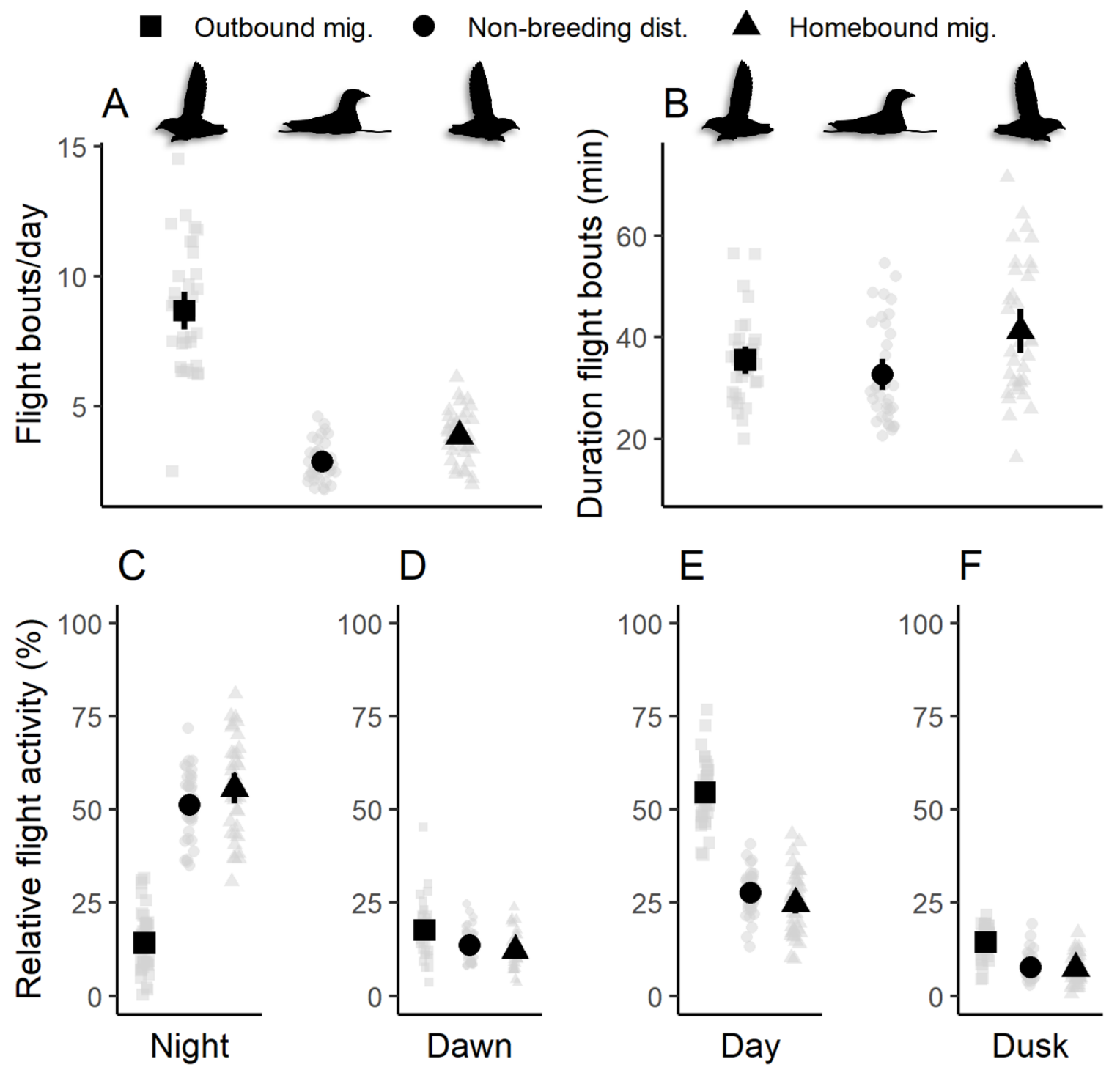

Fig. 16. Number of flight bouts per day (A), duration of flight bouts (B), and relative flight activity per diel category (C-F) per model-estimated phenophase. Black symbols with error bars: means with 95\% CIs, grey symbols: raw data. 


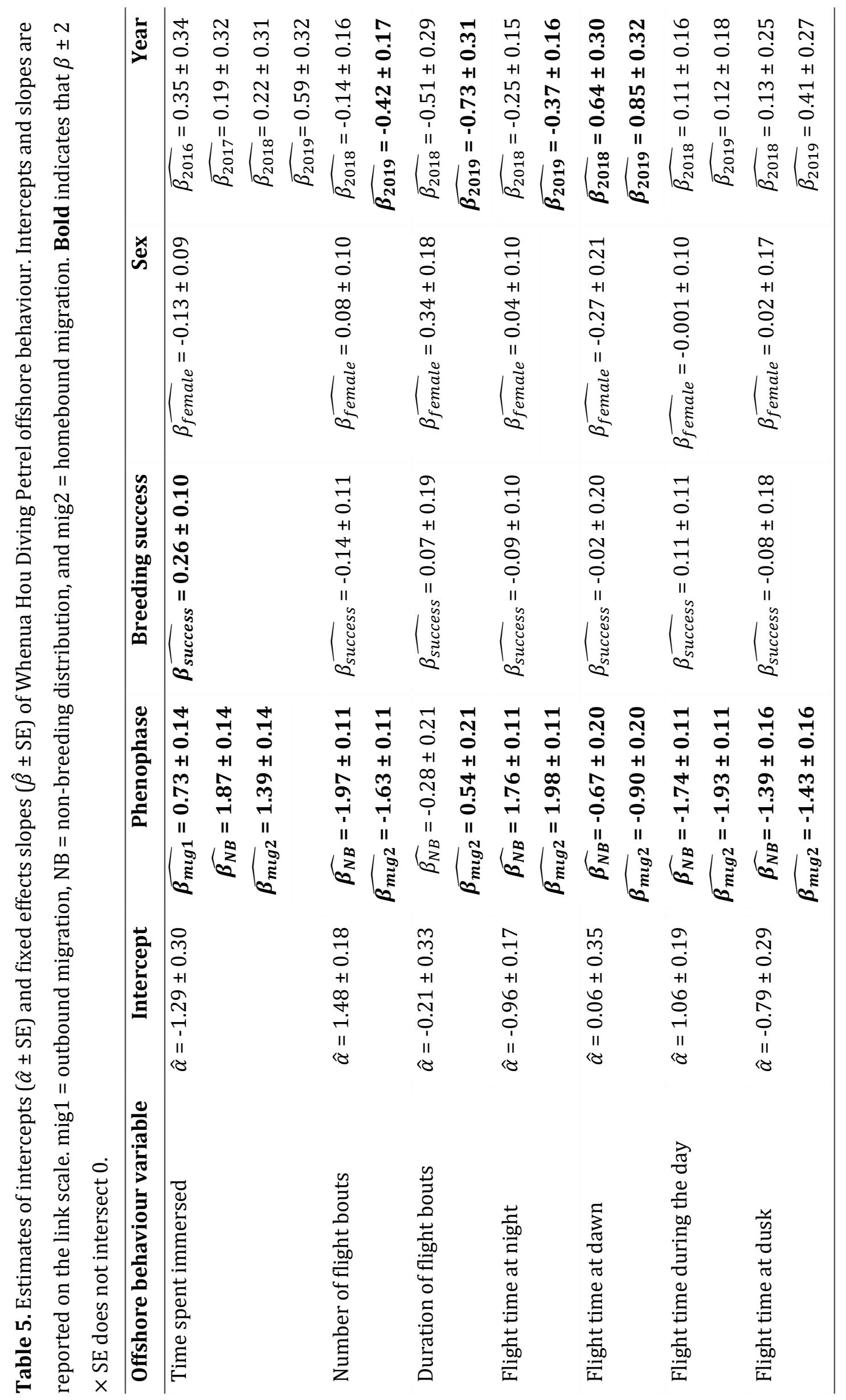




\section{Overlap with commercial fishing effort}

Considerable commercial fishing effort was present within the breeding distribution during the breeding period (11 September to 27 December; Fig. 17A). Concentrations of commercial fishing effort within the WHDP breeding distribution were evident within the exclusive economic zone (EEZ) south of Aotearoa, along the Snares shelf, and east of Maukahuka. Average fishing effort within the breeding distribution (95\% UD) during the breeding period equated to 0.59 hours per $0.1^{\circ}$ cell. Average summed fishing effort equated to 4,399 fishing hours. Fishing effort occurred within $10.92 \%$ of the WHDP breeding distribution. Average fishing effort within the WHDP core area of use (50\% UD) during the breeding period equated to 2.72 hours per $0.1^{\circ}$ cell. Average summed fishing effort equated to 2,948 vessel hours. Fishing effort was recorded within $34.51 \%$ of the WHDP core area of use during the breeding period.

There was almost no recorded commercial fishing effort within the non-breeding distribution during the non-breeding period (5 January to 28 August; Fig. 17B). The only hotspot of commercial fishing effort within the WHDP non-breeding distribution was near Macquarie Island within the Australian EEZ. Average fishing effort within the WHDP non-breeding distribution (95\% UD) equated to 0.004 hours per $0.1^{\circ}$ cell. Average summed fishing effort equated to 166 fishing hours per year. Fishing effort was limited to $0.08 \%$ of the WHDP non-breeding distribution. No fishing effort was recorded within the WHDP core area of use during the non-breeding period (50\% UD). 


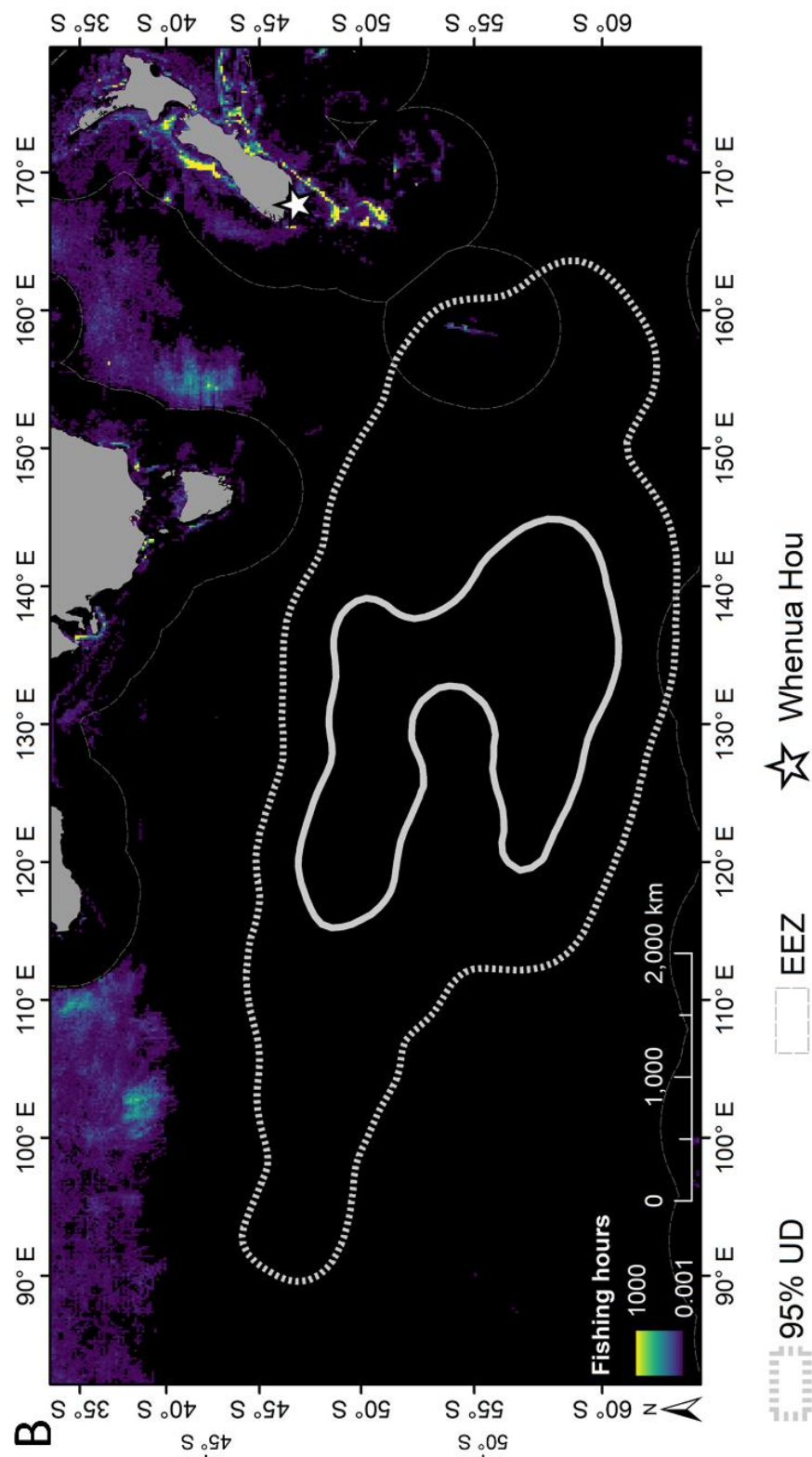

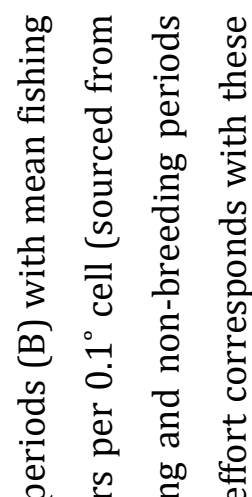

吕

ఏే

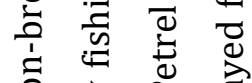

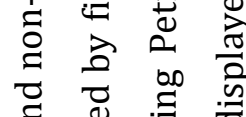

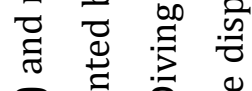

ङ

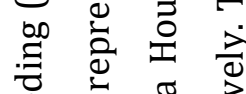

뿐

苋

品苟

ప

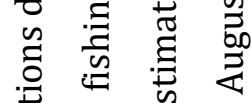

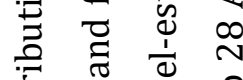

吾告

ర)

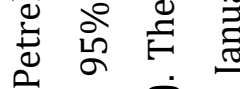

00 ठ

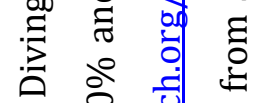

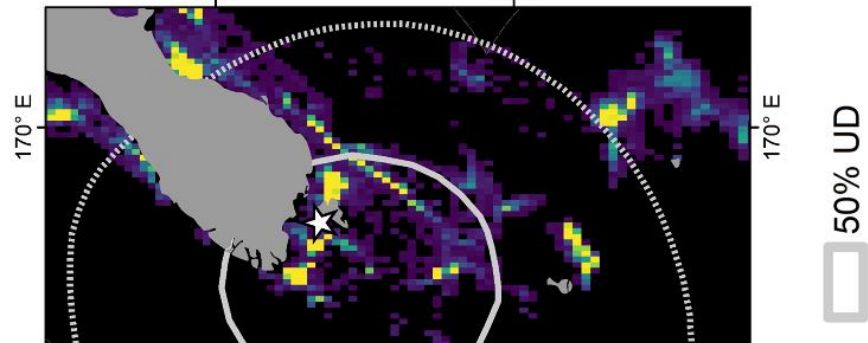

วิ

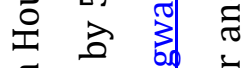

艺

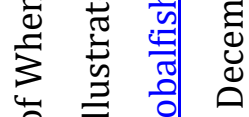

킁

สิ

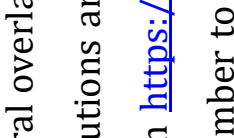

苛

$\Phi$

ㄴ.

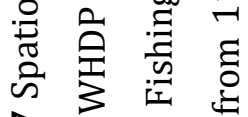

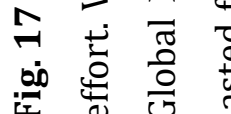

岂 


\section{DISCUSSION}

\section{WHDP movements and distribution}

WHDPs exhibited a truly pelagic lifestyle and spent the vast majority ( $>71 \%$ ) of their annual cycles at sea. During the breeding period, WHDPs did not range very far from Whenua Hou, as birds were bound by central place foraging, and travelling distances appeared to mirror congeneric species (Zhang et al. 2019, Dunphy et al. 2020). Rich feeding grounds, characterized by high productivity (chlorophyll-a concentrations), are located relatively close to Whenua Hou (e.g., the Snares shelf, the Subtropical Front, and around Maukahuka; Tréguer \& Jacques 1993, Orsi et al. 1995). My tracking efforts suggested that WHDP foraged here during the breeding period. These findings aligned with diet analyses, as the presence of larvae of Histiotheuthis sp. and Chirotheuthis sp. in stomachs suggested that WHDPs feed at the edge of the continental shelf (Imber \& Nilsson 1980). WHDPs share these seas with a suite of seabird species including Sooty Shearwaters (Puffinus griseus; Shaffer et al. 2006), Cook's Petrels (Pterodroma cookii; Rayner et al. 2008a), Buller's Albatrosses (T. bulleri; Waugh et al. 2017), and Whiteheaded Petrels (P. lessonii; Taylor et al. 2020).

After the breeding period, WHDPs spent their time around the Polar and Subantarctic Front. WHDPs migrated towards their non-breeding distributions against the prevailing winds (Young 1999) but completed their migrations rapidly through considerable flying efforts. On their homebound migrations, WHDPs exhibited less concerted flying efforts and probably exploited the prevailing westerly winds and currents. The WHDP nonbreeding distribution was, similarly to the breeding distribution, characterized by areas of relatively high productivity. Both the Polar and the Subantarctic Front exhibit heightened concentrations of chlorophyll-a, providing WHDPs with feeding opportunities (Tréguer \& Jacques 1993, Orsi et al. 1995). Other seabird species, such as White-headed Petrels (Taylor et al. 2020) and Grey-headed Albatross (Clay et al. 2016), also use these areas. 


\section{WHDP offshore behaviour}

WHDPs showed extreme aquatic behaviour during the non-breeding period. Even during the breeding period, WHDPs were on, or under, water for two-thirds of their time, while spending considerable amounts of time on land attending their burrows. Despite their predominant aquatic behaviour, WHDPs continued to exhibit flight behaviour throughout the year, indicating they retained flight capability during their non-breeding period, unlike some congenerics (Murphy \& Harper 1921). The aquatic behaviour of WHDPs could be explained by their high wing loadings. Diving petrel wings are adapted to wing-propelled diving, allowing relatively deep dives (e.g., 11 and $18 \mathrm{~m}$ in Common and South Georgian Diving Petrels, respectively; Navarro et al. 2013). Wings adapted to wing-propelled diving, however, have high wing loadings (e.g., 67 and $60 \mathrm{~N} / \mathrm{m}^{2}$ in Common and South Georgian Diving Petrels, respectively; Warham 1977). As such, diving petrels exhibit an energetically costly flight with fast whirring wings low above the sea surface, resembling alcids from the Northern Hemisphere, rather than other Procellariiformes (Rayner et al. 2017, Dunphy et al. 2020). This flight style may render diving petrels vulnerable to predation by larger seabirds (e.g., skuas), which may explain the largely nocturnal flight activity recorded in WHDPs. However, even compared to alcids, WHDPs are unusually aquatic (Mosbech et al. 2012, Dunn et al. 2020). Further investigations into the exact behaviour (i.e., resting vs. diving) would allow more detailed insights into the underlying drivers of their extreme aquatic nature (e.g., high daily energy expenditures; Dunn et al. 2020).

\section{Conservation implications}

The consistent distribution and behaviour of WHDPs has considerable conservation implications, as the regular presence of endangered species is one of the criteria for the designation of protected areas (Delord et al. 2014, Lascelles et al. 2016). Of the intrinsic factors I investigated, none suggested spatial segregation and WHDP distribution appeared highly consistent. The lack of spatial segregation could indicate an absence of intra-specific competition at sea (e.g., Clay et al. 2016, 2020), which could be caused the by the low WHDP population size and/or the lack of sexual dimorphism (Ch. 2, Fischer et al. 2018b, 2020a). The consistent use of the same areas by the critically endangered WHDP is a justification to list these regions as Important Bird and Biodiversity Areas (IBAs). IBA criterion A1 requires the regular presence of a threatened species in an area. 
Criterion A4ii requires the regular presence of $\geq 1 \%$ of the global population of a species in an area (BirdLife International 2010, Delord et al. 2014, Lascelles et al. 2016). While I did not calculate the true proportion of the WHDP population within these areas (Lascelles et al. 2016), I tracked $1.9 \%, 9.3 \%$, and 6.7\% of the global WHDP population in 2015/16, 2017/18, and 2018/19, respectively (Ch. 4). As such, at least the WHDP breeding/non-breeding core areas of use (50\% UDs) warrant listing as marine IBAs following criteria A1 and A4ii (Fig. 18; BirdLife International 2010, Delord et al. 2014).

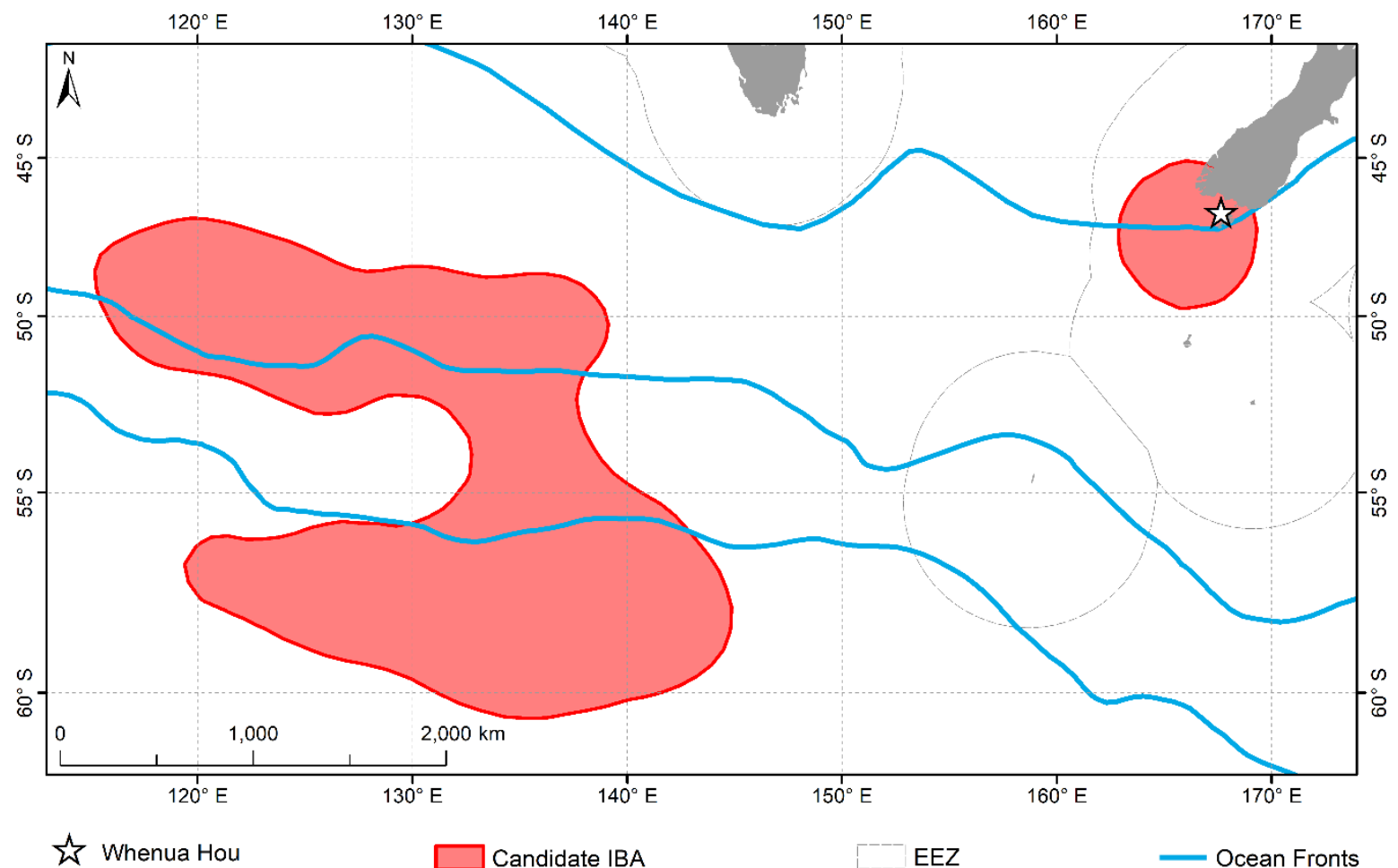

Fig. 18. Candidate marine Important Bird and Biodiversity Areas based on criteria A1 and A4ii triggered by breeding/non-breeding 50\% UDs of Whenua Hou Diving Petrels (based on tracking of $1.9 \%, 9.3 \%$, and $6.7 \%$ of the world population in 2015/16, 2017/18, and 2018/19, respectively). Raw data can be accessed at http://www.seabirdtracking.org/. Approximate location of Ocean Fronts (from north to south: Subtropical Front, Subantarctic Front, and Polar Front) are based on Harris \& Orsi (2006).

WHDP non-breeding distribution did not overlap with commercial fishing effort. The non-breeding distribution of WHDPs is located within one of the last stretches of largely untouched ocean on the planet (Kroodsma et al. 2018, Taconet et al. 2019). The lack of fishing effort recorded by the Global Fishing Watch is mirrored by the lack of marine 
traffic in this area (Wu et al. 2017). This absence of anthropogenic activity could be explained by the remoteness and the challenging conditions (mean wave height $>5 \mathrm{~m}$ and mean wind speed $>15 \mathrm{~m} / \mathrm{s}$; Young 1999) typical of this stretch of ocean. WHDPs exhibited extremely aquatic behaviour during the non-breeding period. Flight behaviour during this period mostly occurred at night, yet the number and duration of flight bouts remained very limited. The limited flight behaviour combined with a lack of human presence in this region indicated that impacts from anthropogenic threats (e.g., deck strikes) during the non-breeding period were unlikely.

In contrast to the non-breeding distribution, the WHDP breeding distributions overlapped considerably with commercial fishing effort and marine traffic (Wu et al. 2017). Several hotspots of commercial fishing effort were located in areas of elevated productivity and these productive areas may be equally attractive to foraging WHDPs (Tréguer \& Jacques 1993, Orsi et al. 1995). This overlap is indicative of the potential for anthropogenic threats at sea, especially to successful breeders, which stayed longer at their breeding distribution. Accidental bycatch of diving petrels has been recorded within the WHDP breeding distribution (Abraham \& Richards 2019). Additionally, the positive correlation between commercial fishing effort and artificial lights at night (Elvidge et al. 2015) in combination with increased WHDP flight activity during the breeding period indicated the potential for deck strikes in this area. Indeed, a record of 273 deck-struck diving petrels (all presumed Common Diving Petrels) occurred in this area (Abraham \& Richards 2019). A single deck strike event of such a magnitude could be detrimental to WHDP. While deck-struck birds are often released alive, post-release mortality (e.g., due to reduced water-proofing and subsequent hypothermia; Black 2005) is poorly understood.

My results illustrated that offshore conservation measures (during the breeding period) could benefit this critically endangered species. However, the threats posed by commercial fisheries within the WHDP breeding distribution spanned close to 1,000,000 $\mathrm{km}^{2}$ and managing threats within this vast area appears challenging. Seasonal (i.e., during the WHDP breeding period) restrictions of anthropogenic activity in the direct vicinity of Whenua Hou (i.e., the breeding colony) could be more feasible. Spatial restrictions to protect unique marine communities are in place around other islands, including Maukahuka and Gough and Tristan da Cunha (Chilvers et al. 2010, Requena et al. 2020). To complement any seasonal spatial restrictions, the following recommendations (Black 
2005) to minimize deck strikes should be encouraged: I) alert vessels to the risks of spotlights, II) use black-out blinds, III) minimize external deck lighting, IV) provide protocols on treatment and release of deck-struck birds, and V) keep records of deck strikes (including photographs to aid identification of diving petrels). Glass \& Ryan (2013) showed that such measures can reduce deck strikes considerably. I recommend that these measures are implemented throughout the WHDP breeding distribution (at least during the breeding period) as well as around Macquarie Island (at least during the non-breeding period). Improved record keeping and identification (e.g., genetically; Wold et al. 2018) of bycaught diving petrels during the WHDP breeding period would further elucidate offshore threats. Finally, higher resolution tracking (i.e., using miniature GPS loggers; Zhang et al. 2019, Dunphy et al. 2020) during the breeding period would provide more detailed insights into spatiotemporal overlap with offshore threats. The extent to which WHDPs are bound by central place foraging may differ among breeding phenophases, as burrow attendance varies among courtship, incubation, guard, and postguard phases (Ch. 5). Therefore, quantifying fine scale differences in overlap with offshore threats among breeding phenophases would be of particular interest.

As WHDPs spent a significant amount of time on land during the breeding period, terrestrial threats should be managed concurrently. This is particularly important as the last remaining WHDP breeding colony is restricted to an area of $0.018 \mathrm{~km}^{2}$ (Ch. 2, Fischer et al. 2018c, 2020a). Here, WHDPs nest in fragile foredunes $<20 \mathrm{~m}$ from the springtide line and are thus vulnerable to extreme weather events and climate change (Cole 2004). Moreover, close to half of the sandy coastlines on Aotearoa may retreat by $>100 \mathrm{~m}$ under the pressure of climate change (Vousdoukas et al. 2020). Consequently, while offshore threats during the breeding period should be mitigated, effective year-round conservation of WHDP will rely on managing terrestrial stressors as well. 
Chapter 4

\title{
Predicting harvest impact and translocation success in small populations: a case study of a critically endangered petrel
}

\begin{abstract}
In small populations, harvesting individuals for translocations could negatively impact source populations and thus, translocation cohorts should remain small, limiting potential establishment of recipient populations. The critically endangered Whenua Hou Diving Petrel (Pelecanoides whenuahouensis) could benefit from translocations to mitigate threats (e.g., storms, storm surges, and climate change), but only one small population remains. I used a novel metapopulation approach to an integrated population model to estimate vital rates and source population size, predict harvest impact on the source, and project the establishment of a recipient population under various translocation scenarios, while accounting for the return-to-source probability (juveniles recruiting back to the source post-translocation; $\psi_{r}$ ). I estimated adult survival at 0.868 , juvenile survival at 0.772 , productivity at 0.548 fledglings per female, population size at 207 adults, and population growth $(\hat{\lambda})$ at 1.023 . Scenarios that resulted in establishment of a recipient without excessive impact on the source were harvests of $\sim 10$ fledglings/year for five years and $\sim 5$ fledglings/year for 10 years. When accounting for $\widehat{\psi_{r}}$, recipient populations remained $\sim 29 \%$ smaller, and harvest regimes had to be increased ( $\sim 15$ fledglings/year for five years or $\sim 10$ fledglings/year for 10 years). I illustrate that establishment of new populations from small (seabird) populations can be feasible, but my results also show considerable uncertainty. Therefore, I recommend that translocations of small populations are conducted within an adaptive management framework, incorporating consistent monitoring of source and recipient populations, to evaluate projected impact and success and adjust harvest intensities when required.
\end{abstract}


Chapter 4

\section{INTRODUCTION}

Translocations are a powerful strategy to counteract the accelerating biodiversity loss in the current sixth mass extinction (Seddon et al. 2014, Parker et al. 2020). A translocation can be defined as the intentional movement of organisms from source to recipient populations for conservation or restoration objectives (Seddon et al. 2007, IUCN 2013, Seddon et al. 2014). Translocations should be considered as a conservation or restoration alternative if: I) suitable translocation sites are available, II) the candidate species is unlikely to naturally colonize these sites, and III) the translocation will not cause negative impacts on the source population (IUCN 2013). Conservation translocations can be used to supplement extant populations (reinforcement), reintroduce the species within their native distribution (reintroduction), or facilitate the colonisation of habitat beyond the species' native distribution (assisted colonisation) (Seddon et al. 2014). Restoration translocations can be used to reinstate ecosystem functioning provided by the candidate species within (reintroduction), or beyond the species' native distribution (ecological replacement). Translocations can address conservation and restoration objectives simultaneously (e.g., Miskelly et al. 2009).

While translocations are often used to rescue species surviving in small populations from extinction, the harvest of individuals for translocations (i.e., live collection) could have detrimental impacts on source populations (Armstrong \& Seddon 2008). Harvest for translocations can impact the viability of the source by lowering genetic diversity, increasing demographic stochasticity, and reducing vital rates (i.e., due to Allee effects; Armstrong \& Wittmer 2011). The impact of translocations on genetic diversity on source (and recipient) populations has been studied extensively (e.g., Ramstadt et al. 2013, Furlan et al. 2020, Hogg et al. 2020). However, the demographic impacts of removing individuals on source populations has received less attention (Dimond \& Armstrong 2007, Bain \& French 2009, Panfylova et al. 2019). Translocations of species persisting in small populations are a balancing act between minimizing impact on sources and harvesting sufficient individuals to establish recipient populations. Forecasting the demographic impact on source populations (Dimond \& Armstrong 2007) as well as projecting the establishment of recipient populations is therefore crucial to translocation planning (Converse et al. 2013, Panfylova et al. 2019). Yet, despite their fundamental importance to translocation planning, such dual forecasting exercises are rarely 
conducted, potentially because available data on endangered species often does not meet the requirements for predictive metapopulation models.

Integrated population models (IPMs) are a powerful tool for conservation management, including translocations, as these models allow for inference and predictions despite the data limitations common in studies of endangered species (Schaub \& Abadi 2011, Kery \& Schaub 2012, Saunders et al. 2018, 2019). IPMs can incorporate incomplete data from a range of studies (e.g., count, capture-recapture, and productivity data) into a single dynamic model (Schaub \& Abadi 2011, Kery \& Schaub 2012). This unified approach allows for the incorporation of all available information with full expression of uncertainty. IPMs can simultaneously estimate demographic processes and population sizes and project future trends and population viability under various environmental or management scenarios (Oppel et al. 2014, Saunders et al. 2018). Yet, these models are still infrequently applied in conservation management in general, and translocations in particular (Schaub \& Abadi 2011, Saunders et al. 2018).

Seabirds are appealing translocation candidates but monitoring of populations is limited and key translocation questions are rarely addressed a priori (Armstrong \& Seddon 2008, Miskelly et al. 2009, Paleczny et al. 2015). Seabirds are among the most threatened species groups and are considered ecosystem engineers; thus, these species are suitable for conservation and restoration translocations (Miskelly et al. 2009, Jones \& Kress 2012, Dias et al. 2019, Agreement on the Conservation of Albatrosses and Petrels 2020). The number of seabird translocations is rapidly increasing and $>200$ translocations have been attempted to date, despite the challenges that come with seabird translocations (i.e., the reliance on translocating pre-fledging chicks to overcome innate philopatry; Miskelly et al. 2009, Jones \& Kress 2012, Friesen et al. 2017, Zhou et al. 2017, Seabird Restoration Database 2020). However, data to evaluate and inform seabird translocations are often limited due to insufficient monitoring (Paleczny et al. 2015). Most notably, monitoring of source populations post-translocations is often considered optional (Gummer et al. 2014ab). This lack of monitoring could be explained by the sometimes very large population sizes of sources (Miskelly et al. 2009), leading to the assumption that source populations may not suffer from translocation harvests. The limited monitoring of sources post-translocations, however, inhibits understanding of the impacts of translocation harvests in small populations. Seabirds are extremely wideranging species and thus juveniles could recruit back to the source populations instead 
of the recipient populations post-translocations (e.g., Miskelly \& Gummer 2013, Rowe 2018). Therefore, limited monitoring at source populations also restricts examinations and predictions of translocation success (i.e., establishment of recipient populations).

I constructed an IPM to predict the impact and success of translocations of a critically endangered seabird: The Whenua Hou Diving Petrel (Pelecanoides whenuahouensis; WHDP). This species may be a suitable candidate for translocations as I) it is under ongoing pressure at its last remaining breeding colony, II) suitable habitat may be available, and III) the species is unlikely to colonize the suitable habitat on its own (or using acoustic attraction; Fischer et al. 2020b). However, the population of the WHDP is extremely small (Ch. 2, Fischer et al. 2020a) and thus harvesting individuals for translocations may have negative effects on the source population. Therefore, I formulated an IPM in a novel metapopulation approach to I) estimate vital rates, population size, and growth rate of the source, II) predict the impact of translocation harvest on the source, and III) project the establishment of a recipient population, under various translocation scenarios. In addition, I accounted for the potential of juveniles recruiting back to the source populations post-translocation.

\section{METHODS}

\section{Study species}

The recently described and critically endangered WHDP once acted as an ecosystem engineer throughout dune systems in southern Aotearoa (New Zealand), but is now restricted to a single colony on one island: Whenua Hou (Codfish Island; $-46.766^{\circ} \mathrm{S}$, $167.645^{\circ}$ E; Fig. 4 \& 5; Taylor 2000b, Fischer et al. 2018b, 2019, BirdLife International 2020). All invasive predators have been eradicated from Whenua Hou (McClelland 2002). Yet, the WHDP population size remains extremely small (194-208 adults; Ch. 2; Fischer et al. 2020a). Based on burrow counts, the population appears to be increasing, but the rate of increase is low compared to other seabirds on the island, indicating ongoing stressors (Ch. 2 \& 3). WHDPs only breed in burrows in fragile foredunes $<20 \mathrm{~m}$ from the springtide line (Fischer et al. 2018c), rendering the species vulnerable to erosion caused by storms, storm surges, and impending climate change (Cole 2004, Vousdoukas et al. 2020). Competition for burrows with Common Diving Petrels (P. urinatrix) may pose an additional threat (Fischer et al. 2017a). WHPDs did not respond to acoustic attraction 
systems to lure them to more secure breeding sites (Fischer et al. 2020b). Consequently, active translocations (i.e., moving pre-fledgling chicks) to another island may be a suitable strategy for to conserve the WHDP and reinstate lost ecosystem functioning.

Life history information is key to the success of translocations (Miskelly et al. 2009, Jones \& Kress 2012). WHDPs are relatively long-lived animals (> 20 years; pers. obs.). The WHDP breeding period lasts from September to January (Ch. 5). Like all Procellariiformes, WHDPs lay a single egg per breeding period (Warham 1996). After the breeding period, adults migrate to the Polar Front south of Australia (Ch. 3) and juveniles likely spend the first years of their lives entirely at sea. WHDPs mirror other diving petrels and generally start breeding at two years of age (Miskelly \& Taylor 2007, Miskelly et al. 2009). In addition, all adult WHDPs appear to attend burrows at the breeding colony every year (pers. obs.) and thus, unlike other Procellariiformes (e.g., Weimerskirch 2018), sabbaticals do not seem part of the WHDP life cycle. WHDPs, like other diving petrels (Miskelly \& Taylor 2004, Miskelly et al. 2009), exhibit an unusually fast life cycle history for a Procellariform seabird, rendering them highly suitable translocation candidates. However, adult survival, juvenile survival, and productivity remain poorly understood, limiting assessments on translocation impact and success.

\section{Capture-recapture data}

To quantify WHDP adult survival, juvenile survival, and population size, I used intermittent capture-recapture data of 391 adult and 79 fledgling WHDPs. Specifically, I captured and banded adult WHDPs at their breeding colony on Whenua Hou at night during September-January in 2015-19 (referring to the calendar year in which the breeding period started). I fused this data with pre-existing capture-recapture data of adults from of 2002-04 and 2008 (G Taylor unpublished). I defined adults as birds returning to the colony, as birds cannot be aged phenotypically (Fischer et al. 2018b). To reduce capture biases, a variety of capture techniques were applied: I) hand capture, sometimes aided by playback/mimics, II) custom-made burrow traps, and III) spotlighting (Fig. 10; Fischer et al. 2017ab, 2018b). In 2015-19, I captured and banded fledglings at their burrows (Ch. 5). I considered each breeding period as a separate sampling occasion to estimate annual survival and detection probabilities. As WHDPs are sexually monomorphic (Fischer et al. 2018b), I also collected four contour feathers from 246 adults and 67 fledglings and used these for genetic sex determination (using 
polymerase chain reaction primers specific to the chromodomain-helicase-DNA-binding gene on the W-chromosome; Norris-Caneda \& Elliott 1998). I sexed 116 adult females and 130 adult males, as well as 30 female fledglings and 37 male fledglings.

\section{Productivity data}

To inform WHDP productivity, I monitored a total of 204 WHDP burrows for the entire breeding period of 2017-19 (65-79\% of all known burrows). WHDP burrows close annually due to the movement of sand dunes and are reopened by birds at the start of every breeding period (Ch. 5 \& 6, Fischer et al. 2019). I defined a WHDP burrow as a burrow $>60 \mathrm{~cm}$ deep and occupied by a WHDP, which I confirmed with a burrowscope (Sextant Technologies, Wellington, New Zealand). I checked burrows at least once per week using a burrowscope (summarized in Ch. 5). The productivity data that I collected consisted of the number of fledglings produced per year in conjunction with the number of burrows surveyed, regardless of whether burrows received an egg. My productivity data thus reflects a product of lay rate and nest success (Ch. 5), allowing me to account for prospecting WHDPs. I assumed that the number of fledglings per burrow was equal to fledglings per female.

\section{Integrated population model}

To estimate WHDP vital rates and population size as well as impact and success of translocations, I formulated an age-structured IPM in a Bayesian framework (Schaub \& Abadi 2011, Saunders et al. 2018). I integrated three subcomponents in my IPM: I) an open-population Cormack-Jolly-Seber model using the annual capture-recapture data, II) a productivity model using the annual productivity data, and III) an abundance model using annual counts of banded and unbanded WHDPs. I used this IPM to simultaneously estimate detection, age-specific survival, productivity, sex ratio, population size, and growth at the source population. Additionally, I included a second (recipient) population in my IPM. Using a novel metapopulation approach, I linked source and recipient populations with vital rates, transition probabilities (harvest rates and return-to-source probabilities), and population estimates of the juveniles arising from translocated fledglings (Fig. 19). Central to my IPM were two age-structured $2 \times 2 \times 2$ Leslie matrices (one each for source and recipient populations; Caswell 2001): 
1. $\left[\begin{array}{l}N_{j u v} \\ N_{a d}\end{array}\right]_{t+1}=\left[\begin{array}{cc}0 & f \times p r_{f e m} \times \varphi_{j u v} \\ \varphi_{j u v} & \varphi_{a d}\end{array}\right]_{t} \times\left[\begin{array}{c}N_{j u v} \\ N_{a d}\end{array}\right]_{t}$

in which $N_{j u v, t}$ is the number of juveniles, $N_{a d, t}$ is the number of adults, $f_{t}$ is the productivity (fledglings per female), $p r_{f e m}$ is the probability of an individual being female, $\varphi_{j u v, t}$ is the juvenile survival probability, and $\varphi_{a d, t}$ is the adult survival probability. The matrices for source and recipient populations were identical, apart from variation between productivity at the source $\left(f_{S, t}\right)$ and the recipient population $\left(f_{R, t}\right)$.

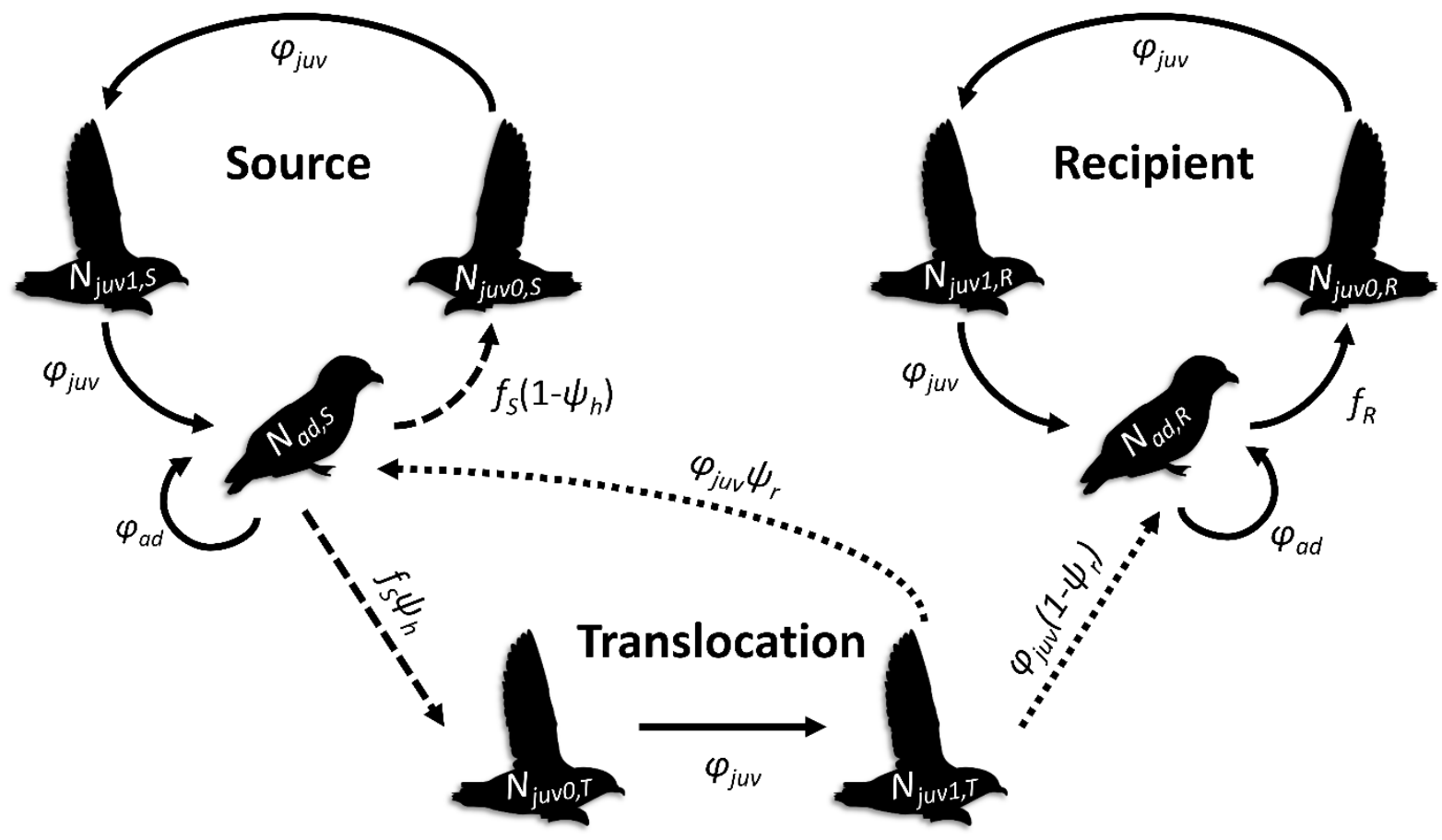

Fig. 19. Conceptual framework of the integrated population model used to estimate Whenua Hou Diving Petrel translocation impact and success. Silhouettes indicate age classes: $N_{a d, S}=$ adults at the source population, $N_{j u v 0, S}=$ juveniles arising from fledglings at the source population, $N_{j u v 1, S}$ $=1$-year-old juveniles at the source population, $N_{j u v 0, T}=$ juveniles arising from fledglings from a translocation cohort, $N_{j u v 1, T}=1$-year-old juveniles from a translocation cohort, $N_{a d, R}=$ adults at the recipient population, $N_{j u v 0, R}=$ juveniles arising from fledglings at recipient the population, $N_{j u v 1, R}=1$-year-old juveniles at the recipient population. Arrows indicate vital rates and transition probabilities: $\varphi_{a d}=$ adult survival, $\varphi_{j u v}=$ juvenile survival, $f_{S}=$ productivity at the source population, $f_{R}=$ productivity at the recipient population, $\psi_{h}=$ harvest rate, $\psi_{r}=$ returnto-source probability. Dashed arrows were subjected to scenarios with varying $\psi_{h}$; dotted arrows were subjected to scenarios with varying $\psi_{r}$. 


\section{Estimation of survival}

I used an open-population Cormack-Jolly-Seber model (Lebreton et al. 1992) in the statespace formulation (Gimenez et al. 2007, Kery \& Schaub 2012) to estimate annual detection $p_{t}$, adult survival $\varphi_{a d, t}$, and juvenile survival probabilities $\varphi_{j u v, t}$ :

\section{2. $\quad Y_{i, t} \mid X_{i, t} \sim \operatorname{Bernoulli}\left(X_{i, t}, p_{i, t}\right)$ \\ 3. $X_{i, t+1} \mid X_{i, t} \sim \operatorname{Bernoulli}\left(X_{i, t}, \varphi_{i, t}\right)$}

Equation 2 described the observation process and Equation 3 described the state process. $Y_{i, t}$ equalled 0 if individual $i$ was not detected at time $t$, and 1 if it was. $X_{i, t}$ equalled 0 if the individual was dead at time $t$, and 1 if the individual was alive. $p_{i, t}$ is the detection probability of individual $i$ at time $t$ and $\varphi_{i, t}$ is the survival probability of individual $i$ over the time interval $t$ to $t+1$. I estimated $p_{i, t}$ using:

\section{4. $\quad \operatorname{logit}\left(p_{i, t}\right)=\alpha_{p}+\varepsilon_{p, t}$}

in which $\alpha_{p}$ is the intercept of the detection equation and $\varepsilon_{p, t}$ is an annual random effect on detection. I used vague priors for $\alpha_{p}(N[$ mean $=0$, precision $=0.1])$ and $\sigma_{\varepsilon_{p, t}}$ $(U[0,3])$. I fixed $p_{i, t}$ at 0 for years during which no surveys were conducted (2005-07 and 2009-14) and for one-year-old juveniles, which I assumed to be out at sea (i.e., I fixed age at first return at two years of age). I did not include any age effects on $p_{i, t}$ due to my low sample size of known-age birds. I estimated $\varphi_{i, t}$ using:

\section{5. $\quad \operatorname{logit}\left(\varphi_{i, t}\right)=\alpha_{\varphi}+\beta_{j u v} \times j u v_{i, t}+\varepsilon_{\varphi, t}$}

in which $\alpha_{\varphi}$ is the intercept of the survival equation, $\beta_{j u v}$ is the age effect on survival, $j u v_{i, t}$ is the juvenile status of individual $i$ at time $t$, and $\varepsilon_{\varphi, t}$ is an annual random effect on survival. I used vague priors for $\alpha_{\varphi}(N[0,0.1]), \beta_{j u v}(N[0,1])$, and $\sigma_{\varepsilon_{\varphi, t}}(U[0,3])$. I thus assumed that survival during the first two years of life was different from older birds and estimated annual adult and juvenile survival as:

6. $\quad \operatorname{logit}\left(\varphi_{a d, t}\right)=\alpha_{\varphi}+\varepsilon_{\varphi, t}$ 
7. $\operatorname{logit}\left(\varphi_{j u v, t}\right)=\alpha_{\varphi}+\beta_{j u v}+\varepsilon_{\varphi, t}$

\section{Estimation of productivity}

I estimated annual productivity (fledglings per female) at the source population $f_{S, t}$ using a generalized mixed effects linear model (GLMM) with a Bernoulli error term:

\section{8. $\operatorname{logit}\left(f_{S, t}\right)=\alpha_{f}+\varepsilon_{f_{t}}$}

in which $\alpha_{f}$ is the intercept of the productivity equation and $\varepsilon_{f_{t}}$ is an annual random effect on productivity. I used a vague prior for $\alpha_{f}(N[0,0.1])$, but as I only had three years of data (2017-19), I used a mildly informative prior for $\sigma_{\varepsilon_{f t}}(U[0,0.2])$. I then estimated the annual productivity at the recipient population $f_{R, t}$ using:

\section{9. $\quad \operatorname{logit}\left(f_{R, t}\right)=\alpha_{f}+\beta_{\text {recipient }}+\varepsilon_{f_{t}}$}

in which $\beta_{\text {recipient }}$ is a fixed effect on the productivity at the recipient site. I assumed that the mean of $f_{R, t}$ will be equal to the mean of $f_{S, t}$, but since I had no data for the recipient population, $f_{R, t}$ could be lower or higher than $f_{S, t}$. As such, I used a mildly informative prior for $\beta_{\text {recipient }}(N[0,2])$ to increase the uncertainty around $f_{R, t}$. I assumed that productivity was the only vital rate that differed between source and recipient populations.

\section{Estimation of population size}

Classic IPMs incorporate count data, separate from capture-recapture and productivity data, into the joint likelihood to estimate population sizes (Abadi \& Schaub 2011, Saunders et al. 2018, 2019). We, however, had no access to separate count data. Therefore, I used the annual counts of banded and unbanded adults (i.e., the number of adults captured for the first time) in conjunction with detection, survival, and productivity estimates to infer adult population size at the source $N_{a d, s, t}$. Specifically, I first estimated the number of 2-year-old juveniles recruiting into the source. I then used this estimate together with the estimated number of surviving undetected adults to estimate the annual pool of unbanded adults available for detection. I then sampled the 
annual number of captured unbanded adults from this pool using the estimated detection probability. I subtracted the number of the captured unbanded adults from the pool of unbanded adults. Ultimately, I summed the estimated pool of undetected unbanded adults and the sum of the surviving banded adults to infer the population size at the source $N_{a d, S, t}$ :

10. $N_{a d . f, S, t} \sim \operatorname{Bin}\left(p r_{f e m}, N_{a d, S, t}\right)$

11. $N_{j u v 0, S, t} \sim \operatorname{Bin}\left(f_{S, t}, N_{a d . f, S, t}\right)$

12. $N_{j u v 1, S, t} \sim \operatorname{Bin}\left(\varphi_{j u v, t-1}, N_{j u v 0, S, t-1}\right)$

13. $N_{j u v 2, S, t} \sim \operatorname{Bin}\left(\varphi_{j u v, t-1}, N_{j u v 1, S, t-1}\right)$

14. $N_{\text {ad.unk.surv }, S, t} \sim \operatorname{Bin}\left(\varphi_{a d, t-1}, N_{a d . u n k, S, t-1}\right)$

15. $N_{\text {ad.unband,S,t }}=N_{\text {ad.unk.surv }, S, t}+N_{j u v 2, S, t}$

16. $N_{\text {ad.new }, S, t} \sim \operatorname{Bin}\left(p_{t}, N_{\text {ad.unband,S,t }}\right)$

17. $N_{\text {ad.unk }, S, t}=N_{\text {ad.unband }, S, t}-N_{\text {ad.new }, S, t}$

18. $N_{a d, S, t}=N_{a d . u n k, S, t}+N_{a d . b a n d, S, t}$

in which $N_{a d . f, S, t}$ is the number of adult females at the source population, $p r_{f e m}$ is the probability that an individual is female. I modelled $p r_{f e m}$ with a Bernoulli error term and a vague prior $(U[0,1])$ and assumed $p r_{f e m}$ to be constant among years. $N_{j u v 0, S, t}$ is the number of juveniles arising from fledglings at the source population, $N_{j u v 1, S, t}$ is the number of 1-year-old juveniles at the source population, and $N_{j u v 2, S, t}$ is the number of 2year-old juveniles that recruit into the source population, $N_{\text {ad.unk.surv }, S, t}$ is the number of undetected adults surviving from the previous year, $N_{\text {ad.unk,S,t }}$ is the number of unknown undetected adults, $N_{\text {ad.unband,s,t }}$ is the number of unbanded adults available for detection, $N_{a d . n e w, S, t}$ is the number of unbanded adults captured for the first time, and $N_{a d . b a n d, S, t}$ is the sum of $X_{i, t}$ (i.e., all banded and surviving adults in year $t$ ). For the first year in my study (2002), I used informative priors for $N_{j u v 1, S, t}(U[0,60])$ and $N_{a d . u n k, S, t}(U[0,200])$. This approach allowed me to estimate population size for years with capture-recapture data and infer population sizes during years for which no data were collected. 


\section{Estimation of population growth rate}

I estimated the average finite rate of population growth $\lambda$ at the source site by solving the quadratic of the matrix in Equation 1, similar to Parlato \& Armstrong (2018), which resulted in the following equation:

19. $\lambda=\frac{\varphi_{a d}+\sqrt{\varphi_{a d^{2}}+4 \times f_{s} \times p r_{f e m} \times \varphi_{j u v^{2}}}}{2}$

in which $\varphi_{a d}$ is the average annual adult survival, $f_{s}$ is the average annual productivity (fledglings per female) at the source population, and $\varphi_{j u v}$ is the average annual juvenile survival.

\section{Projections of the source population}

I projected the size of the source population $N_{a d, S, t}$ under various translocation scenarios, while accounting for juveniles recruiting back into the source post-translocation using:

20. $N_{j u v 0, S, t} \sim \operatorname{Bin}\left(f_{S, t} \times\left(1-\psi_{h, t}\right), N_{f . a d, S, t}\right)$

21. $N_{j u v 1, S, t} \sim \operatorname{Bin}\left(\varphi_{j u v, t-1}, N_{j u v 0, S, t-1}\right)$

22. $N_{j u v 2, S, t} \sim \operatorname{Bin}\left(\varphi_{j u v, t-1}, N_{j u v 1, S, t-1}\right)$

23. $N_{\text {juv }, \text { return }, t} \sim \operatorname{Bin}\left(\varphi_{j u v, t-1} \times \psi_{r}, N_{j u v 1, T, t-1}\right)$

24. $N_{a d, S, t} \sim \operatorname{Bin}\left(\varphi_{a d, t-1}, N_{a d, S, t-1}+N_{j u v 2, S, t-1}+N_{j u v 2, \text { return }, t-1}\right)$

in which $\psi_{h, t}$ is the annual harvest rate, $N_{j u v 1, T, t}$ is the number 1-year-old juveniles arising from a translocation cohort, $\psi_{r}$ is the return-to-source probability, and $N_{j u v 2, r e t u r n, t}$ is the number of 2-year-old juveniles that recruit back to the source post-translocation. I did not account for density-dependence in my projections, because diving petrels can breed at very high densities ( $\sim 6$ burrows $/ \mathrm{m}^{2}$; Taylor $2000 \mathrm{~b}$ ) and densities at the WHDP breeding colony are currently comparatively low (0.02 burrows/m²; Ch. 5). 
Projections of the recipient population

I first projected the number of juveniles arising from translocated fledglings using:

25. $N_{j u v 0, T, t} \sim \operatorname{Bin}\left(f_{S, t} \times \psi_{h, t}, N_{f . a d, S, t}\right)$

26. $N_{j u v 1, T, t} \sim \operatorname{Bin}\left(\varphi_{j u v, t-1}, N_{j u v 0, T, t-1}\right)$

in which $N_{j u v 0, T, t}$ is the number of juveniles arising from translocated fledglings. I assumed that translocations would not influence fledgling survival, based on everimproving seabird translocation and hand-rearing protocols (Miskelly et al. 2009, Jones \& Kress 2012, Agreement on the Conservation of Albatrosses and Petrels 2020). I then projected size of the recipient population $N_{a d, R, t}$ using:

27. $N_{a d . f, R, t} \sim \operatorname{Bin}\left(p r_{f e m}, N_{a d, R, t}\right)$

28. $\quad N_{j u v 0, R, t} \sim \operatorname{Bin}\left(f_{R, t}, N_{a d . f, R, t}\right)$

29. $N_{j u v 1, R, t} \sim \operatorname{Bin}\left(\varphi_{j u v, t-1}, N_{j u v 0, R, t-1}\right)$

30. $N_{j u v 2, R, t} \sim \operatorname{Bin}\left(\varphi_{j u v, t-1}, N_{j u v 1, R, t-1}\right)$

31. $N_{j u v 2, T, t} \sim \operatorname{Bin}\left(\varphi_{j u v, t-1} \times\left(1-\psi_{r}\right), N_{j u v 1, T, t-1}\right)$

32. $N_{a d, R, t} \sim \operatorname{Bin}\left(\varphi_{a d, t-1}, N_{a d, R, t-1}+N_{j u v 2, R, t-1}+N_{j u v 2, T, t-1}\right)$

in which $N_{a d . f, R, t}$ is the number of adult females at the recipient population, $N_{j u v 0, R, t}$ is the number of juveniles arising from fledglings at the recipient population, $N_{j u v 1, R, t}$ is the number of 1-year-old juveniles at the recipient population, $N_{j u v 2, R, t}$ is the number of 2year-old juveniles from the recipient population recruiting into the recipient, and $N_{j u v 2, T, t}$ is the number of 2-year-old juveniles recruiting into the recipient population posttranslocation. My approach thus allowed me to simultaneously project population sizes of source and recipient populations, while accounting for the return-to-source probability. 
Estimation of the return-to-source probability

I wanted to investigate the influence of juveniles returning to the source instead of the recipient population post-translocation, on translocation impact and success. I defined the return-to-source probability $\psi_{r}$ as the proportion of translocated birds returning as adults to the source site relative to the total number of translocated birds surviving to adulthood. I used data published on translocations of members of the family Procellariidae in the scientific literature to inform $\psi_{r}$. I searched Google Scholar and Web of Science with the search terms "petrel" OR "shearwater" OR "prion" AND "translocation" and found seven case studies reporting on $\psi_{r}$ (Table 6). I included one additional report from a seabird translocation practitioner (D Boyle in lit. 2020). I then estimated returnto-source probabilities per case study, and ultimately, the overall $\psi_{r}$ for Procellariidae, as following:

33. $\operatorname{logit}\left(\psi_{r, k}\right)=\alpha_{\psi_{r}}+u_{\psi_{r, k}}$

34. $N_{\text {recruit }, S, k} \sim \operatorname{Bin}\left(\psi_{r, k}, N_{\text {recruit }, \text { tot }, k}\right)$

35. $\operatorname{logit}\left(\psi_{r}\right)=\alpha_{\psi_{r}}+u_{\psi_{r}}$

in which $\psi_{r, k}$ is the return-to-source probability per case study $k, \alpha_{\psi_{r}}$ is the intercept of the return-to-source equation, $u_{\psi_{r, k}}$ is a random effect per study $k, N_{\text {recruit,S,k}}$ is the number of translocated birds returning as adults to the source site per study $k$, and $N_{\text {recruit,tot, } k}$ is the total number of translocated birds surviving to adulthood per study $k$. I used vague priors for $\alpha_{\psi_{r}}(N[0,0.001])$ and $\sigma_{u_{\psi_{r}}}(U[0,10])$. I then used $\operatorname{logit}\left(\psi_{r}\right)$ to create an informed prior, which I used within my IPM to account for WHDP juveniles returning to the source post-translocations. I assumed that, apart from $\psi_{r}$, there was no exchange of juveniles or adults between source and recipient populations. 


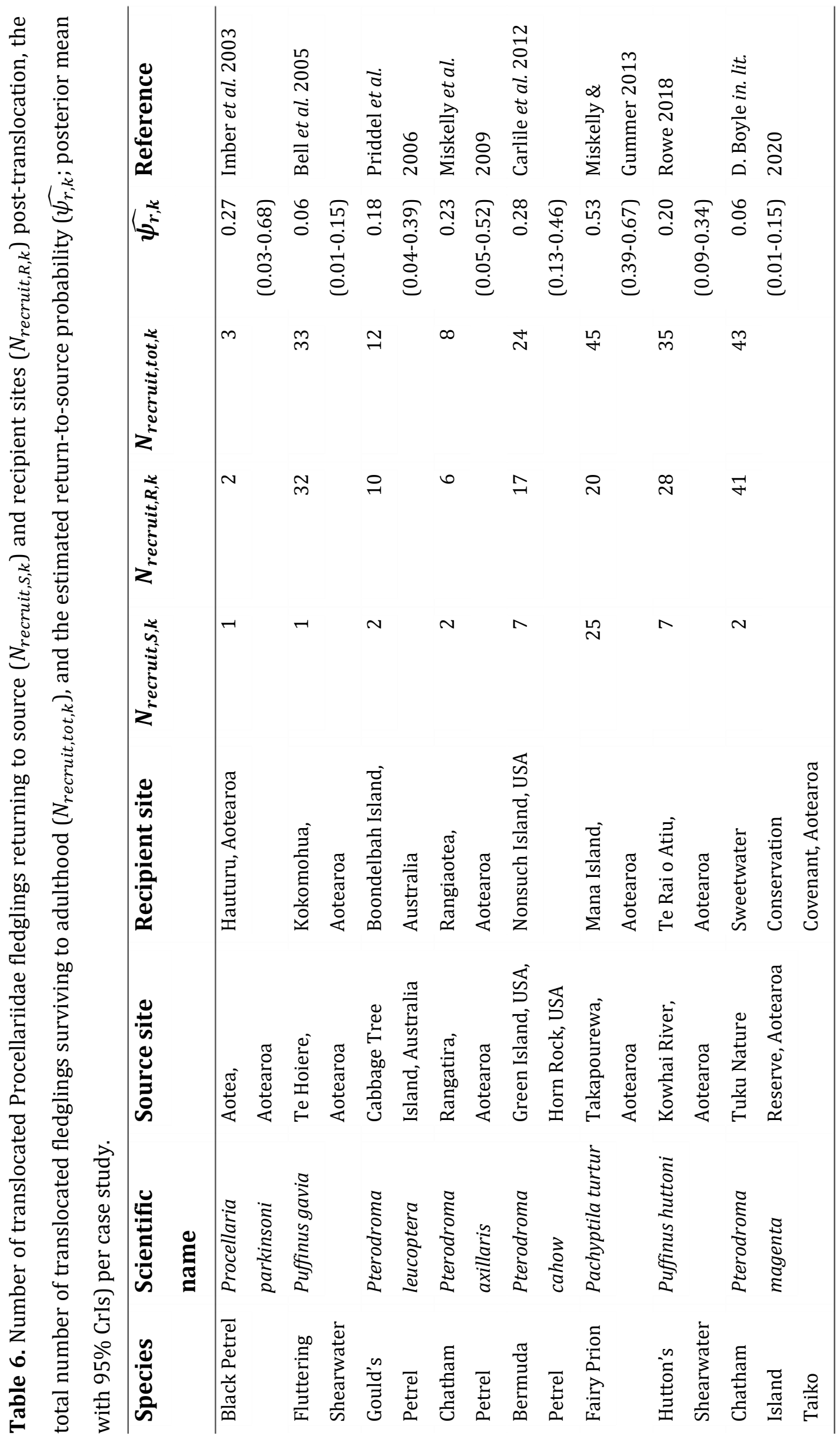




\section{Translocation scenarios}

I projected the source and recipient populations 20 years into the future under varying translocation scenarios. Specifically, I estimated the impact and success of translocations when harvesting $0 \%$ to $30 \%$ of all fledglings per year (i.e., I varied the annual harvest rate $\psi_{h, t}$ at 0.1 increments). Additionally, I modelled the translocation timeframe as five or 10 consecutive years. I considered a mean estimated decrease of the source population $\left(\widehat{N_{a d, S}, t}\right)$ to 175 (pre-eradication population estimate; see results) as a cut-off for acceptable impact on the source population. I considered a mean estimate of the recipient population $\left(\widehat{N_{a d, D}, t}\right)>30$ as a successfully established second breeding colony (similar to Dimond \& Armstrong 2007).

\section{Model fitting}

I fitted my IPMs in the Bayesian modelling program OpenBUGS 3.2.3 (Spiegelhalter et al. 2014), which uses Markov chain Monte Carlo (MCMC) algorithms to obtain posterior distributions of all parameters while simultaneously propagating all sources of uncertainty. I fitted 13 versions of my IPM that relate to the decision landscape managers face when considering translocations: a no-harvest scenario, and a scenario for each value of $\psi_{h, t}$, for five or 10 years of harvesting, while either fixing $\psi_{r}$ at 0 or estimating it. For each IPM, I ran two MCMC chains for 100,000 iterations after a burn-in of 50,000 iterations, which was sufficient to give convergence based on the Gelman-Rubin statistic $(\hat{R}<1.05)$. I report the mean of posterior distributions with $95 \%$ credible intervals (CrI). The OpenBUGS code of my IPM can be found in Supplementary Material 2. 
Chapter 4

\section{RESULTS}

Average adult WHDP survival was estimated at $\widehat{\varphi_{a d}}=0.868$ (0.833-0.930), average juvenile survival was estimated at $\widehat{\varphi_{\text {Juv }}}=0.772(0.689-0.878)$, and average productivity (fledglings per female) at the source population was estimated at $\widehat{f_{S}}=0.548(0.481-0.616$; Fig. 20). The proportion of females was estimated at $\widehat{p r_{f e m}}=0.487$ (0.434-0.540). The source population size $\left(\widehat{N_{a d, S, t}}\right)$ was estimated at 172 (111-232) adults in 2002 and increased to 207 (182-235) adults in 2019 (Fig. 21). Average annual population growth between 2002 and 2019 was estimated at $\hat{\lambda}=1.023(0.979-1.112)$. When projecting the source population 20 years into the future without harvesting for translocations, population size was predicted at 255 (27-710) adults in 2039 (Table 7). Estimated studyspecific return-to-source probabilities ranged from $\widehat{\psi_{r, k}}=0.06(0.01-0.15)$ to $\widehat{\psi_{r, k}}=0.53$ (0.39-0.67) (Table 6, Fig. 22). The estimated overall return-to-source probability was estimated at $\widehat{\psi_{r}}=0.25(0.01-0.87)$. 

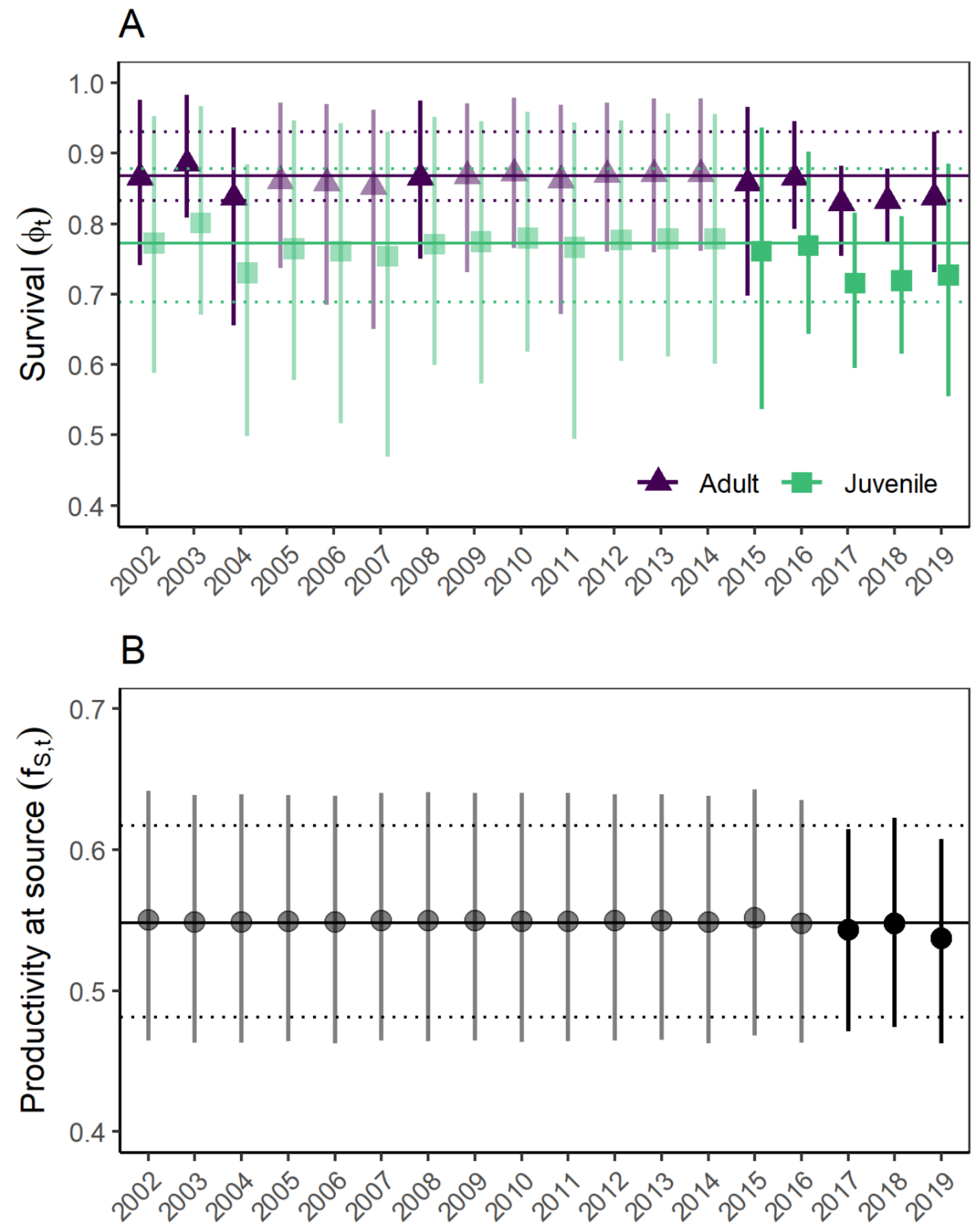

Fig. 20. Annual estimates (posterior means and 95\% CrIs) of Whenua Hou Diving Petrel adult and juvenile survival $\left(\widehat{\varphi_{a d, t}}\right.$ and $\left.\widehat{\varphi_{\jmath u v}, t} ; \mathrm{A}\right)$ and productivity at source population $\left(\widehat{f_{S, t}} ; \mathrm{B}\right)$. Solid and dotted lines indicate average estimates. Solid symbols indicate estimates for years during which surveys took place. Translucent symbols indicate estimates for years without surveys, which were derived using integrated population modelling, fusing inferences of survival, reproduction, and abundance across all years. 


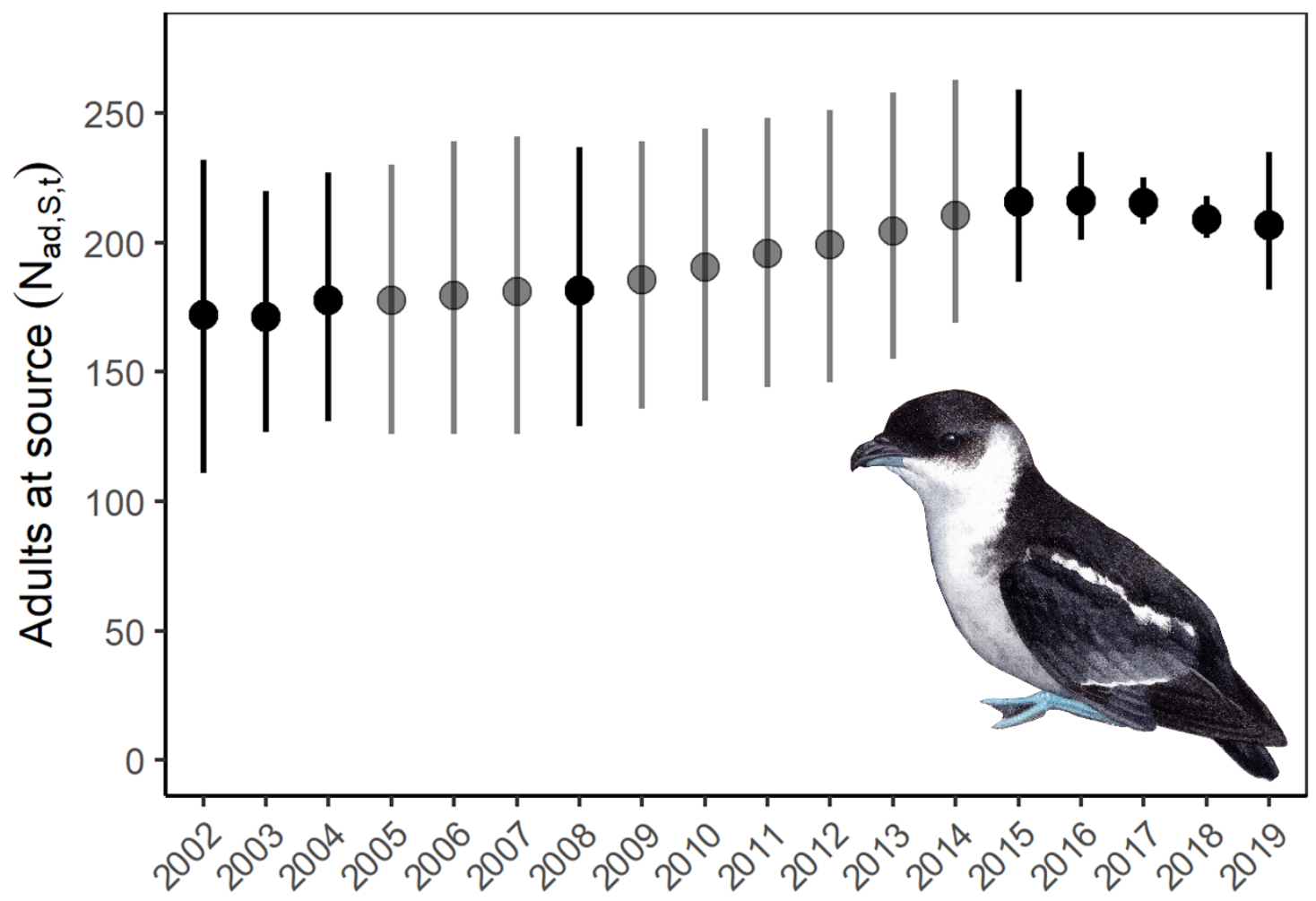

Fig. 21. Estimated Whenua Hou Diving Petrel population sizes at the source site $\left(\widehat{N_{a d, S, t}}\right.$; posterior means and $95 \%$ CrIs). Solid symbols indicate estimates for years during which surveys took place. Translucent symbols indicate estimates for years without surveys, which were derived using integrated population modelling, fusing inferences of survival, reproduction, and abundance across all years.
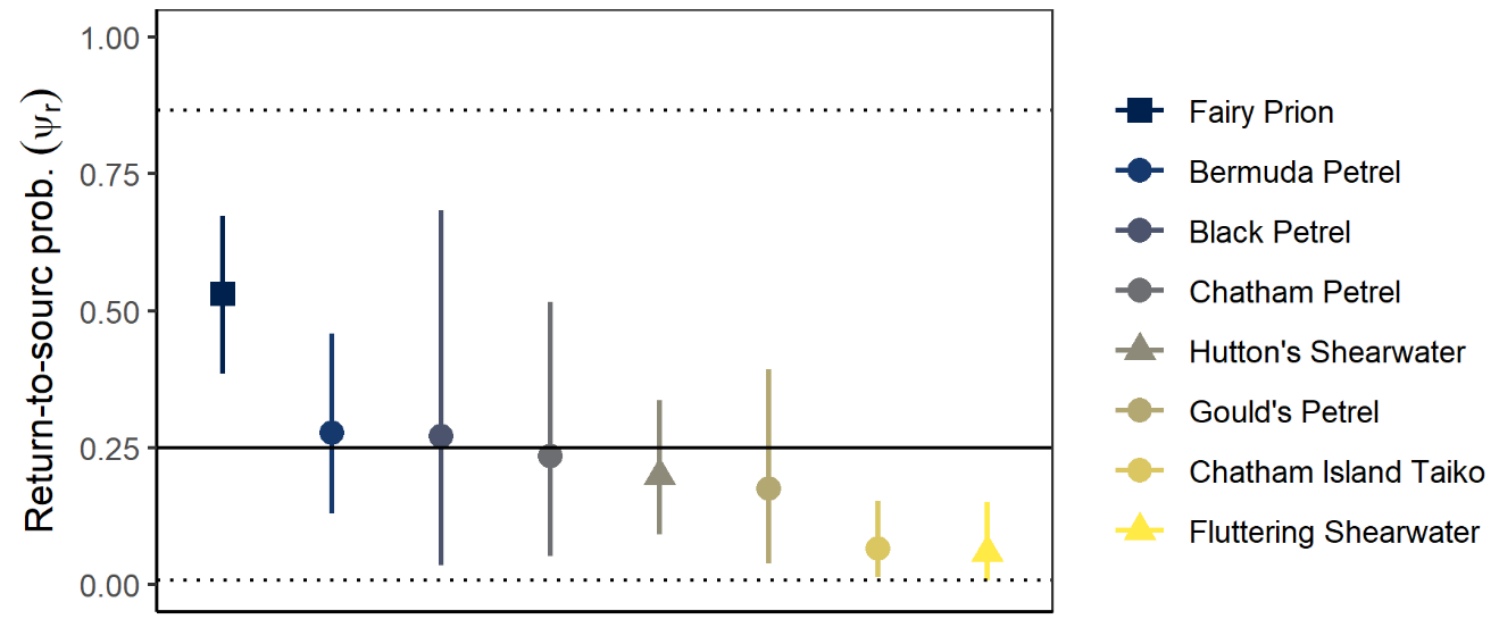

Case studies

Fig. 22. Study-specific estimates of return-to-source probabilities $\left(\widehat{\psi_{r, k}}\right.$; posterior means and 95\% CrIs), based on case studies of Procellariidae translocations as summarized in Table 6 and overall estimated return-to-source probability ( $\widehat{\psi_{r}}$; solid and dotted lines). Squares represent case studies of prions, circles represent case studies of petrels, and triangles represent case studies of shearwaters. 
In all scenarios, translocation harvests caused a temporary reduction at the source population size, but several scenarios resulted in the successful establishment of a recipient WHDP population. When assuming that all juveniles post-translocation recruited to the recipient population (i.e., $\psi_{r}=0$ ), two translocation scenarios met my criteria of success (a mean estimate of the source population of $>175$ adults and a mean estimate of recipient population of $>30$ adults): harvest of $20 \%$ of fledglings $(\sim 10$ individuals) per year for five years and harvest of $10 \%$ of fledglings ( $\sim 5$ individuals) per year for 10 years (Table 7, Fig. 23ABC \& 24ABC).

When accounting for juveniles returning to the source population instead of the recipient population post-translocation (i.e., $\widehat{\psi_{r}}=0.25$ ), source populations were less impacted by harvest regimes, but translocations were also less successful at establishing recipient populations. Specifically, when $\widehat{\psi_{r}}$ was included, source population sizes remained $\sim 2 \%$ larger compared to populations under the same translocation scenarios without $\widehat{\psi_{r}}$ (Table 7). Additionally, when $\widehat{\psi_{r}}$ was included, recipient population sizes were $\sim 29 \%$ smaller compared to populations under the same translocation scenarios without $\widehat{\psi_{r}}$. Two translocation scenarios that included $\widehat{\psi_{r}}$ (i.e., more realistic scenarios) met my criteria of success: harvest of $30 \%$ of fledglings ( $\sim 15$ individuals) per year for five years and harvest of $20 \%$ of fledglings ( $\sim 10$ individuals) per year for 10 years (Fig. 23DEF \& 24DEF). However, in all scenarios, regardless of $\widehat{\psi_{r}}$, the lower $95 \%$ CrIs of both source and recipient populations were close to 0 , indicating considerable uncertainty. 
Without return-to-source prob. $\left(\psi_{\mathrm{r}}\right)$
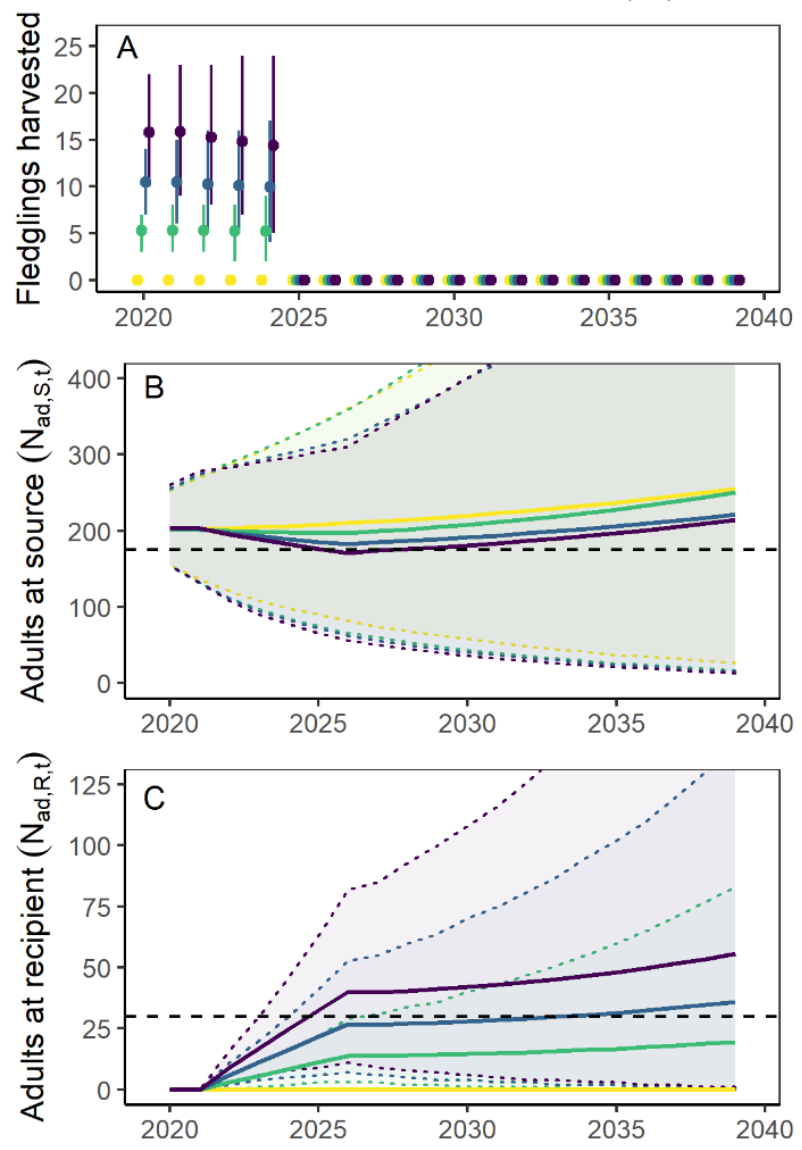

With return-to-source prob. $\left(\psi_{\mathrm{r}}\right)$
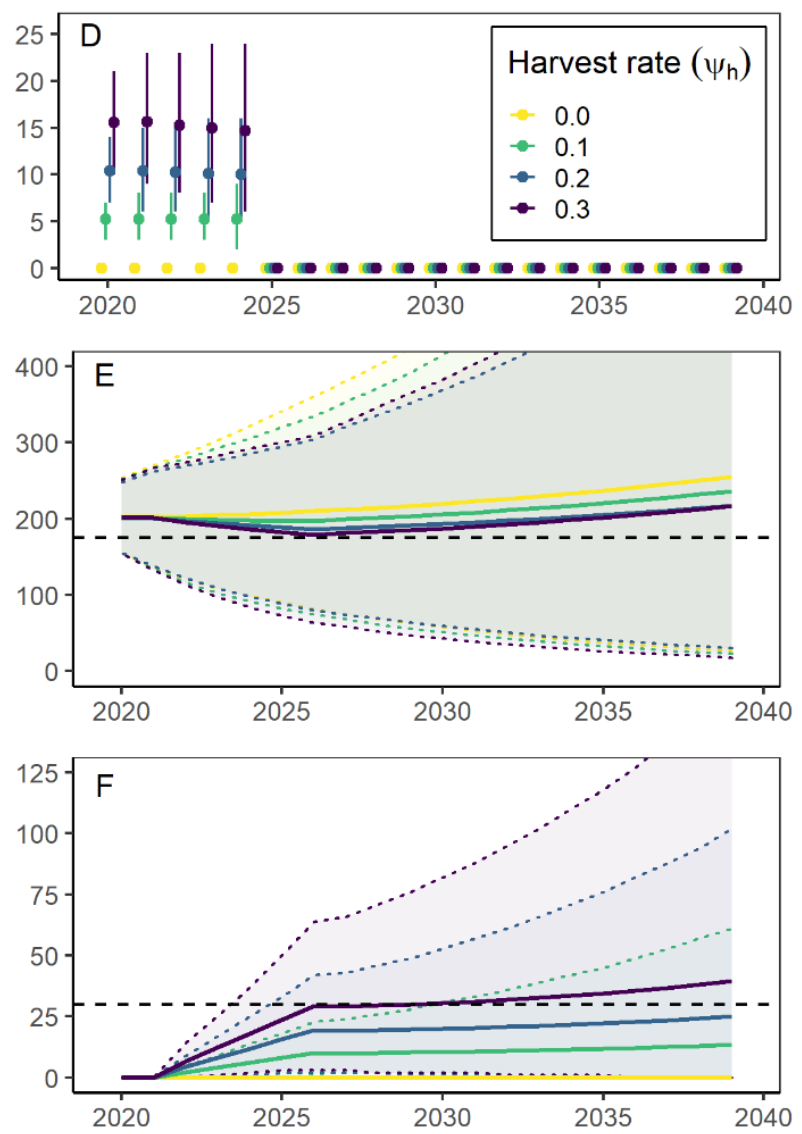

Fig. 23. Projections of Whenua Hou Diving Petrel fledglings harvested for translocation for five years (AD), adults at source $\left(\widehat{N_{a d, S, t}} ; \mathrm{BE}\right)$, and adults at recipient populations $\left(\widehat{N_{a d, R, t}} ; \mathrm{CF}\right)$ under various translocation scenarios, under the assumption that juveniles either always recruit to recipient populations $\left(\psi_{r}=0 ; \mathrm{ABC}\right)$ or can recruit back to the source populations $\left(\widehat{\psi_{r}}=0.25\right.$; DEF). Solid lines represent posterior means, dotted lines represent 95\% CrIs, and dashed lines indicate desired minimum population size at source (175 adults; BE) and recipient populations (30 adults; $\mathrm{CF})$. 
Without return-to-source prob. $\left(\psi_{\mathrm{r}}\right)$
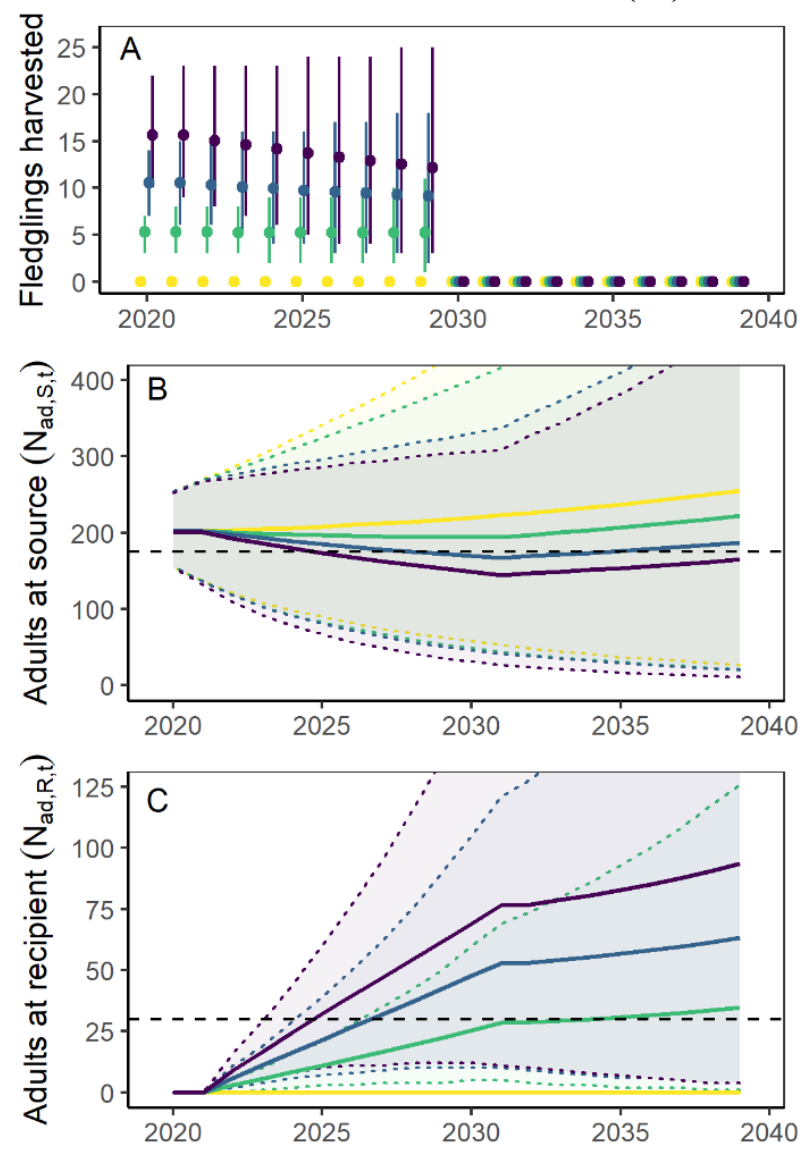

With return-to-source prob. $\left(\psi_{\mathrm{r}}\right)$
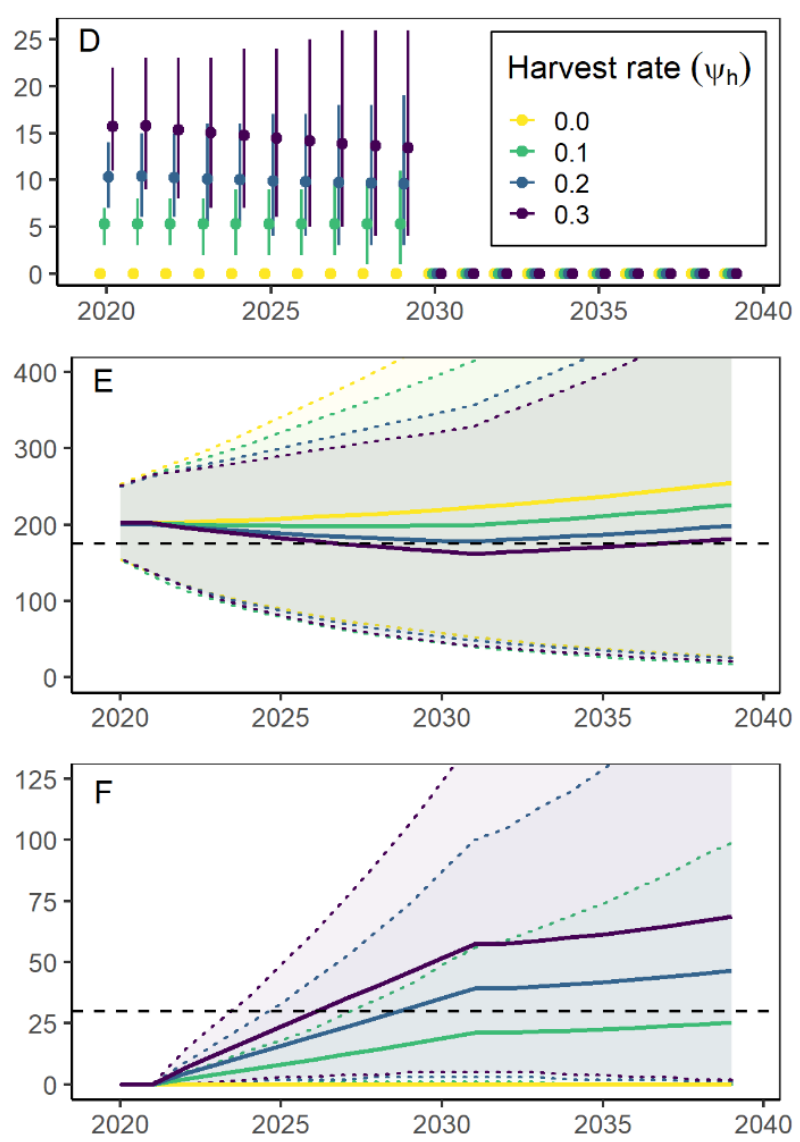

Fig. 24. Projections of Whenua Hou Diving Petrel fledglings harvested for translocation for 10 years (AD), adults at source $\left(\widehat{N_{a d, S, t}} ; \mathrm{BE}\right)$, and adults at recipient populations $\left(\widehat{N_{a d, R, t}} ; \mathrm{CF}\right)$ under various translocation scenarios, under the assumption that juveniles either always recruit to recipient populations $\left(\psi_{r}=0\right.$; $\left.\mathrm{ABC}\right)$ or can recruit back to the source populations $\left(\widehat{\psi_{r}}=0.25\right.$; DEF). Solid lines represent posterior means, dotted lines represent 95\% CrIs, and dashed lines indicate desired minimum population size at source (175 adults; BE) and recipient populations (30 adults; $\mathrm{CF})$. 


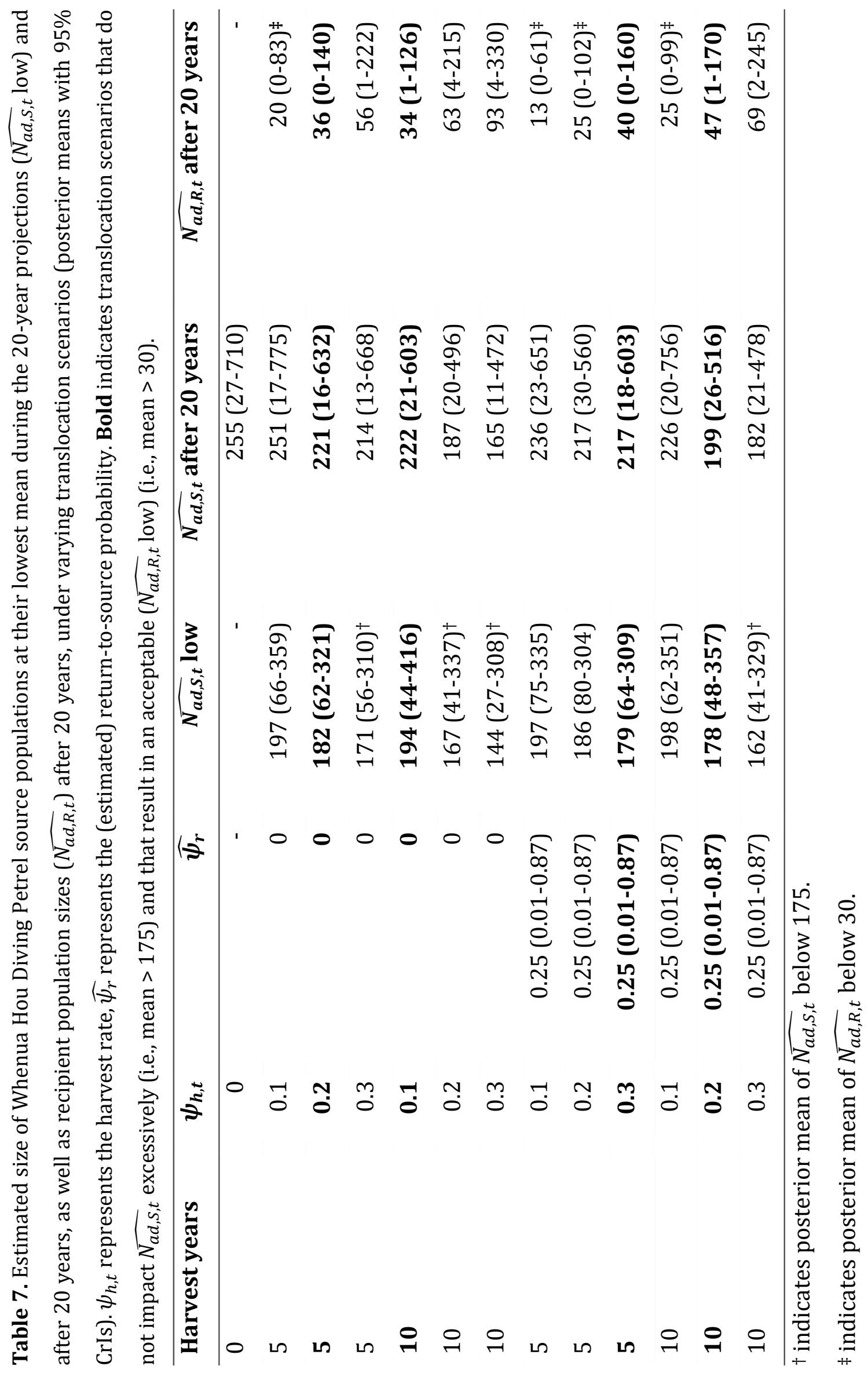




\section{DISCUSSION}

My results indicate that establishing a second WHDP colony through translocations of pre-fledging chicks could be feasible, although small, short-term declines at the source population should be anticipated. Establishing a second WHDP population is highly desirable, as this will reduce the vulnerability of this critically endangered species to storms, climate change, and potentially interspecific competition (Cole 2004, Fischer et al. 2017a, 2018b, Vousdoukas et al. 2020). Additionally, WHDP translocations would reinstate lost ecosystem functioning (Ch. 6, Fischer et al. 2019). The benefits of founding a recipient population appear to outweigh short-term declines at the source population, provided they remain small (i.e., $N_{a d, S, t}>175$ ). Consequently, my projections are encouraging for future WHDP conservation management.

While my results are encouraging, they are based on intermittent (i.e., suboptimal) data and thus continued monitoring to enable more accurate estimates is crucial. My estimates align with estimates of previous analyses, providing confidence in my IPMderived results. For example, based on burrow counts, WHDP population growth following invasive predator eradications was estimated at $\hat{\lambda}=1.017$ (1.006-1.029), aligning with my IPM results (Ch. 2, Fischer et al. 2020a). However, the dataset on knownage birds, which provided key information on juvenile survival in my IPM, was limited due to the delayed maturity of WHDPs. Continued monitoring would allow for more accurate estimates of this, and other parameters, and should therefore be considered a priority. Additionally, a sensitivity analysis could facilitate the identification of the parameters with the largest uncertainty and their impact on population growth (Jenouvrier et al. 2018). Results from such a sensitivity analysis could help further finetune future monitoring of the WHDP population.

My results highlight the range of considerations conservation practitioners have to make when deciding on strategies for translocations of endangered seabirds, and other species persisting in small populations.

Accounting for juveniles returning to source populations post-translocation appears crucial when planning seabird translocations. I show that failure to account for the return-to-source probability can lead to an overestimation of the recipient population size of $\sim 29 \%$. Simultaneously, harvest impact on source populations may be lower. Therefore, juveniles returning to source populations post-translocation can have 
profound impacts on the outcome of translocations and higher harvest intensities may be required to successfully establish recipient populations. I used largely anecdotal insights into return-to-source probabilities from the literature (e.g., Imber et al. 2003, Priddel et al. 2006, Carlile et al. 2012) as this parameter remains poorly understood. Most studies investigated the influence of age of translocated fledglings on this parameter and have shown that birds should be harvested 2-6 weeks prior to fledging to reduce the returnto-source probability (e.g., Miskelly et al. 2009). However, future seabird translocation efforts will benefit from further investigations into this parameter. Quantifying the influence of I) the number of years spent at sea by juveniles, II) the distance between source and recipient populations, III) the size of source populations, and IV) the use of social attraction systems on return-to-source probabilities should be considered research priorities. I encourage practitioners planning seabird translocations to incorporate thorough monitoring of not just the recipient site, but also the source site, into translocation protocols to gain a more complete perspective of translocation outcomes.

Translocation timeframes and harvest intensities are key to anticipating translocation impact, success, and costs, and should be subjected to structured decision-making (SDM) frameworks (Converse et al. 2013, Ewen et al. 2014). I illustrate that two approaches can limit impact on source populations, while ensuring adequate establishment of recipient populations: I) higher harvest rates for shorter time frames, or II) lower harvest rates for longer time frames. At first instance, shorter translocation time frames at higher intensities may be most attractive. Many seabird populations only remain on remote islands (Spatz et al. 2014, Rodríguez et al. 2019). The fixed costs associated with translocations to and from remote islands (e.g., helicopter transfers) are likely to outweigh the costs of hand-rearing individual fledglings at recipient sites (Miskelly et al. 2009). Translocations over shorter time frames at higher intensities thus appear a more efficient use of resources. However, for species with low population growth rates, such as the WHDP, the benefits of using resources efficiently should be weighed against the establishment of more robust recipient populations (Panfylova et al. 2019). For example, translocations of $\sim 15$ fledglings/year for five years resulted in an estimated recipient population of $\sim 40$ adults, while translocations of $\sim 10$ fledglings/year for 10 years resulted in an estimated recipient population of $\sim 47$ adults. With a mean population growth rate of 1.023 , it will take close to a decade for a population of $\sim 40$ adults to grow 
to $\sim 47$ adults. Lower intensity harvesting for longer time frames at higher costs may thus be more attractive. All translocations are centred around value-based objectives (i.e., saving costs is good, or a bigger recipient population size is good; Parker et al. 2020). Therefore, clear articulation of problems, objectives, and management alternatives by key stakeholders within SDM frameworks would improve future translocation planning (Ewen et al. 2014, Converse et al. 2013, Panfylova et al. 2019).

My results show considerable uncertainty in the projections of source and recipient populations, and therefore translocations of species as rare as the WHDP should only be attempted within an adaptive management (AM) framework. AM frameworks involve I) the development of explicit models of a system, II) manipulation of the system and gaining information, and III) the subsequent updating of models to guide management (Armstrong et al. 2007, Converse et al. 2013). Continued and thorough monitoring is central to AM. Here, I developed the explicit model for WHDP translocations. An AM framework that incorporates monitoring of both source and recipient populations during (and after) translocations, combined with continuous updating of the explicit model would allow for more accurate estimates of impact on the source population, establishment of the recipient population, and the return-to-source probability. This would in turn allow for informed adjustments of translocation protocols (i.e., higher or lower harvest intensities over longer or shorter time frames; Dimond \& Armstrong 2007). Furthermore, such an AM framework would also allow for the estimation of demographic parameters currently not included or simulated in my model. Specifically, the estimation of the I) differences in vital rates between source and recipient populations and II) the exchange of adults and juveniles between source and recipient populations (Miskelly \& Taylor 2004, Miskelly et al. 2009) within an AM framework appears crucial. I therefore recommend, a combination of SDM and AM frameworks for translocations to provide realistic estimates of translocation impact and success, subsequent finetuning of translocation protocols, and ultimately the best possible outcome for the target species. 
Chapter 4 
Chapter 5

\title{
Preparing for translocations of a critically endangered petrel through targeted monitoring of nest survival and breeding biology
}

\begin{abstract}
The recently described Whenua Hou Diving Petrel (Pelecanoides whenuahouensis; WHDP) consists of $\sim 200$ adults that all breed in a single $0.018 \mathrm{~km}^{2}$ colony in a dune system vulnerable to erosion. The species would therefore benefit from the establishment of a second breeding population through translocations. However, given the small size of the source population, it is essential that translocations are informed by carefully targeted monitoring data. I therefore modelled nest survival at the remaining population in relation to potential drivers (distance to sea and burrow density of conspecifics and a competitor) across three breeding periods. I also quantified breeding phenology, burrow attendance, and chick growth curves. I estimated egg survival at 0.686 , chick survival at 0.890 , overall nest survival at 0.612 , and found no indication that nest survival was affected by distance to sea or burrow density. WHDPs laid eggs in midOctober, eggs hatched in late November, and chicks fledged in mid-January at $~ 86 \%$ of adult weight. Burrow attendance (i.e., feeds) decreased from 0.94 to 0.65 visits/night as chicks approached fledging. WHDP nest survival and breeding biology were largely consistent among years despite interannual variation in climate due to the southern oscillation cycle. Nest survival estimates will facilitate suitability assessments of prospective translocation sites. Breeding phenology will inform the timing of chick harvest (i.e., live chick collection). Burrow attendance combined with growth curves will inform selection of individuals for harvest and subsequent hand-rearing protocols.
\end{abstract}




\section{TUHINGA WHAKARĀPOPOTO}

Kei te pūrei Kūaka Whenua Hou kātahi anō ka whakaahuria (Whenua Hou Diving Petrel - Pelecanoides whenuahouensis) ka noho atu ai kia rua rau pakeke ka aitia ki tētahi tāhuna pānekeneke nei 0.018 kiromita pūrua te rahi. Nā reira ka whai hua te momo manu nei i te whakatūtanga o tētahi atu taupori whakatupu mā te nukuhanga kōhanga. Engari, nā te tokoiti kei te taupori matua, me mātua whai i te raraunga ka puta i tā mātou āta aroturuki i ngā kūaka nei. Nō reira, i whakatakune i te oranga tonutanga o ngā kōhanga o te toenga o te taupori e hāngai ana ki ètahi kaupapa ārahi (te tawhiti i te moana, te noho kōpipiri o ngā rua o ngā momo manu ōrite, me ngā hoariri) i ngā tau whakatupu e toru he rerekē te āhuarangi i te hurihanga ngapu o te tonga. I aromatawai hoki mātou i te whakatupuranga āhuarangi, te taenga ki ngā rua, me te tupuranga mai o ngā pīpī. I whakatau tata mātou i te oranga o ngā hua ki te 0.686 , te oranga pīpī ki te 0.890 , me te oranga tonutanga o te kōhanga ki te 0.612 , kīhai i kitea tētahi tohu ka raru te kōhanga i te tawhiti ki te moana, i te kōpipiri rānei o ngā kōhanga. Ka whānau hua mai ngā Kūaka Whenua Hou i te puku o te Oketopa, ka paopao mai ngā pīpì i te whiore o te Noema, ā, ka whai huruhuru ngā pīrere i te puku o te Hanuere e $~ 86$ ōrau o te taumaha o te pakeke. Ko te taenga ki ngā rua (arā ki te kai) ka heke mai i te 0.94 toronga ia pō ki te 0.65 i te pakaritanga o te pīpī ki te taumata pīrere. Ko te oranga tonutanga me te whakatupuranga koiora o ngā Kūaka Whenua Hou, i te rahinga o te wā, kua ù i ngā tau ahakoa te rerekētanga o te āhuarangi. Mā te whakatau tata oranga kōhanga e matapae ai ngā ahunga taupori e haere ake nei me ngā wāhi pai hei wāhi nuku kōhanga. Mā te whakatupuranga āhuarangi e ārahi i te wā kohikohi ai i ngā pīpī (arā te kohinga pīpī ora), ā, mā te taenga atu ki te rua me te tupuranga o ngā pīpī e ārahi ai i ngā tikanga whakatupu pīpī ā-ringa. 


\section{INTRODUCTION}

Seabirds, and petrels in particular, are among the most threatened taxa on the planet (Fig. 2; Croxall et al. 2012, Dias et al. 2019). Close to half of all petrel species (i.e., families Procellariidae, Oceanitidae, Hydrobatidae, and Pelecanoididae; $n=125$ species) are threatened with extinction. Petrel species are affected by a wide range of threats (Dias et al. 2019). On land, petrels are threatened by invasive predators (Jones et al. 2008, Dias et al. 2019), extreme weather events (Cole 2004, Rodríguez et al. 2019), and light pollution (Rodríguez et al. 2017), among others. At sea, threats include changes in oceanic productivity and climate patterns as well as fisheries impacts (accidental by-catch and overfishing) (Anderson et al. 2011, Žydelis et al. 2013, Grémillet et al. 2018). Various lifehistory traits render petrels disproportionally vulnerable. Petrels are extremely wideranging (i.e., they use entire ocean basins; Shaffer et al. 2006), $K$-strategists (i.e., low fecundity, delayed sexual maturity, high longevity; Rodríguez et al. 2019), and placed at high trophic levels (i.e., they are top predators; Einoder, 2009). As petrels provide important ecosystem services (e.g., nutrient cycling, bioturbation, and seed dispersal; Ellis, 2005, Orwin et al. 2016, Otero et al. 2018), their conservation is a priority.

Translocations are an increasingly common conservation strategy (Seddon et al. 2007, 2014), including for petrels (Miskelly et al. 2009). A translocation entails the intentional movement of animals for species recovery or ecosystem restoration (Seddon et al. 2014). Translocations may be effective conservation interventions if habitat is available outside a species' current range, if the species is unlikely to naturally colonize that habitat, and if the translocation is unlikely to cause undesirable impacts (Ch. 4). Translocations may involve supporting existing populations (i.e., reinforcement), reinstating populations within the species' indigenous range (i.e., reintroduction), or creating new populations outside of the species' indigenous range (i.e., assisted colonization) (IUCN 2013). As petrels are often threatened and facilitate ecosystem functioning, petrel translocations can be motivated by both species recovery and restoration goals (Miskelly et al. 2009; Jones \& Kress 2012). For example, Gould's Petrels (Pterodroma leucoptera) have been translocated to Boondelbah Island, Australia, within their indigenous range to strengthen the small existing population (reinforcement; Priddel et al. 2006). Common Diving Petrels (Pelecanoides urinatrix; CDP) have been translocated to Mana Island, Aotearoa 
(New Zealand), to reinstate the ecosystem functions they once provided (reintroduction; Miskelly et al. 2009).

Poor understanding of the agents of decline can cause translocation failure, including for petrels (Jones \& Kress 2012, Osborne \& Seddon 2012). Insights into the drivers of nest survival are key for translocations. Many seabirds, including most petrels, are wideranging (e.g., Shaffer et al. 2006). Therefore, foraging ranges and associated threats at sea are unlikely to be affected by translocation, as has been shown for Short-tailed Albatrosses (Phoebastria albatrus; Deguchi et al. 2014, Orben et al. 2018). Understanding drivers of nest survival at source sites may thus be key to predicting nest survival potential translocation sites and consequently, translocation success (Osborne \& Seddon, 2012). As nest survival in seabirds can be subject to interannual fluctuations driven by climatic conditions (Chastel et al. 1995, Quillfeldt et al. 2007), multi-year studies of nest survival are critical.

Poor understanding of the breeding biology of the target species is also a potential cause of translocation failure (Jones \& Kress 2012). Petrels exhibit high philopatry and their semi-precocial chicks are believed to imprint on their natal colonies prior to fledging (Priddel et al. 2006, Miskelly et al. 2009). Thus, the use of chicks, 1-6 weeks prior to fledging, is required to successfully translocate these species (Miskelly et al. 2009, Jones \& Kress 2012). As these chicks then need to be hand-reared at the translocation site, detailed information on the breeding biology of the target species is essential to design protocols. For example, data on breeding phenology (i.e., timing and duration of courtship, incubation, guard, and post-guard stages) will inform translocation timing. Data on feeding regimes and chick growth curves will inform hand-rearing regimes.

The critically endangered Whenua Hou Diving Petrel (Pelecanoides whenuahouensis; WHDP) is a recently described burrowing petrel species that could benefit from translocations (Ch. 4, Fischer et al. 2018c). These birds were once widespread throughout southern Aotearoa, but following local extinctions caused by invasive predators (e.g., rats; Rattus spp.), the species only survives at a single location: Whenua Hou (Codfish Island; Fig. 4 \& 5; Worthy 1998, Holdaway et al. 2003, Wood \& Briden 2008). Here, only 182-235 adults remain in a single colony (Ch. 4). Invasive predators have been eradicated from Whenua Hou (McClelland 2002), but additional threats may still be inhibiting population recovery (Ch. $2 \& 3$, Fischer et al. 2020a). Unlike other petrels, the species breeds exclusively in fragile foredunes $<20 \mathrm{~m}$ from the springtide line (Fischer et al. 
2018c). Erosion caused by storms and storm surges, as well as climate change, may thus be the main threat to this species (Cole 2004, Vousdoukas et al. 2020). Competition with the more aggressive CDP for burrow sites may also inhibit population recovery (Fischer et al. 2017a). An unsuccessful hybridization attempt between a WHDP and a CDP has been recorded (Fischer et al. 2018c), suggesting additional pressures from this closely related species. As CDPs appear to be also attracted to WHDP calls (in contrast to WHDPs), acoustic attraction systems may not be an option to establish new WHDP colonies (Fischer et al. 2020b). Therefore, translocations of WHDPs to a more suitable site appears to offer a solution to ensure long-term viability (Ch. 4). Detailed information on the factors affecting nest survival and breeding biology is required to meaningfully assess site suitability and design translocation protocols.

To inform future translocations, I monitored WHDP burrows across three breeding periods (2017-19) with a burrowscope, stick palisades, and nest boxes. I aimed to quantify nest survival and its underlying drivers. Furthermore, I also quantified breeding phenology, patterns of burrow attendance (as a proxy for feeding regimes), and chick growth curves and the influence of interannual variation. 


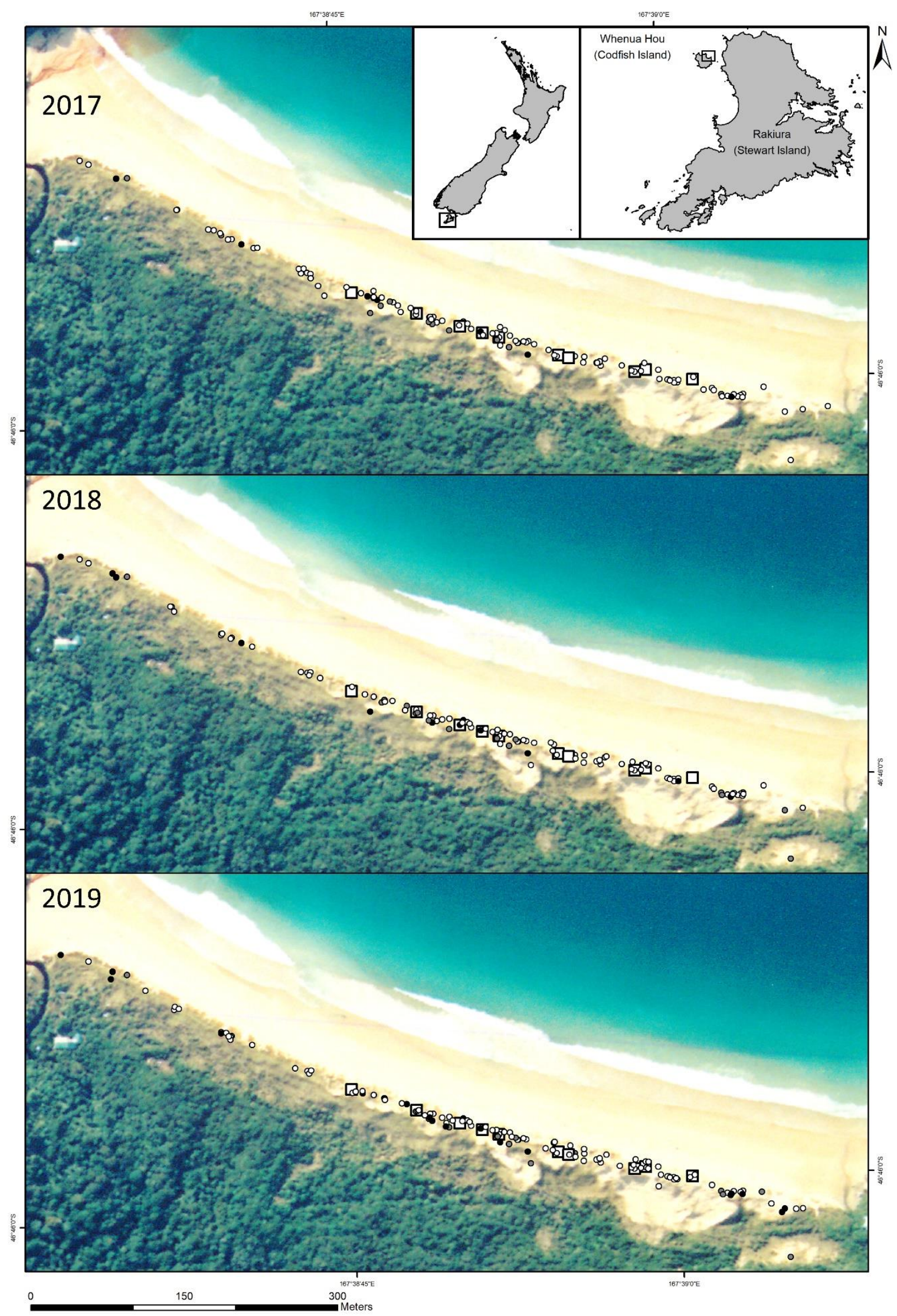

Fig. 25. Distribution of Whenua Hou Diving Petrel (white circles), Common Diving Petrel (black circles), mixed burrows (grey circles), and nest boxes (white squares) 2017-2019. 


\section{METHODS}

\section{Study area}

The entire WHDP colony is restricted to a $0.018 \mathrm{~km}^{2}$ strip of coastal sand dunes on Whenua Hou (Codfish Island; $-46.766^{\circ} \mathrm{S}, 167.645^{\circ} \mathrm{E}$; Fig. 25), which is $3 \mathrm{~km}$ off the west coast of Rakiura (Stewart Island), Aotearoa. This area holds 100 WHDP burrows (Ch. 2, Fischer et al. 2020a). A small number of CDPs (10-20 burrows) breed within the study area, which sometimes attempt to hybridize with WHDPs (Fischer et al. 2017a, 2018c).

\section{Nest survival}

To quantify WHDP nest survival (i.e., egg, chick, and overall nest survival), I monitored 62-78 burrows (65-79\% of the total population) from early September to late January during the 2017-19 breeding periods (I report the calendar year in which breeding commenced). Monitoring was conducted with a burrowscope (Sextant Technologies, Wellington, Aotearoa; see https://youtu.be/6GGIQ25LTYc). Monitoring included daily checks of the burrows monitored for breeding phenology (see below) and weekly checks of all other burrows that allowed access. Eggs were detected in 48 of the 62 monitored burrows in 2017 (apparent lay rate = 0.77), in 57 of the 64 monitored burrows in 2018 (apparent lay rate $=0.89$ ), and in 62 of the 78 monitored burrows in 2019 (apparent lay rate $=0.79$ ), resulting in 167 WHDP burrows used in subsequent analyses. During each nest check, I recorded the phenological stage (egg, chick, or fledged) and fate (dead or alive). These data were compiled in three capture history matrices showing per day whether each egg had hatched, chick had fledged, and was alive ( $1=$ yes, $0=$ no, NA = not checked). I assumed nests to be alive on first detection but otherwise treated the fate of eggs as unknown until a nest was either abandoned or the egg had hatched.

I estimated nest survival using a multi-stage nest survival model within a Bayesian framework (Schmidt et al. 2010, Converse et al. 2013). My custom-made, multi-stage nest survival model allowed for I) unknown transition and failure dates, II) varying lengths of phenological stages among nests, III) estimation of daily survival rates for two phenological stages (eggs and chicks), and IV) the estimation of fixed and random effects affecting the daily survival rate. Specifically, I fitted the data to a generalized mixed effects model (GLMM) with a Bernoulli error term and a logit-link function: 
1) $\operatorname{logit}\left(D S R_{i, j}\right)=\alpha_{D S R}+\beta_{\text {hatch }} \times$ hatch $_{i, j}+\beta_{\text {sea }} \times \operatorname{dist}_{i}+\beta_{W H D P} \times$

$$
\left.W H D P_{i}+\beta_{C D P} \times C D P_{i}+u_{\text {year }, y}\right)
$$

where $D S R_{i, j}$ is the survival probability of nest $i$ on day $j, \alpha_{D S R}$ is the intercept, $\beta_{\text {hatch }}$ is the effect of transitioning from egg stage $\left(\right.$ hatch $\left._{i, j}=0\right)$ to chick stage $\left(\right.$ hatch $\left.h_{i, j}=1\right), \beta_{\text {sea }}$ is the effect of distance to sea $\left(d i s t_{i}\right), \beta_{W H D P}$ is the effect of WHDP burrow density $\left(W H D P_{i}\right), \beta_{C D P}$ is the effect of CDP burrow density $\left(C D P_{i}\right)$, and $u_{y e a r, y}$ is the annual random effect. I then estimated daily survival rate for the egg $\left(D S R_{e g g, y}\right)$, and chick stage $\left(D S R_{\text {chick,y }}\right)$ per year as:

2) $\operatorname{logit}\left(D S R_{\text {egg,y }}\right)=\alpha_{D S R}+u_{\text {year }, y}$

3) $\operatorname{logit}\left(D S R_{\text {chick,y }}\right)=\alpha_{D S R}+\beta_{\text {hatch }}+u_{\text {year }, y}$

Subsequently, I estimated nest survival during the egg $\left(S_{e g g, y}\right)$ and chick $\left(S_{c h i c k, y}\right)$ stage per year as:

4) $S_{\text {egg,y }}=D S R_{\text {egg,y }}{ }^{T_{i n c}}$
5) $\quad S_{\text {chick,y }}=D S R_{\text {chick,y }} T_{\text {rear }}$

in which $T_{i n c}$ and $T_{\text {rear }}$ are the estimated mean durations of the incubation and chickrearing stages, respectively. Ultimately, I estimated overall nest survival per year $\left(S_{y}\right)$ as:

6) $S_{y}=S_{\text {egg,y }} \times S_{\text {chick,y }}$

As I did not know exact dates of phenology events or duration of stages for all nests, missing values for hatching and fledging status were inferred by modelling the duration of each stage for each nest (Miller et al. 2017). I assumed these durations were normally distributed among nests with means $T_{i n c}$ and $T_{\text {rear }}$ and standard deviations $\sigma_{i n c}$ and $\sigma_{\text {rear }}$. I used mildly informative priors for these parameters: $N$ [mean $=45$, precision $=0.1]$ for $T_{\text {inc }}$ and $T_{\text {rear }}, U[0,6]$ for $\sigma_{\text {inc }}$, and $U[0,4]$ for $\sigma_{\text {rear }}$. I based my priors on the breeding phenology of the closely related South Georgian Diving Petrel (P. georgicus; Marchant \& Higgins 1990). I also used a mildly informative prior for $\alpha_{D S R}(N[5,1])$ but used vague 
priors for $\beta_{\text {hatch }} \beta_{W H D P}, \beta_{C D P}$, and $\beta_{\text {sea }}(N[0,1])$ and for the standard deviation of the random effect $u_{y e a r, y}(U[0,1])$.

I measured dist $_{i}$ as the distance from the WHDP burrow to the highest springtide line per year (m). I measured $W H D P_{i}$ as the density of other WHDP burrows within a 3-m radius of the burrow (burrows $/ \mathrm{m}^{2}$ ). Similarly, I measured $C D P_{i}$ as the density of CDP and mixed (WHDP x CDP) burrows within $3 \mathrm{~m}$ (burrows/m²). I z-transformed these three variables.

I fitted the model using the Bayesian modelling software OpenBugs 3.2.3 (Spiegelhalter et al. 2014). The Markov chain Monte Carlo (MCMC) algorithms make it possible to account for multiple sources of uncertainty, such as survival probability, timing, and duration of phenology stages, which are propagated into posterior distributions for parameters. I pooled two MCMC chains of 100,000 iterations, after a burn-in of 25,000 iterations which was sufficient to give convergence based on the Gelman-Rubin statistic $(\hat{R}<1.05)$. I report the mean of posterior distributions with $95 \%$ credible intervals (CrI). The OpenBUGS code of my nest survival model can be found in Supplementary Material 3.

\section{Breeding phenology}

To quantify the timing and duration of WHDP breeding phenology, I monitored 25-30 (26-30\% of the total population) burrows daily between early September and late January each breeding period. I quantified arrival dates of birds based on when their burrows opened. I quantified the timing of subsequent breeding phenology events, including dates for laying, hatching, commencement of post-guard phase (i.e., the first day a chick was left unattended by an adult), and fledging, using a burrowscope. I monitored burrows daily until I recorded a breeding phenology event, after which I ceased monitoring until a week before the next anticipated event. I initially predicted the timing of these events using published data on the closely related South Georgian Diving Petrel (Marchant \& Higgins 1990). I used the timing of phenology events to delineate the phenological stages of courtship, incubation, chick-rearing (consisting of guard and postguard stages), and the total breeding period, as well as to calculate durations thereof. I assessed the influence of interannual variation on timing and duration of breeding phenology stages using generalized linear models (GLMs) with a Gaussian error distribution and an identity-link function. In these GLMs, I treated initiation date or 
duration per stage as the response variable and year as the explanatory variable. I transformed initiation dates into a numerical variable first (i.e., days since 01 September) and subsequently z-transformed initiation dates and durations.

\section{Burrow attendance}

As a proxy for WHDP feeding regimes, I quantified nightly burrow attendance (i.e., visits/night) per phenological stage (i.e., courtship, incubation, guard, and post-guard stages) using stick palisades. I assessed the influence of interannual variation per stage using GLMs with a quasi-binomial error distribution and a logit-link function. In these GLMs, I treated visits/night per stage as the response variable and year as the explanatory variable. In addition, I assessed how nightly burrow attendance during the post-guard stage changed over time using GLMs with a binomial error distribution and a logit-link function treating visits/night as the response variable and chick age (expressed as daysbefore-fledging) as the explanatory variable. I could not account for double feeds (i.e., both parents feeding the chick) using my stick palisade method. Thus, burrow attendance should be considered only a proxy for feeding regimes. 


\section{Chick growth curves}

To quantify WHDP chick growth curves (i.e., wing length and weight), I monitored 10 burrows daily between early December and late January each breeding period. In early September 2017, I installed 10 custom-made, multi-story nest boxes in existing WHDP burrows (Fig. 25 \& 26; Fischer et al. 2018a). I selected burrows for nest box instalment if I) burrows belonged to successful breeders in 2015 and/or 2016, II) brood chambers had a depth of $<60 \mathrm{~cm}$, and III) burrows were $>10 \mathrm{~m}$ from the springtide line. I subjected chicks in nest boxes to daily measurements of weight (g) and wing length (i.e., flattened wing chord; $\mathrm{mm}$ ) once they reached the post-guard stage until they fledged. Only four chicks fledged from a nest box (most pairs dug new brood chambers behind nest boxes). I increased my sample size by taking measurements from all chicks accessible within natural burrows $(n=5)$. I also took measurements from all chicks caught just before fledging $(n=80)$. I compared chick growth with mean adult weight (127 g; $n=136)$ and mean adult wing length (120; $n=111$; Fischer et al. 2018b).

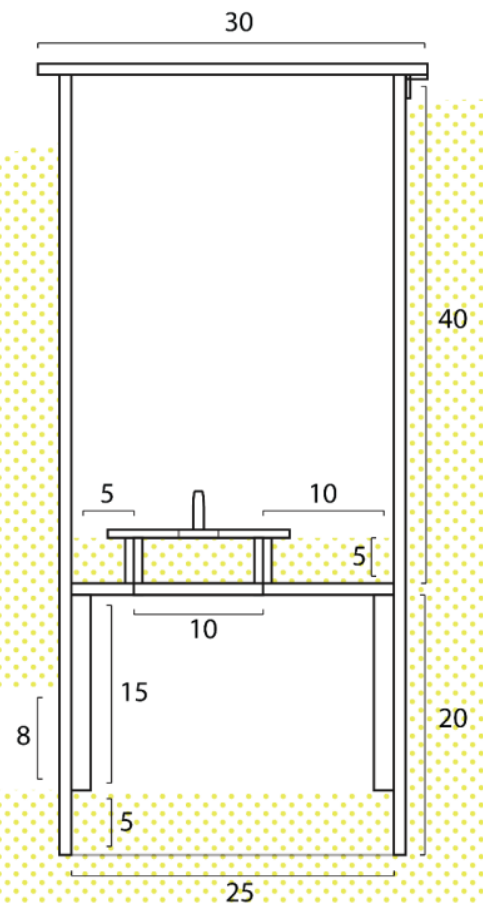

Fig. 26. Design of a Whenua Hou Diving Petrel nest box adopted from Fischer et al. (2018a). Dimensions are given in $\mathrm{cm}$. 


\section{RESULTS}

\section{Nest survival}

The daily survival rate of WHDP eggs was estimated at $\overline{D S R_{e g}}=0.992$ (0.988-0.995; Fig. 27A). The daily survival rate of chicks was estimated at $\overline{D R_{\text {chick }}} 0.998$ (0.996-0.999). The mean duration of the incubation stage was estimated at $\widehat{T_{l n c}}=49.1$ (48.1-50.0) days and the mean duration of the chick-rearing stage was estimated at $\widehat{T_{\text {rear }}}=46.9$ (46.547.3) days. Egg survival was estimated at $\widehat{S_{e g g}}=0.686$ (0.551-0.796). Chick survival was estimated at $\widehat{S_{\text {chick }}}=0.890$ (0.808-0.947; Fig. 27B). Nest survival from laying to fledging was estimated at $\hat{S}=0.611(0.460-0.738$; Fig. 27C). Average distance to sea was $6.7 \mathrm{~m}$ (range $=0.1-20.7$ ), average WHDP density was 0.02 burrows $/ \mathrm{m}^{2}(0.00-0.11)$, and average CDP density was 0.01 burrows $/ \mathrm{m}^{2}(0.00-0.07)$. Estimates for the effects of distance to sea $\left(\widehat{\beta_{\text {sea }}}=-0.01 ;-0.29-0.27\right)$, density of WHDP burrows $\left(\widehat{\beta_{W H D P}}=-0.01 ;-0.25-0.25\right)$, and density of CDP burrows $\left(\widehat{\beta_{C D P}}=0.25 ;-0.03-0.58\right)$ did not indicate a clear impact on nest survival (Fig. 27D). There was also no apparent annual variation in survival. Twenty-four abandoned eggs were extracted from burrows to assess fertility, and 16 of these $(67 \%)$ were found to be infertile. 
A

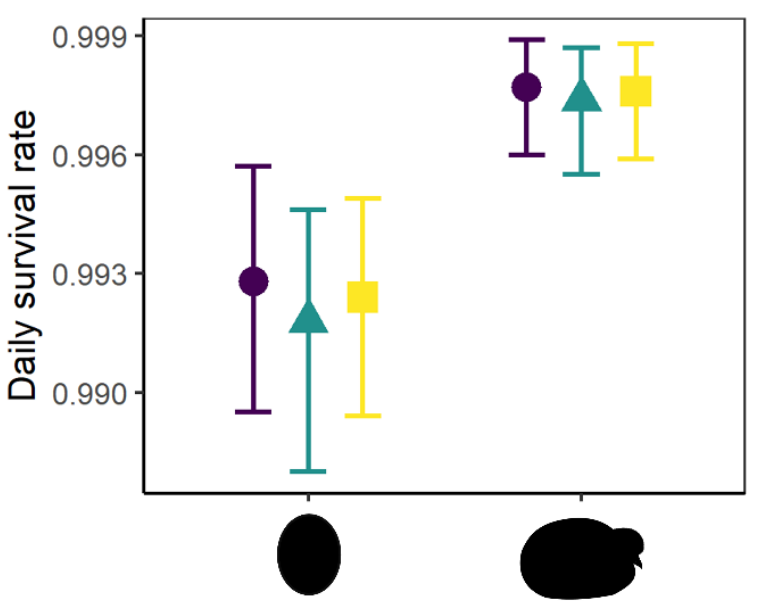

C

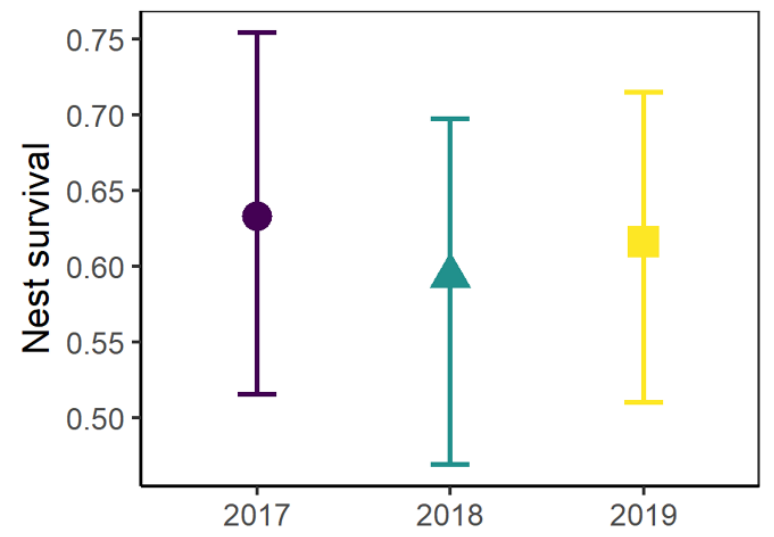

B

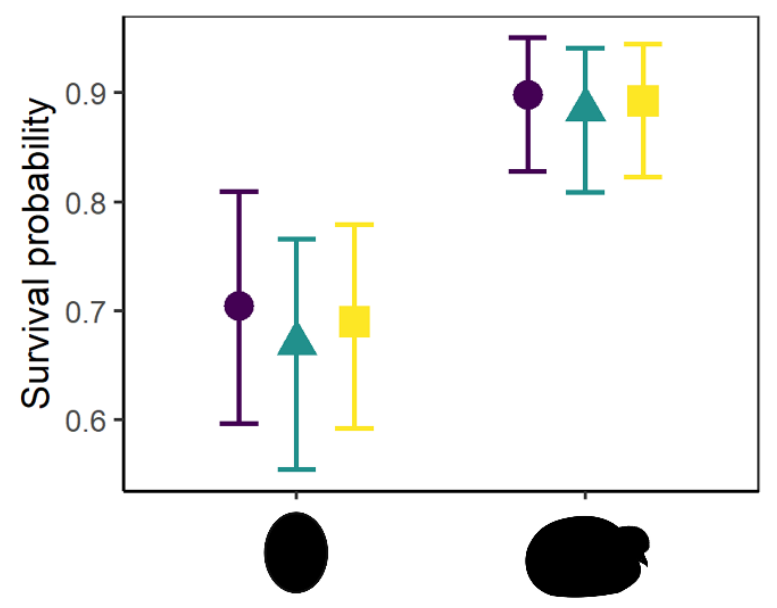

$\mathrm{D}$

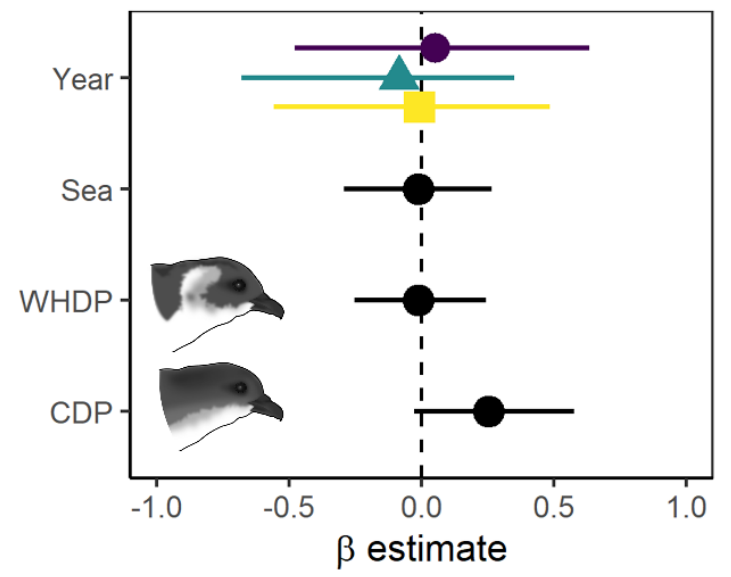

Year

2017

2018

2019

Fig. 27. Estimates of $(\mathrm{A})$ daily survival rates of Whenua Hou Diving Petrel eggs $\left(D \widehat{S R_{\text {eg }}, y}\right)$ and chicks (DS $\left.\widehat{R_{\text {ch } \imath c k}, y}\right),(\mathrm{B})$ probabilities of surviving the egg $\left(\widehat{S_{\text {egg,y }}}\right)$ and chick stages $\left(\widehat{S_{\text {chick,y }}}\right),(\mathrm{C})$ overall nest survival $\left(\widehat{S_{y}}\right)$, and (D) slopes $(\hat{\beta})$ of z-transformed covariates affecting the logit daily nest survival (posterior means with 95\% CrIs). Sea = effect of distance to sea, WHDP $=$ effect of Whenua Hou Diving Petrel burrow density, and CDP = effect of Common Diving Petrel burrow density. 


\section{Breeding phenology}

On average, WHDPs arrived at the colony on 13 September, eggs were laid on 10 October, chicks hatched on 27 November, post-guard stage commenced on 4 December, and fledging occurred on 13 January (Fig. 28). Phenology events were protracted and nonsynchronous among burrows. Timing of breeding phenology varied slightly among years. Specifically, arrival occurred slightly earlier in 2019 (estimates \pm SE: $\widehat{\beta_{2018}}=-0.50 \pm 0.26$, $\left.\widehat{\beta_{2019}}=-0.80 \pm 0.25\right)$, laying and hatching occurred slightly later in $2019\left(\widehat{\beta_{2018}}=-0.53 \pm\right.$ $0.28, \widehat{\beta_{2019}}=0.51 \pm 0.25$ and $\widehat{\beta_{2018}}=-0.31 \pm 0.30, \widehat{\beta_{2019}}=0.64 \pm 0.28$, respectively), postguard commenced slightly earlier in $2018\left(\widehat{\beta_{2018}}=-0.88 \pm 0.33, \widehat{\beta_{2019}}=0.11 \pm 0.34\right)$, and fledging occurred slightly later in $2019\left(\widehat{\beta_{2018}}=-0.49 \pm 0.31, \widehat{\beta_{2019}}=0.81 \pm 0.27\right)$.

The average duration of breeding stages was as following: courtship: 28.0 days, incubation: 48.2 days, chick guard stage: 8.2 days, and post-guard stage: 39.1 days, resulting in 46.9 days for the total chick-rearing period (Fig. 28). The total breeding period lasted 123.5 days. Duration of courtship stages, incubation stages, and total breeding periods varied slightly among years. The courtship and incubation periods lasted slightly longer in 2019 (estimates \pm SE: $\widehat{\beta_{2018}}=-0.13 \pm 0.28, \widehat{\beta_{2019}}=0.86 \pm 0.25$ and $\widehat{\beta_{2018}}=-0.04 \pm 0.33, \widehat{\beta_{2019}}=0.76 \pm 0.29$, respectively), resulting in a longer breeding period $\left(\widehat{\beta_{2018}}=0.05 \pm 0.31, \widehat{\beta_{2019}}=1.13 \pm 0.28\right)$. Durations of the guard and post-guard stages were consistent among years $\left(\widehat{\beta_{2018}}=0.41 \pm 0.36, \widehat{\beta_{2019}}=0.47 \pm 0.38\right.$ and $\widehat{\beta_{2018}}=$ $-0.08 \pm 0.38, \widehat{\beta_{2019}}=0.22 \pm 0.39$, respectively) 

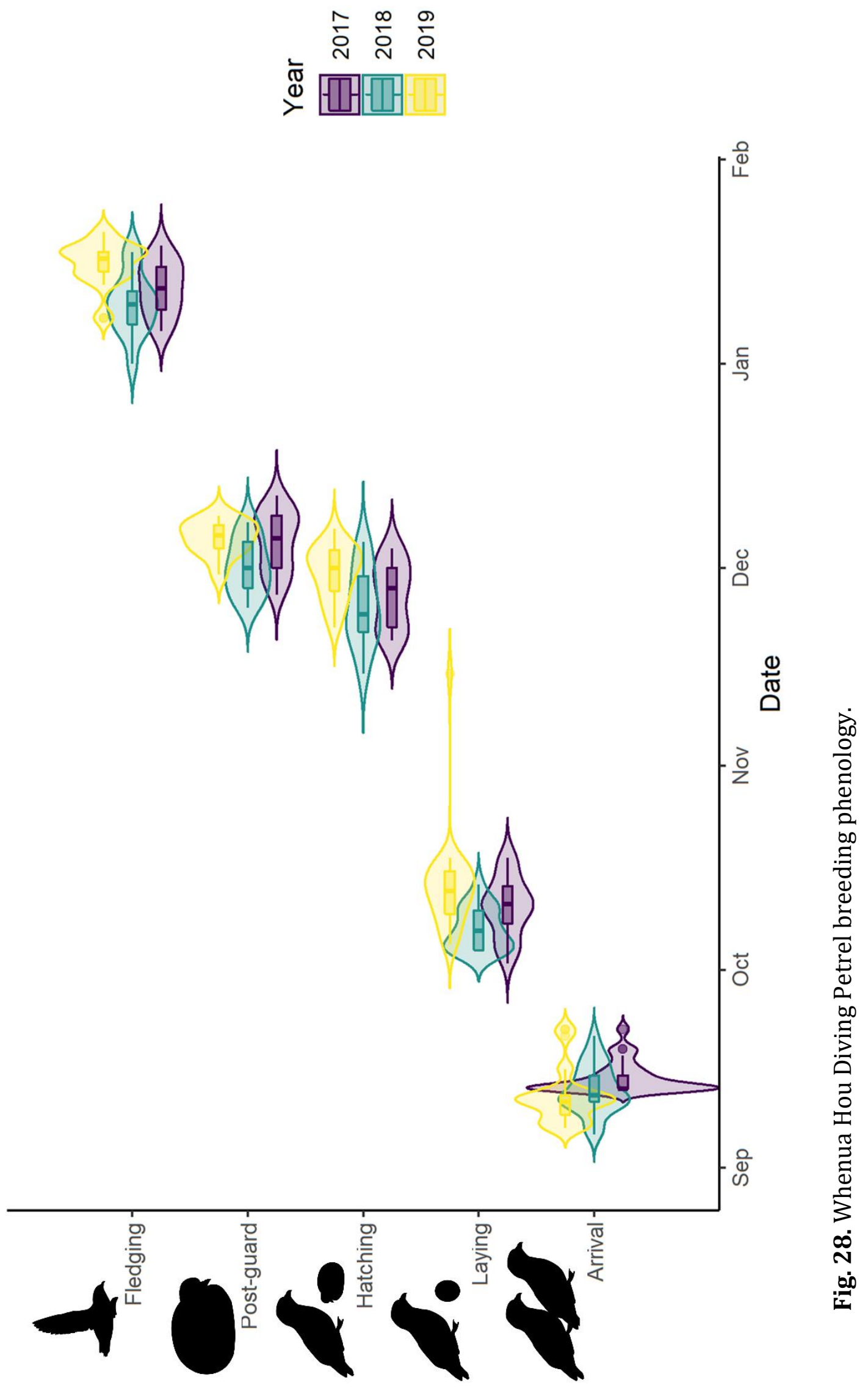


\section{Burrow attendance}

WHDP burrow attendance was not uniform throughout the breeding period. Burrow attendance was lower during incubation (mean $=0.61$ visits/night), compared to burrow attendance during courtship (0.83), guard (0.87), and post-guard (0.85) stages (Fig. 29A). Burrow attendance per stage varied slightly among years. Specifically, burrow attendance during courtship was higher in 2018 (estimates \pm SE: $\widehat{\beta_{2018}}=1.04 \pm 0.29, \widehat{\beta_{2019}}$ $=-0.32 \pm 0.19)$, burrow attendance during incubation was higher in $2019\left(\widehat{\beta_{2018}}=0.04 \pm\right.$ $\left.0.15, \widehat{\beta_{2019}}=0.37 \pm 0.14\right)$, burrow attendance during guard was lower in $2017\left(\widehat{\beta_{2018}}=\right.$ $1.07 \pm 0.39, \widehat{\beta_{2019}}=1.85 \pm 0.42$ ), and burrow attendance during post-guard was higher in $2017\left(\widehat{\beta_{2018}}=-0.62 \pm 0.23, \widehat{\beta_{2019}}=-0.63 \pm 0.21\right.$ ). During the post-guard stage, visitation rates decreased over time from 0.94 visits/night in the early post-guard stage (40-20 days-before-fledging) to 0.65 visits/night during the last week before fledging (Fig. 29B). This decrease in visitation rates was more pronounced in $2019(\hat{\beta}=-0.35 \pm 0.05)$ and $2018(\hat{\beta}=-0.14 \pm 0.02)$ than in $2017(\hat{\beta}=-0.03 \pm 0.01)$.

\section{Chick growth curves}

Wing lengths of WHDP chicks showed, on average, a gradual and consistent growth from $20 \mathrm{~mm}$ at 40 days-before-fledging until approaching a plateau of $111 \mathrm{~mm}$ (93\% of adult mean) around 7 days-before-fledging (Fig. 29C). Maximum recorded wing length was 119 $\mathrm{mm}$ (99\% of adult mean). Weight of chicks, on average, increased from $25 \mathrm{~g}$ at 40 daysbefore-fledging to a maximum of $148 \mathrm{~g}$ (117\% of adult mean) between 20 and 10 daysbefore-fledging and subsequently decreased to $109 \mathrm{~g}$ (86\% of adult mean) around fledging (Fig. 29D). Maximum recorded chick weight was $180 \mathrm{~g}$ (142\% of adult mean). 

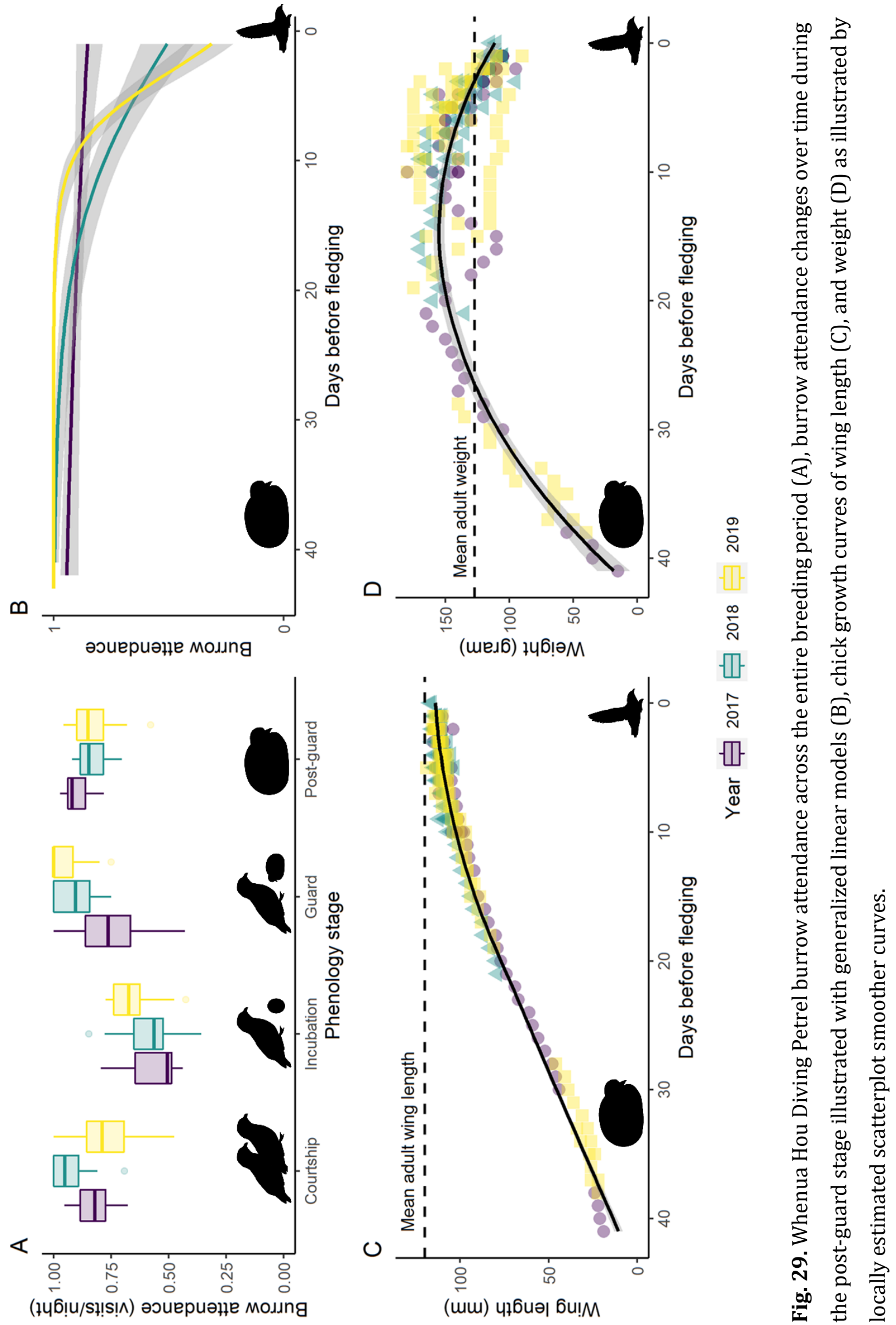


\section{DISCUSSION}

Here I present a detailed nest survival and breeding biology study of a critically endangered petrel species. My results have potential to inform future translocations aimed at establishing a new WHDP breeding colony.

First, by applying a novel Bayesian multi-stage nest survival model, I provide insights into nest survival. Estimates of demographic parameters like nest survival are of vital importance when making structured decisions on conservation management (including translocations) in the face of uncertainty (Panfylova et al. 2019). For wide-ranging species like most petrels, differences in nest survival will be a likely driver of translocation success, making nest survival estimates crucial for projecting future population trajectories at translocation sites (Ch. 4). In addition, my estimates of the effects of parameters on nest survival are important to assess the suitability of translocation sites. While no parameters showed a clear impact on nest survival, these may have an influence at different exposure levels (e.g., nest survival may have been influenced at higher CDP burrow densities). As such, these parameters should still be considered when assessing translocation site suitability (Fischer et al. 2017a).

Second, my results on WHDP phenology, chick growth, and nest survival help determine the ideal timeframe for chick harvest (i.e., live collection) for translocations. As petrel chicks should be harvested 1-6 weeks prior to fledging to prevent imprinting on the natal colony (Miskelly \& Taylor 2004, Miskelly et al. 2009), harvesting of WHDP chicks should occur between early December and early January. As chicks reach a weight maximum 20-10 days-before-fledging and may thus be less susceptible to stress associated with translocations, the last week of December appears the ideal timeframe to harvest chicks of this species.

Third, my growth curves will help select the best suited WHDP chicks for future translocations. Wing length combined with weight allows for the estimation of age and condition of chicks (in days-before-fledging; Miskelly \& Taylor 2004, Miskelly et al. 2009). Chicks selected for translocations should have a wing length of 75-105 mm and a weight of $>140 \mathrm{~g}$, as this combination will ensure the selection of healthy chicks at 20-10 daysbefore-fledging. 
Fourth, while the nest boxes were unpopular with adult WHDPs, four chicks have fledged successfully from these boxes. Nest boxes did not appear to influence nest survival (4/8 nest attempts inside nest boxes were successful). Since these nest boxes are designed specifically for this species (Fischer et al. 2018a), chicks can fledge successfully from these nest boxes, and access to chicks is crucial, the use of these nest boxes appears invaluable at future translocation sites.

Fifth, my results on burrow attendance and chick growth can inform feeding regimes for WHDP chicks post translocation. At the translocation site, chicks should be fed daily until 10-7 days-before-fledging to ensure chicks remain above mean adult weight. When translocated chicks approach fledging, feeds should be slowly reduced to every second day, provided chicks are at, or above, mean chick weight (Miskelly et al. 2009). I did not provide species-specific information on meal size or diet. However, CDP chicks have been successfully hand-reared using average meal sizes of $25 \mathrm{~g}$ (range 10-30; Miskelly et al. 2009). As CDPs have similar adult weights (110-150 g), these meal sizes may be appropriate for WHDP chicks as well. Miskelly et al. (2009) and Miskelly \& Gummer (2013) have shown that many petrel species will thrive on a diet of pureed sardines, regardless of their natural diet, and thus this diet may also be suitable for this species.

WHDP nest survival and breeding biology was largely unaffected by annual variation and therefore varying climatic conditions. The three breeding periods in my study encompassed a range of climatic (El Niño southern oscillation; ENSO) conditions: mean Oceanic Niño Index was -0.79 (La Niña) in 2017, 0.75 in 2018 (El Niño), and 0.43 (approaching ENSO neutral) in 2019 (National Oceanic and Atmospheric Administration Climate Prediction Database repository; available from https://catalog.data.gov/dataset/climate-prediction-center-cpcoceanic-nino-index).

The slight differences in timing and duration of phenology appeared unrelated to ENSO conditions. The breeding period under neutral conditions (2019) was delayed and prolonged compared to other breeding periods under more extreme and varying conditions (i.e., La Niña and El Niño). The apparent phenological insensitivity of WHDPs to climatic conditions is not surprising as it mirrors insensitivity observed in many other seabirds (Keogan et al. 2018). Climatic variables, however, could have influenced burrow attendance (Quillfeldt et al. 2007). In 2017 (La Niña), burrow attendance was higher during the post-guard stage. Food supplies can change with climatic conditions 
(Schreiber \& Schreiber 1984). Thus, adults in 2017 may have spent more time provisioning their chicks during the post-guard stage (Chastel et al. 1995).

The WHDP population is extremely small (182-235 adults; Ch. 4) and room for error in management is slim. Further research is required prior to attempting translocations of this species. The appropriate cohort size and number of cohorts used for translocations should be estimated to minimize risks to the source population while still resulting in the successful establishment of a second population (Ch. 4). Furthermore, infertility appeared a prevalent cause of egg failure. While CDPs can have a similar rate of infertility (Richdale 1945), the current WHDP population likely suffered from a population bottleneck and represents a fraction of the historical genetic diversity (Wood \& Briden 2008). As such, the selection of chicks for future translocations may benefit from including a measure of genetic diversity.

Translocations are a useful tool to combat the ongoing sixth mass extinction by restoring species and ecosystem functioning (Seddon et al. 2007, 2014). Translocations of petrels fit both conservation and restoration goals (Miskelly et al. 2009). I provided the data required to inform future translocations. Such translocations could render this critically endangered species less vulnerable. The WHDP is the only petrel species in Aotearoa that breeds en masse in coastal dunes (Worthy 1998) and is thus considered an ecosystem engineer (Ch. 6, Fischer et al. 2019). The Predator Free 2050 program (Russell et al. 2015) aims to eradicate seven species of invasive mammals from entire Aotearoa by 2050 . If this program is successful, more habitat could become available for potential WHDP translocations. The information provided here may facilitate not only the conservation of a critically endangered species, but also the restoration of ecosystem functioning throughout southern Aotearoa. 
Chapter 6

\title{
Contrasting responses of lizard occurrences to burrowing by a critically endangered seabird
}

\begin{abstract}
Seabirds are considered ecosystem engineers, because they facilitate ecosystem functioning (e.g., nutrient cycling), crucial for other marine and terrestrial species, including reptiles. However, studies of seabird-reptile interactions are limited. Here, I assessed the influence of the critically endangered Whenua Hou Diving Petrel (Pelecanoides whenuahouensis; WHDP) on the occurrence of two threatened skinks, Stewart Island green skink (Oligosoma aff. chloronoton) and southern grass skink (O.aff. polychroma). I surveyed skinks for 26 consecutive days at 51 sites with and 48 sites without diving petrel burrows in the dunes on Whenua Hou (Codfish Island), Aotearoa (New Zealand). I used occupancy modelling to assess the influence of burrows on the occurrence of skinks, while accounting for other factors affecting occupancy $(\psi)$ and detection probabilities $(p)$. Diving petrel burrows had a contrasting effect on the occurrence of skinks. On average, $\hat{\psi}$ of Stewart Island green skinks was $114 \%$ higher at sites with burrows compared to sites without, while $\hat{\psi}$ of southern grass skinks was only $2 \%$ higher. Occurrence of both skinks was negatively influenced by the presence of the other skink species. On average, $\hat{p}$ were low: 0.013 and 0.038 for Stewart Island green and southern grass skinks, respectively. Stewart Island green skinks appear attracted to burrows, which might facilitate thermoregulation (i.e., shelter from temperature extremes). The larger Stewart Island green skinks may subsequently exclude the smaller southern grass skinks at burrows, causing the contrasting relationships. I suggest that these interspecific interactions should be considered when implementing conservation management, e.g., through the order of species translocations.
\end{abstract}




\section{INTRODUCTION}

Seabirds are considered ecosystem engineers as they have disproportionate impacts on their surrounding environments by providing various biophysical and biochemical ecosystem services (Taylor 2000ab, Şekercioğlu et al. 2004, Şekercioğlu 2006). For example, seabirds facilitate nutrient cycling between marine and terrestrial ecosystems through the deposition of their faeces (guano), regurgitated prey items, feathers, and deceased eggs, chicks, and adults at their breeding colonies (Fukami et al. 2006, Otero et al. 2018). These deposits can even result in the creation of soil (Heine \& Speir 1989). In addition, the nutrients deposited at the terrestrial colonies slowly return to the marine ecosystems, increasing productivity in (coastal) marine environments (Lorrain et al. 2017, Graham et al. 2018). Through the increased nutrient deposition, seabirds also change the terrestrial soil pH (Mulder \& Keall 2001, Ellis 2005). Furthermore, the presence of seabirds facilitates terrestrial litter decomposition as well as marine bioerosion rates (Towns et al. 2009, Wardle et al. 2009, Graham et al. 2018). Moreover, many seabirds, small ( $<1 \mathrm{~kg}$ ) Procellariiformes in particular, dig and breed in burrows, facilitating terrestrial bioturbation (i.e., natural soil displacement by burrowing organisms; Buxton et al. 2016, Orwin et al. 2016).

The biophysical and biochemical ecosystem services provided by seabirds have positive effects on unrelated taxa in both terrestrial and marine environments. For example, seabirds indirectly increase the productivity and seed germination of plants at their terrestrial colonies (Bandcroft et al. 2005). In addition, seabirds actively change the vegetation community through trampling and the collection of nesting material (Bancroft et al. 2005, Ellis 2005, Lameris et al. 2016). Seabirds also facilitate seed dispersal, which can result in remarkable trans-oceanic plant colonisations (Ellis 2005, Cheke \& Hume 2008). Furthermore, seabirds indirectly change the composition and boost the diversity and abundance of terrestrial invertebrates (e.g., terrestrial amphipods, spiders, and insects) at their colonies (Markwell \& Daugherty 2002, Towns et al. 2009, Wardle et al. 2009, Orwin et al. 2016). In the marine environments near seabird colonies, the presence of seabirds has an indirect positive effect on other species groups. For example, seabird presence is correlated with increases in overall reef fish biomass and growth rates (Graham et al. 2018). 
Seabirds also have a positive influence on reptiles (Markwell \& Daugherty 2002, Corkery et al. 2015). Seabird-reptile relationships, however, appear poorly studied. Most investigations into these relationships remain anecdotal (e.g., Walls 1978). As an exception, the large and enigmatic tuatara (Sphenodon punctatus) has been shown to profit from co-habiting Fairy Prion (Pachyptila turtur) burrows. Tuatara benefitted from warmer internal temperatures when inhabiting prion burrows and fed on prion chicks (Corkery et al. 2014, 2015). In addition, lizard communities (Scincidae and Diplodactylidae) were found to be more abundant and diverse on islands inhabited by seabirds than seabird-free islands (Markwell \& Daugherty 2002). However, in the latter study, potential biases created by imperfect detections of these small lizards were not accounted for. Accounting for detection probabilities (e.g., through repeat surveys combined with occupancy modelling) is crucial, as non-detection does not indicate that a species is absent (MacKenzie et al. 2002, 2003, 2018).

Seabirds and lizards make up a substantial proportion of the native vertebrate fauna in New Zealand (Aotearoa), but both species groups have suffered major population declines following the introduction of invasive predators (Taylor 2000ab, Trewick \& Gibb 2010, Hitchmough et al. 2016, Jewell 2017). The recently described Whenua Hou Diving Petrel (Pelecanoides whenuahouensis; WHDP) is one of the most endangered species in the world. Only one WHDP colony on Whenua Hou (Codfish Island) survived historical extirpations throughout southern Aotearoa caused by invasive predators (Fig. 4; Taylor 2000b, Holdaway et al. 2003, Wood \& Briden 2008, Wood 2016, Fischer et al. 2017b, $2018 b c)$. Furthermore, storms and storm surges threaten the remaining breeding habitat of this species (i.e., fragile foredunes; Cole 2004, Fischer et al. 2018bc). Consequently, the WHDP is listed as nationally critical in Aotearoa (Robertson et al. 2017) and as critically endangered on the IUCN red list (Fischer et al. 2018b, BirdLife International 2020). Two threatened species of skink also occur within the dune in which the WHDP breeds: Stewart Island green skink (Oligosoma aff. chloronoton) and southern grass skink (O.aff. polychroma). Both are listed as listed as at risk - declining in Aotearoa following considerable range reductions caused by predation by invasive predators and habitat destruction (Hitchmough et al. 2016, Jewell 2017). Based on the studies conducted on tuatara (Corkery et al. 2014, 2015), I hypothesised that the two threatened small lizard species in the dune of Whenua Hou would occur more frequently at sites with WHDP burrows than at sites without. To test my hypothesis, I used a large number of repeat 
surveys and occupancy modelling to account for imperfect detection of both skink species.

\section{METHODS}

\section{Study area}

My study was conducted in the dunes of Waikoropūpū (Sealers Bay; $-46.766^{\circ} \mathrm{S}, 167.645^{\circ}$ E) on Whenua Hou, located approximately $3 \mathrm{~km}$ west of Rakiura (Stewart Island), Aotearoa (Fig. 30). I defined my exact study area (approximately $0.065 \mathrm{~km}^{2}$ ) as following: Waikoropūpū beach (north), the coastal shrub, as defined by Wickes \& Rance (2010) (east and south), and an unnamed stream (west). My study area encompassed the entire WHDP colony (approximately 100 burrows; Ch. 2, 4 \& 5). A small number (10-20 burrows) of Common Diving Petrels (Pelecanoides urinatrix) also nests within the WHDP colony (Ch. 5, Cole 2004, Trainor 2008, 2009). Both Stewart Island green skinks and southern grass skinks are common within my study area, but very little is known about their biology, including whether or not they are territorial (Jewell 2017). The southern skink (O. notosaurus) also occurs on Whenua Hou (Jewell 2017) but appears absent within the confines of my study area (i.e., the foredunes). The vegetation community within the area is relatively uniform and dominated by native grasses, such as pingao (Ficinia spiralis), sand tussock (Poa billardierei), and club rush (Ficinia nodosa), invasive grasses, such as Yorkshire fog (Holcus lanatus) and Cocksfoot (Dactylis glomerata), and bidibids (Aceana novezealandia) (Wickes \& Rance 2010, de Lange et al. 2013). However, the vegetation cover within the study area varies considerably. 


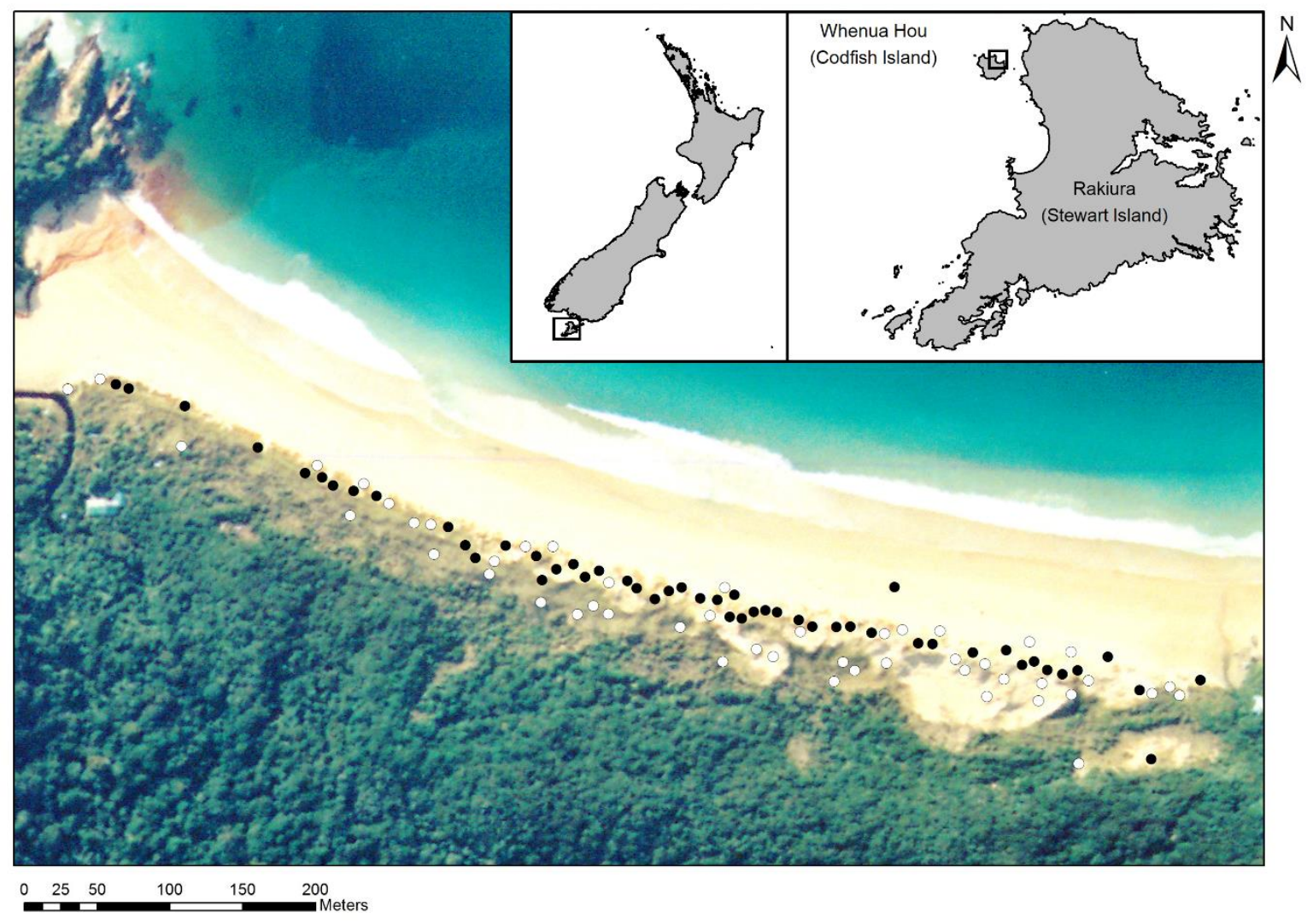

Fig. 30. Skink survey sites $(n=99)$ in the dunes of Waikoropūpū (Sealers Bay), Whenua Hou (Codfish Island), Aotearoa (New Zealand). Sites with Diving Petrel burrows $(n=51)$ are represented by black circles and sites without burrows $(n=48)$ are represented by white circles.

\section{Skink counts}

I surveyed the presence of skinks at sites with and without diving petrel burrows. To select sites with diving petrel burrows, I searched the entire study area for burrows by walking back and forth in pairs (Fischer et al. 2018c) in September-October 2017. I found a total of 120 diving petrel burrows and included all these sites in my skink surveys. All 120 burrows were active in the 2017 breeding season (assessed using stick palisades; Ch. 5 , Cole 2004). Inactive burrows close relatively quickly due to dynamic nature of the dune. To select the sites without diving petrel burrows, I created 59 random points within the study area using ArcMap 10.7.1 and located them within the study area using a handheld GPS. I then physically marked sites with and without diving petrel sites in situ, using fibre glass poles and track markers to ensure skinks were surveyed at the exact same site on every occasion. 
I surveyed skinks at all sites with $(n=120)$ and without diving petrel burrows $(n=59)$ from mid-November to mid-December 2017 (26 repeat surveys). I considered a circle with an area of $1 \mathrm{~m}^{2}$ (radius $=56 \mathrm{~cm}$ ) around each marker pole as the survey site. I alternated surveys between observers $(n=2)$ and visited sites in a pre-defined order to minimise disturbance, but rotated start and end points (i.e., from northeast to southwest or vice versa; Fig. 30). I conducted skink surveys any time between 07:30 and 19:30. I recorded skink sightings as Stewart Island green skink, southern grass skink, or unidentified skink per site per count. Skink identification was based on differences in colouration and size (snout-vent-length of Stewart Island green skinks $\leq 125 \mathrm{~mm}$ compared to $\leq 80 \mathrm{~mm}$ for southern grass skinks; Jewell 2017).

I ensured independence of my survey sites (i.e., the same individual skink cannot be detected at multiple sites) through retrospective subsampling, as diving petrels can breed in extreme proximity of each other (i.e., up to 6 burrows $/ \mathrm{m}^{2}$; Taylor $2000 \mathrm{~b}$ ). For my subsampling, I used data from a closely related skink species (Herbert \& Bell 2012). Most (80\%) of northern spotted skinks (O. kokowai) did not travel further than $4 \mathrm{~m}$ over an eight-month study period (Phillpot 2000, Melzer et al. 2017). I doubled this travelling distance to get a minimum-distance constraint of $8 \mathrm{~m}$ (measured from the centre of each site). I then ran 1,000 iterations of a random subsampling approach. Specifically, I randomly selected the first site to which I applied the minimum-distance constraint. After 1,000 iterations, I selected the subsample with the highest number of remaining sites. After distance-constrained random subsampling, 99 survey sites remained, consisting of 51 sites with burrows and 48 sites without.

I assumed that my ability to identify skinks was equal for both species. I therefore used the naïve occupancy (i.e., number of sites with detected skinks divided by the total number of survey sites) of each species to inform a weighted random allocation to assign unidentified skinks to either of the two species. The naïve occupancy was 0.091 and 0.161 for Stewart Island green skinks and southern grass skinks, respectively. This ratio informed the weighted random allocation of the unidentified skinks $(n=9)$ as following: $P=0.36$ for Stewart Island green skinks, $P=0.64$ for southern grass skinks. Ultimately, my approach of random subsampling and random allocation of unidentified skinks resulted in detection histories for each skink species per independent survey site, consisting of $1 \mathrm{~s}$ (seen) and 0 s (not seen), as required for occupancy modelling (MacKenzie et al. 2002, 2003). 


\section{Occupancy modelling}

I fitted single-species, single-season occupancy models to the detection histories of both skink species to assess the influence of diving petrel burrows on the occurrence of skinks, while accounting for imperfect detection (MacKenzie et al. 2002, 2003, 2018). I included the effects of potentially important covariates on both occupancy $(\psi)$ and detection probabilities $(p)$ in my models. Specifically, I hypothesized that $\psi$ could be affected by the presence of diving petrel burrows (Walls 1978, Markwell \& Daugherty 2002, Corkery et al. 2014, 2015), the presence of the other skink species (Petren \& Case 1998), the vegetation cover (Berry et al. 2005, Seddon et al. 2011), and/or the distance to sea (Fischer et al. 2018c). Consequently, I modelled the influence of I) the presence of a diving petrel burrow (binomial; denoted as burrow), II) the presence of the other skink species (i.e., naïve occupancy; binomial; denoted as sgs or sigs for southern grass skinks and Stewart Island green skinks, respectively), III) the vegetation cover $\left(\mathrm{m}^{2}\right.$; modelled as a quadratic function when a concave relationship was detected, or as a linear function when a convex relationship was detected; denoted as $v e g^{2}$ or veg, respectively), and IV) the distance to sea ( $\mathrm{m}$ from the spring-tide line; denoted as sea) on the $\psi$ of both skink species. Additionally, I hypothesized that my ability to detect skinks could be affected by the vegetation cover (Roughton 2005) and/or the time of day (Armstrong 2016). Consequently, I modelled the influence of I) the vegetation cover $\left(\mathrm{m}^{2}\right.$ and modelled as a linear function; denoted as veg) and II) the timing of each survey (hours after sunrise; denoted as $t$ ) on the $p$ of both skink species. I z-transformed all continuous variables $\left(\mathrm{veg}^{2}\right.$, $v e g$, sea, and $t$ ) prior to the occupancy modelling (MacKenzie et al. 2018).

I used a model-averaging approach informed by the Akaike information criterion (AIC; Burnham \& Anderson 2002) to identify the relative importance of covariates affecting $\psi$ and $p$ for Stewart Island green skinks and southern grass skinks. I compared models with all combinations of covariates affecting $\psi$ while retaining $p$ fully parameterized. I included null models, denoted as $(\cdot)$, but excluded interactions. I only included covariates in the same model with a Spearman's correlation coefficient of $r \leq 0.6$. For each model, I generated the $-2 \times \operatorname{loglikelihood}(-2 L)$, the logit-transformed estimate of the intercepts

$(\hat{\alpha}) \pm$ standard error $(\mathrm{SE})$, the logit-transformed estimate of the slope per covariate $(\hat{\beta}) \pm$ SE, and the variance-covariance matrix (Burnham \& Anderson 2002, MacKenzie et al. 2018). I summed the AIC weights $(w$ ) from the models to quantify the relative variable importance (RVI) per covariate. I then used model averaging to obtain a model-averaged 
$\hat{\beta} \pm$ SE per covariate. I applied the Delta method (Seber 1982; MacKenzie et al. 2018) to obtain $\hat{\psi} \pm$ SEs at sites with and without diving petrel burrows and $p \pm$ SEs per model. When applying the Delta method for $\hat{\psi}$, I used the mean value for veg (and $v e g^{2}$ ) and sea and used 0 (i.e., absence) for sgs or sigs in models that contained these covariates. When applying the Delta method for $\hat{p}$, I used the mean values of veg and $t$ (i.e., between 13:00 and 14:00). Finally, I used model-averaging to obtain model-averaged $\widehat{\psi} \pm$ SEs for sites with and without burrows per species and model-averaged $\hat{p} \pm$ SEs per species.

Statistical analyses were conducted in Program R 3.3.1 (R Core Team 2016) and PRESENCE 2.12.15 (Hines 2006), while data visualisations were created in Program R 3.3.1, using ggplot2 (Wickham 2009) and qgraph (Epskamp et al. 2017).

\section{RESULTS}

Naïve occupancy at sites with burrows was 0.118 (6/51) for Stewart Island green skinks and $0.216(11 / 51)$ for southern grass skinks (following random allocation of unidentified skinks). Naïve occupancy at sites without burrows was 0.083 (4/48) for Stewart Island green skinks and 0.188 (9/48) for southern grass skinks. Spearman's correlation tests indicated that no covariates were highly correlated ( $r \geq 0.6$; Table 8). Summaries of occupancy models for Stewart Island green skinks and southern grass skinks can be found in the Appendix 5 and 6, respectively. A comparison between the $\triangle \mathrm{AIC}$ and $-2 L$ did not indicate the presence of any pretender variables (Anderson 2008). Stewart Island green skink occupancy was positively influenced by the presence of diving petrel burrows $(\mathrm{RVI}=0.68$; model-averaged $\widehat{\beta \text { burrow }}=2.11 \pm 1.37$ ) (Fig. 31). Southern grass skink occupancy also showed a positive, but considerably weaker, relationship with diving petrel burrows (RVI $=0.28$; model-averaged $\widehat{\beta \text { burrow }}=0.09 \pm 0.68$ ). The modelaveraged $\hat{\psi}$ for Stewart Island green skinks was 0.328 (SE $=0.172-0.489$ ) for sites with burrows and 0.153 (SE $=0.092-0.261$ ) for sites without (Fig. 32). The model-averaged $\hat{\psi}$ for southern grass skinks was 0.318 (SE $=0.235-0.415)$ for sites with burrows and 0.312 ( $\mathrm{SE}=0.230-0.409$ ) for sites without. Notably, $5.6 \%$ of the records of Stewart Island green skinks and $6.1 \%$ of the records of southern grass skinks were of communal basking (i.e., two skinks basking within $\leq 50 \mathrm{~cm}$ from each other; Fig. 33). Communal basking of both species was only observed at sites with diving petrel burrows. 
Table 8. Spearman correlation coefficients $(r)$ between covariates included in occupancy models. Covariates included the presence of Stewart Island green skinks (sigs), the presence of southern grass skinks (sgs), vegetation cover (veg), presence of a Diving Petrel burrow (burrow), and distance to sea (sea).

\begin{tabular}{lcccc}
\hline & sigs & sgs & veg & burrow \\
\hline sigs & & & & \\
sgs & -0.09 & & & \\
veg & 0.37 & 0.22 & & \\
burrow & 0.06 & 0.04 & -0.07 & -0.39 \\
sea & 0.11 & 0.09 & 0.43 & \\
\hline
\end{tabular}

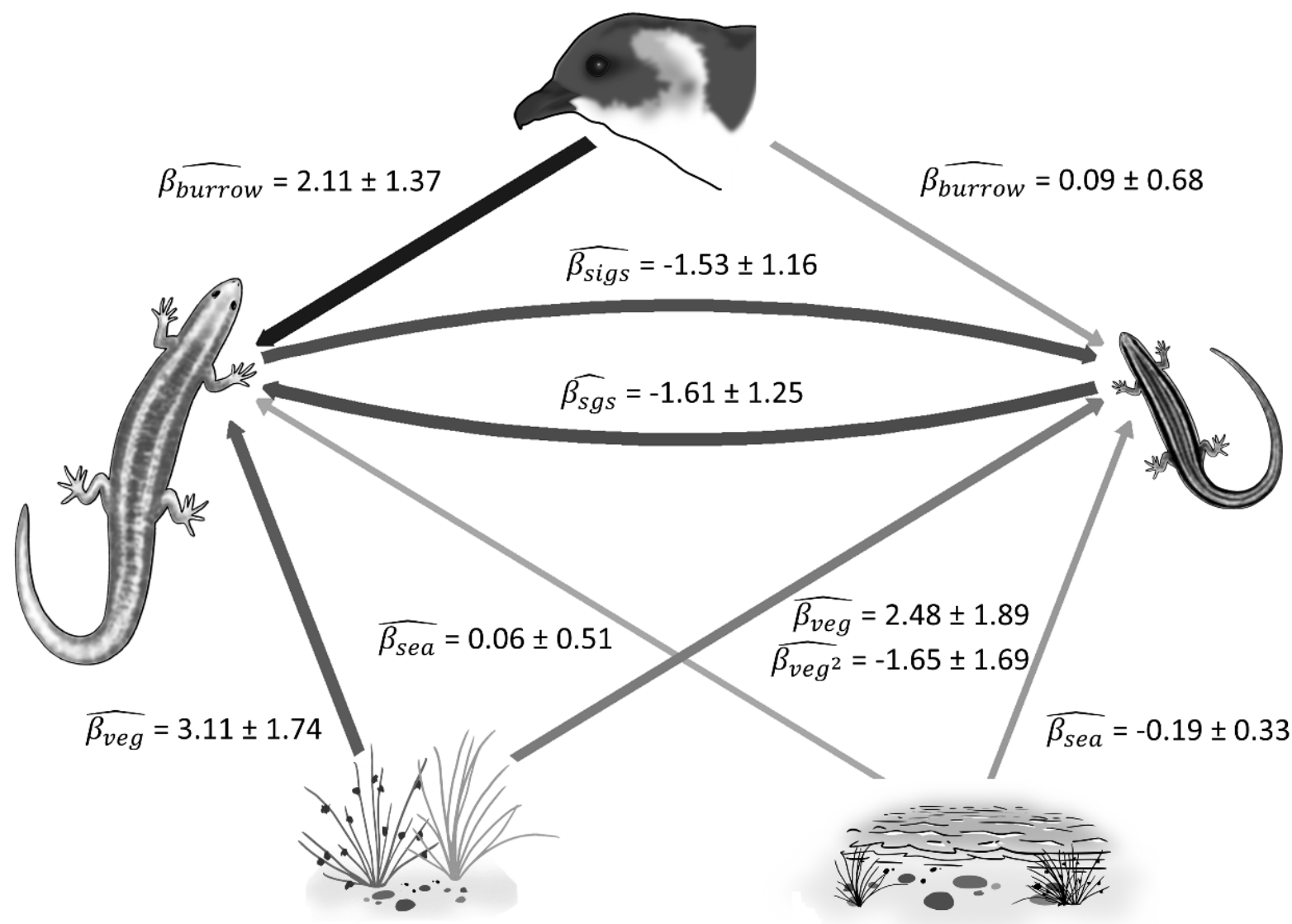

Fig. 31. Relative variable importance (RVI; represented by arrow width and darkness) and model-averaged estimates of logit-transformed slopes $(\hat{\beta}) \pm$ SE of covariates influencing occupancy probabilities $(\psi)$ in occupancy models for Stewart Island green skinks (left) and southern grass skinks (right). 


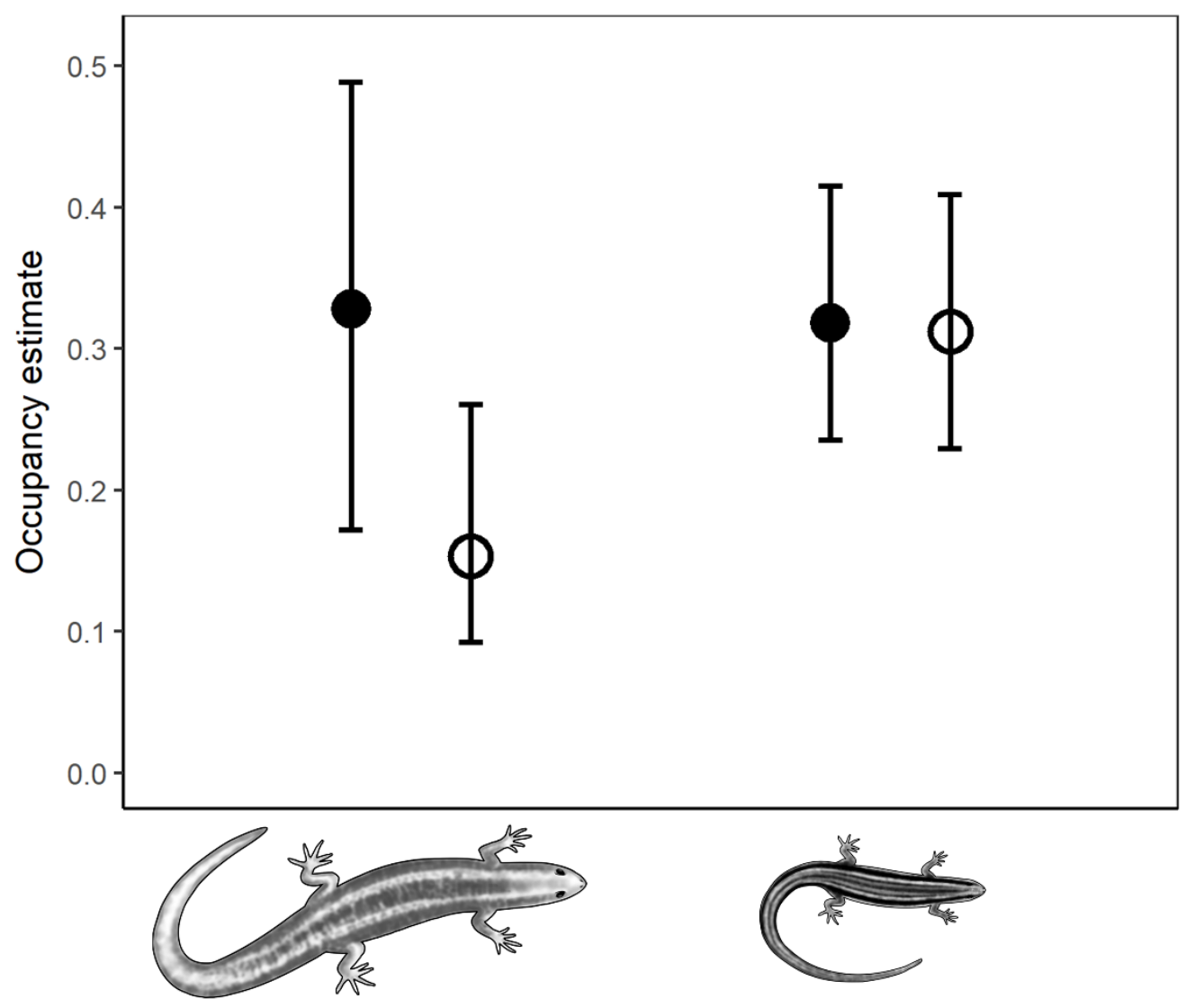

Fig. 32. Model-averaged estimates of occupancy probabilities $(\hat{\psi})$ for Stewart Island green skinks (left) and southern grass skinks (right) at sites with (black circles) and without (white circles) diving petrel burrows, including standard errors.

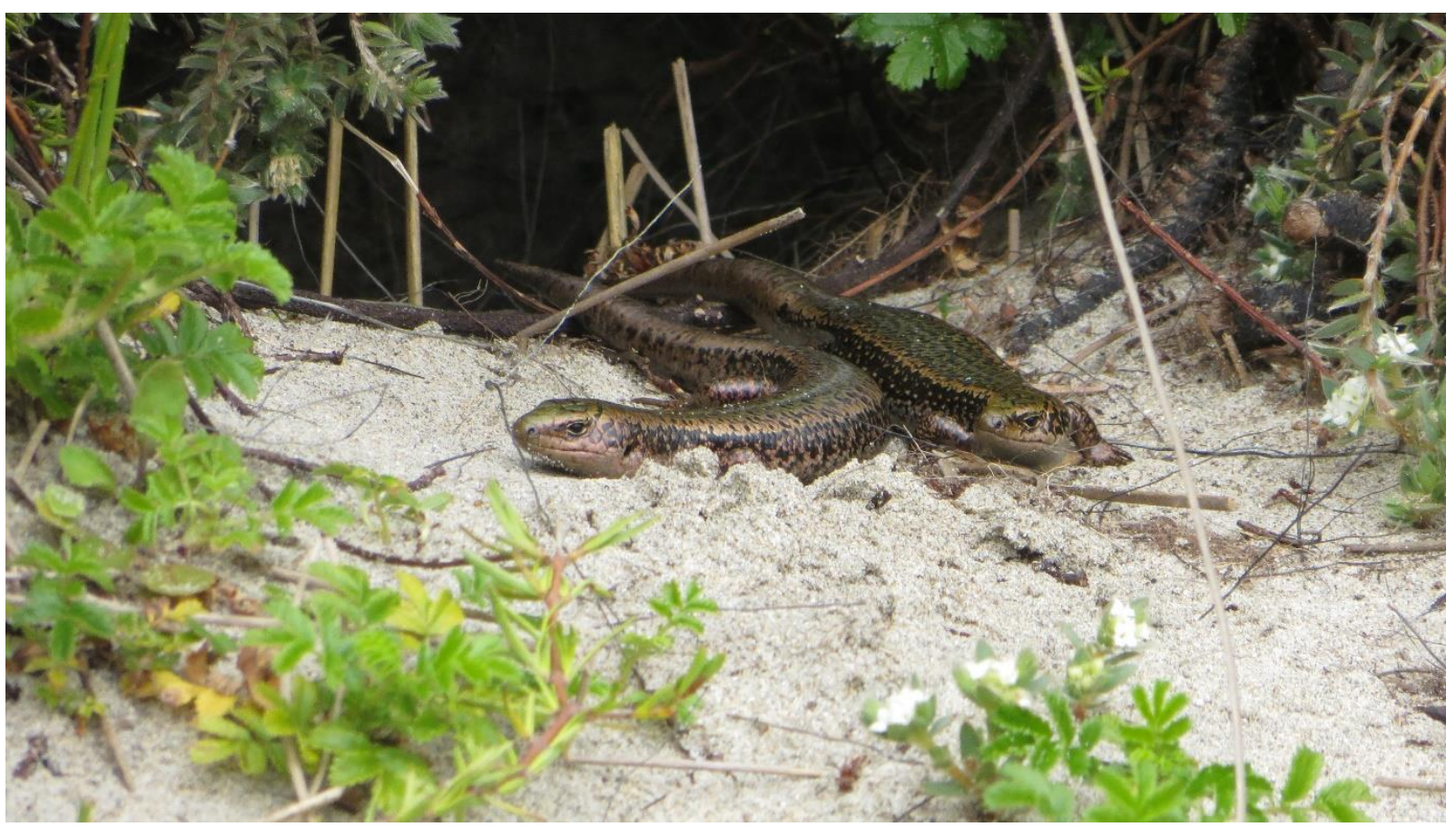

Fig. 33. Communal basking of Stewart Island green skinks at a Whenua Hou Diving Petrel burrow. Photo credit: Johannes H. Fischer. 
Occurrence of Stewart Island green skinks was negatively influenced by the presence of southern grass skinks $\left(\mathrm{RVI}=0.53\right.$; model-averaged $\left.\widehat{\beta_{\text {sgs }}}=-1.61 \pm 1.25\right)$. Vice versa, southern grass skink occurrence was negatively influenced by the presence of Stewart Island green skinks $\left(\mathrm{RVI}=0.52 ;\right.$ model-averaged $\left.\widehat{\beta_{\text {slgs }}}=-1.53 \pm 1.16\right)$. Additionally, Stewart Island green skink occurrence was positively influenced by vegetation cover (RVI $=0.49 ;$ model-averaged $\widehat{\beta_{v e g}}=3.11 \pm 1.74$ ). Contrastingly, southern grass skink occurrence indicated an optimum vegetation cover $\left(\mathrm{RVI}=0.39 ;\right.$ model-averaged $\widehat{\beta_{\text {veg }}}=$ $2.48 \pm 1.89$; model-averaged $\widehat{\beta_{v_{e g}^{2}}}=-1.65 \pm 1.69$ ). Furthermore, Stewart Island green skink occurrence was slightly positively influenced by distance to sea $(\mathrm{RVI}=0.26$; modelaveraged $\widehat{\beta_{\text {sea }}}=0.06 \pm 0.51$ ). Southern grass skink occurrence was slightly negatively influenced by the distance to sea (RVI $=0.31$; model-averaged $\widehat{\beta_{\text {sea }}}=-0.19 \pm 0.33$ ).

Detection probabilities of both skink species were low. Model-averaged $\hat{p}$ was 0.013 $(\mathrm{SE}=0.003-0.053)$ for Stewart Island green skinks and $0.038(\mathrm{SE}=0.028-0.051)$ for southern grass skinks. Detection of Stewart Island green skinks had a negative relationship with time of day (model-averaged $\widehat{\beta_{t}}=-0.38 \pm 0.28$ ), as did detection of southern grass skinks (model-averaged $\widehat{\beta}_{t}=-0.35 \pm 0.18$ ). Counts earlier in the day were more likely to detect skinks. In addition, detection of Stewart Island green skinks had a positive relationship with vegetation cover (model-averaged $\widehat{\beta_{\text {veg }}}=2.12 \pm 1.21$ ). Detection of southern grass skinks was also positively influenced by vegetation cover (modelaveraged $\widehat{\beta_{\text {veg }}}=0.61 \pm 0.31$ ).

\section{DISCUSSION}

My results indicate that diving petrel burrows in sand dunes can have a positive effect on the occurrence of Stewart Island green skinks. Despite not testing for the underlying mechanisms driving the elevated skink occurrence at diving petrel burrows, I hypothesise that the burrows offer refugia from heat stress. Previous research has consistently highlighted that lizard habitat selection is influenced by the need to avoid harsh and/or fluctuating environmental temperatures (Downes \& Shine 1998, Milne et al. 2003, Du et al. 2006, Andersson et al. 2010, Jewell 2017). To thermoregulate, ectotherms such as lizards, can exhibit a behaviour known as "shuttling", whereby they use thermal shelters periodically throughout the day to maintain stable internal 
temperatures (Milne et al. 2003, Andersson et al. 2010, Corkery et al. 2015, Jewell 2017). I thus suggest that diving petrel burrows facilitate "shuttling" behaviour in Stewart Island green skinks, allowing them to shelter from the extreme temperature maxima that are common within dune systems (Fischer et al. 2018a).

Predation may be another possible driver of habitat selection in small lizards (Downes \& Shine 1998). The dunes of Whenua Hou currently harbour comparatively few diurnal skink predators since the eradication of all invasive predators: Weka (Gallirallus australis), brush-tailed possum (Trichosurus vulpecula), and kiore (Rattus exulans; McClelland 2002, Middleton 2007). However, prior to human colonisation, the avifauna of Aotearoa was more diverse, and many bird species were flightless, terrestrial, and potentially predatory (Duncan \& Blackburn 2004, Trewick \& Gibb 2010, Wood et al. 2017). As such, the use of burrows by Stewart Island green skinks could also be explained by predator avoidance on an evolutionary time scale.

My anecdotal records of communal basking of both skink species, limited to diving petrel burrows, suggest that these burrows may play a role in the skinks' social behaviours (Downes \& Shine 1998). Communal basking is rarely documented in the skinks of Aotearoa, and these are the first records of communal basking in both Stewart Island green skinks and southern grass skinks (Jewell 2017, S Herbert in lit. 2018). These intraspecific interactions, however, need further investigations (e.g., into the sex and age of communally basking individuals). Alternatively, my records of communal basking in both species of skinks could be explained by coincidental and independent behaviour of individual skinks.

Stewart Island green skinks may exclude southern grass skinks from occupying sites with diving petrel burrows. Both skink species exhibited a negative relationship with the presence of the other skink species, indicating a level of interspecific competition or avoidance (Downes \& Shine 1998, Petren \& Case 1998). This result is likely due to autocorrelation (i.e., if one species is negatively correlated with the other, then the reverse will be also true). It is probable that the smaller southern grass skink is avoiding the larger Stewart Island green skink, as larger skinks predate on smaller skinks, or consume their autotomized tails (Petren \& Case 1998, S Herbert in lit. 2018). As such, the larger Stewart Island green skinks are likely to exclude the smaller southern grass skinks from sites with diving petrel burrows, causing the observed difference in occurrence at diving petrel burrows. Perhaps, southern grass skinks show a strong relationship with 
diving petrel burrows in the absence of Stewart Island green skinks. We, however, cannot assess the relationship between these two skink species in further detail, because I used single-species occupancy models (MacKenzie et al. 2002, 2018). Co-occurrence occupancy modelling would allow for detailed assessments of these interspecific relationships (MacKenzie et al. 2004, Richmont et al. 2010). However, my current approach suggests uncertainty (multiple models with $\Delta \mathrm{AIC}<2.00$ in both model sets). Therefore, it seems ill-advised to elevate the number of estimated parameters from two $\left(\psi\right.$ and $p$ ) to eight $\left(\psi^{A}, \psi^{B / A}, \psi^{B / a}, p^{A}, p^{B} j, r^{A}, r^{B / A}{ }_{j}\right.$, and $\left.r^{B / a_{j}}\right)$, as would be required for cooccurrence occupancy models (Richmont et al. 2010, MacKenzie et al. 2018).

The low detection probabilities of both skink species in my study illustrate the importance of repeat surveys in combination with occupancy modelling when studying cryptic species (MacKenzie et al. 2002, 2003, 2018). The modelled detection probabilities showed a positive relationship with vegetation cover. This unexpected relationship can be explained by a negative relationship of flight-initiation-distance with vegetation cover (Capizzi et al. 2007). In other words, skinks are less likely to flee with more vegetation cover around them, and thus more likely to be detected. The negative relationship of detection probabilities with time of day can be explained by the need to bask and thermoregulate in the morning (Downes \& Shine 1998, Du et al. 2006, Andersson et al. 2010). While I employed visual surveys, detection probabilities of skinks may be higher when other survey techniques were employed (e.g., pitfall traps; Herbert \& Bell 2012). These techniques, however, have other drawbacks (e.g., trap-related mortalities; Enge 2001), which cannot be overcome with repeat surveys and occupancy modelling.

Seabirds like the Whenua Hou Diving Petrel would have facilitated "shuttling" behaviour, and potentially social behaviours, in skinks throughout Aotearoa prior to the arrival of invasive predators. It is likely that the interspecific interactions between the WHDPs, Stewart Island green skinks, and southern grass skinks were once widespread throughout the historical range of these three species, but disappeared following local extinctions of the WHDP (Taylor 2000b, Holdaway et al. 2003, Wood \& Briden 2008, Wood 2016, Fischer et al. 2017b, Jewell 2017, Fischer et al. 2018bc). For example, both skink species have relict populations on Rakiura, while the WHDP is extirpated from its dune systems (Wood \& Briden 2008, Wood 2016, Jewell 2017). Finally, similar interspecific interactions may have occurred between other, closely related skink species (Oligosoma spp.) and the WHDP, outside the range of Stewart Island green skinks and 
southern grass skinks. Such interactions would have equally vanished with the local extinctions of the WHDPs.

Interspecific interactions form crucial parts of ecosystems and conservation management should take such interactions into account (Şekercioğlu et al. 2004, Fischer et al. 2017c). The WHDPs is the only seabird in Aotearoa that breeds en masse in dune systems (Fischer et al. 2017ab, 2018abc). Aside from the likely biophysical and biochemical ecosystem services provided by WHDPs across dune systems (e.g., nutrient cycling, bioturbation, seed dispersal; Ellis 2005, Orwin et al. 2016, Otero et al. 2018), WHDPs may increase the habitat suitability for skinks (Milne et al. 2003, Corkery et al. 2015). Therefore, this critically endangered species might be a crucial ecosystem engineer within its specific habitat type. All three species clearly merit targeted conservation management, which should take the interactions between these three species into account. One management option for skinks could be to follow Souter et al. (2004) and install diving petrel burrow replicas in areas where relict skink populations persist, but WHDPs have been extirpated (e.g., Rakiura; Jewell 2017). Another management strategy would be translocations of WHDPs into a dune system within its natural range (Ch. 4 \& 5, Miskelly \& Taylor 2004, Miskelly et al. 2009, Fischer et al. 2018bc). Such WHDP translocations would also benefit any relict skink population. A further option would be to follow WHDP translocations with translocations of skinks. Such multi-stage, multi-species reintroductions may result in better translocation outcomes and the reinstatement of interspecific interactions (Tylianakis et al. 2010). Interspecific interactions are lost at higher rates than species, resulting in ecosystem degradation before the extinction of species (Valiente-Banuet et al. 2015). Therefore, translocations aimed at reinstating interspecific interactions (next to locally extirpated species) will improve overall ecosystem health and functioning. 
Chapter 7

\section{General discussion}

\section{DISCUSSION}

This $\mathrm{PhD}$ thesis is my second thesis on the conservation of the Whenua Hou Diving Petrel (Pelecanoides whenuahouensis; WHDP). During my MSc thesis (Fischer 2016), I quantified WHDP nest site selection on Whenua Hou (Codfish Island), resulting in the identification of erosion, caused by storms and storm surges, as a threat to this species (Fischer et al. 2018c). I also monitored WHDP burrows using remote cameras, resulting in the identification of competition for burrow sites with Common Diving Petrel (P. urinatrix; CDP) as a potential minor threat the WHDP (Fischer et al. 2017a). In addition, I quantified phenotypic characteristics of the WHDP and compared these with characteristics of the South Georgian Diving Petrel (P. georgicus), which led to the formal description of the WHDP as a new species to science (Fischer et al. 2018b).

Following this initial work, I set out to complete this PhD thesis. In Ch. 2, I evaluated the WHDP response to previous management strategies (i.e., invasive predator eradications; McClelland 2002). I found that the WHDP did not respond as anticipated to the eradication of invasive predators (i.e., population growth did not increase and remained low when compared to other seabirds on the island) and concluded that additional management is required to facilitate the recovery of the WHDP (Fischer et al. 2020a). In Ch. 3, I quantified WHDP offshore distribution, behaviour, and overlap with commercial fisheries. Results show that WHDPs are exposed to fisheries-related threats during the breeding period but are likely unaffected by these threats during the nonbreeding period. While pelagic threats to the WHDP need further quantification and may need to be managed, terrestrial management actions may be more feasible. Consequently, to assess if establishing a second WHDP population through translocations would be a realistic and suitable conservation strategy, I modelled I) the impact of translocation harvest on the source population and II) the prospects of successfully establishing a recipient population (Ch. 4). My results indicated that WHDP translocations could be feasible, provided the number of harvested individuals and the number of years of harvesting are balanced accordingly to minimize the impact on the source while still 
successfully establishing a recipient population. Since WHDP translocations could be a feasible conservation strategy, I set out to quantify WHDP nest survival and breeding biology to inform translocation protocols (Ch. 5). I attempted to link WHDP nest survival estimates to intra-, interspecific competition, and environmental covariates, but failed to identify clear correlates. As such, future assessments of translocation sites still need to be comprehensive. For example, while my results suggest that interspecific competition does not influence WHDP nest survival, this is based on the CDP density on Whenua Hou. CDPs could influence WHDP nest survival at higher densities and as such CDPs should be surveyed at potential translocation sites. I did, however, identify the ideal harvest window (late December), key measurements of ideal translocation candidates (wing length: 75-105 mm, weight: >140 g), and feeding regimes. In my final chapter (Ch. 6), I investigated the influence of WHDPs (specifically, their burrows) on the occurrence of two threatened skink species. I found that the presence of WHDP burrows elevated the occurrence of the larger skink species, in contrast to the smaller species, indicating competition among skink species. These results indicated that WHDP burrowing activity provides benefits to unrelated species groups (Fischer et al. 2019). As such, WHDPs may fulfil an important role in the dune systems of southern Aotearoa and this role should be considered in future management strategies.

The results of my $\mathrm{PhD}$ chapters highlight the multidimensional landscape that conservation biologists face in their efforts to reduce ongoing and rampant biodiversity loss (Hoffman et al. 2010, Bolam et al. 2020). Conservation biology is complex, as threats and corresponding management actions are species-specific, subject to variation across time and space, and can be affected by both small and declining conservation paradigms (Caughley 1994, Dias et al. 2019). Ch. 2 highlights that conservation biologists cannot assume that management strategies, such as invasive predator eradications, will automatically result in species recovery, even if most species have responded positively (Brooke et al. 2018a). Detailed assessments of outcomes of interventions, based on thorough monitoring, are key to informing the efficacy of conservation management and guiding future strategies (Towns 2018). Ch. 3 highlights that for the conservation of vulnerable migratory species threats should be quantified across their range (HardestyMoore et al. 2018). In addition, accounting for temporal variation in exposure to these threats is key to effective conservation management (Robinson et al. 2020). Ch. 3 also underlines the importance of multi-year approaches to these spatial threat assessments 
(Pardo et al. 2017). Ch. 4 highlights the small margin of error involved when applying management strategies to small populations. Ch. 4 also highlights the importance of thorough, long-term monitoring in combination with comprehensive modelling approaches to inform conservation management a priori while acknowledging uncertainty (Willis et al. 2007, Saunders et al. 2018). Ch. 5 further illustrates the importance of species-specific information, based on monitoring and subsequent modelling, for planning conservation management. Finally, Ch. 6 highlights that even if a population is small, positive interspecific interactions can be present with unrelated species groups. As such, interspecific interactions should be taken into consideration when applying management, even when management is species-specific (i.e., umbrella species concept; Branton \& Richardson 2011). In summary, the conservation of the critically endangered WHDP is a good example of how complex conservation management can be, the variety of threats that should be assessed, the range of conservation strategies that should be considered, and the implications management can have.

\section{OUTLOOK}

The aim of this thesis was to facilitate the identification of a suitable conservation strategy for the recovery of the WHDP. The information compiled in this PhD thesis (as well as the information contained in my MSc thesis; Fischer 2016) is of considerable value to the future conservation of the WHDP. Invasive predator eradications were insufficient to stimulate WHDP recovery (Ch. 2, Fischer et al. 2020a). Additionally, an attempt to attract WHDPs in situ to dunes less vulnerable to storm erosion using an acoustic attraction system did not succeed, as WHDPs were not attracted to the intended site, but CDPs were (Fischer et al. 2020b). Therefore, other conservation strategies are required to conserve the WHDP. A potential management action, as outlined in $\mathrm{Ch}$. 3, would be to reduce pelagic threats (e.g., collisions with vessels) by introducing seasonal spatial restrictions of vessels within the direct vicinity of the WHDP colony (i.e., within Waikoropūpū, Sealers Bay, during the WHDP breeding period). An additional benefit of such spatial restrictions would be the reduction of the re-incursion potential of invasive predators (Russel \& Clout 2005). Spatial restrictions will, however, will have negative impacts on local stakeholders (i.e., fisheries). Another potential management option 
would be translocating pre-fledging chicks to establish a second WHDP population at another predator-free dune system in Southern Aotearoa (Ch. 4 \& 5). Translocations could render the WHDP less vulnerable to storms, storm surges, future climate change, and potentially competition with CDPs (Cole 2004, Fischer et al. 2017a, 2018b, Vousdoukas et al. 2020). As a drawback, translocating WHDPs is likely a long-term and costly undertaking (Ch. 4). A third option would be to address putative negative interactions with CDPs (i.e., potential competition and hybridization attempts; Ch. 5, Fischer et al. 2017a, 2018b). Specifically, management could involve preventing CDPs from entering WHDP burrows with exclusion devices (e.g., burrow flaps) or more extreme (i.e., lethal) control measures (Gummer et al. 2015). WHDP-CDP interactions, however, should be studied in further detail. In Ch. 5, I only investigated CDP impacts on nest survival (showing the absence of direct impacts) and thus impacts on lay rates (e.g., through competition or hybridization attempts) remain unknown. Yet another option would be the in-situ management of the dune system on Whenua Hou to render this system less vulnerable to erosion through, for example, ecosystem restoration or physical structures (Coastal Restoration Trust of New Zealand 2011). Nonetheless, the potential short-term benefits of restoring the dune system on Whenua Hou may be undone by the onset of future climate change (Vousdoukas et al. 2020). Furthermore, intensive management of the dune on Whenua Hou may not be realistic as it holds several urupā (Māori burial grounds; Middleton 2007). As outlined by the examples above, a range of potential management options exists. However, every decision made in relation to the management of the WHDP should acknowledge I) that every management alternative (i.e., conservation action) will have consequences, not just for the WHDP, but also for a range of stakeholders, II) that considerable uncertainty is present for each management alternative (including doing nothing), and III) the unique status of tangata whenua (people of the land). I will attempt to outline how decisions in (WHDP) conservation management can be made in an appropriate and integrated fashion, while addressing stakeholder interests, accounting for current uncertainty, and acknowledging the unique status of tangata whenua. 
Management alternatives are subject to complex, multi-dimensional decision landscapes that should be approached using standardized processes to acknowledge the consequences and trade-offs of each alternative. Structured decision-making (SDM) is a standardized process for making management decisions and is informed by a combination of stakeholder input and modelling (Gregory et al. 2012). SDM processes can effectively facilitate decision-making in conservation management (e.g., Gregory \& Long 2009, Converse et al. 2013, O’Donnell et al. 2017). SDM processes consists of six successive stages (Fig. 34): I) defining the problem, II) articulating fundamental objectives, III) identifying potential management alternatives (i.e., conservation actions), IV) predicting consequences of management alternatives, $V$ ) weighing trade-offs between the consequences of the management alternatives, and VI) identifying the best options for conservation management (i.e., making a decision). Integral to SDM processes is the involvement of the stakeholders. Problems, objectives, alternatives, and the weighing of trade-offs are based on underlying values of stakeholders. SDM processes are centred around stakeholder meetings during which key stakeholders decide on the first three stages as informed by their underlying values. Subsequently, modelling can predict the consequences of each management alternative. Trade-offs of each alternative can then be weighed during further stakeholder meetings allowing further propagation of the underlying values. Once consequences are estimated and trade-offs are weighed, a management decision can be made. The combination of stakeholder engagement and modelling thus allows for making informed decisions on conservation management. However, SDM typically requires large amounts of data. Both my MSc thesis and this PhD thesis provide this initial data on WHDP conservation. Therefore, a SDM approach to identifying the best course of action for WHDP conservation is now possible and highly encouraged. This process should involve all relevant stakeholders including: Te Rūnanga o Ngāi Tahu, the New Zealand Department of Conservation, and Fisheries New Zealand. It should be noted that Te Rūnanga o Ngāi Tahu (tangata whenua) are more than stakeholders, they are Treaty partners following Te Tiriti o Waitangi (1840; the founding document of Aotearoa that outlines the relationship between Māori and non-Māori people). 


\section{Structured decision-making}

Example:

A species is

declining

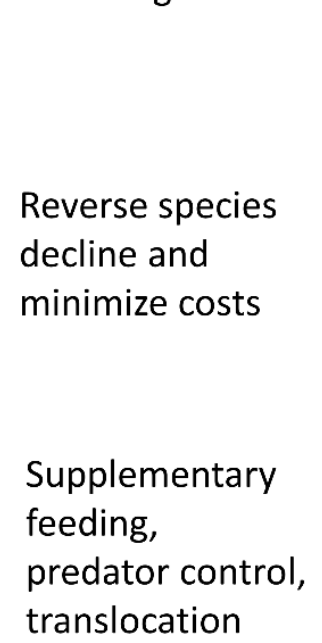

Model population trajectories and estimate costs

Optimize population outcome and costs

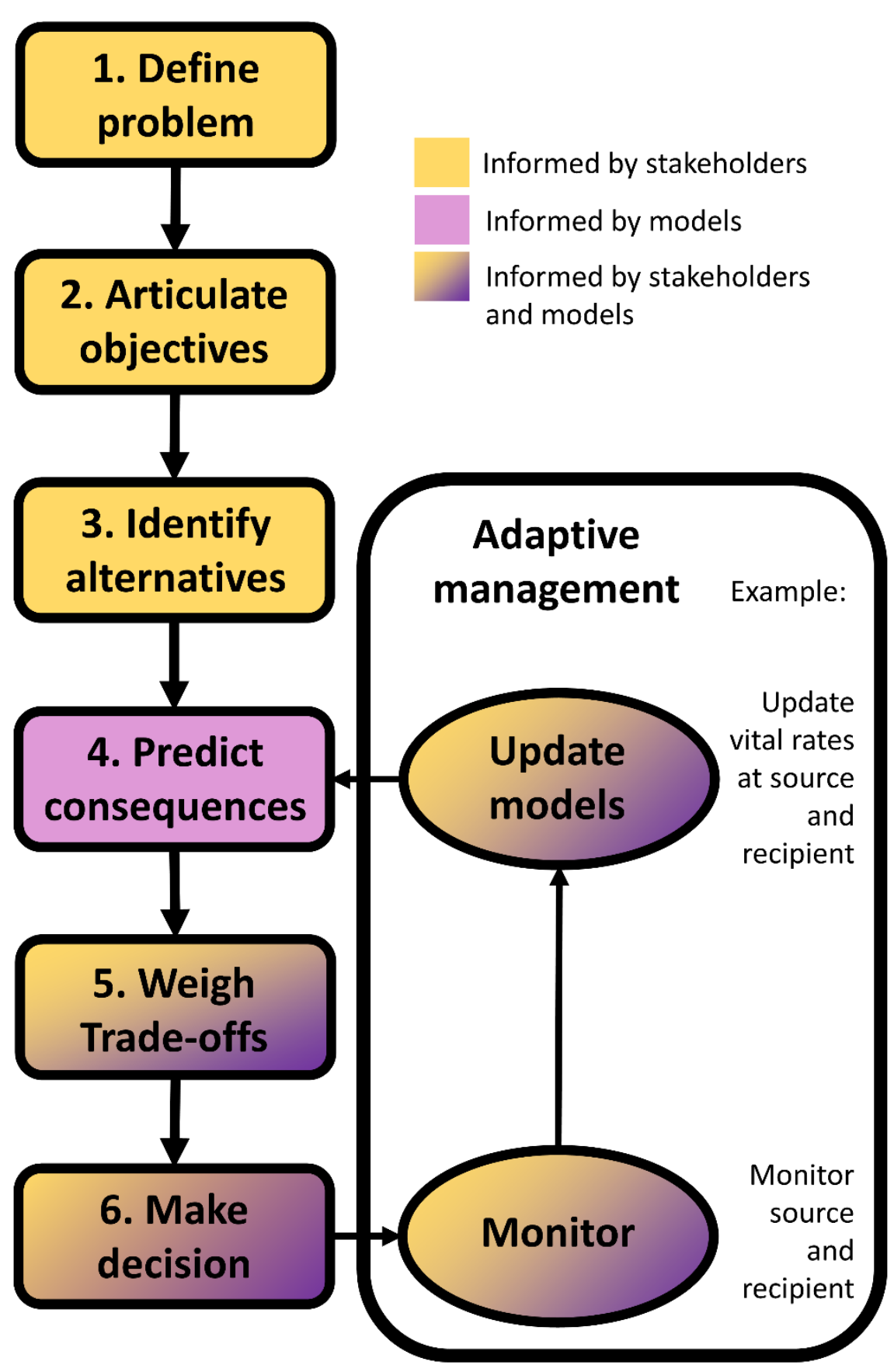

Fig. 34. A simplified diagram (adopted from Gregory et al. 2012, Converse et al. 2013, and O'Donnell et al. 2017) representing the structured decision-making process in combination with an iterative adaptive management loop, including a simplistic example of how this process can be applied to conservation management. 
In addition to SDM, future WHDP management should also use adaptive management (AM) approaches to reduce uncertainty surrounding the outcomes of management alternatives. AM approaches consist of iterative feedback loops that involve I) developing models of a system, II) manipulating the system (e.g., by applying management alternatives) and subsequently gaining information, and III) updating the existing models to guide future management (Fig. 34; Armstrong et al. 2007, Williams 2011, Converse et al. 2013). Continued and thorough monitoring to update understanding of the system (by comparing predicted with observed values) is central to AM approaches. AM can be passive or active (Williams 2011). Active AM revolves around actively (i.e., experimentally) reducing the existing uncertainty, while passive AM reduces the associated uncertainty as a by-product of focusing on management objectives. In other words, the fundamental objectives (as identified, for example, through SDM), determine whether AM is active or passive. As fundamental objectives of conservation management usually involve the recovery of a species (e.g., Fig. 34; O’Donnell et al. 2017), rather than reducing existing uncertainty, AM approaches within conservation management are generally passive. AM (most likely passive) could improve WHDP recovery. For example, for WHDP translocations, (passive) AM could be applied to improve management by I) monitoring both source and recipient populations during and after translocations, II) updating the existing estimates of vital rates and projections of population sizes using existing models, and III) and adjusting harvest intensities and timeframes when necessary (Ch. 4). In summary, AM can improve (WHDP) conservation management, as AM allows for alternatives to evolve over time, while uncertainty surrounding consequences and trade-offs is reduced. Consequently, AM enables conservation biologists to move away from potentially detrimental trial-and-error approaches and identify in the most beneficial outcomes for target species. 
Finally, future conservation management of the WHDP must acknowledge the unique position of tangata whenua. Indigenous Peoples around the globe exercise traditional rights over vast areas ( $\sim 38$ million $\mathrm{km}^{2}$ or a quarter of Earth's terrestrial surface; Garnett et al. 2018). Furthermore, $\sim 40 \%$ of all terrestrial protected areas fall within Indigenous People's lands. As such conservation management around the globe can no longer ignore and must include Indigenous perspectives (Ban et al. 2018, Rayne et al. 2020). In Aotearoa, conservation management legally must acknowledge the unique status of tangata whenua. Conservation management of the WHDP is no exception to this. Tangata whenua (Ngāi Tahu, specifically) have a deep genealogical, cultural, and spiritual connection to Whenua Hou (Middleton 2007). In fact, Whenua Hou was the site of the first bicultural Māori-Pākehā (non-Māori) settlement in Southern Aotearoa (Smith \& Anderson 2009). Additionally, the WHDP is considered a taonga (culturally significant and treasured species) by Ngāi Tahu (New Zealand Government 1998). This connection is signified in both the common name "Whenua Hou Diving Petrel" and the scientific name "P. whenuahouensis" which were elected by Ngāi Tahu prior to the formal description of this taxon (Fischer et al. 2018b). Consequently, to acknowledge the position of Ngāi Tahu and to uphold agreements made in Te Tiriti o Waitangi (1840) and subsequent settlements (New Zealand Government 1998), Ngāi Tahu must be involved in all phases of future WHDP management.

Conservation biology can be effective and rescue species from extinction (Bolam et al. 2020), but more integrative approaches are urgently required to stem the rampant biodiversity loss (Leclère et al. 2020). Combining SDM and AM, while acknowledging the unique position of Indigenous Peoples, allows conservation biologists to operate in truly integrated approaches. SDM and AM facilitate informed conservation approaches that acknowledge the complex species-specific nature of species recovery, incorporate stakeholder interests, underline the importance of monitoring and modelling, and allow management to evolve over time as uncertainty is reduced (William 2011, Converse et al. 2013). Acknowledging and actively involving Indigenous Peoples in all stages of conservation management will facilitate the much-needed decolonisation of this field (Adams \& Mulligan 2003, Smith 2013). The approach outlined here is a way forward for future WHDP management and could be applied to many other conservation projects. As such, I encourage conservation biologists to embrace these points and combat the everaccelerating sixth mass extinction in truly integrated conservation approaches. 
He waka eke noa. 
Chapter 7 


\section{References}

Abraham ER \& Richard Y. 2019. Estimated capture of seabirds in New Zealand trawl and longline fisheries, 2002-03 to 2015-16. Ministry of Primary Industries, Wellington, New Zealand.

Adam RJ, Hilton MJ, Jowett T \& Stephenson WJ. 2020. The magnitude and frequency of storm surge in southern New Zealand. New Zealand Journal of Marine and Freshwater Research. DOI:10.1080/00288330.2020.1764596.

Adams J \& Takekawa JY. 2008. At-sea distribution of radio-marked Ashy Storm-Petrels Oceanodroma homochroa captured on the California Channel Islands. Marine Ornithology 36: 9-17.

Adams WM \& Mulligan M. 2003. Decolonizing Nature. Strategies for conservation in a post-colonial era. Earthscan Publications, London, UK.

Agreement on the Conservation of Albatrosses and Petrels. 2014. Best practice seabird bycatch mitigation criteria and definitions. Available at: https://www.bmisbycatch.org/references/s62anjgw. Accessed on 23 June 2020.

Agreement on the Conservation of Albatrosses and Petrels. 2017. ACAP review and best practice advice for reducing the impact of pelagic longline fisheries on seabirds. Available at: https://www.acap.aq/resources/bycatch-mitigation/mitigationadvice/3242-acap-2017-review-and-best-practice-advice-for-reducing-the-impactof-pelagic-longline-fisheries-on-seabirds/file. Accessed on 23 June 2020.

Agreement on the Conservation of Albatrosses and Petrels. 2020. Guidelines for translocations of albatrosses and petrels. Available at: https://www.acap.aq/resources/acap-conservation-guidelines/2640-translocationguidelines/file. Accessed on 23 June 2020.

Anderson ORJ, Small CJ, Croxall JP, Dunn EK, Sullivan BJ, Yates O \& Black A. 2011. Global seabird bycatch in longline fisheries. Endangered Species Research 14: 91-106.

Andersson DR. 2008. Model Based Inference in the Life Sciences: A Primer on Evidence. Springer, Berlin, Germany.

Andersson M, Krockenberger A \& Schwarzkopf L. 2010. Experimental manipulation reveals the importance of refuge habitat temperature selected by lizards. Austral Ecology 35: 294- 299. 
Armstrong DP \& Seddon PJ. 2008. Directions in reintroduction biology. Trends in Ecology and Evolution 23: 20-25.

Armstrong DP \& Wittmer HU. 2011. Incorporating Allee effects into reintroduction strategies. Ecological Research 26: 687-695.

Armstrong DP, Castro I \& Griffiths R. 2007. Using adaptive management to determine requirements of re-introduced populations: the case of the New Zealand hihi. Journal of Applied Ecology 44: 953-962.

Armstrong DP. 2016. Using reference sites to account for detection probability in occupancy surveys for freshwater turtles. Herpetological Conservation and Biology 11: 505-518.

Bain D \& French K. 2009. Impacts on a threatened bird population of removals for translocation. Wildlife Research 36: 516-521.

Ban NC, Frid A, Reid M, Edgar B, Shaw D \& Siwallace P. 2018. Incorporating Indigenous perspectives for impactful research and effective management. Nature Ecology \& Evolution 2: 1680-1683.

Bancroft WJ, Roberts DJ \& Garkalis MJ. 2005. Burrowing seabirds drive decreased diversity and structural complexity, and increased productivity in insular-vegetation communities. Australian Journal of Botany 53: 231-241.

Barbraud C, Delord K, Marteau C \& Weimerskirch H. 2009. Estimates of population size of white-chinned petrels and grey petrels at Kerguelen Islands and sensitivity to fisheries. Animal Conservation 12: 258-265.

Barnovsky AD, Matzke N, Tomiya S, Wogan GOU, Swarts B, Quental TB, Marshall C, et al. 2011. Has the earth's sixth mass extinction already arrived? Nature 471: 51-57.

Bar-on YM, Phillips R \& Milo R. 2018. The biomass distribution on earth. Proceedings of the National Academy of Sciences USA 115: 6506-6511.

Bates D, Maechler M, Bolker B \& Walker S. 2015. Fitting linear mixed-effects models using lme4. Journal of Statistical Software 67:1-48.

Bell M, Bell BD \& Bell EA. 2005. Translocation of fluttering shearwater (Puffinus gavia) chicks to create a new colony. Notornis 52: 11-15.

Berry 0, Tocher MD, Gleeson DM \& Sarre SD. 2005. Effect of vegetation matrix on animal dispersal: genetic evidence from a study of endangered skinks. Conservation Biology 19: 855-864. 
Bird JP, Carlile N \& Miller MGR. 2014. A review of records and research actions for the critically endangered Beck's Petrel Pseudobulweria becki. Bird Conservation International 24: 287-298.

Bird JP, Martin R, Akcakaya HR, Gilroy J, Burfield IJ, Garnett S, Symes A, et al. 2020. Generation lengths of the world's birds and their implications for extinction risk. Conservation Biology. DOI: 10.1111/cobi.13486.

BirdLife International Seabird Tracking Database. 2020. Tracking Ocean Wanderers. Available at: www.seabirdtracking.org. Accessed on 10 July 2020.

BirdLife International. 2010. Marine Important Bird Areas toolkit: standardised techniques for identifying priority sites for the conservation of seabirds at sea. Cambridge, UK.

BirdLife International. 2020. IUCN Red List for Birds. Species Factsheets. Available at: http://datazone.birdlife.org/home. Accessed on 10 April 2020.

Black A. 2005. Light induced seabird mortality on vessels operating in the Southern Ocean: incidents and mitigation measures. Antarctic Science 17: 67-68.

Bodey TW, Cleasby IR, Bell F, Parr N, Schultz A, Votier SC, Bearhop S. 2017. A phylogenetically controlled meta-analysis of biologging device effects on birds: Deleterious effects and a call for more standardized reporting of study data. Methods in Ecology and Evolution $31: 1-10$.

Bolam FC, Mair L, Angelico M, Brooks TM, Burgman M, Hermes C, Hoffman M, et al. 2020. How many bird and mammal extinctions have we prevented? Conservation Letters e12762.

Brander LM, van Beukering P, Nijsten L, McVittie A, Baulcomb C, Eppink FV \& van der Lelij JAC. 2020. The global costs and benefits of expanding Marine Protected Areas. Marine Policy 116: 103953.

Branton M \& Richardson JS. 2011. Assessing the value of the umbrella-species concept for conservation planning with meta-analysis. Conservation Biology 25: 9-20.

Brooke ML, Bonnaud E, Dilley BJ, Flint EJ, Holmes ND, Jones HP, Provost P, et al. 2018a. Seabird population changes following mammal eradications on islands. Animal Conservation 21: 3-12.

Brooke ML, Bonnaud E, Dilley BJ, Flint EJ, Holmes ND, Jones HP, Provost P, et al. 2018b. Enhancing the value of future island eradications needs improved understanding of past outcomes. Animal Conservation 21: 19-20. 
Brooks TM, Mittermeier RA, Mittermeier CG, Da Fonseca GAB, Rylands AB, Konstant WR, Flick P, et al. 2002. Habitat loss and extinction in the hotspots of biodiversity. Conservation Biology 16: 909-923.

Brown KP \& Sherley GH. 2002. The eradication of possums from Kapiti Island, New Zealand. Turning the tide: the eradication of invasive species 27: 46-52.

Buckingham R, Torr S, Hamish L. \& Cole R. 1995. Management of Codfish Island: October 1992 - June 1993. Department of Conservation, Invercargill, New Zealand.

Bunnefeld N, Borger L, van Moorter B, Rolandsen CM, Dettki H, Solberg EJ, Ericsson G. 2011. A model-driven approach to quantify migration patterns: individual, regional and yearly differences. Journal of Animal Ecology 80: 466-476.

Burnham KP \& Anderson DR. 2002. Model selection and multimodel inference: a practical information-theoretic approach. Springer, New York, USA.

Butchart SHM, Stattersfield AJ \& Collar NJ. 2006. How many bird extinctions have we prevented? Oryx 40: 266-278.

Butchart SHM, Walpole M, Collen B, van Strien A, Scharlemann JPW, Almond REA, Baillie JEM, et al. 2010. Global biodiversity: Indicators of recent declines. Science 328: 11641168.

Buxton RT \& Jones IL. 2012. An experimental study of social attraction in two species of storm-petrel by acoustic and olfactory cues. Condor 114: 733-743.

Buxton RT, Jones CJ, Lyver PO, Towns DR \& Borelle SB. 2016. Deciding when to lend a helping hand: a decision-making framework for seabird island restoration. Biodiversity and Conservation 25: 467-484.

Calenge C. 2006. The package adehabitat for the R software: a tool for the analysis of space and habitat use by animals. Ecological modelling 197: 516-519.

Capizzi D, Luiselli L \& Vignoli L. 2007. Flight initiation distance in relation to substratum type, sex, reproductive status and tail condition in two lacertids with contrasting habitats. Amphibia-Reptilia 28: 403-407.

Carlile N, Priddel D \& Madeiros J. 2012. Establishment of a new, secure colony of Endangered Bermuda Petrel Pterodroma cahow by translocation of near-fledged nestlings. Bird Conservation International 22: 46-58.

Caswell H. 2001. Matrix population models: construction, analysis, and interpretation. Second edition. Sinauer Associates, Sunderland, USA. 
Caughley G. \& Sinclair ARE. 1994. Wildlife ecology and management. Blackwell Science, Oxford, UK.

Caughley G. 1977. Analysis of vertebrate populations. John Wiley and Sons, Toronto, Canada.

Caughley G. 1994. Directions in conservation biology. Journal of Animal Ecology 63: 215244.

Ceballos G, Ehrlich PR \& Dirso R. 2017. Biological annihilation via the ongoing sixth mass extinction signalled by vertebrate population losses and declines. Proceedings of the National Academy of Sciences USA 114: E6089-E6096.

Ceballos G, Ehrlich PR, Barnosky AD, Garcia A, Pringle RM \& Palmer TM. 2015. Accelerated modern human-induced species losses: Entering the sixth mass extinction. Science Advances 1: e1400253.

Chastel O, Weimerskirch H \& Jouventin P. 1995. Body condition and seabird reproductive performance: a study of three petrel species. Ecology 76: 2240-2246.

Cheke A \& Hume JP. 2008. Lost Land of the Dodo: An Ecological History of Mauritius, Reunion \& Rodrigues. Bloomsbury Publishing, London, UK.

Chilvers BL, Amey JM, Huckstadt LA \& Costa DP. 2010. Investigating foraging utilization distribution of female New Zealand sea lions, Auckland Islands. Polar Biology 34: 565574.

Clark CE. 1962. Letter to the editor - the PERT model for the distribution of an activity time. Operations Research 10: 405- 406.

Clay TA, Joo R, Weimerskirch H, Phillips RA, den Ouden, Basille M, Clusella-Trullas S, et al. 2020. Sex-specific effects of wind on the flight decisions of a sexually dimorphic soaring bird. Journal of Animal Ecology 89: 1811-1823.

Clay TA, Manica A, Ryan PG, Silk SRD, Croxall JP, Ireland L \& Phillips RA. 2016. Proximate drivers of spatial segregation in non-breeding albatrosses. Scientific Reports: 29932.

Clay TA, Phillips RA, Manica A, Jackson HA \& Brooke ML. 2017. Escaping the oligotrophic gyre? The year-round movements, foraging behaviour and habitat preferences of Murphy's petrels. Marine Ecology Progress Series 579: 139-155.

Clay TA, Small C, Tuck GN, Pardo D, Carneiro APG, Wood AG, Croxall JP, et al. 2019. A comprehensive large-scale assessment of fisheries bycatch risk to threatened seabird populations. Journal of Applied Ecology 56: 1882-1893. 
Cleeland JB, Pardo D, Raymond B, Terauds A, Alderman R, McMahon CR, Phillips RA, Lea MA \& Hindell MA. 2020. Introduced species and extreme weather as key drivers of reproductive output in three sympatric albatrosses. Scientific Reports 10: 8199.

Coastal Restoration Trust of New Zealand. 2011. Restoration of coastal sand dunes using native plants. Technical handbook: practical guide for coastal communities adapting to climate change. Available at: https://www.coastalrestorationtrust.org.nz/resources/coastal-restorationhandbook/. Accessed on 16 September 2020.

Cole R \& Roberts A. 1994. Management of Codfish Island: July 1993 - June 1994. Department of Conservation, Invercargill, New Zealand.

Cole R. 2004. Summary of South Georgian Diving Petrel field observations for 2003/04, Codfish Island/Whenua Hou. Department of Conservation, Invercargill, New Zealand.

Convention of Biological Diversity. 2010. Strategic plan for biodiversity 2011-2020. Tenth conference of parties to the Convention on Biological Diversity. Convention on Biological Diversity, Nagoya, Japan.

Converse SJ, Moore CT \& Armstrong DP. 2013. Demographics of reintroduced populations: estimation, modelling, and decision analysis. Journal of Wildlife Management 77: 1081-1093.

Converse SJ, Royle A, Adler PH, Urbanek RP \& Barzen JA. 2013. A hierarchical nest survival model integrating incomplete temporally varying covariates. Ecology and Evolution 3: 4439-4447.

Corkery I, Bell B \& Nelson N. 2014. Investigating kleptothermy: A Reptile-Seabird association with thermal benefits. Physiological and Biochemical Zoology 87: 216-221.

Corkery I, Bell B \& Nelson NJ. 2015. Is the breeding behaviour of nesting seabirds influenced by the presence of a predatory reptile-the tuatara? Journal of the Royal Society of New Zealand 45: 21-30.

Cox A. 1991. Scientific and management marking Codfish Island. Department of Conservation, Invercargill, New Zealand.

Crawford R, Ellenberg U, Frere E, Hagen C, Baird K, Brewin P, Crofts S, et al. 2017. Tangled and drowned: a global review of penguin bycatch in fisheries. Endangered Species Research 34: 373-396. 
Croxall JP, Butchart SHM, Lascelles B, Stattersfield AJ, Sullivan B, Symes A \& Taylor P. 2012. Seabird conservation status, threats and priority actions: a global assessment. Bird Conservation International 22:1-34.

Database of Island Invasive Species Eradications. 2015. The Database of Island Invasive Species Eradications. Developed by Island Conservation, Coastal Conservation Action Laboratory UCSC, IUCN SSC Invasive Species Specialist Group, University of Auckland and Landcare Research New Zealand. Available at: http://diise.islandconservation.org/. Accessed on 14 March 2018.

Database of Island Invasive Species Eradications. 2020. The Database of Island Invasive Species Eradications. Developed by Island Conservation, Coastal Conservation Action Laboratory UCSC, IUCN SSC Invasive Species Specialist Group, University of Auckland and Landcare Research New Zealand. Available at: http://diise.islandconservation.org/. Accessed on 16 June 2020.

de Lange PJ, Rolfe JR, Champion PD, Courtney SP, Heenan PB, Barkla JW, Cameron EK, et al. 2013. Conservation status of New Zealand indigenous vascular plants, 2012. Department of Conservation, Wellington, New Zealand.

Defos du Rau P, Bourgeois K, Thevenet M, Ruffino L, Dromzee S, Ouni R, Abiadh A, et al. 2015. Reassessment of the size of the Scopoli's Shearwater population at its main breeding site resulted in a tenfold increase: implications for the species conservation. Journal of Ornithology 156: 877-892.

Deguchi T, Suryan RM, Ozaki K, Jacobs JF, Sato F, Nakamura N \& Balgh GR. 2014. Translocation and hand-rearing of the short-tailed albatross Phoebastria albatrus: early indicators of success for species conservation and island restoration. Oryx 48: 195-203.

Delord K, Barbraud C, Bost CA, Deceuninck B, Lefebvre T, Lutz R, Micol T, Phillips RA, et al. 2014. Areas of importance for seabirds tracked from French southern territories and recommendations for conservation. Marine Policy 48: 1-13.

Dias MP, Martin R, Pearmain EJ, Burfield IJ, Small C, Phillips RA, Yates O, et al. 2019. Threats to seabirds: A global assessment. Biological Conservation 237: 525-537.

Diaz S, Settele, Brondizio ES, Ngo HT, Agard J, Arneth A, Balvanera P, et al. 2019. Pervasive human-driven decline of life on earth points to the need for transformative change. Science 366: eaax3100. 
Dimond WJ \& Armstrong DP. 2007. Adaptive harvesting of source populations for translocations: a case study with New Zealand Robins. Conservation Biology 21: 114124.

Domingo A, Jiminez S, Abreu M, Forselledo R \& Yates 0. 2017. Effectiveness of tori lines to reduce seabird bycatch in pelagic long line fishing. PLoS ONE 12: e0184465.

Downes S \& Shine R. 1998. Heat, safety or solitude? Using habitat selection experiments to identify a lizard's priorities. Animal Behaviour 55: 1387-1396.

Du WG, Shou L \& Shen JY. 2006. Habitat selection in two sympatric Chinese skinks, Eumeces elegans and Sphenomorphus indicus: do thermal preferences matter? Canadian Journal of Zoology 84: 1300- 1306.

Duncan RP \& Blackburn TM. 2004. Extinction and endemism in the New Zealand avifauna. Global Ecology and Biogeography. 13:509-517.

Dunn RE, Wanless S, Daunt F, Harris MP \& Green JA. 2020. A year in the life of a North Atlantic Seabird: behavioural and energetic adjustments during the annual cycle. Scientific Reports 10: 5993.

Dunphy BJ, Vickers SI, Zhang J, Sagar RL, Landers TJ, Bury SJ, Hickley AJR, et al. 2020. Seabirds as environmental indicators: foraging behaviour and ecophysiology of common diving petrels (Pelecanoides urinatrix) reflect local-scale differences in prey availability. Marine Biology 167: 53.

Einoder LD. 2009. A review of the use of seabirds as indicators in fisheries and ecosystem management. Fisheries Research 95: 6-13.

Ellis JC. 2005. Marine birds on land: a review of plant biomass, species richness, and community composition in seabird colonies. Plant Ecology 181: 227-241.

Elvidge CD, Zhizhin M, Baugh K \& Hsu FC. 2015. Automatic boat identification system for VIIRS low light imaging data. Remote sensing 7: 3020-3036.

Enge KM. 2001. The pitfalls of pitfall traps. Journal of Herptology 35: 467-478.

Epskamp S, Costantini G, Haslbeck J, Cramer AOJ, Waldorp LJ, Schmittmann VD \& Borsboom D. 2017. qgraph - Graph plotting methods, psychometric data visualisations and graphical model estimation. R package version 1.4.4. CRAN.

Erb KH, Kastner T, Plutzar C, Bais ALS, Carvalhais N, Fetzel T, Gingrich S, et al. 2018. Unexpectedly large impacts of forest management and grazing on global vegetation biomass. Nature 553: 73-76. 
Eriksen M, Lebreton LCM, Carson HS, Thiel M, Moore CJ, Borerro JC, Galgani F, et al. 2014. Pollution in the world's oceans: more than 5 trillion pieces weighing over 250,000 tons afloat at sea. PLoS ONE 9: e111913.

Ewen JG, Soorae PS \& Canessa S. 2014. Reintroduction objectives, decisions and outcomes: global perspectives from the herpetofauna. Animal Conservation 17: 74-81.

Falla RA, Taylor RH \& Black C. 1979. Survey of Dundas Island, Auckland Islands, with particular reference to Hooker's sea lion (Phocarctos hookeri). New Zealand Journal of Zoology 6: 347-355.

Fieberg J \& Kochanny CO. 2005. Quantifying home-range overlap: the importance of the utilization distribution. Journal of Wildlife Management 69: 1346-1359.

Finkelstein ME, Doak DF, Nakagawa M, Sievert PR \& Klavitter J. 2010. Assessment of demographic risk factors and management priorities: impacts on juveniles substantially affect population viability of a long-lived seabird. Animal Conservation 13: $148-156$.

Fischer JH, Chambon J, Debski I, Hiscock JA, Cole R, Taylor GA \& Wittmer HU. 2018a. Buffering artificial nest boxes for Procellariiformes breeding in exposed habitats: investigating effects on temperature and humidity. Notornis 65: 35-41.

Fischer JH, Debski I, Miskelly CM, Tennyson AJD, Fromant A, Tessler J, Hiscock JA, et al. 2018b. Analyses of phenotypic differentiations between South Georgian Diving Petrel (Pelecanoides georgicus) populations reveal an undescribed and highly-endangered species from New Zealand. PLoS ONE 13: e0197766.

Fischer JH, Debski I, Taylor GA \& Wittmer HU. 2017a. Assessing the suitability of noninvasive methods to monitor interspecific interactions and breeding biology of the South Georgian diving petrel (Pelecanoides georgicus). Notornis 64:13-20.

Fischer JH, Debski I, Taylor GA \& Wittmer HU. 2018c. Nest-site selection of South Georgia Diving-petrels on Codfish Island (Whenua Hou), New Zealand: implications for conservation management. Bird Conservation International 28: 216-227.

Fischer JH, Hjorsvarsdottir FO, Hiscock JA, Debski I, Taylor GA \& Wittmer HU. 2017b. Confirmation of the extinction of South Georgian diving petrels (Pelecanoides georgicus) on Enderby Island. Notornis 64:48-51.

Fischer JH, McCauley CF, Armstrong DP, Debski I \& Wittmer HU. 2019. Contrasting responses of lizard occurrences to burrowing by a critically endangered seabird. Community Ecology 20: 64-74. 
Fischer JH, Taylor GA, Cole R, Debski I, Armstrong DP \& Wittmer HU. 2020a. Population growth estimates of a threatened seabird indicate necessity for additional management following invasive predator eradications. Animal Conservation 23: 94103.

Fischer JH, Taylor GA, Debski I \& Wittmer HU. 2020b. Acoustic attraction system draws in competing seabird species. Notornis 67: 568-572.

Fischer JH, Wittmer HU, Setiawan E, Jaffe S \& Marshall AJ. 2017c. Incipient loss of a rainforest mutualism? Journal of Threatened Taxa 9: 9734-9737.

Fischer JH. 2016. Ecology, taxonomic status, and conservation of the South Georgian Diving Petrel (Pelecanoides georgicus) in New Zealand. MSc Thesis. Victoria University of Wellington, Wellington, New Zealand.

Friesen MR, Beggs JR \& Gaskett AC. 2017. Sensory-based conservation of seabirds: a review of management strategies and animal behaviours that facilitate success. Biological Reviews 92: 1769-1784.

Fukami T, Wardle DA, Bellingham PJ, Mulder CPH, Towns DR, Yeates GW, Bonner KI, et al. 2006. Above- and belowground impacts of introduced predators in seabird-dominated island ecosystems. Ecology Letters 9: 1299-1307.

Furlan EM, Gruber B, Attard CRM, Wager RNE, Kerezsy A, Faulks LK, Beheregaray LB et al. 2020. Assessing the benefits and risks of translocations in a depauperate species: A theoretical framework with empirical validation. Journal of Applied Ecology 57: 831841.

Garnett ST, Burgess ND, Fa JE, Fernandez-Llamazares A, Molnar Z, Robinson CJ, Watson JEM, et al. 2018. A spatial overview of the global importance of Indigenous lands for conservation. Nature Sustainability 1: 369-374.

Geldman J, Manica A, Burgess ND, Coad L \& Balmford A. 2019. A global-level assessment of the effectiveness of protected areas at resisting anthropogenic pressures. Proceedings of the National Academy of Sciences USA 116: 23209-23215.

Genovart M, Arcos JM, Alvarez D, McMinn M, Meier R, Wynn RB, Guilford T \& Oro D. 2016. Demography of the critically endangered Balearic shearwater: the impact of fisheries and time to extinction. Journal of Applied Ecology 53: 1158-1168.

Gimenez O, Rossie V, Choquet R, Dehais C, Doris B, Varella H, Vila JP, et al. 2007. Statespace modelling of data on marked individuals. Ecological Modelling 206: 431-438. 
Glass J \& Ryan P. 2013. Reduced seabird night strikes and mortality in the Tristan rock lobster fishery. African Journal of Marine Science 35: 589-592.

Glen AS, Atkinson R, Campbell KJ, Hagen E, Holmes ND, Keitt BS, Parkes JP, et al. 2013. Eradicating multiple invasive species on inhabited islands: the next big step in island restoration? Biological Invasions 15: 2589-2603.

Goad D, Debski I \& Potts J. 2019. Hookpod-mini: a smaller potential solution to mitigate seabird bycatch in pelagic longline fisheries. Endangered Species Research 39: 1-8.

Gonzales-Solis J, Croxall JP \& Wood AG. 2000. Sexual dimorphism and sexual segregation in foraging strategies of northern giant petrels, Macronectes halli, during incubation. Oikos 90: 390-398.

Graham NAJ, Wilson SK, Carr P, Hoey AS, Jennings S \& MacNeil MA. 2018. Seabirds enhance coral reef productivity and functioning in the absence of invasive rats. Nature 559: 250- 253.

Gregory R \& Long G. 2009. Using structured decision making to help implement a precautionary approach to endangered species management. Risk Analysis 29: 518532.

Gregory R, Failing L, Harstone M, Long G, McDaniels T \& Ohlson D. 2012. Structured decision making: a practical guide to environmental management choices. John Wiley \& Sons, West Sussex, UK.

Grémillet D, Péron C, Kato A, Amélineau F, Ropert-Coudert Y, Ryan PG \& Pichegru L. 2016. Starving seabirds: unprofitable foraging and its fitness consequences in Cape gannets competing with fisheries in the Benguela upwelling ecosystem. Marine Biology 163: 35.

Grémillet D, Ponchon A, Paleczny M, Palomares M-LD, Karpouzi V \& Pauly D. 2018. Persisting worldwide seabird-fishery competition despite seabird community decline. Current Biology 28: 4009-4013.

Gummer H, Taylor G \& Collen R. 2014a. Best practice techniques for the translocation of Chatham Petrels (Pterodroma axillaris), Cook's petrels (P. cookii) and Pycroft's Petrel (P. pycrofti). Department of Conservation, Wellington, New Zealand.

Gummer H, Taylor G, Collen R, Ward-Smith T \& Mitchell C. 2014b. Best practice techniques for the translocation of grey-faced petrels (Pterodroma macroptera gouldi). Department of Conservation, Wellington, New Zealand. 
Gummer H, Taylor G, Wilson KJ \& Rayner MJ. 2015. Recovery of the endangered Chatham Petrel (Pterodroma axillaris): A review of conservation management techniques from 1990 to 2010. Global Ecology and Conservation 3: 31-330.

Halley JM, van Houtan KS, Mantua N. 2018. How survival curves affect population's vulnerability to climate change. PLoS ONE 13: e0203124.

Halpin LR, Pollet IR, Lee C, Morgan KH \& Carter HR. 2018. Year-round movements of sympatric Fork-tailed (Oceanodroma furcata) and Leach's (O. leucorhoa) storm petrels. Journal of Field Ornithology 89: 207-2020.

Hardesty-Moore M, Deinet S, Freeman R, Titcomb GC, Dillon EM, Stears K, Klope M, et al. 2018. Migration in the Anthropocene: how collective navigation, environmental system and taxonomy shape the vulnerability of migratory species. Proceedings of the Royal Society B: Biological Sciences 373: 20170017.

Harris U \& Orsi A. 2006. Locations of the various fronts in the Southern Ocean. Australian Antarctic Data Centre - CAASM Metadata. Available at: https://data.aad.gov.au/metadata/?md=AMD/AU/southern ocean fronts. Accessed on 10 April 2020.

Hedd A, Pollet IL, Mauck RA, Burke CM, Mallory ML, McFarlane Tranquila LA, Montevecchi WA, et al. 2018. Foraging areas, offshore habitat use, and colony overlap by incubating Leach's storm-petrels Oceanodroma leucorhoa in the Northwest Atlantic. PLoS ONE 13: e0194389.

Heine JC \& Speir TW. 1989. Ornithogenic soils of the Cape Bird Adelie penguin rookeries, Antarctica. Polar Biology 10: 89- 100.

Herbert S \& Bell T. 2012. Survey design options for monitoring lizards at Baring Head, East Harbour Regional Park. EcoGecko Consultants, New Plymouth, New Zealand.

Hindell MA, Reisinger RR, Ropert-Coudert Y, Huckstadt LA, Trathan PN, Bornemann H, Charrassin JB, et al. 2020. Tracking of marine predators to protect Southern Ocean ecosystems. Nature 580: 87-92.

Hines JE. 2006. PRESENCE - Software to estimate patch occupancy and related parameters. Available at: https://www.mbr-pwrc.usgs.gov/software/presence.html. Accessed on 13 February 2018.

Hitchmough R, Barr B, Lettink M, Monks J, Reardon R, Tocher M, van Winkel D, et al. 2016. Conservation status of New Zealand reptiles, 2015. Department of Conservation, Wellington, New Zealand. 
Hoffmann M, Hilton-Taylor C, Angulo A, Bohm M, Brooks TM, Butchart SHM, Carpenter $\mathrm{KE}$, et al. 2010. The impact of conservation on the status of the world's vertebrates. Science 330: 1503-1509.

Hogg CJ, McLellan EA, Wise P, Lee AV, Pemberton, Fox S, Belov K, et al. 2020. Preserving demographic and genetic integrity of a single source population during multiple translocations. Biological Conservation 241: 108318.

Holdaway RN, Jones MD \& Athfield NRB. 2003. Establishment and extinction of a population of South Georgian diving petrel (Pelecanoides georgicus) at Mason Bay, Stewart Island, New Zealand, during the late Holocene. Journal of the Royal Society of New Zealand 33: 601-622.

Holmes ND, Spatz DR, Oppel S, Tershy B, Croll DA, Keitt B, Genovesi P, et al. 2019. Globally important island where eradicating invasive mammals will benefit highly threatened vertebrates. PLoS ONE 14: e0212128.

Humphreys AM, Govaerts R, Ficinski SZ, Lughadha EN \& Vorontsova MS. 2019. Global dataset shows geography and life form predict modern plant extinction and rediscovery. Nature Ecology \& Evolution 3: 1043-1047.

Imber MJ \& Nilsson RJ. 1980. South Georgian diving petrels (Pelecanoides georgicus) breeding on Codfish Island. Notornis 27:325-330.

Imber MJ, McFadden I, Bell EA \& Scofield RP. 2003. Post-fledging migration, age of first return and recruitment, and results of inter-colony translocation of black petrels (Procellaria parkinsoni). Notornis 50: 183-190.

Imber MJ, West JA \& Cooper WJ. 2003. Cook's petrel (Pterodroma cookii): historic distribution, breeding biology, and effects of predators. Notornis 50: 221-230.

Imber MJ. 1999. Report on Codfish Island trip to set up Cook's petrel long-term monitoring grids for Southland Conservancy. Department of Conservation, Invercargill, New Zealand.

IUCN. 2013. Guidelines for reintroductions and other conservation translocations. Version 1.0. Species Survival Commission, Gland, Switzerland.

Jarvis RM, Borrelle SB, Bollard Breen B \& Towns DR. 2015. Conservation, mismatch, and the research implementation gap. Pacific Conservation Biology 21: 105-107.

Jenouvrier S, Despres M, Fay R, Barbraud C, Weimerskirch H, Delord K \& Caswell H. 2018. Climate change and functional traits affect population dynamics of a long-lived seabird. Journal of Animal Ecology 87: 906-920. 
Jensen T. 2019. Guilts Plasticity. In: Ecologies of Guilt in Environmental Rhetorics. Palgrave studies in Media and Environmental Communication, Palgrave Pivot, London, UK.

Jewell T. 2017. Skinks of Southern New Zealand (2nd Ed.). Online publication. Accessed on 13 February 2018.

Johnson FA, Eaton MJ, Williams JH, Jensen GH \& Madsen J. 2015. Training conservation practitioners to be better decision makers. Sustainability 7: 8354-8373.

Johnson P \& Rance B. 1990. Codfish Island Trip Report. Department of Conservation, Invercargill, New Zealand.

Jones HP \& Kress SW. 2012. A review of the world's active seabird restoration projects. Journal of Wildlife Management 76: 2-9.

Jones HP, Holmes ND, Butchart SHM, Tershy BR, Kappes PJ, Corkery I, Aguirre-Munoz A, et al. 2016. Invasive mammal eradication on island results in substantial conservation gains. Proceedings of the National Academy of Sciences USA 113: 4033-4038.

Jones HP, Tershy BR, Zavaleta ES, Croll DA, Keitt BS, Finkelstein ME \& Howald GR. 2008. Severity of the effects of invasive rats on seabirds: A global review. Conservation Biology 22: 16-26.

Jones HP. 2010. Seabirds take mere decades to recover following rat eradications. Ecological Applications 20: 2075-2080.

Kendall RJ, Klein CJ, Halpern BS, Venter O, Grantham H, Kuempel CD, Shumway N, et al. 2018. The location and protection status of the earth's diminishing marine wilderness. Current Biology 28: 2506-2512.

Keogan K, Daunt F, Wanless S, Phillips RA, Walling C, Agnew P, Ainley DG, et al. 2018. Global phenological insensitivity to shifting ocean temperatures among seabirds. Nature Climate Change 8: 313-318.

Kery M \& Schaub M. 2012. Bayesian Population Analysis using WinBUGS: A hierarchical perspective. Elsevier, London, UK.

Knutson TR, McBride JL, Chan J, Emanuel K, Holland G, Landsea C, Held I, et al. 2010. Tropical cyclones and climate change. Nature Geoscience 3: 157-163.

Kroodsma DA, Mayorga J, Hochberg T, Miller NA, Boerder K, Ferretti F, Wilson A, et al. 2018. Tracking the global footprint of fisheries. Science 359: 904-908.

Kuhnert PM, Martin TG \& Griffiths SP. 2010. A guide to eliciting and using expert knowledge in Bayesian ecological models. Ecology Letters 13: 900-914. 
Lago P, Austad M \& Metzger B. 2019. Partial migration in the Mediterranean Storm Petrel Hydrobates pelgicus melitensis. Marine Ornithology 47: 105-113.

Lameris TK, Bennett JR, Blight LK, Giessen M, Janssen MH, Schaminee JJHJ \& Arcese P. 2016. A century of ecosystem change: human and seabird impacts on plant species extirpation and invasion on islands. PeerJ 4: e2208.

Lascelles B, Notarbartolo G, Argardy T, Cuttelod A, Eckert S, Glowka L, Hoyt E, et al. 2014. Migratory marine species: their status, threats and conservation management needs. Aquatic Conservation: Marine and Freshwater Ecosystems 24: 111-127.

Lascelles BG, Taylor PR, Miller MGR, Dias MP, Oppel S, Torres L, Hedd A, et al. 2016. Applying global criteria to tracking data to define important areas for marine conservation. Diversity and Distributions 22: 422-431.

Lavers JL, Bond AL \& Hutton I. 2014. Plastic ingestion by Flesh-footed Shearwaters (Puffinus carneipes): Implications for fledging body condition and the accumulation of plastic-derived chemicals. Environmental Pollution 187: 124-129.

Lavers JL, Hutton I \& Bond AL. 2019. Changes in technology and imperfect detection of nest contents impedes reliable estimates of population trends in burrowing seabirds. Global Ecology and Conservation 17: e00579.

Lebreton JD, Burnham KP, Clobert J \& Anderson DR. 1992. Modelling survival and testing biological hypothesis using marked animals: a unified approach with case studies. Ecological Monographs 62: 67-118.

Leclère D, Obersteiner M, Barrett M, Butchart SHM, Chaudhary A, de Palma A, DeClerck FAJ, et al. 2020. Bending the curve of terrestrial biodiversity needs an integrated strategy. Nature. DOI: 10.1038/s41586-020-2705-y.

Linstone HA \& Turoff M. 1975. The Delphi Method. Addison-Wessley, Reading, UK.

Lorrain A, Houlbreque F, Benzoni F, Barjon L, Tremblay-Boyer L, Menkes C, Gillikin DP, et al. 2017. Seabirds supply nitrogen to reefbuilding corals on remote Pacific islets. Scientific Reports 7: 3721.

Lunn DJ, Thomas A, Best N \& Spiegelhalter D. 2000. WinBUGS - a Bayesian modelling framework: concepts, structure, and extensibility. Statistics and Computing 10: 325337.

MacKenzie DI, Bailey LL \& Nichols JD. 2004. Investigating species co-occurrence patterns when species are detected imperfectly. Journal of Animal Ecology 73: 546-555. 
MacKenzie DI, Nichols JD, Hines JE, Knutson MG \& Franklin AB. 2003. Estimating site occupancy, colonization, and local extinction probabilities when a species is detected imperfectly. Ecology 84: 2200-2207.

MacKenzie DI, Nichols JD, Lachman GB, Droege S, Royle JA \& Langtimm CA. 2002. Estimating site occupancy rates when detection probabilities are less than one. Ecology 83: 2248-2255.

MacKenzie DI, Nichols JD, Royle JA, Pollock KH, Bailey LL \& Hines JE. 2018. Occupancy estimation and modelling - Inferring patterns and dynamics of species occurrence. 2nd edition. Elsevier, London, UK.

Mangel JC, Wang J, Alfraro-Shigueto J, Pingo S, Jimenez A, Carvalho F, Swimmer Y, et al. 2018. Illuminating gillnets to save seabirds and the potential for multi-taxa bycatch mitigation. Royal Society Open Science 5: 180254.

Marchant S \& Higgins PJ. 1990. Handbook of Australian, New Zealand and Antarctic birds. Volume 1, ratites to ducks, part A, ratites to petrels. Oxford University Press, Melbourne, Australia.

Maree BA, Wanless RM, Fairweather TP, Sullivan BJ \& Yates 0. 2014. Significant reductions in mortality of threatened seabirds in a South African trawl fishery. Animal Conservation 17: 520-529.

Marine Conservation Institute. 2020. Available at https://mpatlas.org/. Accessed on 24 June 2020.

Markwell TJ \& Daugherty CJ. 2002. Invertebrate and lizard abundance is greater on seabird-inhabited islands than on seabird-free islands in the Marlborough Sounds, New Zealand. Ecoscience 9: 93-299.

Martin GR \& Crawford R. 2015. Reducing bycatch in gillnets: a sensory ecology perspective. Global Ecology and Conservation 3: 28-50.

Martin TG, Burgman MA, Fidler F, Kuhnert PM, LowChoy S, McBride M \& Mengersen K. 2012. Eliciting expert knowledge in conservation science. Conservation Biology 26: 29-38.

Mattern T, Masello JF, Ellenberg U \& Quilfeldt P. 2015. Actave.net - a web-based tool for the analysis of seabird activity patterns from saltwater immersion geolocators. Methods in Ecology and Evolution 6: 859-864.

McCauley DJ, Woods P, Sullivan B, Bergman B, Jablonicky C, Roan A, Michael H, et al. 2016. Ending hide and seek at sea. Science 351: 1148-1150. 
McClelland PJ. 2002. Eradication of Pacific rats (Rattus exulans) from Whenua Hou Nature Reserve (Codfish Island), Putauhinu and Rarotoka Islands, New Zealand. Turning the tide: the eradication of invasive species 27: 173-181.

Melzer S, Bell T \& Patterson GB. 2017. Hidden conservation vulnerability within a cryptic species complex: taxonomic revision of the spotted skink (Oligosoma lineoocellatum; Reptilia: Scincidae) from New Zealand. Zootaxa 4300: 355-379.

Merkel B, Phillips RA, Descamps S, Yoccoz NG, Moe B \& Strom H. 2016. A probabilistic algorithm to process geolocation data. Movement Ecology 4:26.

Middleton A. 2007. Two hundred years on Codfish Island (Whenuahou). Department of Conservation, Invercargill, New Zealand.

Miller MW, Leech DI, Pearce-Higgins JW \& Robinson RA. 2017. Multi-state, multi-stage modelling of nest success suggests interaction between weather and land-use. Ecology 98: 175-186.

Milne T, Bull CM \& Hutchinson MN. 2003. Use of burrows by the endangered pygmy bluetongue lizard, Tiliqua adelaidensis (Scincidae). Wildlife Research 30: 523-528.

Miskelly CM \& Gummer H. 2013. Attempts to anchor pelagic fairy prions (Pachyptila turtur) to their release site on Mana Island. Notornis 60: 29-40.

Miskelly CM \& Taylor GA. 2004. Establishment of a colony of Common Diving Petrels (Pelecanoides urinatrix) by chick transfers and acoustic attraction. Emu 104: 205-211. Miskelly CM \& Taylor GA. 2007. Common Diving Petrel (Pelecanoides urinatrix) breeding at 1 year old. Notornis 54: 239-240.

Miskelly CM, Taylor GA, Gummer H \& Williams R. 2009. Translocations of eight species of burrow-nesting seabirds (genera Pterodroma, Pelecanoides, Pachyptila and Puffinus: Family Procellariidae). Biological Conservation 142: 1965-1980.

Monroe MJ, Butchart SHM, Mooers AO \& Bokma F. 2019. The dynamics underlying avian extinction trajectories forecast a wave of extinctions. Biology Letters 15: 20190633.

Moreno CA, Castro R, Mujica LJ \& Reyes P. 2008. Significant conservation benefits obtained from the use of a new fishing gear in the Chilean Patagonian toothfish fishery. CCAMLR Science 15: 79-91.

Mosbech A, Johansen KL, Bech NI, Lyngs P, Harding AMA, Egevang C, Phillips RA, et al. 2012. Inter-breeding movement of little auks Alle alle reveal a key post-breeding staging area in the Greenland Sea. Polar Biology 35: 305-311. 
Mulder CP \& Keall SN. 2001. Burrowing seabirds and reptiles: impact on seeds, seedlings and soils in an island forest in New Zealand. Oecologia 127: 350-360.

Murphy RC \& F Harper. 1921. A review of the diving petrels. Bulletin of the American Museum of Natural History 44: 496-554.

Navarro J, Cardador L, Brown R \& Phillips RA. 2015. Spatial distribution and ecological niches of non-breeding planktivorous petrels. Scientific Reports 5: 12164.

Navarro J, Votier SC, Aguzzi J, Chiesa JJ, Forero MG \& Phillips RA. 2013. Ecological segregation in space, time, and trophic niche of sympatric planktivorous petrels. PLoS ONE 8: e62897.

New Zealand Government. 1998. Ngāi Tahu Claims Settlement Act 1998. New Zealand Legislation.

Norris-Caneda KH \& JD Elliott. 1998. Sex identification in raptors using PCR. Journal of Raptor Research 32: 278-280.

O’Donnell KM, Messerman AF, Barichivich WJ, Semlitsch RD, Gorman TA, Mitchell HG, Allan N, et al. 2017. Structured decision making as a conservation tool for recovery planning of two endangered salamanders. Journal for Nature Conservation 37: 66-72.

Oliveira N, Henriques A, Miodonski J, Pereira J, Marujo D, Almeida A, Barros N, et al. 2015. Seabird bycatch in Portuguese mainland coastal fisheries: an assessment through onboard observations and fishermen interviews: Global Ecology and Conservation 3: 5161.

Oppel S, Hilton G, Ratcliffe N, Fenton C, Daley J, Gray G, Vickery J \& Gibbons D. 2014. Assessing population viability while accounting for demographic and environmental uncertainty. Ecology 95: 1809-1818.

Orben RA, O’Connor AJ, Suryan RM, Ozaki K, Sato F \& Deguchi T. 2018. Ontogenic changes in at-sea distributions of immature short-tailed albatrosses Phoebastria albatrus. Endangered Species Research 35: 23-27.

Oro D, Aguilar JS, Igual JM \& Louzao M. 2004. Modelling demography and extinction risk in the endangered Balearic shearwater. Biological Conservation 116: 93-102.

Orsi AH, Whitworth T \& Nowlin WD. 1995. On the meridional extent and fronts of the Antarctic Circumpolar Current. Deep See Research Part I: Oceanographic Research Papers 42: 641-673. 
Orwin KH, Wardle DA, Towns DR, John MG, Bellingham PJ \& Jones C. 2016. Burrowing seabird effects on invertebrate communities in soil and litter are dominated by ecosystem engineering rather than nutrient addition. Oecologia 180: 217-230.

Osborne PE \& Seddon PJ. 2012. Selecting suitable habitats for reintroductions: variation, change and the role of species distribution modelling. In: Even JG, Armstrong DP, Parker KA \& Seddon PJ (eds.). Reintroduction biology: integrating science and management. Blackwell Publishing, West Sussex, UK.

Otero XL, de la Peña-Lastra S, Pérez-Alberti A, Ferreira TO \& Huerta-Diaz MA. 2018. Seabird colonies as important drivers in the nitrogen and phosphorus cycles. Nature Communications 9: 246.

Paiva WH, Ramos JA, Nava C, Neves V, Bried J \& Magalhaes M. 2018. Inter-sexual habitat and isotopic niche segregation of the endangered Monteiro's storm-petrel during breeding. Zoology 126: 29-35.

Paleczny M, Hammill E, Karpouzi V \& Pauly D. 2015. Population trend of the world's monitored seabirds, 1950-2010. PLoS ONE 10: e0129342.

Panfylova J, Ewen JG \& Armstrong DP. 2019. Making structured decisions for reintroduced populations in the face of uncertainty. Conservation Science and Practice 1: e90.

Pardo D, Forcada J, Wood AG, Tuck GF, Ireland L, Pradel R, Croxall JP, et al. 2017. Additive effects of climate and fisheries drive ongoing decline in multiple albatross species. Proceedings of the National Academy of Sciences USA 114: E10829-E10837.

Parker KA, Ewen JG, Weiser EL, Rayne A, Steeves T, Seddon PJ, Innes J, et al. 2020. Conservation translocations in Aotearoa New Zealand in the predator-free era. EcoEvoRxiv. DOI:10.32942/osf.io/bdaxh.

Parlato EH \& Armstrong DP. 2018. Predicting reintroduction outcomes for highly vulnerable species that do not currently coexist with their key threats. Conservation Biology 32: 1346-1355.

Paterson AM, Wallis LJ \& Wallis GP. 2000. Preliminary molecular analysis of Pelecanoides georgicus (Procellariiformes: Pelecanoididae) Whenua Hou (Codfish Island): implications for its taxonomic status. New Zealand Journal of Zoology 27: 415 - 423.

Paterson JRB, Yates O, Holtzhausen H, Reid T, Shimooshili K, Yates S, Sullivan BJ, et al. 2017. Seabird mortality in the Namibian demersal longline fishery and recommendations for best practice mitigation measures. Oryx 53: 300-309. 
Pauly D, Christensen V, Dalsgaard J, Froese R \& Torres F. 1998. Fishing down marine food webs. Science 279: 860-863.

Paxton EH, Camp RJ, Gorresen PM, Crampton LH, Leonard DL \& VanderWerf EA. 2016. Collapsing avian community on a Hawaiian Island. Science Advances 2: e1600029.

Petren, K. and T.J. Case. 1998. Habitat structure determines competition intensity and invasion success in gecko lizards. Proceedings of the National Academy of Sciences USA 95:11739-11744.

Phillips RA, Croxall JP, Silk JRD \& Briggs DR. 2008. Foraging ecology of albatrosses and petrels form South Georgia: two decades of insights from tracking technologies. Aquatic Conservation 17: 6-21.

Phillips RA, Gales R, Baker GB, Double MC, Favero M, Quintana F, Tasker ML, Weimerskirch H, Uhart M \& Wolfaart A. 2016. The conservation status and priorities for albatrosses and large petrels. Biological Conservation 201: 169-183.

Phillips, RA, JC Xavier \& JP Croxall. 2003. Effects of satellite transmitters on albatrosses and petrels. The Auk 120: 1082-1090.

Phillpot P. 2000. The skinks of Northern Brother Island: Abundance, habitat use, and species interactions. MSc Thesis. Victoria University of Wellington, Wellington, New Zealand.

Piatt JF, Parrish JK, Renner HM, Schoen SK, Jones TT, Arimitsu, Kuletz KJ, et al. 2020. Extreme mortality and reproductive failure of common murres resulting from the northeast Pacific marine heatwave of 2014-2016. PLoS ONE 15: e0226087.

Pierre JP, Abraham ER, Richard Y, Cleal J \& Middleton DAL. 2012. Controlling trawler waste discharge to reduce seabird mortality. Fisheries Research 131-133: 30-38.

Pimm SL, Russell GJ, Gittleman JL \& Brooks TM. 1995. The future of biodiversity. Science 269: 347-350.

Podolsky R \& Kress SW. 1992. Attraction of the endangered dark-rumped petrel to recorded vocalizations in the Galápagos Islands. Condor 94: 448-453.

Pollet IL, Ronconi RA, Leonard ML \& Shutler D. 2019. Migration routes and stopover areas of Leach's Storm Petrels Oceanodroma leucorhoa. Marine Ornithology 47: 55-65.

Priddel D, Carlile N \& Wheeler R. 2006. Establishment of a new breeding colony of Gould's Petrel (Pterodroma leucoptera leucoptera) through the creation of artificial nesting habitat and the translocation of nestlings. Biological Conservation 128: 553-563. 
Quillfeldt P, McGill RAR, Furness RW, Mostl R, Ludynia K, Masello JF. 2012. Impact of miniature geolocation loggers on a small petrel, the thin-billed prion Pachyptila belcheri. Marine Biology 159: 1809-1816.

Quillfeldt P, Strange IJ \& Masello JF. 2007. Sea surface temperatures and behavioural buffering capacity in thin-billed prions Pachyptila belcheri: breeding success, provisioning and chick begging. Journal of Avian Biology 38: 298-308.

R Core Team. 2016. R: A language and environment for statistical computing. R foundation for statistical computing, Vienna, Austria.

R Core Team. 2019. R: A language and environment for statistical computing. $\mathrm{R}$ foundation for statistical computing, Vienna, Austria.

Raine AF, Holmes ND, Travers M, Cooper BA \& Day HR. 2017. Declining population trends of Hawaiian Petrel and Newell's Shearwater on the island of Kaua'i, Hawaii. The Condor 119: 405-415.

Ramstad KM, Colbourne RM, Robertson HA, Allendorf FW \& Daugherty CH. 2013. Genetic consequences of a century of protection: serial founder events and survival of the little spotted kiwi (Apteryx owenii). Proceedings of the Royal Society B: Biological Sciences 280: 20130576.

Rayne A, Byrnes, Robinson L, Hollows J, McIntosh A, Ramsden M, Rupene M, et al. 2020. Centring Indigenous knowledge systems to re-imagine conservation translocations. People and Nature 2: 512-526.

Rayner MJ, Hauber ME, Clout MN, Seldon DS, van Dijken S, Bury S \& Phillips RA. 2008a. Foraging ecology of the Cook's petrel Pterodroma cookii during the austral breeding season: a comparison of its two populations. Marine Ecology Progress Series 370: 271284.

Rayner MJ, Parker KA \& Imber MJ. 2008b. Population census of Cook's petrel Pterodroma cookii breeding on Codfish Island (New Zealand) and the global conservation status of the species. Bird Conservation International $18: 211-218$.

Rayner MJ, Taylor GA, Gaskin CP \& Dunphy BJ. 2017. Seasonal activity and unpredicted polar front migration of northern New Zealand Common Diving Petrels (Pelecanoides urinatrix). Emu 117: 290-298.

Requena S, Oppel S, Bond AL, Hall J, Cleeland J, Crawford RJM, Davies D, et al. 2020. Marine hotspots of activity inform protection of a threatened community of pelagic species in a large oceanic jurisdiction. Animal Conservation. DOI: doi.org/10.1111/acv.12572. 
Reynolds MH, Berkowitz P, Klavitter JL \& Courtot KN. 2017. Lessons from the Tohoku tsunami: a model for island avifauna conservation prioritization. Ecology and Evolution 7: 5873-5890.

Reynolds RW, Smith TM, Liu C, Chelton DB, Casey KS \& Schlax MG. 2007. Daily highresolution-blended analyses for sea surface temperature. Journal of Climate 20: 54735496.

Richard Y, Abraham ER \& Berkenbusch K. 2020. Assessment of the risk of commercial fisheries to New Zealand seabirds, 2006-07 to 2016-17. Ministry of Primary Industries, Wellington, New Zealand.

Richdale LE. 1945. Supplementary notes on the diving petrel. Transactions of the Royal Society of New Zealand 75: 42-53.

Richmont OMW, Hines JE \& Beissinger SR. 2010. Two species occupancy models: a new parameterization applied to co-occurrence of secretive rails. Ecological Applications 20: 2036-2046.

Robertson CJR \& Bell BD. 1984. Seabird status and conservation in the New Zealand region. In: Status and conservation of the world's seabirds: 573-586. In: Croxall JP, Evans PGH \& Schreiber RW (eds.). Status and conservation of the world's seabirds. Cambridge: ICBP Technical publication 2.

Robertson HA, Baird K, Dowding JE, Elliott GP, Hitchmough RA, Miskelly CM, McArthur N, et al. 2017. Conservation status of New Zealand birds, 2016. Department of Conservation, Wellington, New Zealand.

Robinson RA, Meier CM, Witvliet W, Kery M, Schaub M. 2020. Survival varies seasonally in a migratory bird: Linkages between breeding and non-breeding periods. Journal of Animal Ecology 89: 2111-2121.

Rodríguez A, Arcos JM, Bretagnolle V, Dias MP, Holmes ND, Louzao M, Provencher J, et al. 2019. Future directions in conservation research on petrels and shearwaters. Frontiers in Marine Science 6: 94.

Rodríguez A, Holmes ND, Ryan PG, Wilson K-J, Faulquier L, Murillo Y, Raine AF, et al. 2017. Seabird mortality induced by land-based artificial lights. Conservation Biology 31: 986-1001.

Roman L, Bell E, Wilcox C, Hardesty BD \& Hindell M. 2019. Ecological drivers of marine ingestion in Procellariiform Seabirds. Scientific reports 9: 916. 
Rotger A, Sola A, Tavecchia G \& Sanz-Aguilar A. 2020. Foraging far from home: gpstracking Mediterranean storm-petrels Hydrobates pelagicus melitensis reveals longdistance foraging movements. Ardeola 68: 3-16.

Roughton CM. 2005. Assessment of Methods to Monitor Otago Skink and Grand Skink Populations, New Zealand. Department of Conservation, Wellington, New Zealand.

Rowe L. 2018. Observations of Hutton's shearwaters (Puffinus huttoni) at a natural colony in the Kowhai River and a newly established by translocation colony at Te Rae o Atiu, Kaikoura Peninsula. Notornis 65: 42-50.

Russell JC \& Clout M. 2005. Rodent incursions on New Zealand islands. Landcare Research: Proceedings of the $13^{\text {th }}$ Australasian Vertebrate Pest Conference.

Russell JC, Innes JG, Brown PH \& Byrom AE. 2015. Predator-Free New Zealand: conservation country. BioScience 65: 520-525.

Russell JC, Taylor CN \& Aley JP. 2018. Social assessment of inhabited islands for wildlife management and eradication. Australasian Journal of Environmental Management 25: 24-42.

Ryan PG, Moore CJ, van Franeker JA \& Moloney CL. 2009. Monitoring the abundance of plastic in the marine environment. Philosophical Transactions of the Royal Society B: Biological Sciences 364: 1999-2012.

Ryan PG. 1991. The impact of the commercial lobster fishery on seabirds at the Tristan da Cunha Islands, South Atlantic Ocean. Biological Conservation 57: 339-350.

Saunders SP, Cuthbert FJ \& Zipkin EF. 2018. Evaluating population viability and efficacy of conservation management using integrated population models. Journal of Applied Ecology 55: 1380-1392.

Saunders SP, Farr MT, Wright AD, Bahlai CA, Ribeiro Jr. JW, Rossman S, Sussman A, et al. 2019. Disentangling data discrepancies with integrated population models. Ecology 100: e02714.

Schaub M \& Abadi F. 2011. Integrated population models: a novel analysis framework for deeper insights into population dynamics. Journal of Ornithology 152: 227-237.

Schmidt JH, Walker JA, Lindberg MS, Johnson DS \& Stephens SE. 2010. A general Bayesian hierarchical model for estimating survival of nests and young. The Auk 127: 379-386.

Schreiber RW \& Schreiber EA. 1984. Central Pacific seabirds and the El Niño Southern Oscillation: 1982 to 1983 perspectives. Science 225: 713-716. 
Schultz H, Hohnhold RJ, Taylor GA, Bury SJ, Bliss T, Ismar SMH, Gaskett AC, et al. 2018. Non-breeding distribution and activity patterns in a temperate population of brown skua. Marine Ecology Progress Series 603: 215-226.

Seabird Restoration Database. 2020. Available at: https://www.seabirddatabase.org/. Accessed on 21 July 2020.

Seber GAF. 1982. The Estimation of Animal Abundance and Related Parameters, 2nd Edition. Macmillan, New York, USA.

Seddon PJ, Armstrong DP \& Malony RF. 2007. Developing the science of reintroduction biology. Conservation Biology 21: 303-312.

Seddon PJ, Griffiths CJ, Soorae PS \& Armstrong DP. 2014. Reversing defaunation: Restoring species in a changing world. Science 345: 406-412.

Seddon PJ, Roughton CM, Reardon J \& MacKenzie DI. 2011. Dynamics of an endangered New Zealand skink: accounting for incomplete detectability in estimating patch occupancy. New Zealand Journal of Ecology 35: 247-253.

Şekercioğlu Ç, Daily GC \& Ehrlich PR. 2004. Ecosystem consequences of bird declines. Proceedings of the National Academy of Sciences USA 101: 18042-18047.

Şekercioğlu ÇH. 2006. Increasing awareness of avian ecological function. Trends in Ecology and Evolution 21: 464-471.

Shaffer SA, Tremblay Y, Weimerskirch H, Scott D, Thompson DR, Sagar PM, Moller H, et al. 2006. Migratory shearwaters integrate oceanic resources across the Pacific Ocean in an endless summer. Proceedings of the National Academy of Sciences USA 103: 12799-12802.

Smith IWG \& AJ Anderson. 2009. An archaeological sequence for Codfish Island (Whenua Hou), Southland, New Zealand. New Zealand Journal of Archaeology 30: 5-21.

Smith LT. 2013. Decolonizing methodologies: Research and Indigenous Peoples. Second edition. Zed Books Ltd., London, UK.

Soulé ME. 1985. What is conservation biology. BioScience 35: 727-734.

Souter NJ, Bull CM \& Hutchinson MN. 2004. Adding burrows to enhance a population of the endangered pygmy blue tongue lizard, Tiliqua adelaidensis. Biological Conservation 116: 403-408.

Spatz DA, Holmes ND, Reguero BG, Butchart SHM, Tershy BR \& Croll DA. 2017. Managing invasive mammals to conserve globally threatened seabirds in a changing climate. Conservation Letters 10: 736-747. 
Spatz DR, Newton KM, Heinz R, Tershy B, Holmes ND, Butchart SHM \& Croll DA. 2014. The biogeography of globally threatened seabirds and island conservation opportunities. Conservation Biology 28: 1282-1290.

Spiegelhalter D, Thomas A, Best N \& Lunn D. 2014. OpenBUGS User Manual, Version 323. Cambridge, UK.

Spitz DB, Hebblewhite M, Stephenson TR. 2017. 'MigrateR': extending model driven methods for classifying and quantifying animal movement behaviour. Ecography 40 : 788-799.

Sullivan BJ, Brickle P, Reid TA, Bone DG \& Middleton DAJ. 2006. Mitigation of seabird mortality on factory trawlers: trials of three devices to reduce warp cable strikes. Polar Biology 29: 745-753.

Sullivan BJ, Kibel B, Kibel P, Yates O, Potts JM, Ingham B, Domingo A, et al. 2018. At-sea trialling of the Hookpod: a 'one-stop' mitigation solution for seabird bycatch in pelagic longline fisheries. Animal Conservation 21: 159-167.

Sutherland DR \& Dann P. 2012. Improving the accuracy of population size estimates for burrow-nesting seabirds. Ibis 154: 488-498.

Taconet M, Kroodsma D \& Fernandes JA. 2019. Global atlas of AIS-based fishing activity challenges and opportunities. Food and Agriculture Organization of the United Nations, Rome, Italy.

Tamini LL, Chavez LN, Gongora ME, Yates O, Rabuffetti FL \& Sullivan B. 2015. Estimating mortality of black-browed albatross (Thalassarche melanopris, Temmink, 1828) and other seabirds in the Argentinian factory trawl fleet and the use of bird-scaring lines as a mitigation measure. Polar Biology 38: 1867-1879.

Taylor G \& Cole R. 2002. South Georgian Diving Petrel (Pelecanoides georgicus) survey, Codfish Island/Whenua Hou. Department of Conservation, Wellington, New Zealand.

Taylor G. 1991. Report on a visit to Codfish Island 1-7 November 1991. Department of Conservation, Wellington, New Zealand.

Taylor GA, Elliott GP, Walker KJ \& Bose S. 2020. Year-round distribution, breeding cycle, and activity of white-headed petrels (Pterodroma lessonii) nesting on Adams Island, Auckland Islands. Notornis 67: 369-386.

Taylor GA. 2000a. Action Plan for Seabird Conservation in New Zealand. Part A: Threatened Seabirds. Department of Conservation, Wellington, New Zealand. 
Taylor GA. 2000b. Action Plan for Seabird Conservation in New Zealand. Part B: Nonthreatened Seabirds. Department of Conservation, Wellington, New Zealand.

Te Tiriti o Waitangi. 1840. Treaty of Waitangi. Māori version.

Tennyson AJD. 2020. Holocene bird bones found at the subantarctic Auckland Islands. Notornis 67: 269-294.

Tershy BR, Shen KW, Newton KM, Holmes ND \& Croll DA. 2015. The importance of islands for the protection of biological and linguistic diversity. BioScience 65: 592-597.

Tizard J, Patel S, Waugh, J, Tavares E, Bergman T, Gill B, Norman J, et al. 2019. DNA barcoding a unique avifauna: an important tool for evolution, systematics and conservation. BMC Evolutionary Biology 19: 52.

Tobias JA, Butchart SHM \& Collar NJ. 2006. Lost and found: a gap analysis for the neotropical avifauna. Neotropical Birding 1: 4-22.

Towns DR, Wardle DA, Mulder CPH, Yeates GW, Fitzgerald BM, Parrish GR, Bellingham PJ, et al. 2009. Predation of seabirds by invasive rats: multiple indirect consequences for invertebrate communities. Oikos 118: 420-430.

Towns DR. 2018. Understanding seabird responses to invasive mammal eradications from islands needs systematic monitoring. Animal Conservation 21: 15-16.

Trainor S. 2008. Codfish Island South Georgian Diving Petrel: a summary of field observations 2004-2007 and recommendations for future management. Department of Conservation, Invercargill, New Zealand.

Trainor S. 2009. South Georgian Diving Petrel: a summary of field observations 20072009 on Codfish Island. Department of Conservation, Invercargill, New Zealand.

Tréguer P \& Jacques G. 1993. Dynamics of nutrients and phytoplankton, and fluxes of carbon, nitrogen and silicon in the Antarctic Ocean. In: Hempel G (ed.). Weddell Sea Ecology: Results of EPOS European Polarstern Study. Springer, Berlin Heidelberg, Germany.

Trewick SA \& Gibb GC. 2010. Vicars, tramps and assembly of the New Zealand avifauna: a review of molecular phylogenetic evidence. Ibis 152: 256-253.

Tylianakis JM, Laliberté E, Nielsen A \& Bascompte J. 2010. Conservation of species interaction networks. Biological Conservation 143: 2270-2279.

Valiente-Banuet A, Aizen AM, Alcántara JM, Arroyo J, Cocucci A, Galetti M, García MB, et al. 2015. Beyond species loss: the extinction of ecological interactions in a changing world. Functional Ecology 29: 299-307. 
Vousdoukas MI, Ranasinghe R, Mentaschi L, Plomaritis TA, Athanasiou P, Luijendijk A \& Feyen L. 2020. Sandy coastlines under threat of erosion. Nature Climate Change 10: 260-263.

Walls G. 1978. The influence of the tuatara on Fairy Prion breeding on Stephens Island, Cook Strait. New Zealand Journal of Ecology 1: 91-98.

Wardle DA, Bellingham BJ, Boot KI \& Mulder CPH. 2009. Indirect effects of invasive predators on plant litter quality, decomposition and nutrient resorption on seabirddominated islands. Ecology 90: 452-464.

Warham J. 1977. Wing loadings, wing shapes, and flight capabilities of procellariiformes. New Zealand Journal of Zoology 4: 73-83.

Warham J. 1996. The behaviour, population biology and physiology of the petrels. Academic Press, London, UK.

Watkins BP, Peterson SL \& Ryan PG. 2008. Interactions between seabirds and deep-water hake trawl gear: an assessment of impacts in South African waters. Animal Conservation 11: 247-254.

Watson JEM, Shanahan DF, Di Marco M, Allan MD, Laurance WF, Sanderson EW, Mackey B, et al. 2016. Catastrophic declines in wilderness areas undermine global environment targets. Current Biology 26: 2929-2934.

Waugh SM, Poupart TA, Miskelley CM, Stahl JC \& Arnould JPY. 2017. Human exploitation assisting a threatened species? The case of muttonbirders and Buller's albatross. PLoS ONE 12: e0175458.

Weimerskirch H. 2018. Linking demographic processes and foraging ecology in wandering albatross-Conservation implications. Journal of Animal Ecology 87: 945955.

West J \& Imber MJ. 1989. Surveys of South Georgian Diving Petrels (Pelecanoides georgicus) on Codfish Island. Notornis 36: 157-158.

Wickes C \& Rance B. 2010. Sealers Beach Vegetation Survey. Department of Conservation, Invercargill, New Zealand.

Wickham H. 2009. ggplot2: Elegant Graphics for Data Analysis. Springer, New York, USA. Wikelski M \& Kays R. 2020. Movebank: archive, analysis and sharing of animal movement data. Available at: https://www.movebank.org/cms/movebank-main. Accessed on 10 April 2020. 
Wilcox C, van Sebille E \& Hardesty BD. 2015. Threat of plastic pollution to seabirds is global, pervasive, and increasing. Proceedings of the National Academy of Sciences USA 112: 11899-11904.

Williams BK. 2011. Passive and active adaptive management: Approaches and an example. Journal of Environmental Management 92: 1371-1378.

Willis KJ, Araujo MB, Bennett KD, Figueroa-Rangel B, Froyd CA \& Myers N. 2007. How can a knowledge of the past help to conserve the future? Biodiversity conservation and the relevance of long-term ecological studies. Philosophical Transactions of the Royal Society B: Biological Sciences 362: 175-187.

Wold JR, Robertson CJR, Chambers GK \& Ritchie PA. 2018. Phylogeographic structure and a genetic assignment method for Buller's albatross ssp. (Thalassarche bulleri ssp.). Notornis 65: 152-163.

Wood JR \& Briden S. 2008. South Georgian Diving Petrel (Pelecanoides georgicus) bones from a Maori midden in Otago Peninsula, New Zealand. Notornis 55: 46-47.

Wood JR, Scofield RP, Hamel J, Lalas C \& Wilmshurst JM. 2017. Bone stable isotopes indicate a high trophic position for New Zealand's extinct South Island adzebill (Aptornis defossor) (Gruiformes: Aptornithidae). New Zealand Journal of Ecology 41: 240-244.

Wood JR. 2016. Spatial distribution of late Holocene bird bones in the Mason Bay dune system, Stewart Island, New Zealand. Journal of the Royal Society of New Zealand 46: 103-116.

Worthy, TH. 1998. Fossils indicate Pelecanoides georgicus had large colonies at Mason Bay, Stewart Island, New Zealand. Notornis 45: 229-246.

Wu L, Xu Y, Wang Q, Wang F \& Xu Z. 2017. Mapping global shipping density from AIS data. Journal of Navigation 70: 67-81.

Wynn J, Padget O, Mouritsen H, Perrins C \& Guilfort T. 2020. Natal imprinting to the earth's magnetic field in a pelagic seabird. Current Biology 30: 2869-2873.

Young IR. 1999. Seasonal variability of the global ocean wind and wave climate. International Journal of Climatology 19: 931-950.

Young LC, Vanderwerf EA, Lohr MT, Miller CJ, Titmus AJ, Peters D \& Wilson L. 2013. Multispecies predator eradication within a predator-proof fence at Ka'ena Point, Hawai'i. Biological Invasions 15: 2627-2638. 
Zhang J, Rayner M, Vickers S, Landers T, Sager R, Stewart J \& Dunphy B. 2019. GPS telemetry for small seabirds: using hidden Markov models to infer foraging behaviour of Common Diving Petrels (Pelecanoides urinatrix urinatrix). Emu 119: 126-137.

Zhou X, Chen D, Kress SW \& Chen S. 2017. A review of the use of active seabird restoration techniques. Biodiversity Science 25: 364-371.

Žydelis R, Small C \& French G. 2013. The incidental catch of seabirds in gillnet fisheries: a global review. Biological Conservation 162: 76-88. 
References 


\section{Appendices}

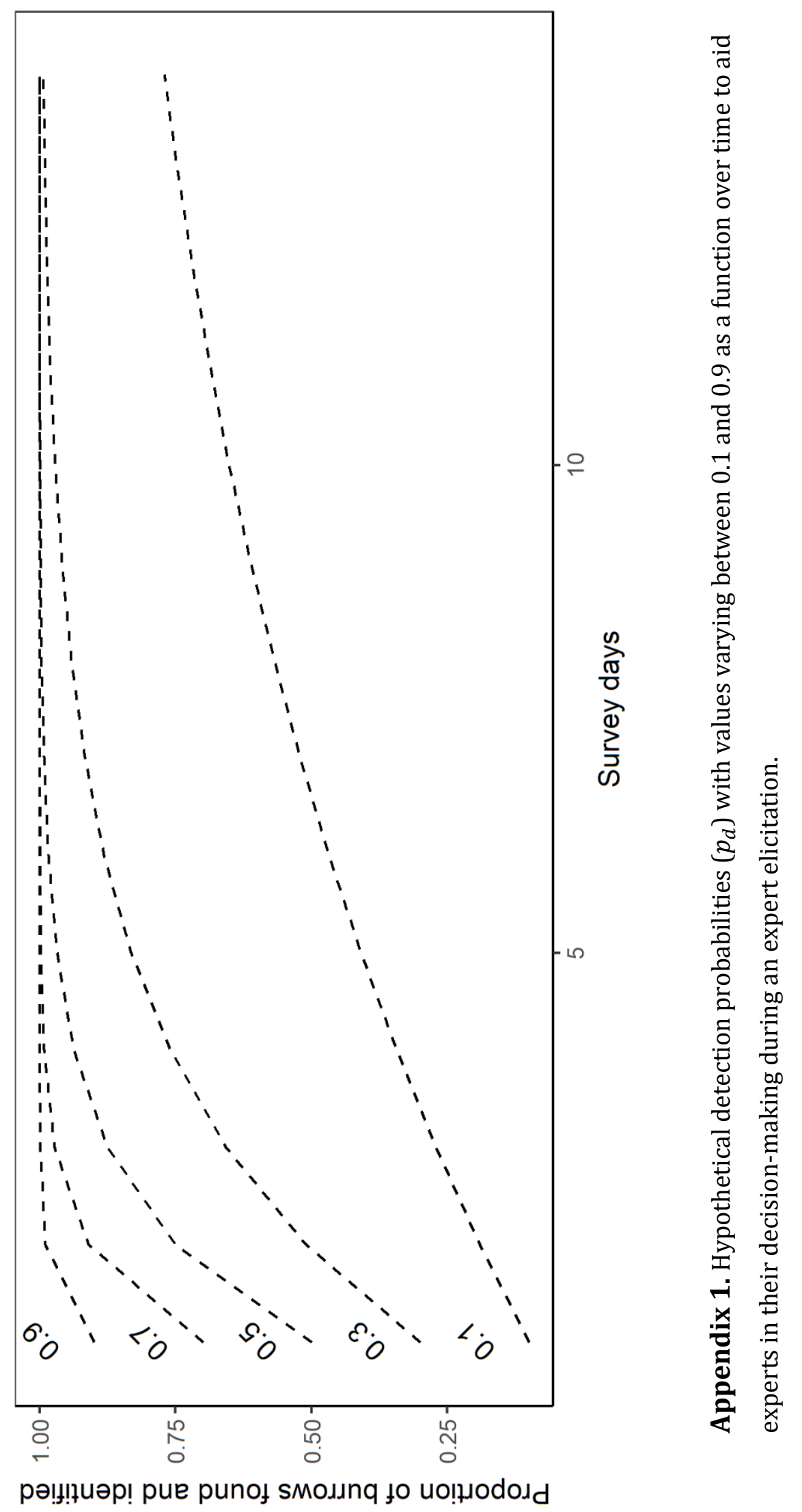




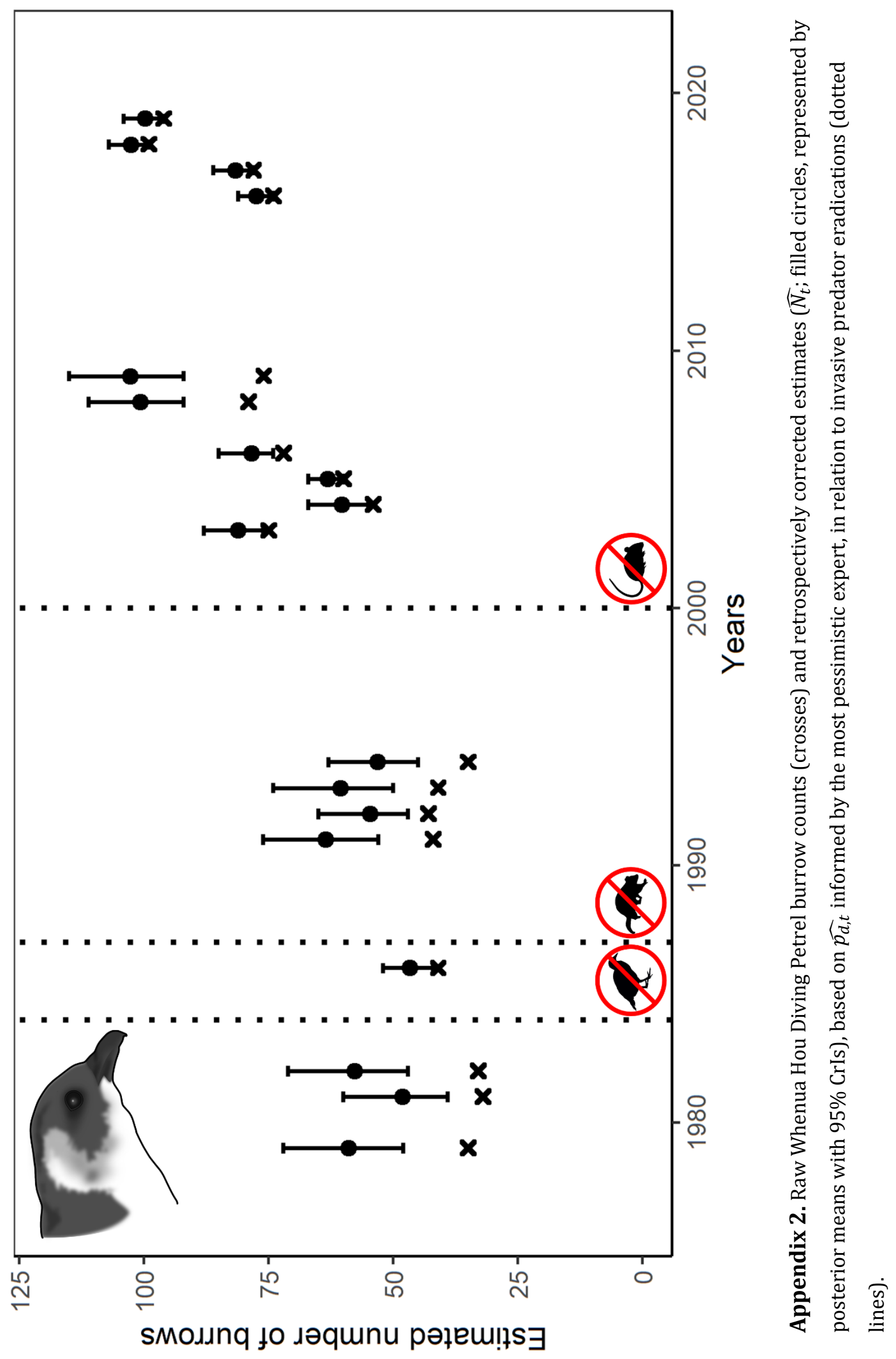




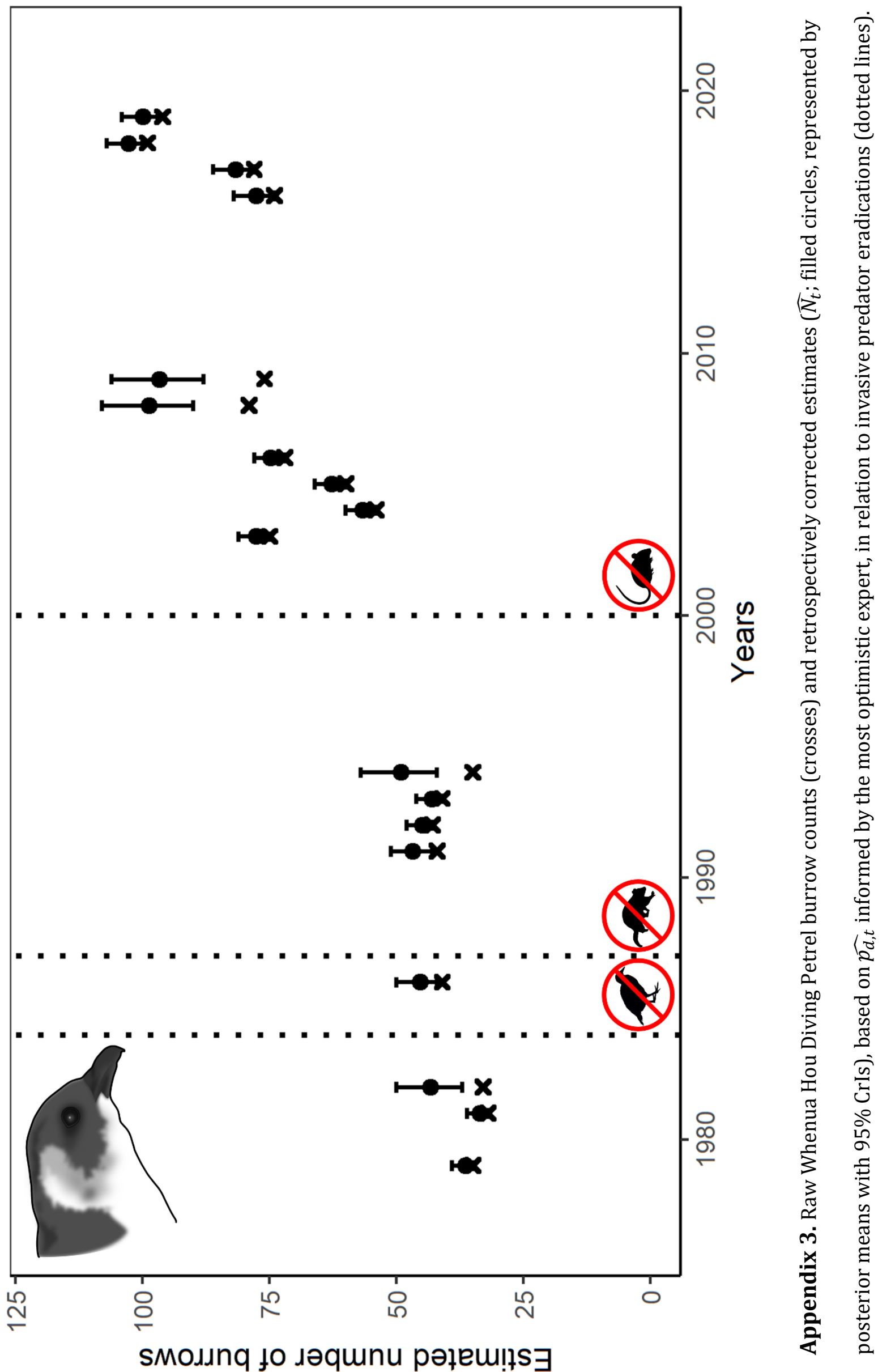


Appendices

\section{Appendix 4}

Equations of movement models used in the net squared displacement (NSD) modelling in the R package MigrateR (1.1.0; Bunnefeld et al. 2011, Spitz et al. 2017, DB Spitz, B Cristescu, CC Wilmers, RE Wheat, T Levi \& HU Wittmer unpublished), which allowed me to objectively identify presence and quantify timing in migratory movements in Whenua Hou Diving Petrels:

Residency model:

1. $N S D=\gamma \times[1-\exp (K \times t)]$,

in which $\gamma$ is the mean NSD of all locations, $K$ is the logarithm of the rate constant, and $t$ is the time from start.

Nomadic model:

2. $N S D=\beta \times t$,

in which $\beta$ is a linear constant.

Dispersal model:

3. $N S D=\frac{\delta}{1+\exp \left(\frac{\theta_{1}-t}{\varphi_{1}}\right)}$,

in which $\delta$ is the distance between the two seasonal distributions, $\theta_{1}$ is the midpoint of the outbound migration, and $\varphi_{1}$ is the time required to complete $50-75 \%$ of the outbound migration.

Migration model:

4. $\quad N S D=\frac{\delta}{1+\exp \left(\frac{\theta_{1}-t}{\varphi_{1}}\right)}+\frac{-\delta}{1+\exp \left(\frac{\theta_{2}-t}{\varphi_{2}}\right)}$ 
in which $\theta_{2}$ is the midpoint of the homebound migration and $\varphi_{2}$ is the time required to complete $50-75 \%$ of the homebound migration.

Mixed-migration model:

5. $\quad N S D=\frac{\delta}{1+\exp \left(\frac{\theta_{1}-t}{\varphi_{1}}\right)}+\frac{-\delta \times \zeta}{1+\exp \left(\frac{\theta_{2}-t}{\varphi_{2}}\right)^{\prime}}$

in which $\zeta$ is a factor allowing an individual to return to a breeding distribution different than the original one.

Multi-range migration model:

6. $\quad N S D=\sum_{i=1}^{n} \frac{\delta_{i}}{1+\exp \left(\frac{\theta_{i^{-t}}}{\varphi_{i}}\right)^{\prime}}$

in which $n$ is the number of range transitions, $\delta_{i}$ is the distance between $i$ seasonal distributions, $\theta_{i}$ is the midpoint of migration $i$, and $\varphi_{i}$ is the time required to complete $50-75 \%$ of migration $i$. The number of range transitions for each individual was determined based on the number of peaks in the moving mean (window width $=3$ days) of $|\triangle \mathrm{NSD}|$ that exceeded the global mean by more than one standard deviation (DB Spitz, B Cristescu, CC Wilmers, RE Wheat, T Levi \& HU Wittmer unpublished). To delineate phenophases, I defined the onset of migratory movements when an individual was predicted to exceed $5 \%$ of the total distance travelled $\left(\delta_{\mathrm{i}}\right)$ and the conclusion of migratory movements when an individual was predicted to exceed $95 \%$ of the total distance $\left(\delta_{\mathrm{i}}\right)$. 


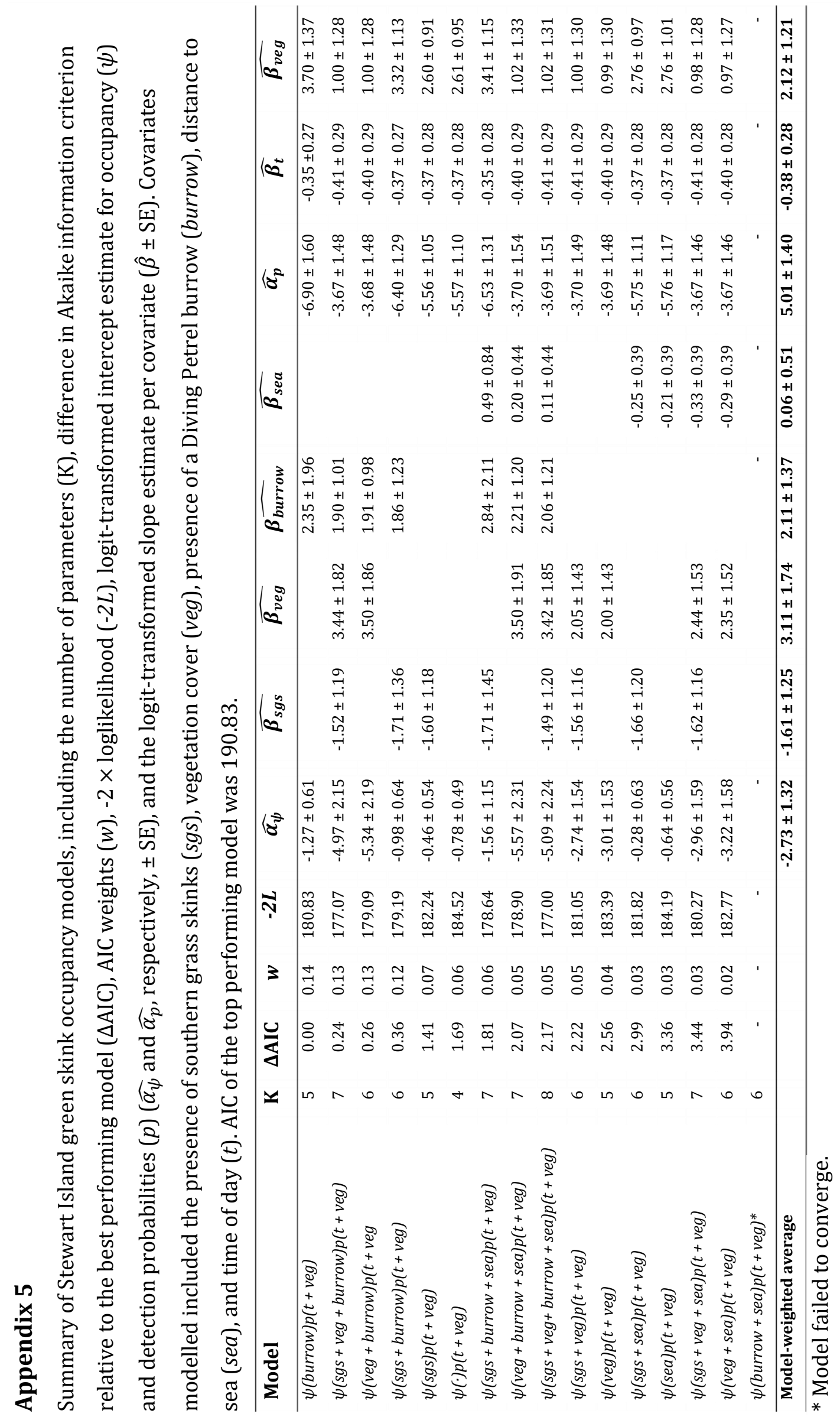




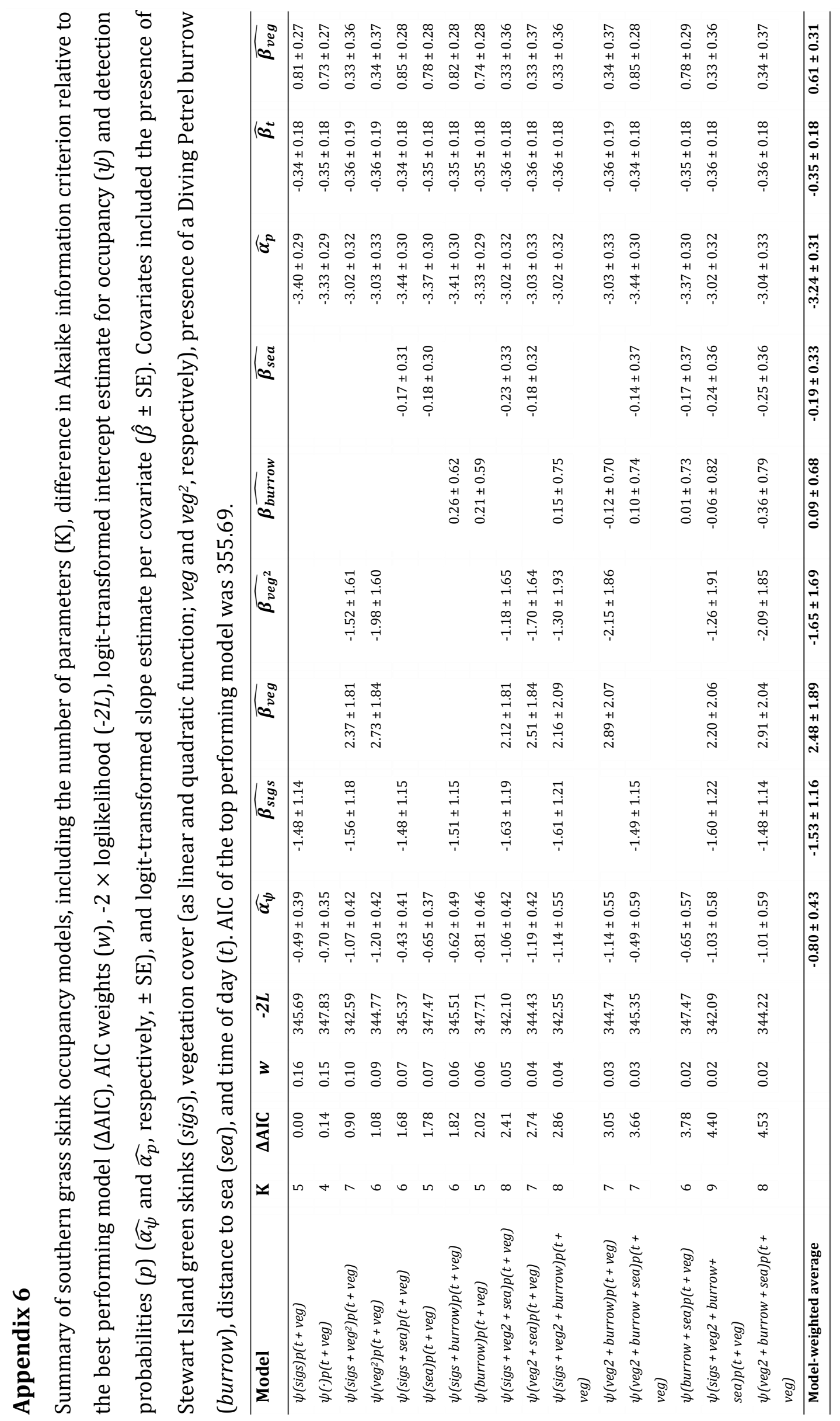


Appendices 


\section{Supplementary material}

\section{Supplementary material 1}

OpenBUGS code used to estimate the yearly rate of Whenua Hou Diving Petrel population growth in Ch. 2.

Model \{

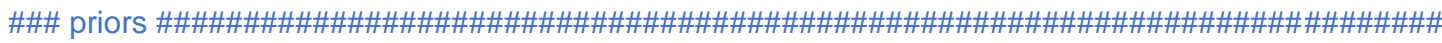
alpha $\sim \operatorname{dnorm}(0,0.01) \quad$ \# log of intercept (expected $n$ burrows in 1978)

$r \sim \operatorname{dnorm}(0,0.01)$

sd $\sim \operatorname{dunif}(0,20)$

\# log of lambda

tau <- pow $($ sd,-2)

\# residual standard deviation in $\mathrm{N}$ among years

\# convert standard deviation to precision (i.e. 1/var)

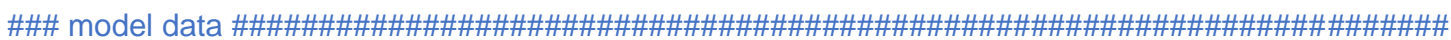
for (i in $1:$ :nears) \{

\# for each year

$\log (\mathrm{N} . \mathrm{mu}[\mathrm{i}])<-$ alpha $+\mathrm{r}^{*}(\operatorname{year}[\mathrm{i}]-1978) \quad$ \# calculate expected $\mathrm{N}$ based on log-linear model $\mathrm{N}[\mathrm{i}] \sim \operatorname{dpois}(\mathrm{N} . \mathrm{mu}[\mathrm{i}])$ \# model residual var in $\mathrm{N}$ P.year[i] <- Pa[phenology[i]]*(1-pow(1-Pd.ave[marked[i]],d[i])) \# calculate detection prob. \} $\mathrm{n}[\mathrm{i}] \sim \mathrm{dbin}(\mathrm{P} . \operatorname{year}[\mathrm{i}], \mathrm{N}[\mathrm{i}]) \quad$ \# model $\mathrm{n}$ burrows based on detection prob.

\#\#\# obtain Beta.PERT distribution for daily detection prob based on expert elicitation \#\#\#\#\#\#\#\#\#\#\#\#\# for (i in 1:2) \{ \# for marked and unmarked burrows
\#\#\# average elicited values across exp
Pd.ave.mode[i] <- mean(Pd.mode[i,])
Pd.ave.min[i] <- mean(Pd.min[i,])

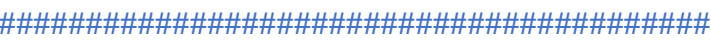
Pd.ave.min[i] <- mean(Pd.min[i,]) \# best guess of daily detection probability
\# minimum daily detection probability
\# maximum daily detection probability

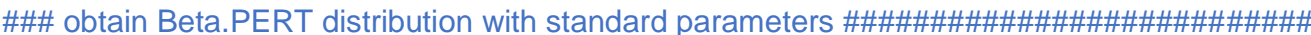 mu.Pd.ave[i] <- $\left(P d\right.$.ave.min[i]+Pd.ave $\max [i]+4^{*} P d$.ave.mode[i])/6
v.Pd.ave[i] <- (mu.Pd.ave[i]-Pd.ave.min[i])*(2*Pd.ave.mode[i]-Pd.ave.min[i]-
Pd.ave.max[i])/((Pd.ave.mode[i]-mu.Pd.ave[i])*(Pd.ave.max[i]-Pd.ave.min[i]))
w.Pd.ave[i] <- v.Pd.ave[i]*(Pd.ave.max[i]-mu.Pd.ave[i])/(mu.Pd.ave[i]-Pd.ave.min[i])
p.Pd.ave[i] dbeta(v.Pd.ave[i],w.Pd.ave[i])
Pd.ave[i] <- Pd.ave.min[i]+p.Pd.ave[i](Pd.ave.max[i]-Pd.ave.min[i])

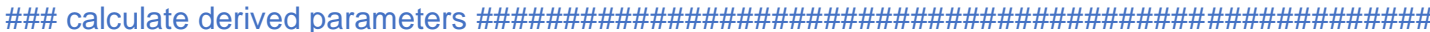
\# expected no. of burrows in 1978
\# lambda

\}

$\log (\mathrm{N} .0)<-$ alpha

$\log ($ lambda $)<-r$

\} \# model end 


\section{Supplementary material 2}

OpenBUGS code of the Whenua Hou Diving Petrel integrated population model in Ch. 4 (including 10 years of harvest of fledglings and accounting for the return-to-source probability).

\section{Model \{}

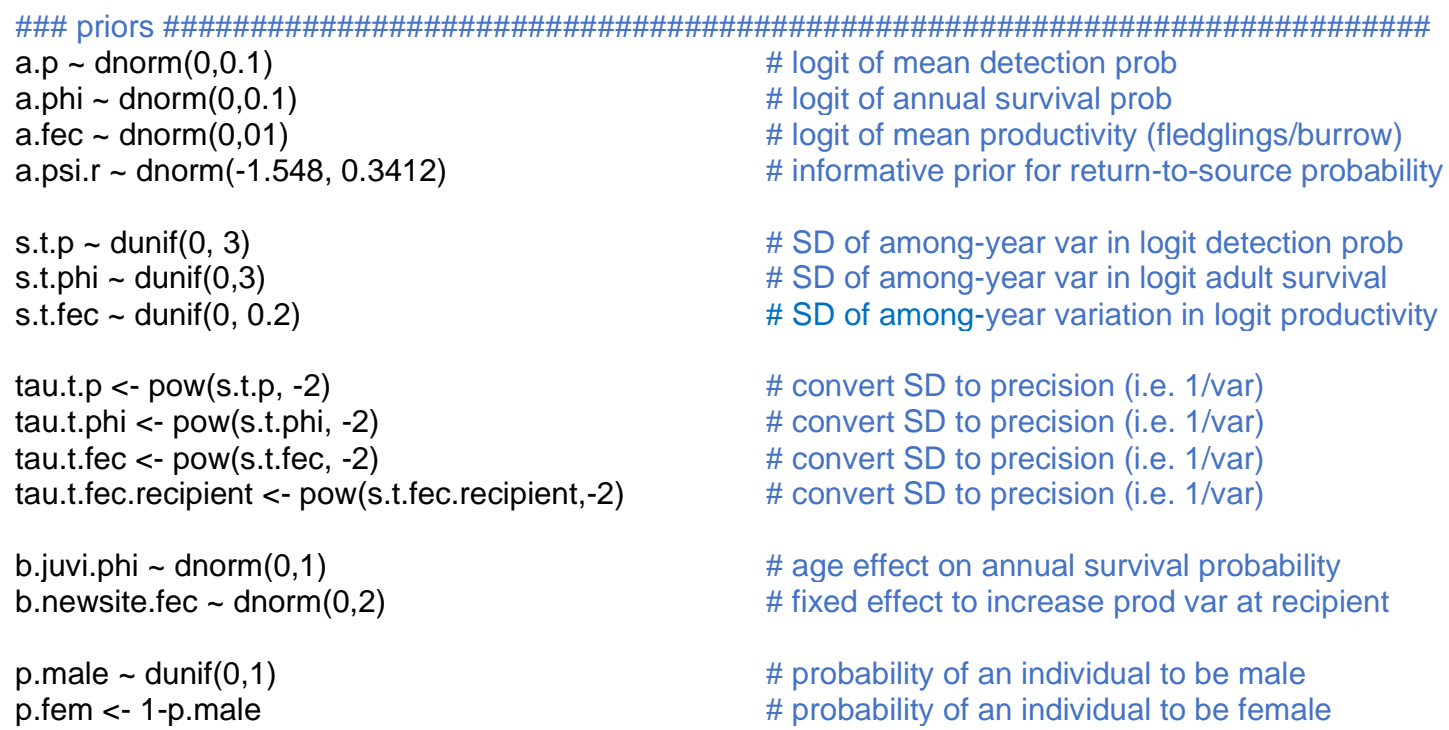

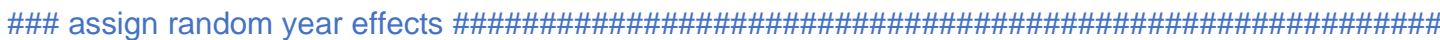
for ( $j$ in $1: n . y e a r+n . y e a r . t r a n s+n . y e a r . p r o j+2)\{$

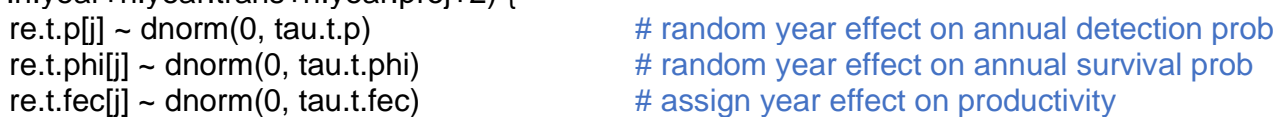

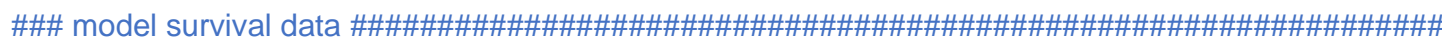
for (i in $1:$ :n.ind) \{ sex[i] $\sim$ dbern (p.male) \# for each marked individual \# model sex ratio

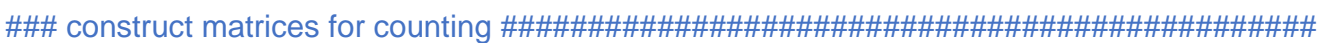
\# assign "alive" = 0 before first detection in matrices for ( $\mathrm{j}$ in 1 :first[i]-1) \{

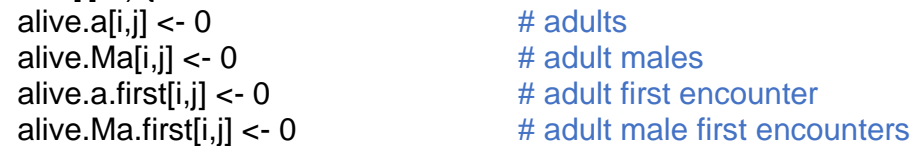




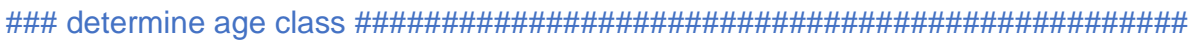
juvi[i,j] <- age[i] ${ }^{*}$ step(first $\left.[i]-j+1\right) \quad$ \# whether a juvenile remains a juvenile at time $j$

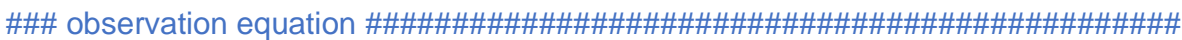
$y[i, j] \sim$ dbern(psight[i,j]) \# whether individual recorded or not psight[i, j] <- $p[i, j]^{*}$ alive $[i, j] \quad$ \# depends on $p$ and whether the individual is alive logit(p.hyp[l,j]) <- a.p+re.t.p[j] \# hypothetical detection equation

$p[I, j]<-$ p.hyp $[l, j]^{\star}$ survey[j] $]^{\star}(1-j u v i[l, j])$ \# fix detection at 0 for non-survey years and juveniles out at sea

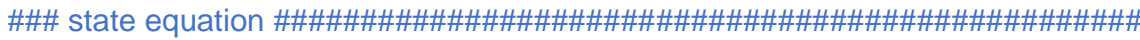
alive[i, j] dbern(palive[i, j]) \# whether individual is alive palive $[i, j]<-$ phi $[i, j]^{*}$ alive $[i, j-1] \quad$ \# depends on survival prob and if alive last year logit(phi[i,j]) <- a.phi+b.juvi.phijuvi[i,j-1]+re.t.phi[j] \# survival equation

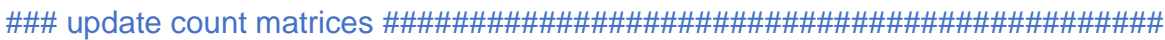
alive.a[i,j] <- alive $[i, j]]^{*}(1-j u v i[i, j])$ alive.Ma[i,j] <- alive.a[i,j] ${ }^{*} \operatorname{sex}[i]$ alive.a.first[i,j] $<-0$ \# adult first encounter \} alive.Ma.first $[i, j]<-0$

\# adult male first encounters \}

\#\#\# model productivity data (whether or not a burrow produces a fledgling) \#\#\#\#\#\#\#\#\#\#\#\#\#\#\#\#\#\#\#\# for (i in 1 :n.burrow) \{ fec[i] dbern(p.fec[i]) \} logit(p.fec[i]) <- a.fec+re.t.fec[year.fec[i]] \# productivity equation

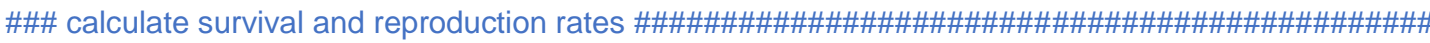
for ( $\mathrm{j}$ in $1: n \cdot$ year+n.year.trans+n.year.proj+2) \{

logit(phi.a.year[j]) <- a.phi+re.t.phi[j] logit(phi.j.year[j]) <- a.phi+b.juvi.phi+re.t.phi[j] logit(f[j]) <- a.fec+re.t.fec[j] \} logit(f.recipient[j]) <-a.fec+b.newsite.fec+re.t.fec[j]
\# adult survival

\# juvenile survival

\# productivity at source pop

\# productivity at recipient pop

\#\#\# calculate detection and abundances of banded adults \#\#\#\#\#\#\#\#\#\#\#\#\#\#\#\#\#\#\#\#\#\#\#\#\#\#\#\#\# for (j in $1:$ n.year) \{

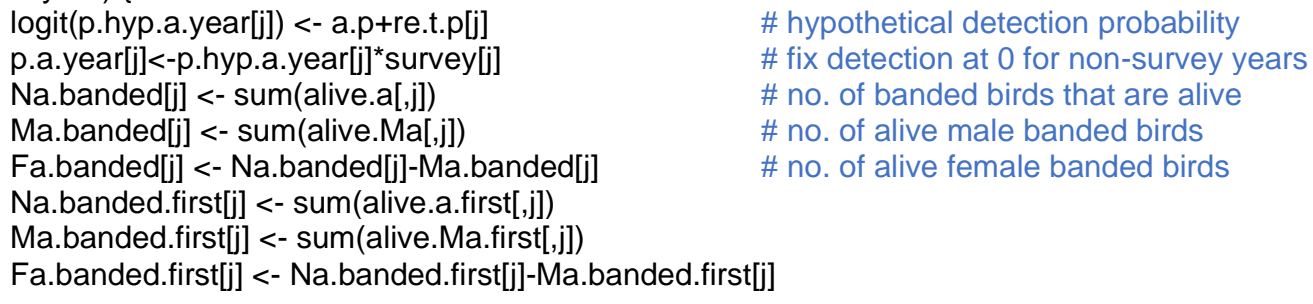

\# hypothetical detection probability \# fix detection at 0 for non-survey years \# no. of banded birds that are alive \# no. of alive male banded birds \# no. of alive female banded birds

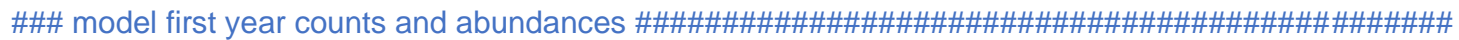

Na.unk.c[1] dunif $(0,200)$

Na.unk[1] <- round(Na.unk.c[1])

$\mathrm{U}[1]<-$ Na.unk[1]+u[1]

$\mathrm{u}[1] \sim \mathrm{dbin}($ p.a.year[1], $\mathrm{U}[1])$

Ma.unk[1] dbin(p.male,Na.unk[1])

Fa.unk[1] <- Na.unk[1]-Ma.unk[1]

N.M[1] <- Ma.banded[1]+Ma.unk[1]

N.F[1] <- Fa.banded[1]+Fa.unk[1]

$\mathrm{N}[1]<-\mathrm{N} . \mathrm{M}[1]+\mathrm{N} . \mathrm{F}[1]$
\# prior for all undetected adults

\# no. adults present first year

\# sample count of adults detected first year

\# sample no. of undetected adult males \# sample no. of undetected adult females \# add banded and undetected males \# add banded and undetected females \# add males and females 
JO[1] $\sim \operatorname{dbin}(f[1]$, N.F[1])
J1.c[1] $\sim \operatorname{dunif}(0,60)$
J1[1] <- round(J1.c[1])

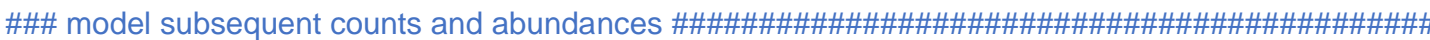
for (j in 2:n.year) \{
\# no. of juveniles from fledglings produced \# prior for no.s of one-year-old juveniles $\begin{array}{ll}\text { J0[j] } \sim \text { dbin(f[j], N.F[j]) } & \text { \# no. juveniles from fledglings produced } \\ \text { J1[j] } \sim \text { dbin(phi.j.year[j-1], J0[j-1]) } & \text { \# no. one-year-old juveniles from last year's } \\ \text { J2[j] } ~ d \text { dbin(phi.j.year[j-1], J1[j-1]) } & \text { \# no. second-year juveniles from last year's }\end{array}$

Na.surv[j] dbin(phi.a.year[j-1],Na.unk[j-1]) \# no. survivors from last year's undetected adults

$\mathrm{U}[\mathrm{j}]<-$ Na.surv[j]+J2[j]

$\mathrm{u}[\mathrm{j}] \sim \mathrm{dbin}($ p.a.year[j],U[j])

Na.unk[j] <- $\max (1, \mathrm{U}[\mathrm{j}]-\mathrm{u}[\mathrm{j}])$

Ma.unk[j] dbin(p.male,Na.unk[j])

Fa.unk[j] <- Na.unk[j]-Ma.unk[j]

N.M[j] <- Ma.banded[j]+Ma.unk[j]

N.F[j] <- Fa.banded[j]+Fa.unk[j]

$N[j]<-N . M[j]+N . F[j]$
\# all unbanded adults available for detection

\# sample count of adults detected

\# no. unknown undetected adults + constraint

\# sample no. undetected adult males \# sample no. undetected adult females

\# add banded and undetected males

\# add banded and undetected females

\# add males and females

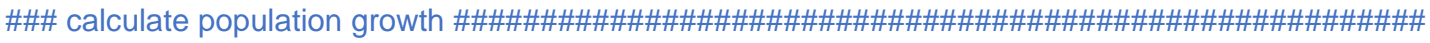
logit(phi.a.year.ave) <- a.phi \# average adult survival

logit(phi.j.year.ave) <- a.phi+b.juvi.phi

\# average juvenile survival

logit(f.ave) <- a.fec

\# average productivity

f1.ave $<-0$

\# set productivity of juveniles at 0

f2.ave $<-$ f.ave* p.fem*phi.j.year.ave

\# sum av. productivity, fem prob., and av. juv surv

s1.ave <- phi.j.year.ave

s2.ave <- phi.a.year.ave

lambda.ave <- $(\mathrm{f} 1$.ave + s2.ave + sqrt (pow $(\mathrm{f} 1$.ave-s2.ave,2) + 4*f2.ave*s1.ave $)) / 2 \#$ population growth equation

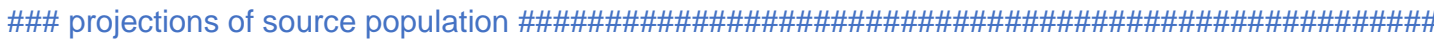
for (j in n.year+1:n.year+n.year.trans+n.year.proj $)\{$
$\mathrm{J} 1[\mathrm{j}] \sim \mathrm{dbin}($ phi.j.year[j-1],J0[j-1])
J2[j] dbin(phi.j.year[j-1],J1[j-1])
\# 1-year old juveniles at source population
N.F.surv[j] dbin(phi.a.year[j-1],N.F[j-1])
\# 2-year juveniles at source population
N.M.surv[j] dbin(phi.a.year[j-1],N.M[j-1])
\# survivors from last year's adult fem at source
\# survivors from last year's adult males at source
J2.F[j] dbin(p.fem, J2[j])
\# female 2-year juveniles at source
J2.M[j] <- J2[j]-J2.F[j]
\# male 2-year juveniles at source
N.F[j] <- N.F.surv[j]+J2.F[j]+J2.Ft.return[j] \# ad $f=$ surv + recruits from source and transloc
N.M[j] <- N.M.surv[j]+J2.M[j]+J2.Mt.return[j] \# ad $m$ = surv + recruits from source and transloc $N[j]<-N . F[j]+N . M[j]$
\# add males and females

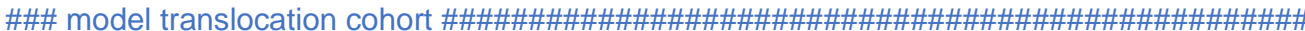 J0.preharv[j] dbin(f[j], N.F[j]) \# sample juvs from fledglings pre-harvest trans[j] <- round(psi.h[j] $]^{*}$ J0.preharv[j]) \# remove harvested portion JO[i] <- J0.preharv[i]-trans[j] \# no. juveniles left at source \}

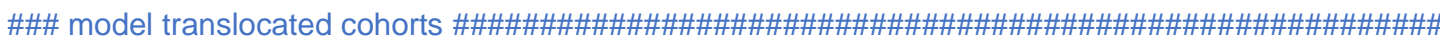
J1.t[19] <- $0 \quad$ \# 1-year juvs from transloc birds (fix to 0 for this year, as no transloc) for ( $\mathrm{j}$ in 20:n.year+n.year.trans+1) \{
J1.t[j] dbin(phi.j.year[j-1],trans[j-1])
\# 1-year old juvs from transloc birds

\}

for ( $\mathrm{j}$ in 30:38)

J1.t[j] $<-0$

\# 1-year juvs from transloc birds (fix to 0 for these years, as no transloc)

\} 
for $(j$ in $1: 20)\{$

J2.t[j] $<-0$

J2.Ft[j] $<-0$

J2.Mt[j] <- 0

J2. Ft.return[j] $<-0$

J2. Mt.return[j] $<-0$

J2.Ft.recruit[j] <- 0

\}

J2.Mt.recruit[i] <- 0

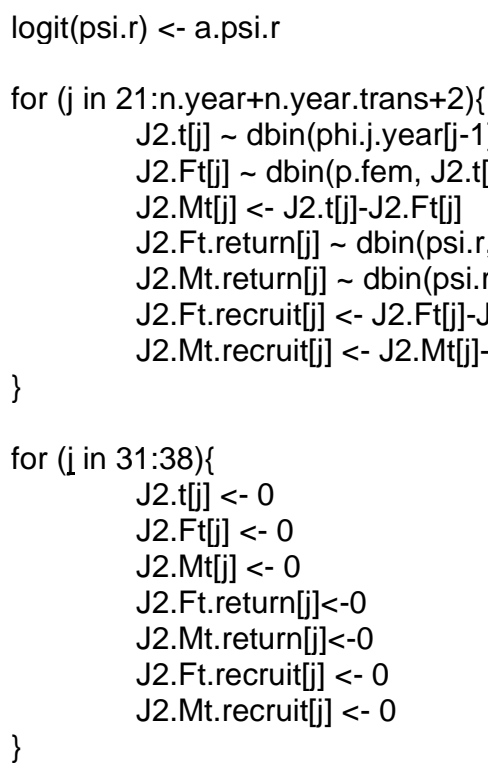

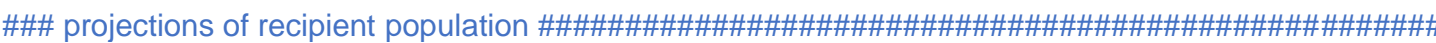
N.FT.surv[21] $<-0$

\# ad $\mathrm{f}$ at recipient (fix to 0 for this year)

N.MT.surv[21] $<-0$

\# ad $\mathrm{f}$ at recipient (fix to 0 for this year)

for (j in 22:n.year+n.year.trans+n.year.proj) \{

N.FT.surv[j] dbin(phi.a.year[j-1],N.FT[j-1]) \# surviving ad f from last year at recipient

N.MT.surv[j] dbin(phi.a.year[j-1],N.MT[j-1]) \# surviving ad m from last year at recipient \}

for (j in 21:n.year+n.year.trans+n.year.proj) \{

N.FT[j] <- N.FT.surv[j]+J2.Ft.recruit[j]+J2.FT[j]

N.MT[j] <- N.MT.surv[j]+J2.Mt.recruit[j]+J2.MT[j]

N.T[j] <- N.FT[j]+N.MT[j]

\# add ad $\mathrm{m}$ and ad $\mathrm{f}$

$\#$ ad $\mathrm{f}=$ surv + recruits from recipient + transloc cohort

$\#$ adult $\mathrm{m}=$ surv + recruits from recipient + translocation cohort

\}

for (j in $21: n . y e a r+n . y e a r . t r a n s+n . y e a r . p r o j)\{$ \}

J0.T[j] dbin(f.recipient[j], N.FT[j])

for (j in 22:n.year+n.year.trans+n.year.proj)\{ \} J1.T[j] dbin(phi.j.year[j-1], J0.T[j-1])

J2.FT[21] $<-0$

J2.FT[22] $<-0$

J2.MT[21] $<-0$

J2.MT[22] $<-0$

for ( $\mathrm{j}$ in 23:n.year+n.year.trans+n.year.proj) \{

J2.T[j] dbin(phi.j.year[j-1], J1.T[j-1])

J2.FT[j] dbin(p.fem, J2.T[j])

J2.MT[j] <- J2.T[j]-J2.FT[j]

\}
\# sample juveniles at recipient

\# 1st year juveniles at recipient

\# 2nd-year $\mathrm{f}$ at recipient (fix to 0 for this year)

\# 2nd-year $f$ at recipient (fix to 0 for this year)

\# 2nd-year $m$ at recipient (fix to 0 for this year)

\# 2nd-year $m$ at recipient (fix to 0 for this year)

\# 2nd-year juveniles at recipient

\# 2nd-year $f$ at recipient

\# 2nd-year $m$ at recipient 


\section{Supplementary material 3}

\section{OpenBUGS code of the model used to estimate Whenua Hou Diving Petrel nest survival in}

Ch. 5.

Model \{

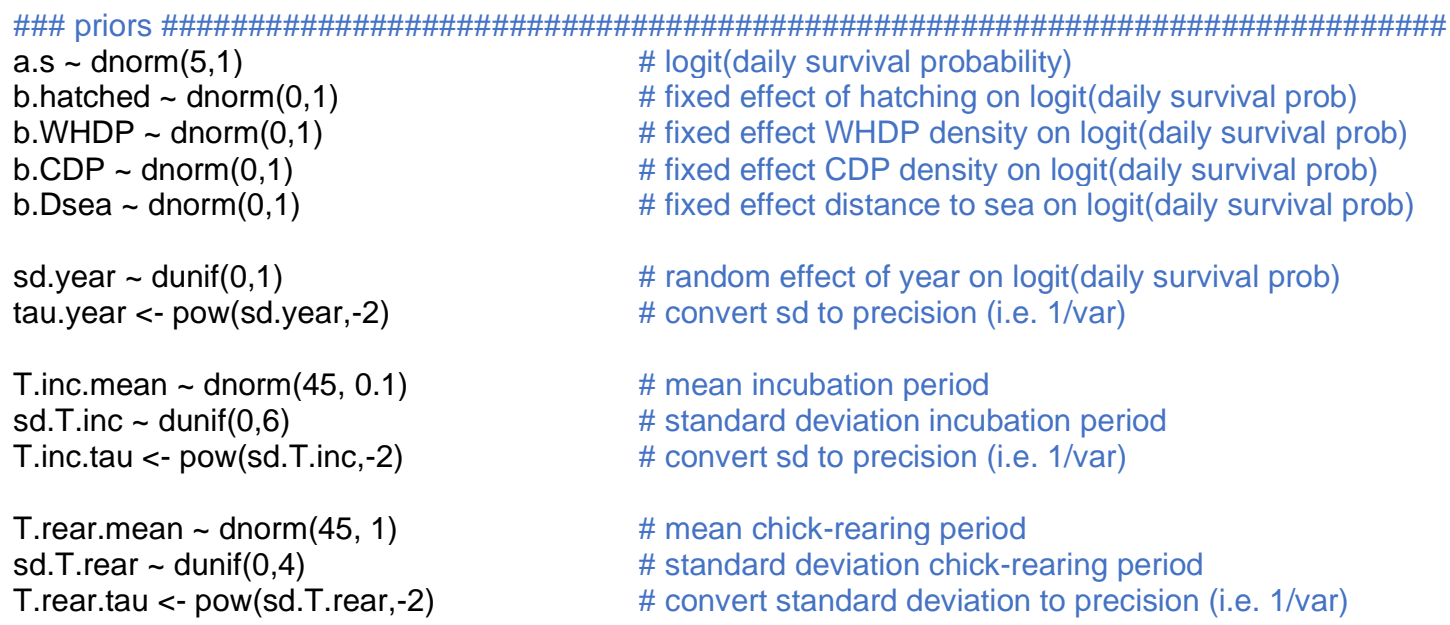

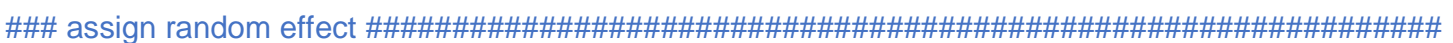
for (i in 1:3) \{

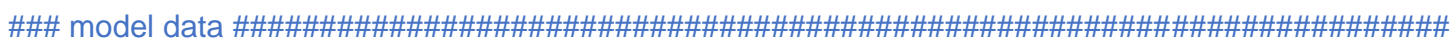
for (i in 1 :n.burrows) \{

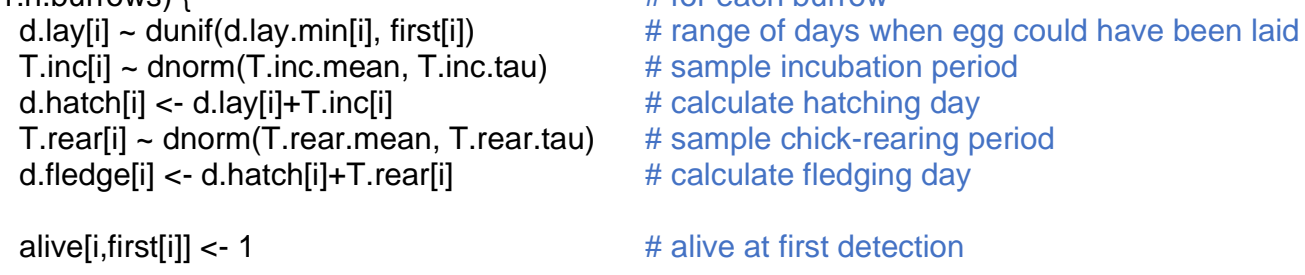




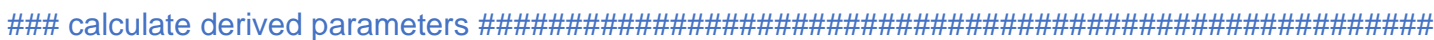
logit(DSR.egg17) <- a.s+re.year[1]

logit(DSR.egg18) <- a.s+re.year[2]

\# daily survival prob for egg stage in 2017

logit(DSR.egg19) <- a.s+re.year[3]

\# daily survival prob for egg stage in 2018

logit(DSR.chick17) <- a.s+b.hatched+re.year[1]

logit(DSR.chick18) <- a.s+b.hatched+re.year[2]

\# daily survival prob for egg stage in 2019

logit(DSR.chick19) <- a.s+b.hatched+re.year[3]

\# daily survival prob for chick stage in 2017

\# daily survival prob for chick stage in 2018

\# daily survival prob for chick stage in 2019

p.egg.success $17<-$ pow(DSR.egg17,T.inc.mean)

\# survival during egg stage in 2017

p.egg.success $18<-$ pow(DSR.egg18,T.inc.mean)

\# survival during egg stage in 2017

p.egg.success 19 <- pow(DSR.egg19,T.inc.mean)

\# survival during egg stage in 2017

p.chick.success 17<- pow(DSR.chick17,T.rear.mean)

\# survival during chick stage in 2017

p.chick.success 18 <- pow(DSR.chick18,T.rear.mean)

\# survival during chick stage in 2018

p.chick.success $19<-$ pow(DSR.chick19,T.rear.mean)

\# survival during chick stage in 2019

p.success 17 <- pow(DSR.egg17,T.inc.mean) ${ }^{*}$ pow(DSR.chick17,T.rear.mean) \# nest survival in 2017

p.success 18 <- pow(DSR.egg18,T.inc.mean)*pow(DSR.chick18,T.rear.mean) \# nest survival in 2018

p.success 19 <- pow(DSR.egg19,T.inc.mean)*pow(DSR.chick19,T.rear.mean) \# nest survival in 2019

\# model end 
Supplementary material 